\title{
VALUING PRIVATE COMPANIES: A DEA APPROACH
}

by

\section{Burcu Anadol}

A Thesis submitted in conformity with the requirements for the Degree of Masters of Applied Science Graduate Department of Mechanical and Industrial Engineering University of Toronto

CCopyright by Burcu Anadol, 2000 
Acquisitions and Bibliographic Services

395 Wellington Street Ottawa ON K1A ON4 Canada
Bibliothèque nationale du Canada

Acquisitions et services bibliographiques

395, ne Wellington Ottawa ON KIA ONA Canada
The author has granted a nonexclusive licence allowing the National Library of Canada to reproduce, loan, distribute or sell copies of this thesis in microform, paper or electronic formats.

The author retains ownership of the copyright in this thesis. Neither the thesis nor substantial extracts from it may be printed or otherwise reproduced without the author's permission.
L'auteur a accordé une licence non exclusive permettant à la

Bibliothèque nationale du Canada de reproduire, prêter, distribuer ou vendre des copies de cette thèse sous la forme de microfiche/film, de reproduction sur papier ou sur format électronique.

L'auteur conserve la propriété du droit d'auteur qui protège cette thèse. $\mathrm{Ni}$ la thèse ni des extraits substantiels de celle-ci ne doivent être imprimés ou autrement reproduits sans son autorisation.

$0-612-54101-0$

\section{Canadä̀}


Valuing Private Companies: A DEA Approach

M.A.Sc. 2000

Burcu Anadol

Department of Mechanical and Industrial Engineering

University of Toronto

\begin{abstract}
Traditionally company valuation methods are based on discounted cash flows and liquidation values, but all have a number of known shortcomings. The application of Data Envelopment Analysis (DEA) for finding comparable tirms and predicting the market values of companies is an extension of the market-based approach and replaces the traditional method where DEA is used for assessing relative efficiencies.

For the inefficient units, the DEA-Valuation analysis correctly classified the market ranges for $70 \%$ of the companies. An upper bound was predicted for the inefficient companies based on their efficient peers. Of these, $75 \%$ were below their upper bound. For the efficient peers, DEA was able to find a lower bound for their market value based on peers being compared to them $50 \%$ of the time. Although some of the ranges specified by the peers are quite wide, the method still does a relatively good job in classifying market values.
\end{abstract}


Dedication

Jo my family

VALUING PRIVATE COMPANIES: A DEA APPROACH

III 


\section{ACKNOWLEDGEMENTS}

I wish to sincerely thank my supervisor Dr. Joseph C. Paradi for his advice, guidance, and insighttul comments throughout this research. It is a very wonderful group he has set up here at the University of Toronto and I have had a fantastic time working at the CMTE. The deepest appreciation also goes to the other members of my committee, Professor McCabe and Professor Vicente, for their comments and suggestions.

I would also like to thank Fai. Sandra. Heather, James, Robin, Taraneh. Kerry, Zijiang, Paul. John, Ozren. Audrey and all the CMTE members for their support and friendship. Also many thanks to great friends. Elcin, Cigdem, Aviva, Nihan. Wendy, Joe, Eric, Jot, Semih, all the Indy 9T8's, and to Def and Fun.

Very special thanks to my family and triends. My father, mother and brother Onur were of great support during this work. and I would not be here without them. With the exception of the bout with pneumonia this has been a wonderful experience. 


\section{TABLE OF CONTENTS}

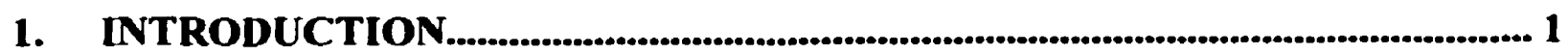

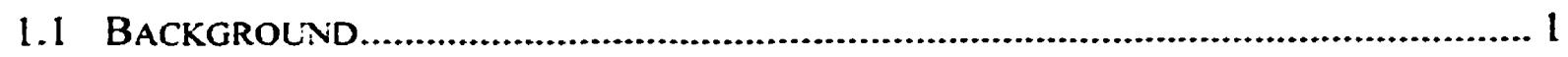

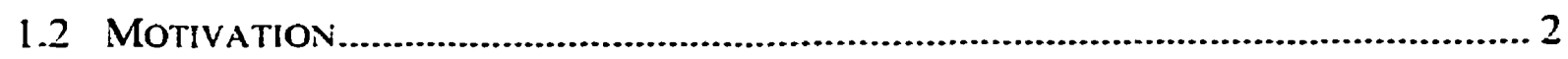

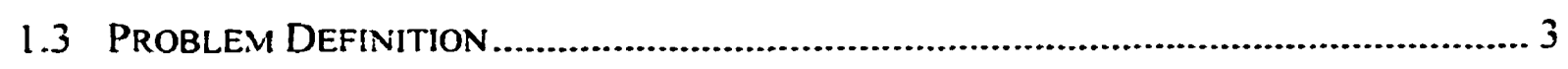

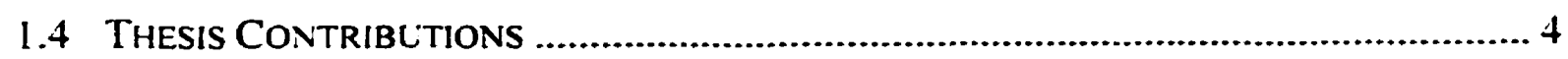

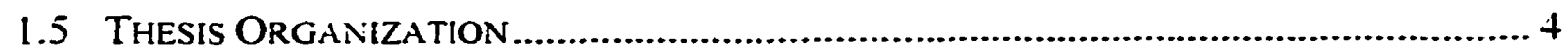

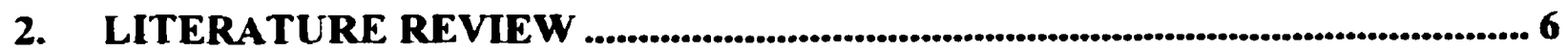

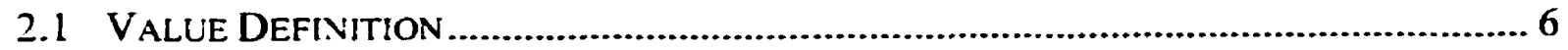

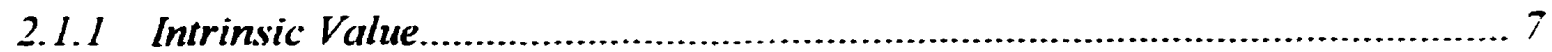

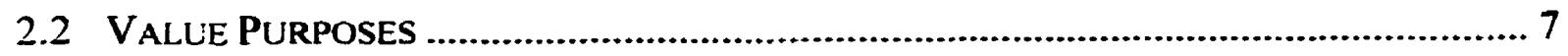

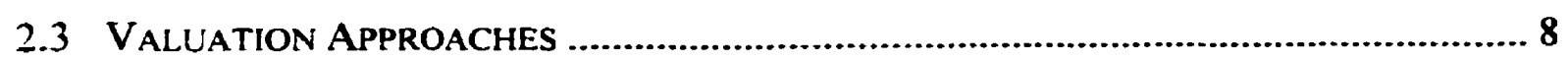

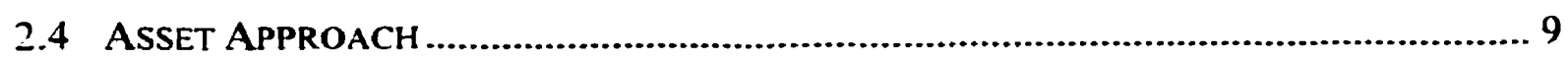

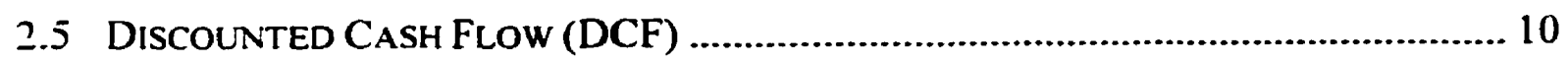

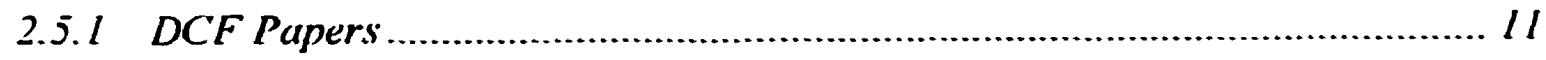

2.5.2 Capitalization Rates.................................................................... 12

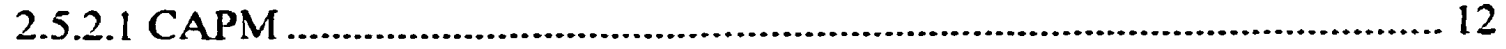

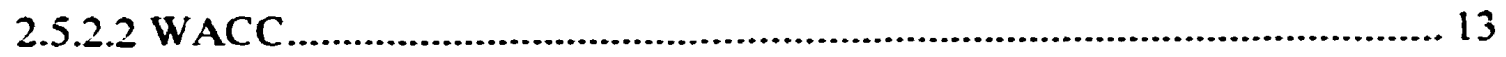

2.5.2.3 Analyst Estimates of DCF Parameters.................................................. 14

2.5.3 Disadvantages of the DCF Method...................................................... It

2.6 Problems WITH ACCOUNTING Ratios ...................................................... 15

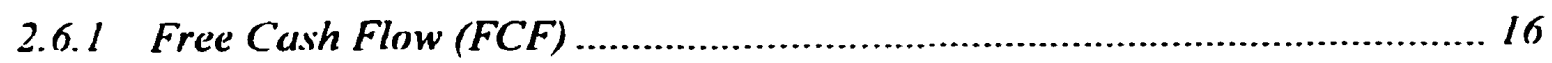

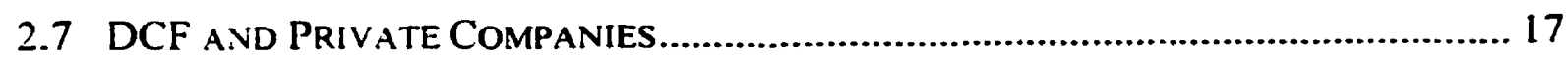

2.7.I A Beta C'oefficient for Private Companies.............................................. I7

2.8 Comparable Fir.MS OR THE MARKET-BaSEd APPROACH ............................... 19

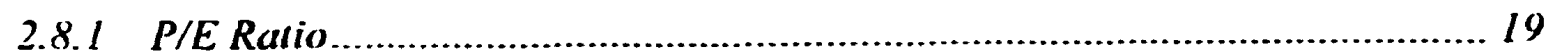

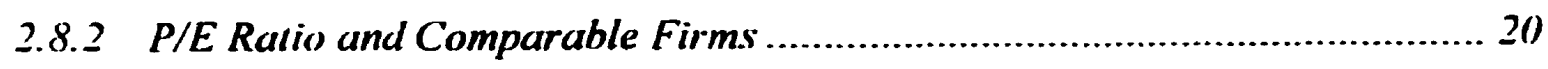

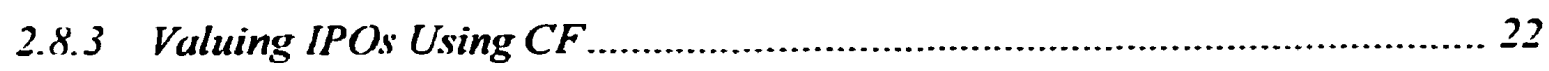

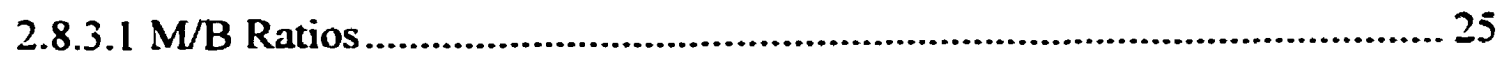




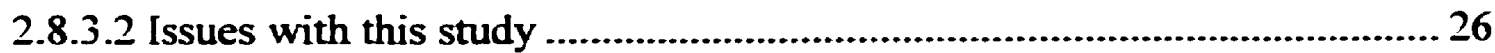

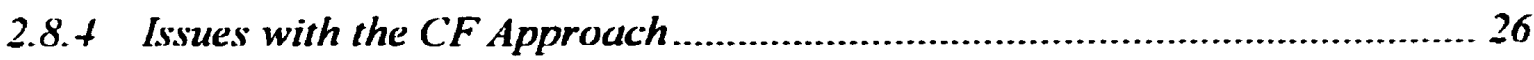

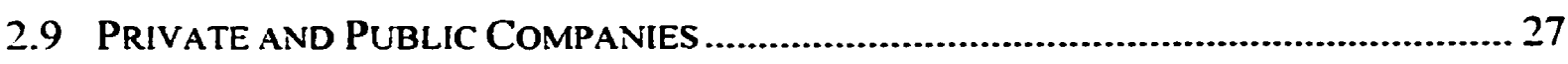

2.9.1 Issues in Valuing Private Companies ............................................... 27

2.9.2 Adjustments to Private Companies for Valuation Purposes ........................ 29

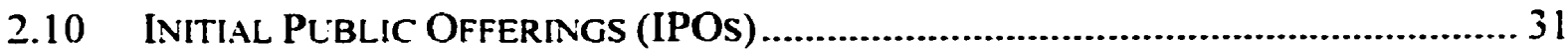

2.10.I Underpricing and Signaling Factors .............................................. 31

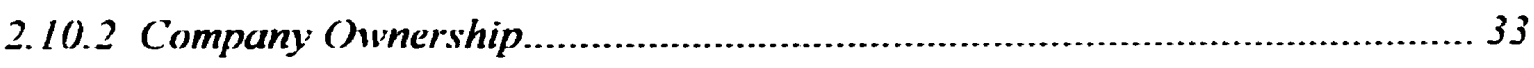

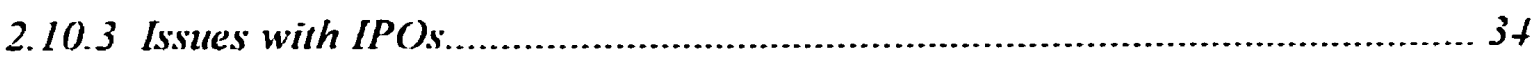

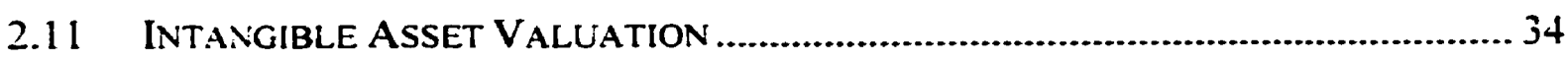

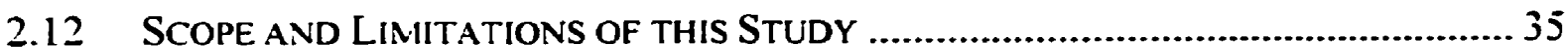

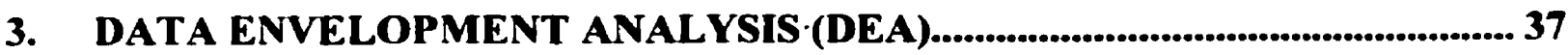

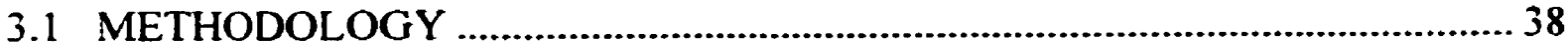

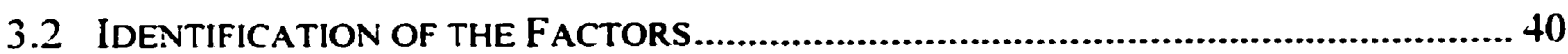

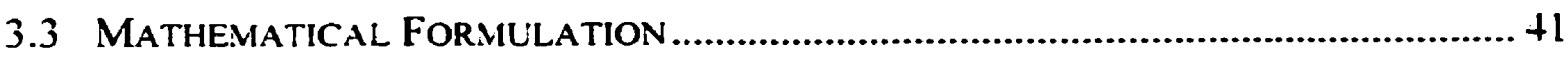

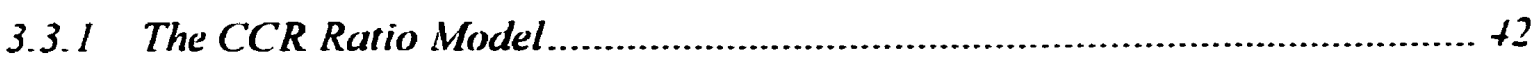

3.3.1.1 CCR Input Oriented ..................................................................... 43

3.3.1.2 CCR Output Oriented ..................................................................... 43

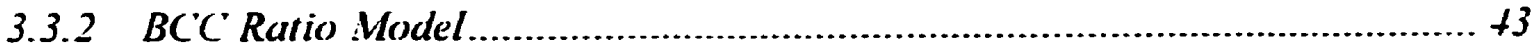

3.3.2.1 BCC Input Orientation .......................................................................... 44

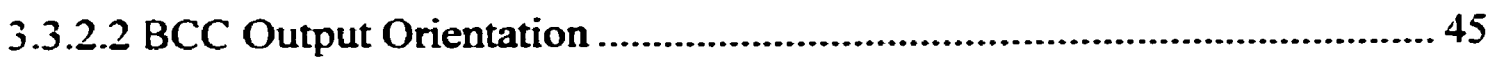

3.4 DIFFERENCES BETWEEN THE BCC AND THE CCR MODEL ................................46

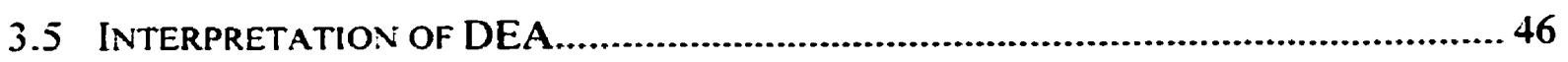

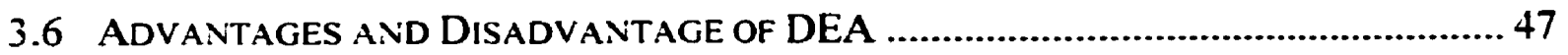

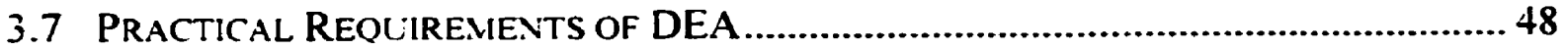

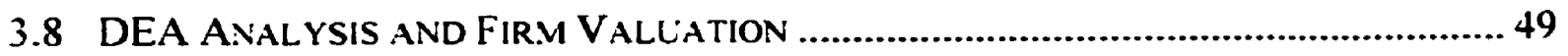

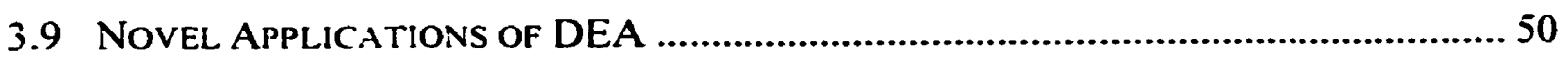

4. DEA-VALUATION MODEL FORMULATION ........................................... 54

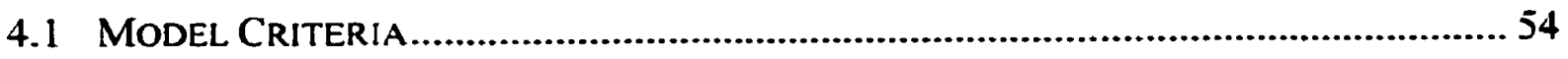

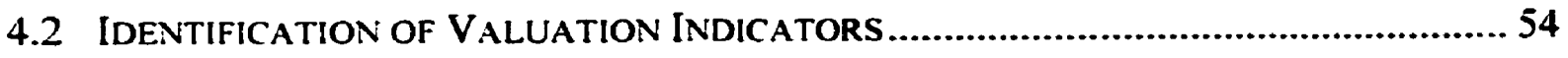


4.3 DEA Modeling - New DEA Company VAluation Models ............................ 55

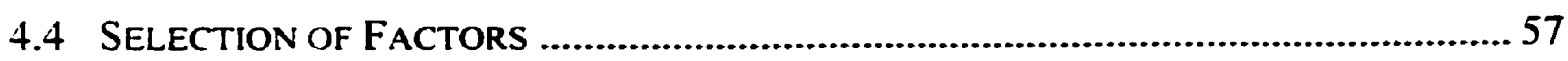

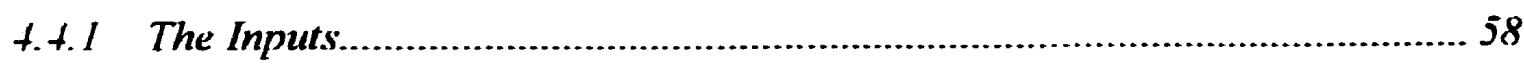

4.4.1.1 Total Assets \& Total Liabilities........................................................ 58

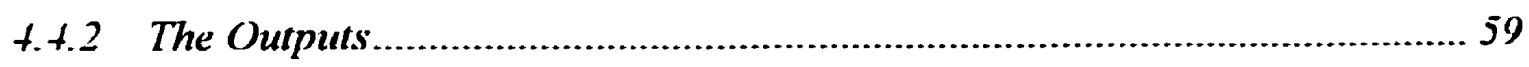

4.4.2.1 Cash flow from operation: ................................................................ 59

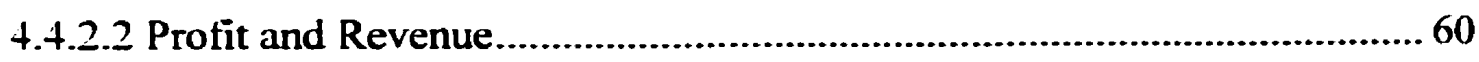

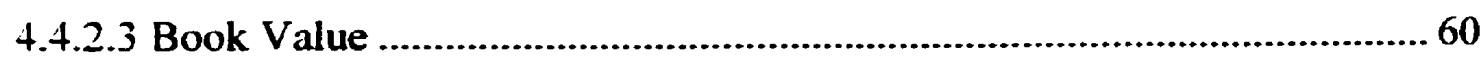

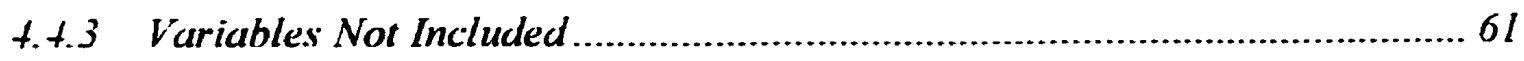

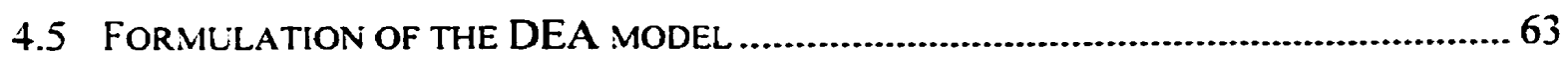

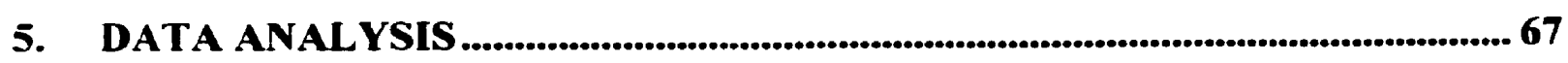

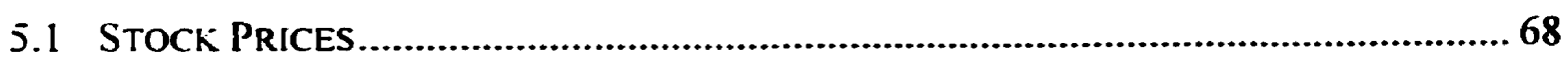

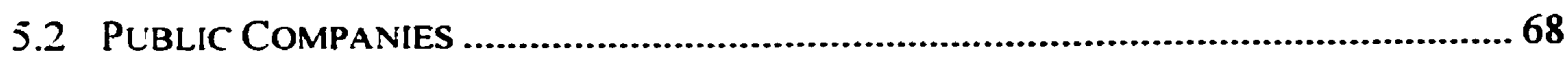

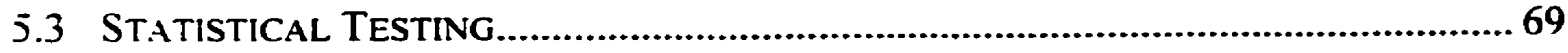

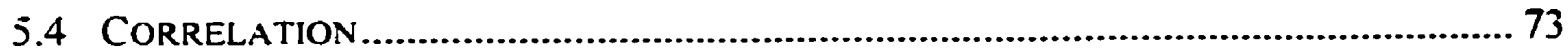

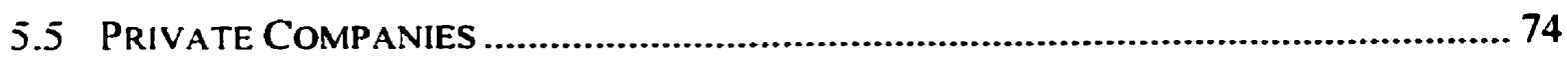

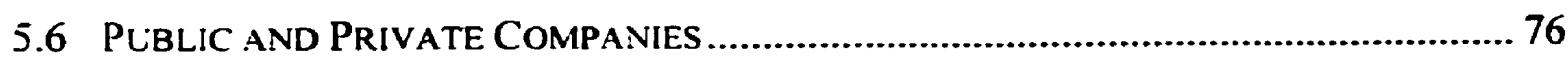

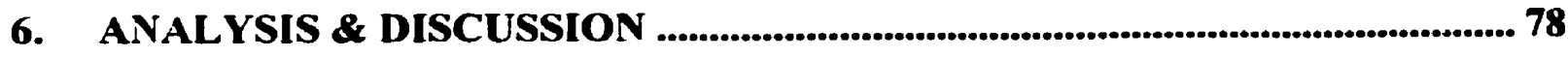

6.1 BCC ANALYSIS OF COMPANIES WITH SIC CODE 3600S .................................. 79

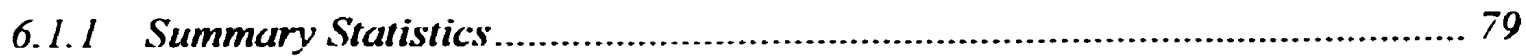

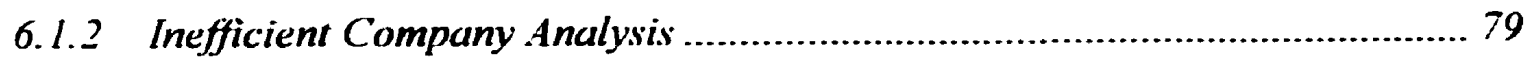

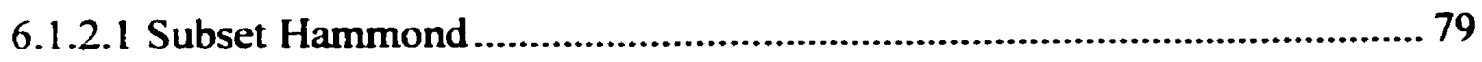

6.1 2.2 Upper Bound for Subset Hammond...................................................... 81

6.1.2.3 Subset 2 - Company Inverpower......................................................... 83

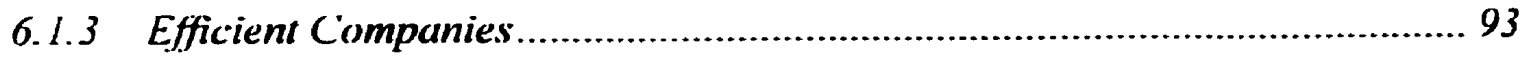

6.1.3.1 Lower bound tor Efficient Company Camco.......................................... 93

6.2 ANALYSIS OF THE COMPANIES WITH SIC CODE 3700S ................................... 99

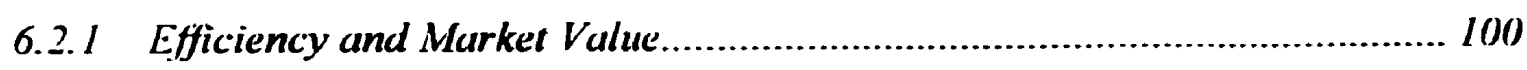

6.2.2 Efficiency and Total Assets .......................................................... I0I

6.2 .3 Graph of Virtual Outputs................................................................ 102 
Table of Contents

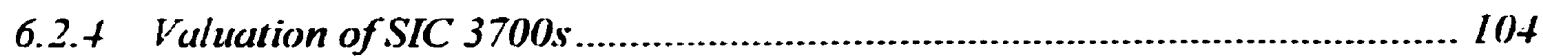

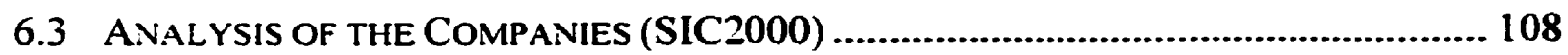

6.4 ANALYSIS UTILIZING ALL 452 COMPANIES .......................................... 110

6.4.I Inefficient Hammond compared to all $\$ 52$ Companies .......................... II0

6.4.2 Efficient Company Wescast Compared to all $\$ 52$ Companies .................. III

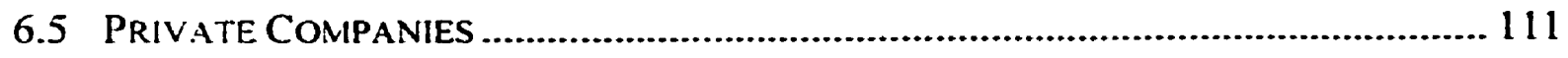

6.5.1 Inefficient Private Companies........................................................... 112

6.5.2 Efficient Private Companies .......................................................... 112

7. CONCLUSIONS \& RECOMMENDATIONS ................................................ 114

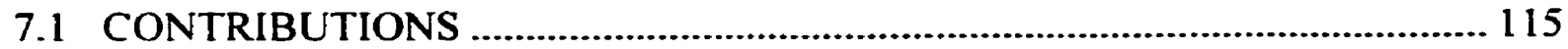

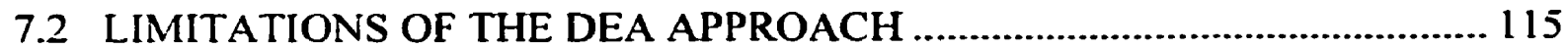

7.3 AREAS OF FUTURE WORK............................................................. 116

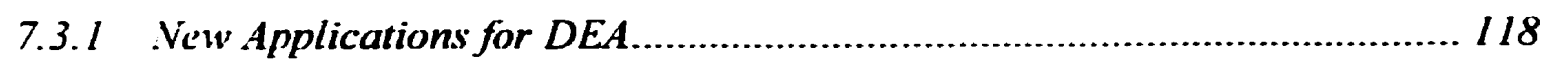

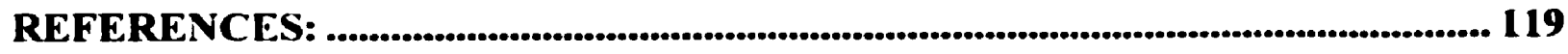

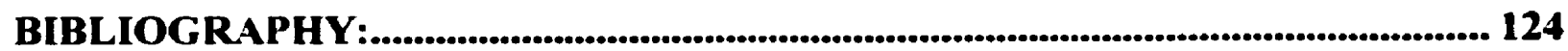

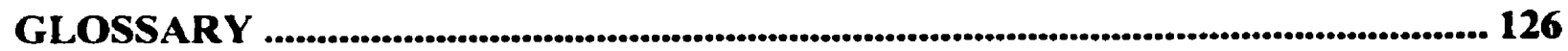

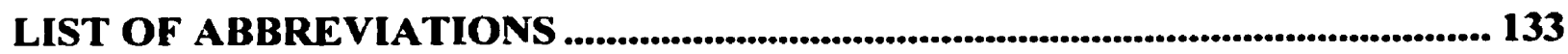




\section{LIST OF TABLES}

Table 2-1 Valuation Approach - Advantages and Disadvantages 8

Table 2-2 Desirability of the Different Valuation Methods 9

Table 2-3 Example of Estimating the Discount Rate 18

Table 2-t Information Requirements on Private Companies for Valuation 29

Table 3-1 Summary results for Zhu analysis 52

Table 5-1 Financial Information Sources 69

Table 5-2 Statistical Testing for the Public Companies 69

Table 5-3 Market Value Statistic:s 71

Table 5-t Correlation Between the Public Company Data 73

Table 5-5 Private Company Statistical Information 7

Table 5-6 Correlation Matrix for the Private Companies $-5$

Table 5-7 List of the SIC codes and the Corresponding Name of the Industry 77

Table 6-1 Hammond Subset Statistics 80

Table 6-2 Distances to Hammond 81

Table 6-3 - Subset Hammond and the Predicted Market Values 82

Table 6-t Company Inverpower and Distance to other peers 83

Table 6-5 Subset Inverpower and the Predicted Market Values 83

Table 6-6 Inefficient DMUs and Predicted Market Values 86

Table 6-7 Efficient Company Camco Inc (\#7) 94

Table 6-8 - Efficient DMUs \& Number of Peers (SIC 3600s) 95

Table 6-9 Efficient DMUs SIC 3700s 99 


\section{List of Tables}

Table 6-10 DMU 3700s Statistics

Table 6-11 Range for Market Values (SIC3700) 104

Table 6-12 Range for Market Values -Inefficient Companies(SIC2000) 109

Table 6-13 Range for Market Values -Efficient Companies(SIC2000) 110

Table 6-1+ Inefficient-Range for Market Values (Private Companies) 112

Table 6-15 Efficient-Range for Market Values (Private Companies) 113 


\section{LIST OF FIGURES}

Figure 3-I DEA Frontier _ـ 39

Figure 3-2 Projecting the Inefficient Unit to the Frontier ___ +2

Figure 3-3 Graph of VRS and CRS___ t6

Figure 3-t Zhu's DEA Model for Company Performance ___

Figure +-I DEA Valwation Model___ 61

Figure 5-1 Distribution of the Total Assets for the Public Companies ___ io

Figure 5-2 Distribution of the Total Assets for the Companies Under \$100,000,000 _ 71

Figure 5-3 Graphical Representation of the Distribution of Market Value:

Figure 5-t Distribution of the Assets of the Private Companies ___ 75

Figure 6-I Inefficient Companies and their Predicted and Actual Market Values __ 88

Figure 6-2 Inefficient Companies-Real MC versus Predicted Upper Bound ___ 89

Figure 6-3 Inefficient Companies-Percent Difference (Real \& Predicted Upper)__ 90

Figure 6-t Efficiency and Market Value (SIC3600)____ 91

Figure 6-5 Efficiency and Tolal Assets $($ SIC 3600) ___ 92

Figure 6-6 Efficient Companies-Real MC versus the Predicted Lower Bound ___ 97

Figure 6-7 Efficient Companies-Pcrcent Difference (Real \& Predicted Lower MV) _ 98

Figure 6-8 Efficiency and Market Value (SIC3700)___ IOI

Figure 6-9 Efficiency and Total Asssets (SIC 3700) __ 102

Figure 6-10 Virtual Outputs of ('ompanies (S/C3700)___ 103 
Figure 6-11 Range for Predicted Market Values and the Real Value (SIC3700) 105

Figure 6-12 Inefficient Company-Real \& Predicted Upper Market Value (SIC3700) 106

Figure 6-13 Efficient Firms-Real and Predicted Upper Bound(SIC3700) 107 


\section{LIST OF APPENDICES}

Appendix A Public Company Data - 1998_ 135

Appendix B DEA Results \& Analysis of Inefficient Companies SIC 3600_ $1+5$

Appendix C Analysis of Efficient Companies SIC 3600___ 188

Appendix D Efficient and Inefficient Companies SIC 3700 199

Appendix E Efficient and Inefficient Companies SIC 2000___ 203

Appendix F Analysis Utilizing all +52 Companies___ 207

Appendix G Efficient and Inefficient Companies SIC 2800__ 212 


\section{Chapter 1 Introduction}

\section{INTRODUCTION}

This chapter presents an overview of this thesis by providing background information on the corporate valuation field, and establishes the motivations for this research. Detailed problem detinition and research objectives are presented as well as solution approaches and contributions. The chapter concludes with a summary of the organization of the remaining document.

\subsection{Background}

Valuation arose out of the need for appraisals of land. its management. and use. As a consequence, there have been multitudes of surveyor organizations in existence throughout history, but in the recent years. as businesses have become more complex, a new form of valuation was required. Business valuation in Canada consisted of people being trained by the provincial governments to operate in what was known as the "death duty field." This came about due to the need for additional tax revenues. and gave rise to the valuation of not only property, but of intangible, tangible and business interest items. The Canadian Association of Business Valuators was formed in 1972 to organize the different professions dealing in valuations under one umbrella organization.

The business of valuation is a multi-billion-dollar field. In 1996 . $\$ 650$ billion (USD) was invested in mergers and acquisitions (M\&A). This figure was double that of the peak M\&A boom of the 1980s [ETTO97]. The reasons for business valuations differ, but most businesses are appraised to obtain an impartial opinion on the value of the business. Improper valuations can lead to losses adding up to hundreds, thousands. and often millions of dollars. Moreover, the range in prices that different buyers will offer is large. Often, the difference between offers may be 200 percent or more [DENNO0]. 


\section{Chapter 1 Introduction}

Company valuation studies include the use of the asset-based approach. the discounted cash flow method and the comparable firms approaches. In comparable tirms, the subject company is benchmarked relative to specific comparable companies from which useful public valuation data can be obtained. When using discounted cash flows. public companies ${ }^{-}$risk/return characteristics are analyzed. adjusted and applied to the subject company.

\section{$1.2 \quad$ Motivation}

The motivation for this research stems from studies in several areas of corporate finance and from applications of Data Envelopment Analysis (DEA). The importance of business valuation has received considerable attention over the past years. however. a comprehensive review of using "comparable" firms has not been considered in the present literature. For this reason, this work concentrates on finding a peer group of comparable firms using DEA; a unique application for this powerful tool.

DEA is ideal for finding comparable firms in many ways. The basic underlying methodology is a linear programming based comparison of the units under analysis. be it banks. hospital, or in this case businesses. DEA identifies best practice (efficiency trontier) units, allows multiple inputs and outputs. is non-parametric. and deterministic (does not require the specification of a functional form). DEA provides an efficiency score for each DMU (Decision Making Unit), identifies inefficient units, tinds a peer group of similar companies for the units under analysis. and it projects the inefficient units to the efficient frontier (targets for improvement). It incorporates all relevant factors in a single model and no single factor is given preference (non-biased). It measures relative efficiency from the best-observed performance rather than from 


\section{Chapter 1 Introduction}

averages. Also, it does not make judgments on the importance of the variables (unrestricted weights).

This paper continues the approach started by Simak [SIMA00], but differs in several respects. First, the sample includes over 400 publicly traded Canadian tirms and over 40 private ones. The models for valuation differ with respect to the input/output variables. as these variables appear to be more appropriate to measure value. Simak does not carry out the actual analysis of the private companies with DEA. so this work will fill that gap. The data consisted of known SIC (Standard Industrial Classification) codes with analysis carried out only for the companies that had the same 4-digit SIC code. Further, one can propose to determine an upper bound on the market values of the inefficient companies and a lower bound for the efficient companies as determined by the lambda values (resulting trom the DEA model) found from the analysis.

\subsection{Problem Definition}

The primary objective of this research is to value private companies using DEA. A secondary objective is to find the factors that determine market capitalization for companies and in particular. to find the tirms that can be used for comparison purposes in a valuation study employing DEA. The first goal of the project is to develop a procedure for valuing public companies using DEA by finding comparable firms. hence. appropriate market value ranges, and then to validate the ranges with the known market values of the public companies. The next goal is to apply the procedures available in the public domain for valuing private companies. Some of the most pressing issues in developing a model are to determine a set of relevant inputs and outputs that serves the objective and ensuring that important variables are accounted for. 


\section{Chapter 1 Introduction}

\subsection{Thesis Contributions}

The major contributions of this thesis are:

1. Development of appropriate valuation models for public and private companies.

2. Establishing a set of peer groups for the companies based on multiple inputs and outputs.

3. For each individual company. etficiency scores and a difference indicator are provided.

4. To gather a comprehensive data set consisting of data for $\mathbf{4 5 2}$ public companies and 49 private companies.

5. Finding a market value range for the subject (inefficient) company based on its comparative peers.

6. For the inefficient companies, establish an upper bound on their market value based on the efficient companies they are being compared with.

7. For the efficient companies, find a lower bound for their market value based on the companies being compared to them.

8. To provide an additional tool for business valuators and others to utilize in order to determine the value of a company.

\subsection{Thesis Organization}

The remaining chapters of this thesis are organized as follows:

- Chapter 2 provides a review of the relevant literature in the area of valuation. It identifies the different valuation methods and the shortcomings of each method, and starts to identify why data envelopment analysis may be a good tool for this application. 


\section{Chapter 1 Introduction}

- Chapter 3 explains the DEA solution approach. The development of the methodology and the different DEA models are presented. The compatibility with valuation is discussed.

- Chapter 4 demonstrates the valuation model illustrating the important variables to utilize. It demonstrates how each variable was selected and why certain ones were not included.

- Chapter 5 summarizes the data acquisition process and describes the data treatment that had to be pertormed for the research.

- Chapter 6 presents the results of the analysis and provides a discussion of the results. An analysis of all the public companies with a SIC code in the 3600 s is provided using the BCC (Banker, Charnes and Cooper) model. A complete analysis of companies having a SIC code in the 3700 s and 2000 s is examined including examinations of correlation's between efficiency and market value. A valuation analysis of two of the companies with all 452 companies is provided. Finally, the lessons learned from the public company valuation are used to analyze three private companies having SIC codes in the 3600 s.

- Chapter 7 presents the conclusions of the work and provides recommendations for future work. 


\section{LITERATURE REVIEW}

"In pricing an acquisition, we can always agree on the numbers. What value is tends to be more in the realm of poets than financial people" [NEED86]

Valuation of private companies is a key area of focus for accountants, lawyers. business valuators, investment bankers. and venture capitalists. The purpose of a business valuation is to find the financial worth of a company. DEA's application to measure this worth is a fairly new concept, but the multidimensional nature of corporate valuation makes it an ideal application area for DEA. This section highlights the literature related to company valuation and discusses the issues and limitations of the approaches.

The valuation concept can be dated back to the time of Napoleon and even King Henry the VIII, although. its main purpose at that time was for inheritance taxation [OVEN72]. As the business world developed. starting with the Industrial Revolution. new methodologies for valuation became necessary. Present day valuations of IPOs (Initial Public Offerings) and selling and acquiring businesses have taken centre stage in the valuation world. but there is still a significant need to value firms for estate, taxation. and divorce settlements. As there are many different applications of valuations. so are there methods to analyze them.

\subsection{Value Definition}

Value is the highest price a knowledgeable buyer. at arm 's length, is willing to pay in an open and unrestricted market. Price and value are often used interchangeably but value generally means a willingness to sell or to buy. while price is the value at which a deal is carried out. The U.S. Internal Revenue Service defines fair market value as -the price at which a property would change hands between a willing buyer and a willing 
seller when the former is under no compulsion to sell, with both parties having reasonable knowledge of the facts" [PRAT96].

\subsubsection{Intrinsic Value}

Intrinsic vaiue of common stock is the price that is justified for a share when the primary tactors of value are considered. In other words, it is the real worth of the stock, as distinguished from the current market price of the stock. It is a subjective value in the sense that the analyst must apply his or her own individual background. expertise and skills to determine it, and estimates of intrinsic value will vary from one analyst to another ${ }^{1}$ [PRAT96].

\subsection{Value Purposes}

The need for business valuation may arise from a variety of circumstances and the different circumstances will require different valuations. Valuations of estate and divorce settlements are quite different than valuations for IPOs. Here is a listing of the varying needs for a valuation:

- IPOs - the company intends to sell shares to the public

- Mergers and Acquisitions (M\&A)

- Selling a Business

- Estate and Gift Tax Purposes

- Re-capitalizing a Business

- ESOP (Employee Stock Ownership Plans) Valuation

- Litigation Purposes or divorce settlements

\footnotetext{
' From the Handbook for Financial Decision Makers, John J. Hampton. Reston VA. Publishing Co., 1979 p $543-4$.
} 


\subsection{Valuation Approaches}

There are many different methods that can be used to assess the value of a business. but these methods can be grouped under three main approaches. namely. assetbased. income-based. and comparable tirms or market value based. The two main approaches for valuation are the comparable firm approach and the income-based approach. with discounted cash flow being the most popular of the latter method. There have been articles expounding the benefits of both methods. Whether one method is used or several. each method has associated benetits and disadvantages as illustrated in Table 2-1:

Table 2-1 Valuation Approach - Advantages and Disadvantages

\begin{tabular}{|l|l|l|}
\hline Approach & Advantage & Disadvantage \\
\hline $\begin{array}{l}\text { Comparable } \\
\text { firms (CF) }\end{array}$ & $\begin{array}{l}\text { Works best when a highly } \\
\text { comparable group is available }\end{array}$ & $\begin{array}{l}\text { There is a chance that an entire sector is } \\
\text { under or over valued }\end{array}$ \\
\hline DCF & Firmer theoretical footing & $\begin{array}{l}\text { Difficult to estimate future cash flows } \\
\text { and an appropriate discount rate }\end{array}$ \\
\hline Asset-based & $\begin{array}{l}\text { Looks at the underlying value } \\
\text { of a company's assets }\end{array}$ & $\begin{array}{l}\text { More relevant when a signiticant portion } \\
\text { of the assets can be liquidated readily. } \\
\text { For small, high-tech IPOs. this method } \\
\text { has little relevance since it does not } \\
\text { consider growth opportunities. }\end{array}$ \\
\hline
\end{tabular}

The purpose for the valuation may influence the method applied. Of the different value approaches the method most popular with companies is the DCF method. Booth examined a survey conducted by Mohan et al on what valuation methods large companies use and recorded the results shown in Table $\mathbf{2 - 2}$ (based on a scale from $1-7$, where a score of 7 is the most desirable): [BOOT00] 
Table 2-2 Desirability of the Different Valuation Methods

\begin{tabular}{|l|l|}
\hline METHOD & SCORE 1-7 \\
\hline DCF & 6.1 \\
\hline Market Value of Comparable & 5.7 \\
\hline Projected Earnings & 4.4 \\
\hline Revenue Multiples & 4.1 \\
\hline Earnings Multiples & 4.0 \\
\hline Book Value & 3.6 \\
\hline Liquidation Approach & 2.3 \\
\hline
\end{tabular}

\subsection{Asset Approach}

This method is mainly employed on companies that are asset intensive. for example manufacturing and retail businesses. Among asset valuations, book value, replacement cost. and liquidation can determine value. One of the most basic approaches is to calculate the book value. hence the shareholders' equity. One of the problems of this method is that the assets are based on historical costs. Another method that can be used relies on established benchmarks, which are used to estimate the value of a business. For example. a small investment advisory sells for 3-4 times the current year's revenue.

Factors analyzed in asset valuation are the market value for fixed assets. leasehold improvements, owners` benetits, goodwill (intellectual property, patents, trademarks, copyrights, etc.) and inventory. The sum of these factors will give an estimate of the market value for the business.

Asset valuation is the least favoured method and considered by some to be the most difficult. Sometimes earnings have been "stored up for a number of years ...to the point at which two valuations are required, one for the operational side of the business including sufficient assets for the maintenance of earnings. and the other for what has become the investment side of the business“ [OVEN59]. 


\subsection{Discounted Cash Flow (DCF)}

The DCF method calculates the expected future income stream of a company discounted back to present value. at a risk-adjusted rate. It is based on the Gordon Price Model and is mathematically represented as:

$$
\mathrm{P}=\sum \frac{D_{n}}{(1+k)^{n}}
$$

Where $P$ is the price, $D_{n}$ is the dividend in year $n$, and $k$ is the cost of equity or discount rate. On the other hand, the Gordon Price Model assumes constant growth so the above equation is adjusted accordingly. In this instance. g represents the growth, $\mathrm{k}$ and $\mathrm{d}$ are the same as in the above equation:

$$
P_{0}=\frac{d t}{(k-g)}
$$

Another way of representing DCF is to show that the DCF formulation values only the assets that give rise to the free cash flow:

$$
\mathrm{V}_{\mathrm{o}}=\sum_{t=1}^{T} \frac{\mathrm{C}_{\mathrm{t}}}{(1+\mathrm{K})^{\mathrm{t}}}+\frac{\mathrm{V}_{\mathrm{t}}}{(1+\mathrm{K})^{\mathrm{t}}}
$$

Where $T$ is the time period, $C$ represents the free cash flow, $K$ is the discount rate, and $V_{t}$ is the terminal value.

\section{Price Earnings Ratio/Multiple (PER) Formulation}

Another variation of the Gordon Model called the Price Earnings Ratio/Multiple (PER) is based on forecasted earnings [BOOT98a]:

$$
\text { PER }=\frac{(1-b)}{K-g}
$$




\section{Chapter 2 Literature Review}

Where $b$ is the firm's retention rate of earnings, $(1-b)$ is the dividend payout rate, $K$ is the discount rate and $\mathrm{g}$ represents growth.

\subsubsection{DCF Papers}

Ruback [RUBA96] prefers the DCF approach rather than the comparable firms method. He investigated the valuation of 51 highly leveraged transactions. He showed that the DCF valuation method produces more reliable estimates of market value. $\mathrm{He}$ examined three CAPM-based approaches to estimate discount rates that correspond to tirm-level, industry-level. and market level measures of risk. All three methods performed better when compared to the comparable firms approach.

Kaplan and Ruback studied highly leveraged buyouts and re-capitalization`s using the DCF approach [KAPL95]. They found that a CAPM based DCF approach has approximately the same valuation accuracy as the CF approach, using the capitalization of EBITDA?

For most companies, future earnings potential is more important than past performance, that is why calculating DCF is such an important issue in valuation. The DCF method is used predominately for companies that are not asset intensive. like the service sector. In the DCF method, certain variables and unknowns must be calculated which include: the amount of future cash flow, growth potential of the cash flow, duration of the future cash flow, risks associated with them. and the discount rate to apply to arrive at the net present value [MULL90]. Other factors to analyze include risk within the industry, quality and size of the customer base. length of time the company has been in busincss. and the level of technology.

\footnotetext{
- EBITDA - Earnings before interest, taxes, depreciation and amortization. also known as operating cash How
} 


\section{Chapter 2 Literature Review}

\subsubsection{Capitalization Rates}

The most problematic aspect of this method is the selection of an appropriate discount rate. For private companies, the discount rates are chosen based on the perceived riskiness of the business. Risk is a part of any business. In 1776 . from the Wealth of Nations, Adam Smith remarked that "the ordinary rate of profit always rises more or less with the risk" [BOOT98a]. A higher rate of return. or. a higher discount rate is to be employed to value the risky firm's operations. Usually, the discount rate is a percentage added to the current 90 day $\mathrm{T}$-bill interest rate. For better-established businesses the discount rate may be $5-10 \%$ above the $\mathrm{T}$-bill rate, and for riskier companies about $20-25 \%$. The riskier the business the higher the discount rate. For determining an appropriate discount rate several methods can be employed: they include CAPM. WACC and analyst estimates.

\subsubsection{CAPM}

Markowitz. in 1959. analyzed the behaviour of a portfolio of securities and showed that. "unless portfolios were perfectly correlated, risk would decrease as imperfectly correlated securities were combined into portfolios" [BOOT98a]. Sharpe added to this theory. addressing the issue of covariance, highlighting the measure of risk known as a security`s "beta coefficient and (it) is estimated by a simple least squares regression of the security's return against that on the market portfolio“ [BOOT98a]. It was Sharpe who introduced the Capital Asset Pricing Model (CAPM). otherwise known as the market equilibrium model. which can be used to derive the required rate of return for DCF calculations. It states that the required rate is equal to the risk free rate plus 


\section{Chapter 2 Literature Review}

some sort of premium. It measures the risk of a security by relating the expected return on an asset to its beta:

$$
K_{t}=R_{f}+\left(R_{m}-R_{f}\right) \beta
$$

Where. $K_{t}$ is equal to the cost of equity capital. $R_{f}$ is the risk-tree rate of return. $R_{m}$ is the market required rate of return. and $\beta$ is a measure of the systematic risk of an asset due to the co-movement with the market. If a company has a beta of one then the stock has the same volatility as the market index it is being compared to. If beta is 0.5 . than the company is half as volatile. and if it is two than the company is twice as volatile. In order to estimate beta. one needs to regress the stock's price against the level of some broad market index such as the S\&P $\mathbf{5 0 0}$ and the beta factor is just the slope of the regression line.

\subsubsection{WACC}

Another method to calculate the capitalization rate is to use the weighted average cost of capital (WACC); it is represented mathematically as:

$$
\mathrm{WACC}=\frac{E}{V} \mathrm{~K}_{\mathrm{c}}-\frac{D}{V} \mathrm{~K}_{\mathrm{d}}(\mathrm{l}-\mathrm{T})
$$

In the equation. $K_{c}$ and $K_{d}(I-T)$ are the costs of equity and debt capital respectively, where the cost of debt is on an after tax basis. The weights. $E / V$ and $D / V$, are the equity and debt financing proportions. WACC is the weighted average of the costs of borrowing and of selling shares. The weights are the fractions of total capital that come from the different sources. WACC is not really a separate method; it combines two or more capitalization rates to get one. It assumes that the purchase of a business can be partly financed with debt and partly with equity. It weighs the cost of capital to the cost of indebtedness. 


\subsubsection{Analyst Estimates of DCF Parameters}

For the selection of the capitalization rate. valuators have information about the capitalization rates of several companies, and they try to apply these to the business under consideration. The parameters they consider in a DCF approach are the time horizon, the discount rate. and the cash flow forecasts. Most analysts choose a time horizon of less than 10 years and $55 \%$ use less than 7 years. For the discount rate. $55 \%$ of analysts used the acquiring firm's WACC. and $41 \%$ used management judgment. Also. most analysts apply industry growth trends and "expected" performance to cash flow forecasts [BOOT00].

\subsubsection{Disadvantages of the DCF Method}

The two major problems with the DCF procedure are the discount rate used and the estimate of future cash tlows. Earnings are effected by tluctuations within a certain industry and by the state of the economy. Past earnings are no guarantee of future earnings. Underlying factors may be at play and each company should be examined thoroughly to insure the business is sound. In the case of Internet start-ups. no formula is valid. Their characteristics are such that they usually have little or no earnings. they do not have historical earnings as they have existed for only a short time. most of their value is in future growth opportunities, which are very uncertain, and their employees.

Problems manutacturing plants can have include:

- Plant may become obsolete

- Manufacturing and distribution outdated

- Products suffering due to competition or lack of sales

- Location might no longer be suitable. closeness to market

- Problems with employees

[OVEN59] 


\section{Chapter 2 Literature Review}

In 1959 , according to a pamphlet put out by the CICA (Canadian Institute of Chartered Accountants), it was presumed that the capitalization of future profits was not widely used. Little proved that the opposite was true [LITT59]. He showed that it was the most widely used method in Canada. He quoted Mr. Justice Douglas of the United States Supreme Court, who urged caution when applying this method:

-Since its application requires a prediction as to what will occur in the future, an estimate, as distinguished from mathematical certitude. is all that can be made. That estimate must be based on an informed judgment which embraces all facts relevant to future earning capacity and hence to present worth. Including, of course. the nature and condition of the properties, the past earnings record, and all circumstances which indicate whether or not that record is a reliable criterion of future performance“ [LITT59].

The risk free rate (RFR) is usually acquired from business news, but it is usually correct for only a short time period and it has to be adjusted to imitate the growth of the firm for longer time horizons. The base CAPM ignores issues such as taxation and it does not consider multiple time periods. It also does not model the real world, by ignoring transaction costs and assuming all risky assets are traded. Selecting the appropriate discount rate is a key issue in valuation. These and many other reasons make it difficult to apply the DCF approach in trying to value a company.

\subsection{Problems with Accounting Ratios}

There are also some problems associated with using only an accounting approach. Each company tiling an annual report has to adhere to their countries' Generally Accepted Accounting Principles (GAAP). In Canada, many of the larger public 


\section{Chapter 2 Literature Review}

companies also, or exclusively, report according to U.S GAAP. When carrying out a complete valuation.- the accounting numbers have to be adjusted for the different accounting procedures. Some accounting items to examine are whether the company accounts for inventory by LIFO or FIFO. In Canada most firms use FIFO because there is an additional $3 \%$ inventory write-off allowed for tax purposes [BOOT98]. Companies using LIFO will have decreased profits, reduced taxes but a stronger cash tlow since the last item in is typically more expensive. Other issues to address include:

- Purchase or pooling of goodwill.

- Capitalization or expense items (R\&D. etc.)

- Depreciation policy (accelerated. straight line, etc.)

- Off balance sheet items-pension fund liability, warranties or litigation

- Capital structure

- Discounted rate differences (risk, time value of money)

For these reasons. when conducting a full valuation it is important to adjust the income statement and the balance sheet to reflect these concerns.

\subsubsection{Free Cash Flow (FCF)}

Hunt [Hunt75] introduced the theory that the firm's capital expenditure (Capex), needed to sustain operations. should be subtracted from the Cash Flow from Operations (CFO) to get the true cash generating ability of the firm. The result is what is now known as Free Cash Flow (FCF). It is mathematically represented as:

FCF $=$ net income + non-cash items - increase Net Working Capital (NWC) - Capex

Non-cash items include depreciation, goodwill, and deferred income taxes and after tax interest. FCF -"captures whether or not the firm actually generated cash from its operations. after adjusting the earnings for non-cash items, the need to reinvest in NWC 


\section{Chapter 2 Literature Review}

and new capital expenditures to maintain the firm's operations"[BOOT00]. However. FCF's effects on asset poor companies and service organizations is an issue that has to be dealt with. In this sort of area. it is more important to address the cash dollars spent by these companies. such as for advertising. R\&D. planned losses, and so on.

According to Booth [BOOT00], using FCF is one possible solution to the accounting problem. By analyzing FCF. one can get a true picture of a company`s operating results. instead of the diluted view presented through the pure accounting changes used by tirms.

\subsection{DCF and Private Companies}

How do all of these factors impact private companies? For estimating risk premiums one needs data and the data are only available in public markets. Booth [BOOT98a] examined the effect of size and transaction costs on the discount rate. He looked at the total return data on size based US portfolios going back from 1926 to 1995. This information is available from the University of Chicago's Centre for Research into Security Prices (CRSP). The data showed that smaller tirms constantly outperformed larger ones. They earned close to double that of the larger tirms $22.62 \%$ versus $11.41 \%$ respectively. Smaller firms pertorming better than CAPM predictions are referred to as the "small firm effect." Private companies are usually valued (discounted) on lower PERs than public tirms are since they are considered to be riskier endeavors. Rules of thumb approximate this discount to be around $20 \%$ for private companies.

\subsubsection{A Beta Coefficient for Private Companies}

A beta for the DCF of a private tirm is impossible to acquire but Booth [BOOT98a] suggested two alternatives, the pure play approach (PPA) and the 


\section{Chapter 2 Literature Review}

instrumental variables approach. The PPA *tinds public companies with similar operations and use(s) their beta...(or) use(s) the broad industry classifications of the TSE or S\&P market indexes" [BOOT98a]. From this he found that "a firm in the general industrial products area has a beta of 1.2 or a CAPM risk premium of $4.2-4.8 \%$. whereas a private retailer would have a CAPM equity risk premium of $2.7-3.1 \%$ [BOOT98a].

The instrumental variables approach. [BOOT98a]. "statistically estimates the relationship between actual betas and the particular characteristics of traded firms. such as their financial structure. growth rate. dividend policy. etc." This relationship is then used to approximate the beta for the private firm by substituting back the private firm`s financial values. For the non-traded firms, the variables act as instruments to estimate their betas as if they were traded.

The potential discount for a tirm based on these findings could be 15.5 to $17 \%$, as displayed in Table 2-3:

Table 2-3 Example of Estimating the Discount Rate

\begin{tabular}{|l|l|}
\hline CAPM discount rate for industrial products firm with beta of 1.2 \\
\hline Item & \% Discount \\
\hline Long Canada rate & 5.5 \\
\hline Equities tax preferred in Canada & 1 \\
\hline Market risk premium in Canada & $3.5-4$ \\
\hline Small tirm earning since 1926 & 4 \\
\hline Non-marketability. transaction cost & $1.5-2.5$ \\
\hline TOT AL & $15.5-17$ \\
\hline
\end{tabular}
[BOOT98a]

Booth extended the CAPM to include private tirms. where the variables $\gamma_{1}$ and $\gamma_{2}$ are the small firm and private firm premiums. This forces the discount rates of the small firms to be higher than the larger firms:

$$
K_{e}=R_{f}+\left(R_{m}-R_{i}\right) \beta+\gamma_{1}+\gamma_{2}
$$




\subsection{Comparable Firms or the Market-Based Approach}

The comparable firms (CF) approach or market approach as it is sometimes known. implies comparison with publicly traded companies. It is implemented by capitalizing the earnings per share (EPS) of the firm under consideration at the average or median $\mathrm{P} / \mathrm{E}$ ratio of the complementary publicly traded tirms. Earnings forecast. market to book. and price to sales are other factors that can be used instead of $\mathrm{P} / \mathrm{E}$ ratios.

\subsubsection{P/E Ratio}

The $\mathrm{P} / \mathrm{E}$ ratio is the relationship between the current price of a stock to its earnings. It shows the shares selling at so many times their actual or anticipated annual earnings. The $\mathrm{P} / \mathrm{E}$ is calculated by dividing the current market price of common stock by the earnings per share. Investors use it to ascertain the market demand for stocks. Companies with a high $\mathrm{P} / \mathrm{E}$ have greater earnings potential than low $\mathrm{P} / \mathrm{E}$ stocks, but also are more volatile and somewhat riskier investments.

$\mathrm{P} / \mathrm{E}$ ratios enable one share to be compared with another, they also reflect the views of thousands of investors on the quality of an issue. They indicate liquidity. earnings trend, profitability. and dividend payout along with intangible factors such as quality of management. and prospects for the industry or segment [CSI89]. To rate the $\mathrm{P} / \mathrm{E}$ for a company's common shares with those of others. the companies must be comparable which usually means they must be in the same industry. $\mathrm{P} / \mathrm{E}$ ratios for different industries are available in various media and industry sources. for example the TSE monthly review. 


\section{Chapter 2 Literature Review}

The P/E ratio is probably the most useful and widely used of all tinancial ratios because it is. in fact, all the other ratios combined into one figure since it represents the ultimate evaluation of a company and its shares by the investing public [CSI89].

\subsubsection{P/E Ratio and Comparable Firms}

Many studies examine the use of the $\mathrm{P} / \mathrm{E}$ ratio for comparable firms. Boatsman and Baskin [BOAT81] compared the accuracy of two different types of P/E models. The tirst model tinds a random company in the same industry. The second model uses a company from the same industry but with similar ten-year average growth rate for earnings. They tound the accuracy of the second model to be better.

Kim reported on an article by Alford [KIM99]. where Alford evaluated the accuracy of the P/E valuation method when the comparable firms are chosen by industry. firm size and earnings growth. He found that the 4-digit SIC code is the most effective in choosing comparable firms. It is also interesting to note that Alford did not find improved accuracy when size and industry membership were used together in the $P / E$ valuation [KIM99].

Kim cited a study by De Angelo [KIM99] that demonstrated that investment bankers make extensive use of accounting data and that they depend on the CF approach. He did this by examining working papers and faimess opinions on management buyouts. He showed that underwriters base their pricing decisions on an analysis of the market price ratios. with adjustments for tirm-specific differences, and determine a range of minimum and maximum offering price, then, after gathering more information they set the market price. 


\section{Chapter 2 Literature Review}

Ratios other than $\mathrm{P} / \mathrm{E}$ can be used in conjunction with the $\mathrm{CF}$ approach. One can have any sort of ratio, even those that are specific to an industry, for example. market value divided by cable subscriber. Amir and Lev. cited from [KIM99], provided a valuation study of the wireless communication industry. They showed that the primary determinant of company value is the population of the franchise territory. rather than financial variables.

The value relevance of $\mathrm{P} / \mathrm{E}$ and market to book $(\mathrm{M} / \mathrm{B})$ ratios has been demonstrated by empirical studies. Kim quotes two articles, one by Zerowin and the other by Liu and Ziebert [KIM99], who examined cross-sectional variability in P/E and found a signiticant relationship between $\mathrm{P} / \mathrm{E}$ and growth, dividend payment and size.

According to Campbell "trading statistics with respect to shares of so-called comparable public companies can be. and moreover should be, a significant factor to consider" [CAMP92]. He stated that it is important to use CF where the privately held business under valuation is similar in size, business structure and business operations to one or more of the publicly traded companies.

In the U.S.. the Internal Revenue Service (IRS) considers the analysis of public companies an important tool in determining the value of private companies. although this is mainly for income-tax purposes. Ruling 59-60 urges "using comparisons from quotations found in the prices at which similar companies are selling in tree and open markets, including not only listed securities but also actively traded over-the-counter and unlisted securities“ [OVEN59].

Morris [MORR92] reaffirmed the fact that the best multiple may come from a public market comparable. If it exists it should be given full and complete consideration. 


\section{Chapter 2 Literature Review}

He points out "it is difficult to depart from price, or multiple, set in the public marketplace. These public companies are one's best empirical data" [MORR92].

\subsubsection{Valuing IPOs Using CF}

Systematic studies on the usefulness of the CF approach have not been performed. Kim and Ritter [KIM99] come closest to filling this gap with their significant paper on IPO valuation. A detailed explanation of IPOs is discussed in a later section. Most literature recommends the use of accounting data in conjunction with comparable firm multiples when valuing IPOs. Generally, younger tirms vary in terms of ratios, P/E, M/B. and price to sales. and may need further adjustments. The best way to employ $P / E$ ratios is through the use of forecasted earnings rather than trailing earnings. Another ratio that can be used in valuations is enterprise value to sales and enterprise value to operating cash flow. Enterprise value is equal to the market value of equity plus the book value of debt minus cash. "Ratios seem more useful especially when adjusted to reflect differences between protitability and growth rates of the IPO in question and the comparable tirms used"“ [KIM99]. However. it is difficult to forecast the future cash flow for very young companies, which is the category most IPOs fall into. That is one of the main reasons why the DCF method is imprecise. and the key advantage of the comparable firms method. The CF method is supported by academics and practitioners and widely used in case studies in business schools [KIM99].

Kim and Ritter [KIM99] use sales. earnings. operating cash flow and book value to determine value, as well as comparable firm multiples. They tested the accuracy of the comparable firms method by using two sets of comparable firms. The first set consisted of recent IPOs in the same industry and the second set was chosen by a research 


\section{Chapter 2 Literature Review}

boutique $^{3}$. The results showed that the second set worked better than the first, and applying forecasted earnings worked better than using historical earnings. They also tested the hypothesis that young firms are harder to value by splitting the data into "age' groups and applying the second set. They found that the "valuation errors of the comparable firm multiples are noticeably smaller for the older firms than for the younger firms, especially when using earnings“” [KIM99].

The recent IPOs set consists of companies that went public not more than 12 months prior to the IPO under investigation's offer date and that has the same 4-digit SIC code. If there were more than 5 comparable firms to compare with they suggested using the 5 firms with the closest sales and ignored the rest (firm $=$ recent IPOs). Earnings for the first year after going public typically include substantial amounts of interest income thus in the analysis EPS is used and sales numbers from prospectuses only, rather than more recent financial statements that may be skewed by interest income.

The variables they selected were offer date (cannot be more than 12 months before the offer date of the new IPO). EPS, Sales (12 month revenues prior to IPO as stated in prospectus), and book value per share (BPS) (both pre and post IPO). Another condition placed on the variables is that they must be positive. They then computed the following ratios: $\mathrm{P} / \mathrm{E} . \mathrm{P} / \mathrm{S}$, and $\mathrm{M} / \mathrm{B}$. The median of these market multiples is then used as the CF multiple for the company. The company's ratios are computed based on its offer price (post-issue).

CF multiples are typically higher than the multiples for the firms going public. partly because they are using market prices for the comparable firms and offer prices for the IPOs. Also, because of the short-run underpricing phenomenon (average tirst-day 


\section{Chapter 2 Literature Review}

return in the sample is $12 \%$ ), one would expect the IPO multiples to be discounted by about 12\% [KIM99]. The functional tixation hypothesis asserts that the market mechanically capitalizes reported EPS numbers, without adjusting for the quality and or persistence of the earnings. Friedlan et al [KIM99] suggested that the market does not fully incorporate the information content of discretionary accruals in valuing new issues, consistent with the functional tixation hypothesis.

The first model of the CF approach is surprisingly weak for the following reasons. First, because historical earnings of IPOs are transitory in nature they have little value relevance. Second, using market multiples and past data have an intrinsic limitation in that they do not reflect future growth. This leads to the third issue, which is allowing for adjustment of differences in growth and protitability. Finally, there is an element where the comparable firms may have been chosen improperly [KIM99].

A "boutique" firm. Renaissance Capital, chose the second set of comparable tirms. The research boutique chose the CFs based on the major competitor firms mentioned in the prospectus of the IPO. While historical earnings contained in the prospectus are available to all market participants. practitioners also frequently use earnings forecasts for valuation purposes. In addition, Renaissance Capital did not restrict the comparable firms to the same SIC codes.

Kim and Ritter used "the geometric mean of the Renaissance Capital comparable firm $\mathrm{P} / \mathrm{E}$ multiples as the explanatory variable in regressions using the three $\mathrm{P} / \mathrm{E}$ ratios of the [POs as the dependent variables" [KIM99]. The three P/E ratios, using the midpoint of the POP (preliminary offer price) for the IPO. are the last 12 months. current fiscal year's forecast. and next year`s forecast of the EPS. Comparing the regressions, the 
average prediction error falls from $55 \%$ to $43.7 \%$ to $28.5 \%$ respectively. and the percentage of firms that are valued within $15 \%$ of the actual multiple increases. Younger firm valuation using forecasted earnings works better than using historical earnings, as there is a potential growth opportunity that needs to be addressed.

They also tested the presumption that older firms will be easier to value since capitalized earnings represent more of their value than expectations about future growth rates. Consistent with that presumption. the mean absolute prediction error for the tirms that are less than 10 years old at the time they go public is higher than for older firms. $31.9 \%$ and $23 \%$ respectively.

\subsubsection{M/B Ratios}

Renaissance Capital does not utilize $M / B$ ratios. They find $M / B$ ratios to be poor valuation metrics. They claim that $\mathrm{M} / \mathrm{B}$ ratios have a disadvantage because the book value is arbitrary for IPOs since there is a large change from before the issue to after (influx of new capital from new shareholders). Rather, they recommend using enterprise value ( $\mathrm{EV}$ ) where they look at market value to sales, $\mathrm{EV}$ to sales and $\mathrm{EV}$ to operating cash flow (EBITDA) in their analysis.

To summarize Kim and Ritter [KIM99], the variation in these ratios is so large, both for public firms and IPOs. that they have only modest predictive value. Many idiosyncratic factors are not captured by industry multiples unless various adjustments for differences in growth and protitability are made. In practice. analysts place more weight on a given multiple for some industries than others. Taking this into account would probably show that CF multiples result in more accurate valuations. In practice, one starts with industry multiples and adds or subtracts adjustments of $10-20 \%$ to reflect 


\section{Chapter 2 Literature Review}

differences in growth rates. profitability, and quality of earnings. Investment bankers use the midpoint of the offer price range resulting in smaller prediction errors than using comparable firms. They canvas the market place for demand before setting the final issue price [KIM99].

\subsubsection{Issues with this study}

One issue with this study is the use of a maximum of 5 comparable firms and the deletion of the rest. The comparable firms approach works best with a high number of comparable firms and exclusion of tirms to simplify a study may not give meaningful results. It is better to have as many comparable companies as possible.

\subsubsection{Issues with the CF Approach}

Three main issues with this approach are the P/E ratios employed, the use of the right multiplier for the industry, and the availability of a highly comparable group of companies. P/E ratios are dynamic and vary widely over time and among companies. The problems with P/E ratios and the right multiplier can be remedied by looking at industry trends and the broader market to forecast trends and adjust historical P/E ratios accordingly. Companies can be public and not usetul tor these comparisons because:

- They are not listed anywhere (traded over the counter)

- Not liquid

- Shares are priced very high (Hathaway Corp.)

- Share prices are too low because of too many shares

- Small tloat

- Huge stock options outstanding at low prices compared to market

- Only few very large firms are listed. private tirms are one or two orders of magnitude smaller. 


\subsection{Private and Public Companies}

In order to apply the above valuation techniques to private tirms. adjustments have to be made to account for the differences that exist between public and private companies. One of the issues to keep in mind is that private companies are not as well established. and most of their value lies in their growth opportunities. Exceptions to this include Goldman Sachs and Eatons. which were both very large and well established before their respective IPOs. Private companies have less than 50 shareholders and their shares are highly concentrated. leading to liquidity risk concerns. Private companies are under no obligation to report their earnings or to produce annual reports and hence their value is often times subjective.

On the other hand. information on public companies is readily available, through financial statements, annual reports. and such. Public markets are organized places of exchange. their prices are intluenced by coverage in the press and by analysts, and there is more intormation available about them. When compared to private firms, they are:

- Typically (but not always) larger;

- They tend to participate in more than one industry (this leads to diversified risk):

- They cover a broader geographical area;

- They have rules and regulations governing them (BOD):

- They have greater liquidity:

- They have greater access to financial resources and funding sources:

- They usually have better developed products, management teams, and strategies

\subsubsection{Issues in Valuing Private Companies}

When pricing privately held business interests the analyst needs to look at all available data. The important issues are: 
- The nature and history of the business

- The industry's economic outlook

- Financial condition of the business

- Earnings capacity

- Intangible assets

- Market prices of stocks of corporations engaged in the same or similar businesses that have stocks actively traded in free and open markets

Other issues to examine include the reasons for the sale. Are there large capital expenditure requirements, changing market conditions, increased competition or working capital shortages? In any case. a strict review of the financial statements is necessary. Redundant assets ${ }^{4}$ (RA) should be separated from the operating assets and either excluded from the negotiations or sold with the proceeds distributed to the owners. Consequences of not dealing with RAs may mean that the "vendor does not receive full value when the business is sold. The purchaser may have an opportunity of disposing of the RAs and applying the net proceeds to the business, either in its operations or as a reduction of the acquisition debt incurred" [HEND88]. As well. real estate assets should be separated from operating assets. Returns on real estate may be less or more than the business return but seldom the same and therefore, may not fully be taken into account in pricing the business. Moreover. in businesses with a long history. many of their real estate assets are significantly undervalued because they were bought for much less than they are worth now and evaluating them at market is often not possible [HEND88].

Information packages must be prepared containing the qualitative and quantitative information about the private company. These are listed in Table 2-4. 
Table 2-4 Information Requirements on Private Companies for Valuation

\begin{tabular}{|l|l|l|}
\hline History of the company & Reasons for selling & Opportunities \\
\hline Description. of current operations & Products/services & Market analysis \\
\hline Summary of tinancial performance & Corporate profile & Competition \\
\hline Key financial assumptions & Customer profile & Supplier profile \\
\hline Fixed assets description & Organizational chart & Employee base \\
\hline
\end{tabular}
[HEND88]

\subsubsection{Adjustments to Private Companies for Valuation Purposes}

Wise examined the discounts that apply when valuing shares of private corporations [WISE90]. He observed factors that could affect the outcome of a valuation. This included portfolio, dis-synergy, key-men. and income tax discount. Portfolio discount deals with the fact that while the "value of each property may represent. on an individual basis, the highest price obtainable. the mix and quantity of the property may result in the bundle en bloc being less attractive to a purchaser than each one viewed individually“ [WISE90]. Thus, a discount to the price has to apply. Synergy is a benefit expected from a purchase, for example. economies of scale, reduction or elimination of competition, or increase in market share. Dis-synergy discount is the opposite of this. and would account for the disadvantages that come from increasing in size. such as increased operations, management, and such. Key-men discount recognizes that there are some employees that are vital to the business. and this value, sometimes 25$45 \%$ of the price, must be discounted in arriving at the fair market value of the business. Finally. income-tax discount considers the impact on share valuation of taxes and takes into account the recapture of tax depreciation, capital gains, and tax on proceeds of intangibles.

\footnotetext{
${ }^{4}$ Redundant assets are assets owned by the company that are not required in its day to day operations, examples include properties, investment in subsidiaries that are not of the core business, and investment portfolios. [HEND88]
} 


\section{Chapter 2 Literature Review}

Weaver looked at discounts caused by lack of control and lack of liquidity and marketability [WEAV98]. Perception dictates that risk is less if the investor has the right to control the business. An adjustment to the price of a business has to be made for lack of control. He quoted many studies that try to determine an appropriate amount for this rate. The important issue here is that a rate actually exists but quoting values from other studies is futile; each case is unique and must be examined individually to arrive at the discount rate. Studies included Lyons and Wilczynski [LYON89] who found the range to be $27-28 \%$. This amount was found from premiums paid in M\&A from 1968-1987. Pratt [PRAT93] studied takeovers of companies and the premium paid by the company taking over. The premium is converted to a percentage that acts as an estimate for lack of control. and is directly abstracted from actual market transactions. The discount level was found to be $26-33 \%$. Weaver noted that it is "interesting to see this level of discount (that) exists even for SEC regulated companies where minority shareholders have more protection than with small partnerships" [WEAV98].

Lack of marketability and liquidity is concerned with the lack of a real market for the shares and the fact that investors prefer liquidity. Again, quoting many studies. one can conclude that this rate exists [but it is specific for each situation and there is no easy formula to apply. Chaffe [CHAF93] used Options Pricing Theory to tind this amount. He applied a European option. which results in a lower price than using American options. and showed a minimum applicable discount. Applying the Black-Scholes Put Formula the amount is $28-41 \%$ when the marketability is constrained for 2 years. It is $32-49 \%$ using 4 years. Smaller firms with weaker earnings trade at much higher discounts than larger firms. Management Planning Inc, a valuation company, prescribed 


\section{Chapter 2 Literature Review}

five factors that are predictive of restricted stock discounts. The more stable/higher these variables are the lower the market discount [MERC97]:

1. Revenue

2. Recent earnings

3. Market price per share

4. Price stability

5. Eamings stability

\subsection{Initial Public Offerings (IPOs)}

An initial public offering is a company"s first sale of stock to the public.

Companies generally issue an IPO to raise money and to increase their financial base and ability to make acquisitions. Most IPO literature recommends that to price an IPO one should initially look at and compare its operational and financial performance with that of several public companies in the same or a similar industry. In order to compare private manufacturing companies one should look at the industry as a whole. and then at the specific 4-digit SIC Code. For companies going public. the factors that influence price include the ownership retention in the business. and the risks associated with the IPOs. All this information should be applied back into and included in a complete valuation procedure.

\subsubsection{Underpricing and Signaling Factors}

There is an extensive amount of literature on the underpricing phenomenon of IPOs and their average first day return and the signaling factors associated with them. Signaling factors are issues such as percentage retention of stock by the original owner(s). A number of studies find that IPOs experience large increases in value during their tirst day of trading. Ibbotson et al [BBBO94] found an average return of $16 \%$, while others have found $1.91 \%$ [LEVI95]. Most found that IPOs underperform by the end of 


\section{Chapter 2 Literature Review}

their first year or within 3 years [LEVI95]. Underpricing is due to uninformed investors and the uncertainty surrounding the true value of the issue. The underpricing can be explained by the "winner's curse." that is, smaller less informed investors suffer winner's curse because they receive a smaller fraction of the coveted issues and more of the unpopular issues [IBBO94]. Stoughton [STOU98] tound a relation between the fraction of shares owned by large investors and company performance. He concluded that the value of a firm 's IPO is determined by its ownership structure. If larger investors buy stakes in the company, the offering price and revenues raised are higher. Firth also found a positive ownership retention signal [FIRT97]. Jain [JAIN99]. on the other hand, investigated whether the performance of IPOs is improved by lead investment bank monitoring. He found that bank reputation is positively correlated with post-issue performance of IPO firms. He used a Carter and Manaster [JAIN99] study on ranking underwriters according to reputation. The "reputation proxy is based on the relative placement of underwriters in tombstone advertisements over the period of 1979-1984" [JAIN99]. It is aiso important to investigate if the underwriters have warrants in the company as this can influence an increase in monitoring. Warrant holders are tied to the long-term performance of the company, and will want to insure that the company is doing well.

[LJUN97] investigated the underpricing of IPOs. He found that stock market returns. the macroeconomic climate. ownership retention. and inverse offer size have a positive effect on underpricing. He also showed that German IPOs experience losses of $12 \%$ over the tirst three years of trading when compared with the market (exclusive of the initial underpricing return). 


\section{Chapter 2 Literature Review}

[KIM95] investigated the information contained in the prospectuses for new issues and found important financial variables that affect the pricing of IPOs. These variables included EPS, offer size. offer type. and industry-wide prospects. [BYRN94] found initial returns are related to firm size. method of issue, the market in which the issue is made. and the concurrent return on the market index. The average returns can be in part modeled by $\mathrm{P} / \mathrm{E}$ ratios.

[SEGU97] found a higher rate of mortality for lower priced (e.g. penny stocks) stocks than for higher priced securities and that investors were not properly compensated for this risk. However, mortality is not linked to market capitalization. Market capitalization acts as a discriminatory variable for returns, volatility and liquidity. If lower otfering prices signal a greater degree of lower returns, he speculated about why underwriters choose to signal this lower risk. "-If an underwriter intends to make a market in an issue following an IPO, both spread and commission revenues could be enhanced by setting a lower offer price. It is at least conceivable that the increase in revenues due to a lower offer price would be sufficient in magnitude to outweigh the additional marketing costs inherent in signaling lower quality" [SEGU97].

\subsubsection{Company Ownership}

One other issue to note, there have been dozens of articles on the performance of companies that go public and the role of management ownership. Jensen and Meckling [JENS76] claimed that the interests of managers and other stockholders become less closely aligned as managers' stakes decrease and ownership becomes more dispersed. They documented that the ownership stake of officers declines significantly from the year previous to going public to ten years later. They also observed that the median operating 


\section{Chapter 2 Literature Review}

return on assets declines from the year previous to going public to the end of the first year of public trading, but thereatter, performance does not decline in ten years. However. they found that operating performance both within one year of the offering and during the first ten years of public trading is unrelated to ownership by officers.

When specifically dealing with IPOs of private companies, insiders have better information about expected values. Ownership retained by insiders is used as a signaling model where the higher the percentage of retained shares, the higher the market valuations [RITT84]. [KLEI96], and [LELA77].

\subsubsection{Issues with IPOs}

It is important to note that there is hidden value in receiving an influx of funds/cash. either in the process of the IPO, or in a secondary offering. For example. when the company receives funds, they may now be able to attract better supplier commitments that were not possible before the addition of equity. Alternately, additional funds could change the tinancial risk of the company and improve its balance sheet.

\subsection{Intangible Asset Valuation}

Valuation is not only about fixed assets. Mullen looked at valuation of intangible assets such as brand names, trademarks, and patents [MULL90]. Intangible assets are valued just like regular assets; find the net present value of the future cash flows for the intangible assets. He suggested using the market transaction comparative method to derive multiples of sales or earnings from sales of acquisitions of similar assets. and applying these multiples, after making appropriate adjustments. to the sales or earnings of the asset to be valued. 


\section{Chapter 2 Literature Review}

The cost of a well-recognized brand name can add billions of dollars to a company's worth. The most recognizable name in the world, Coca-Cola, is estimated to be worth $\$ 72$ billion followed by Microsoft at $\$ 70$ billion [CBC00].

\section{Valuation Summary}

To summarize, there are many different methods to conduct a valuation, but each valuator or person who values companies is quick to point out that a combination of these methods works best. Therefore. no study is done in isolation. different methods are applied and a range of values reached. as supported by [MULL90], [FITC88], and [OVEN59].

Although the market-based approach finds comparable firms it is not a comprehensive search. the DEA-Valuation method will fill this gap.

\subsection{Scope and Limitations of this Study}

All these factors should be taken into account when conducting a private company valuation. However. all this information is not readily available and only applies to a complete valuation study. As well, the earnings outlook and tinancial conditions of the private company are not known. other than what can be interpreted from the financials. This far exceeds the scope and premises of this study. This study is intended to be a guide for valuators and should be considered as another tool they have at their disposal. Use of the DEA-CF method is to determine the best and most comparable public companies. Calculation of the market value is attempted by considering the lambda values to be a percentage, and multiplying this by the known market values in order to find unknown market values and also by inferring a market value range from the 


\section{Chapter 2 Literature Review}

groupings. The methodology is discussed in detail in the analysis and discussion section. Another application of this approach could be to first, find the similar companies then, instead of trying to calculate the market value, the known multiples/earnings of the public companies can be applied to the private companies. Thus one can project the earnings of the private companies using the multiples from similar public companies. Again this is information beyond the scope of this study but it is an issue to consider in a future research project. The valuation approaches examined and the analysis conducted herein are intended mainly for companies that are being acquired or sold and for IPOs. Valuation of protessional practices, dentist offices. travel agencies and such, is not included in this analysis as more often than not, rules of thumb procedure is applied to these businesses. 


\section{DATA ENVELOPMENT ANALYSIS (DEA)}

Data Envelopment Analysis (DEA) is a linear programming technique for calculating the relative performance of a population of operating entities referred to as decision-making units (DMUs). This technique considers multiple inputs and outputs of DMUs simultaneously. DEA handles multiple inputs and outputs by measuring the efficiency of a DMU as the ratio of a weighted sum of outputs to a weighted sum of inputs. subject to the constraint that the ratio is less than or equal to unity. Essentially, DEA "compares" the information available from a group of DMUs with all others in the group optimizing each individual DMU with the objective of calculating a discrete. piece-wise linear, "best practice“ trontier.

The origin of DEA is from a Ph.D. dissertation done in 1978 by Rhodes [CHAR78] supervised by Cooper and Charnes. In this dissertation. Rhodes examined the efficiency of educational institutions in the New York City district with regards to their ability to improve the development of disadvantaged children. The resulting model. named CCR after the three authors. allows calculation of relative efficiencies on the units under investigation based on a constant-returns-to-scale model. The CCR model of DEA was an extension of Farrell's single output/input technical efficiency measure [FARR57]. Following the CCR model was the introduction of the BCC model in 1984. by Banker. Charnes. and Cooper [BANK84]. The BCC model contains an added constraint of convexity. which allows DMUs to be measured on a variable-returns-to-scale basis.

In this way, DEA's original design was to measure the relative efficiency within not-for-profit organizations. Through the years. DEA has been expanded to study the efficiency of over 50 industries including banking, fast food retail. healthcare. insurance, 


\section{Chapter 3 Data Envelopment Analysis}

credit unions, highway road maintenance, and capital budgeting projects. Over 1.300 papers have been written by academics on a wide variety of theoretical and practical advances in DEA. DEA can be considered to be a combination of economics, statistics. engineering, operations research, and management techniques.

\subsection{METHODOLOGY}

DEA is a form of frontier analysis that recognizes that some DMLis perform below optimum levels. In this method, each DMU is optimized against all other DMUs. That is. the linear program assigns weights to the variables so that each DMU looks the best it can. DEA constructs the efficiency frontier and calculates the efficiency score tor each DMU based on its distance from the frontier. The score indicates the "proportion by which the unit can increase its outputs without consuming any more inputs, or conversely the proportion by which it can decrease its inputs and maintain its current output level" [SIMA00].

The graphical representation, refer to Figure 3-1, of the efficiency scores identifies the efficient as well as the inefficient DML's in the observed population. The efficiency frontier. or envelopment surface, consists of the best practice DMUs. Connecting the efficient units forms the frontier and the inefficient units are enveloped within. DEA links the estimation of the technical efficiency and the production frontier. Somewhere above the efficiency frontier is the theoretical frontier. This frontier is beyond the reach of human performance, as there is always a chance for performance improvement when human labour is involved. The DMUs that are below the best practice trontier are considered to be inefficient. For each inefficient DMU, the DEA analysis identifies the sources and the levels of inefficiency for both the inputs and 


\section{Chapter 3 Data Envelopment Analysis}

outputs by comparing the inefficient unit with a single, hypothetical, reference unit formed from the linear combination of efficient units that operate under similar conditions. This comparison determines the potential improvement obtainable by the inefficient DMU.

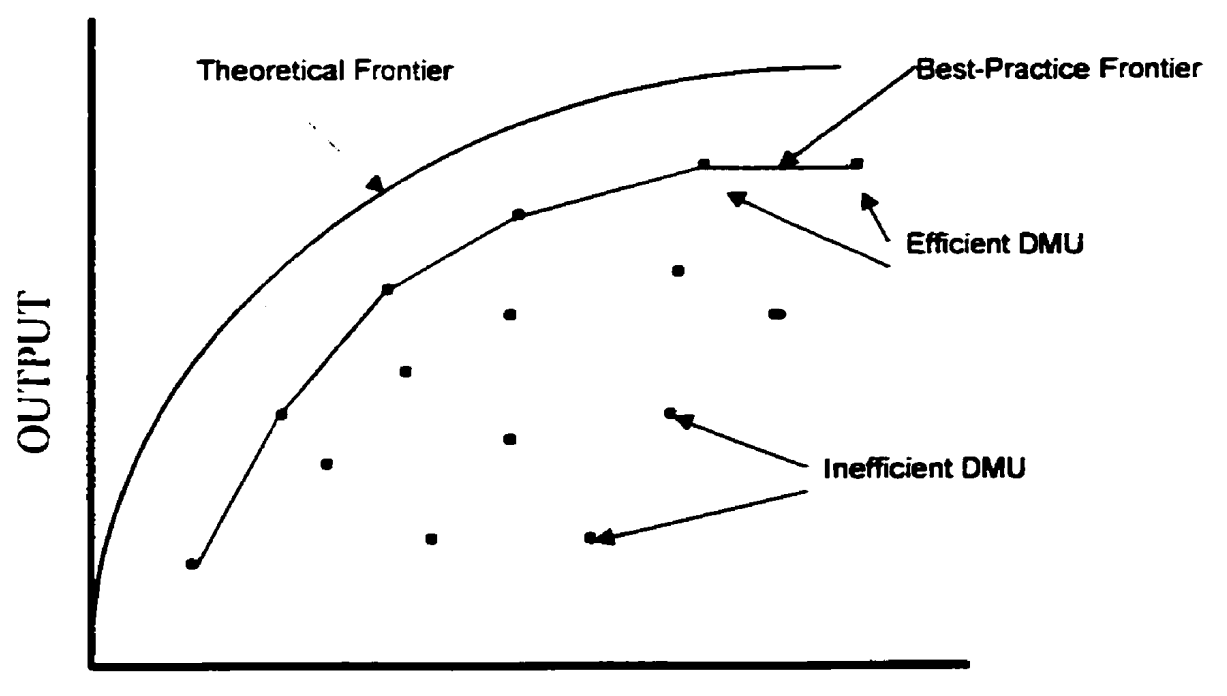

INPUT

Figure 3-1 DEA Frontier

Efficiency is typically evaluated using a ratio of output to input. The fundamental idea behind the DEA methodology is the generalization of the single-output to singleinput ratio for a DMU. using a fractional linear programming technique. The efficiency of a DMU is the ratio of the weighted sum of its outputs to the weighted sum of its inputs. This allows the DEA methodology to maximize the relative efticiency score of each DMU, given that a set of assigned weights for a particular DMU is also feasible for all the other DMUs included in the analysis. 


\section{Chapter 3 Data Envelopment Analysis}

\subsection{Identification of the Factors}

DEA provides an analytical tool for determining effective and ineffective performance, in particular, when multiple measures of performances and various discretionary and exogenous variables are involved. The first step involving the formulation of the DEA model is to identify all relevant and significant resources that are utilized by the DMUs. These resources are generally the inputs used by the DMU to produce its outputs. The outputs are the factors, which represent and describe the amount of desirable goods or services produced by each DMU. There are also many other environmental factors or exogenous factors that may influence the formulation of the model. For any of the non-quantifiable or qualitative factors, certain proxies may be assigned and then be included in the analysis.

The general desire by management when conducting a DEA analysis is to maximize their outputs while minimizing inputs used in producing the outputs. This is a particularly important issue during the formulation of the model and the identification of the factors. 


\subsection{Mathematical Formulation}

The Charnes et al. [CHAR94] model for DEA was formulated to maximize the efficiency of each DMU subject to the constraint that the efficiency of all DMUs be less than or equal to one. The algebraic representation of the model is as tollows:

$$
\begin{aligned}
& \max Z=\frac{\sum_{i} u r y_{n}}{\sum_{i} v_{i} r_{i n}} \\
& \text { subject to } \frac{\sum_{r} u r y n}{\sum_{r} v_{i j}} \leq 1 \text { for each unit } j \\
& \mu_{r}, v_{i} \geq \varepsilon \\
& \mu_{i}=\text { the weight given to output } i \\
& v_{i j}=\text { amount of output } i \text { from unit } j \\
& v_{i}=\text { the weight given to input } i \\
& x_{i j}=\text { amount of input } i \text { to unit } j
\end{aligned}
$$

The two most prominent models of the DEA methodology are the CCR and BCC ratio models. The CCR model is also referred to as constant returns to scale (CRS), and the BCC model is used interchangeably with the name variable returns to scale (VRS). Both of these models address managerial and economic issues and provide useful results, but the orientations are somewhat different. Within both the CCR and BCC model a decision can be made as to whether an input or output orientation is required for the analysis. This information is usually derived from the objectives given by the management or the executives of a particular organization. The formulation of the model can be oriented towards output maximization or input minimization. If a particular output level is demanded. or more specifically. if a corporation has a production standard for these DMUs. an inefficient unit can be made efficient through the reduction of its input levels while holding its output levels constant; this is referred to as an input- 


\section{Chapter 3 Data Envelopment Analysis}

oriented model. If the corporation has established amounts of input resources available to these DMUs, the inefficient units can be made efficient through increases in its outputs, while holding input resources constant; this is the output-oriented model.

Figure 3-2 represents how inefficient units are projected onto the frontier depending on whether the analysis requires input minimization or output maximization. The peers tor the inefficient company $C$ are company $A$ and company $B$ for input minimization and company $\mathrm{B}$ and company $\mathrm{D}$ for output maximization.

Figure 3-2 Projecting the Ineficient Unit to the Frontier

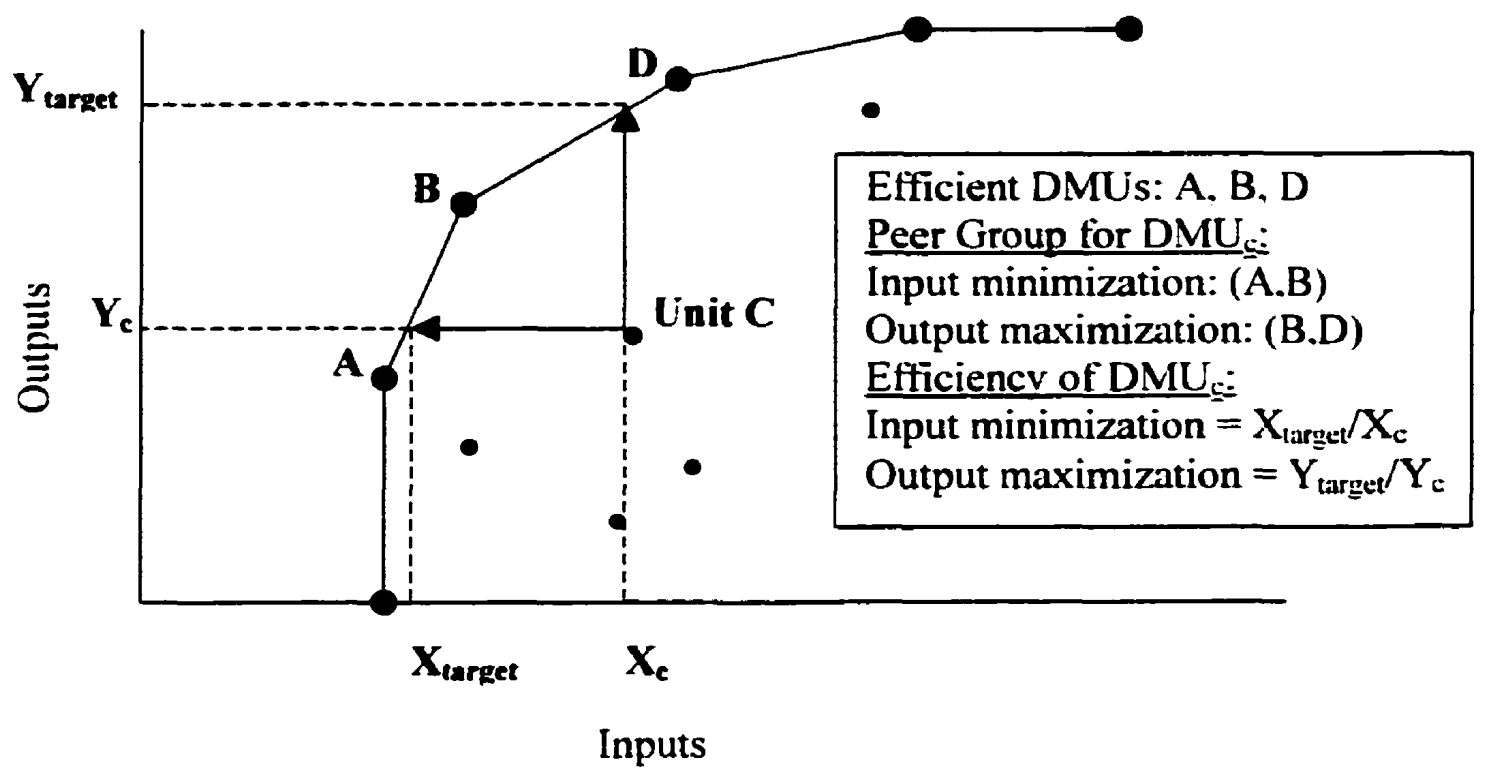

\subsubsection{The CCR Ratio Model}

The CCR ratio model focuses on the identitication of the overall efficiency of the DMUs studied. It also identifies the sources and estimates the potential improvements available for the inefficient DMUs. It is important to note that the CCR model provides the envelopment surface that represents CRS. This assumption illustrates that any 


\section{Chapter 3 Data Envelopment Analysis}

increase in one input results in a proportional increase in at least one output or a proportional decrease in one or more inputs must hold true among all the DMUs.

\subsubsection{CCR Input Oriented}

Input-Oriented CCR Primal

Min. $z_{1}=\theta-\varepsilon \cdot \overrightarrow{1} \mathrm{~s}^{-}-\varepsilon \cdot \overrightarrow{1} \mathrm{~s}^{-}$ Q. ins?.s.

s.t.

$$
\begin{aligned}
Y \lambda-s^{-} & =Y_{0} \\
\theta X_{0}-X \lambda-s^{-} & =0 \\
\lambda . s^{-} \cdot s^{-} & \geq 0
\end{aligned}
$$

\section{Input-Oriented CCR Dual}

Max.

$\mu, \mathrm{v}$

s.t.

$$
\begin{aligned}
v^{T} X_{0} & =1 \\
\mu^{T} Y-v^{T} X & \leq 0 \\
-\mu^{T} & \leq-\varepsilon \cdot \vec{l} \\
-v^{\top} & \leq-\varepsilon \cdot \vec{l}
\end{aligned}
$$

\subsubsection{CCR Output Oriented}

The two approaches of CCR lead to the same envelopment surface, the only difference is how the inefficient DMU is projected to the frontier.

\section{Output-Oriented CCR Primal}

$$
\begin{array}{ll}
\max _{0 . \lambda s^{+} . s_{-}} & z_{0}=\phi+\varepsilon \vec{l} s^{+}+\varepsilon \cdot \overrightarrow{1} s^{-} \\
\text {s.t. } & \phi Y_{0}-Y \lambda+s^{-}=0 \\
& X \lambda+s^{-}=X o \\
& \lambda . s^{+} \cdot s^{-} \geq 0
\end{array}
$$

\subsubsection{BCC Ratio Model}

\section{Output-Oriented CCR Dual}

$$
\begin{aligned}
& \min q_{0}=v^{\top} X_{0} \\
& \text { s.t. } \\
& \begin{aligned}
-\mu^{T} Y_{u} & =1 \\
-\mu^{T} Y+v^{T} X & \geq 0 \\
\mu^{T} & \geq \varepsilon \overrightarrow{1} \\
v^{T} & \geq \varepsilon \cdot \overrightarrow{1}
\end{aligned}
\end{aligned}
$$

The BCC model [BANK84] distinguishes between technical and scale inefficiencies by estimating pure technical efficiencies at the given scale of operation and by identifying whether increasing. decreasing, or constant returns to scale possibilities are present for further exploitation. This model interprets the efficiency of the DMUs with the underlying assumption that a VRS mechanism exists among the population of observations. It incorporates the notion that an increase in the inputs does not necessary translate to the same proportional increase in outputs throughout all scales of operation. 
This is different from the CCR model. which assumes the input and output relationships of all DMUs exhibit a proportional or a linear relationship for all scales of DMUs. The BCC model allows the DMUs with varying scale sizes to be compared in the same DEA analysis. This is a result of the BCC model being technically efficient while CCR is scale and technically efficient. Technical efficiencies are efficiency measures that ignore the impact of scale-size by comparing a DMU only to other units of similar scale. On the other hand. scale efficiency depends on the size of operations and makes this optimal. Any modification to the size will cause the unit to be less efficient.

\subsubsection{BCC Input Orientation}

The input oriented BCC model focuses on maximizing the DMUs performance by reducing the inputs or, in other words. produces the observed outputs with a minimum resource level. The linear programming model for the BCC model is:

Input-Oriented BCC Primal

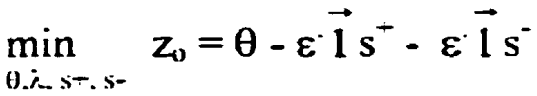

$$
\begin{aligned}
& Y \lambda-s^{-}=Y_{0} \\
& \theta X_{0}-X \lambda-s^{-}=0
\end{aligned}
$$

(Constraint of Convexity) $\overrightarrow{1} \lambda \geq 1$

$$
\lambda, s^{+}, s^{-} \geq 0
$$

Input-Oriented BCC Dual

$$
\begin{array}{lr}
\max _{\mu . v} & w o=\mu^{\mathrm{T}} Y_{0}+\mu_{0} \\
\text { s.t. } & v^{\mathrm{T}} X_{00}=1 \\
\mu^{\mathrm{T}} Y-v^{T} X+\mu_{0} \overrightarrow{1} \leq 0 \\
-\mu^{\mathrm{T}} \leq-\varepsilon \overrightarrow{1} \\
-v^{\mathrm{T}} \leq-\varepsilon \overrightarrow{\mathrm{l}}
\end{array}
$$

Where $s^{+}$and $s-$ are the input slacks and output slacks respectively; $\mu$ and $v$ are the multipliers: $\mu_{v}$ is the measure of scale efficiency. If $\mu_{0}$ is negative then it indicates increasing returns to scale (IRS). If it is positive then it is operating at decreasing returns to scale (DRS), and if it is zero then it is operating CRS. Theta. $\theta$, is the proportional reduction which has to be applied to all inputs of the DMU being evaluated to improve its efficiency. The $\varepsilon$ allows optimization to occur in two steps. First, the inputs are 


\section{Chapter 3 Data Envelopment Analysis}

minimized by the optimal $\theta$. Then the optimization involves a movement to the frontier by the input and output slacks. Lambda, $\lambda$, indicates the level of contribution of efficient firms to the virtual DMU created by the projection of an inefficient DMU onto the frontier. Those units that contribute to the construction of the imaginary composite unit will have non-zero dual weights. $\lambda_{k}$. and make up the reference set for unit $\mathrm{DMU}_{0}$ (the DMU under consideration). The reference set for $\mathrm{DMU}_{0}$ is thus solely comprised of efficient units and serves as a basis for computing the efficiency score of unit $\mathrm{DMU}_{0}$. The magnitude of $\lambda$ indicates the "degree to which the characteristics of the efficient DMUs are used to construct the virtual DMU on the frontier to which the inefficient unit is projected" [SIMA00].

\subsubsection{BCC Output Orientation}

The output oriented $\mathrm{BCC}$ model focuses on maximizing the DMUs by proportional augmentation of the outputs. The objective is to maximize output production while not exceeding the given resource levels. The envelopment surfaces for either the input or the output-oriented BCC model are identical. The only difference is how the inefficient DMU is projected to the frontier. If $\phi$ is greater than one, than the DMU is inefficient.

\section{Output-Oriented BCC Primal}

$$
\begin{aligned}
\max _{0 . j-\mathrm{s}_{-}} \mathrm{z}_{0}=\phi+\varepsilon \cdot \overrightarrow{1} \mathrm{~s}^{+}+\varepsilon & \overrightarrow{1} \mathrm{~s}^{-} \\
\text {s.t. } \quad \phi Y_{0}-\mathrm{Y} \lambda+\mathrm{s}^{+} & =0 \\
X \lambda+\mathrm{s}^{-} & =\mathrm{Xo} \\
\overrightarrow{1} \lambda & =1 \\
\lambda, \mathrm{s}^{+}, \mathrm{s}^{-} & \geq 0
\end{aligned}
$$

\section{Output-Oriented BCC Dual}

$$
\begin{array}{rr}
\min _{\mu . v} & q_{0}=v^{T} X_{0}+v_{0} \\
\text { s.t. } & -\mu^{T} Y_{0}=1 \\
-\mu^{T} Y+v^{T} X+v_{0} \vec{l} \geq 0 \\
\mu^{r} \geq \varepsilon \vec{i} \\
v^{T} \geq \varepsilon \vec{l} \\
v_{0} \text { tree }
\end{array}
$$




\subsection{Differences between the BCC and the CCR model}

There are some key differences between the BCC and the CCR model. The BCC frontier does not have to start from the origin while the CCR does. In the CCR model. there are less efficient DMUs. the values of $\theta$ are generally smaller, and the values of $\phi$ are generally larger. To convert the BCC input oriented model to the CCR input oriented model the constraint of convexity, $\overrightarrow{1} \lambda \geq 1$. is removed from the primal model, along with the $\mu_{0}$, from the dual model. In a similar manner, $\vec{i} \lambda=1$ and $v_{0}$ are removed from the BCC output model to arrive at the CCR output model. Figure 3-3 depicts the difterences between the models.

Figure 3-3 Graph of VRS and CRS

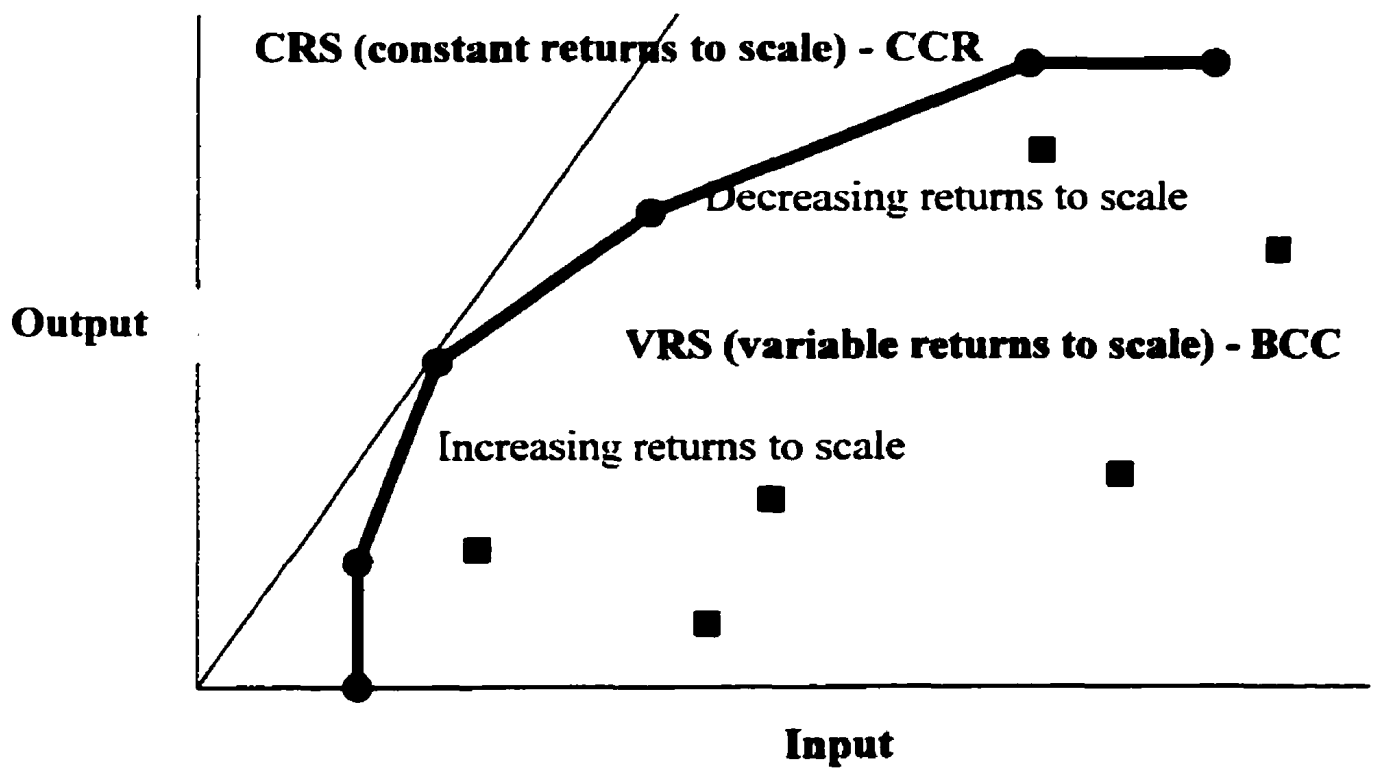

\subsection{Interpretation of DEA}

Using these formulations, DEA identifies the potential improvement for the inefficient DMUs. The information derived trom the analysis is intended as a guide for policy making and managerial decision making in an organization. It provides a better 


\section{Chapter 3 Data Envelopment Analysis}

understanding of efficiency. and guides the management in establishing benchmarks for similar operations. Most importantly, the analysis helps direct management's attention to the DMUs that are not performing as well as their peers in similar environments. This knowledge directs the organization towards a more effective management process.

\subsection{Advantages and Disadvantage of DEA}

DEA calculations give new insight and permits new ways to examine data. Some of the new insights are:

1. Focus on individual observations in contrast to population averages

2. Produce a single aggregate measure for each DMU in terms of its utilization of input factors (independent variables) to produce desired outputs (dependent variables)

3. Can simultaneously utilize multiple outputs and multiple inputs with each being stated in different units of measurement

4. Can adjust for exogenous variables

5. Can incorporate categorical (dummy) variables

6. Are value tree and do not require specification or knowledge of a priori weights or prices for the inputs or outputs

7. Place no restriction on the functional form of the production relationship

8. Can accommodate judgment when desired

9. Produce specific estimates tor desired changes in inputs and/or outputs for projecting DMUs below the efficient frontier onto the efficient trontier

10. Are Pareto optimal

11. Focus on revealed best-practice frontiers rather than on central-tendency properties of frontiers

12. Satisfy strict equity criteria in the relative evaluation of each DMU

[CHAR94]

\section{Disadvantages}

Major issues with DEA are that there are no possible improvements or targets for the efficient DMUs. correlation among the variables cannot exist, and weights are assigned freely and may thus ignore important variables. 


\section{Chapter 3 Data Envelopment Analysis}

\subsection{Practical Requirements of DEA}

There are certain issues in DEA that need to be addressed. mainly the number of DMUs. the environment, the weights, and the difference between the data. First, DEA works best when there is at least three times as many DMUs as the sum of the number inputs and outputs. If this requirement is not met, the majority of DMUs will be on the efficient frontier and the assessment will not convey proper results. Second, it is essential that the DMUs evaluated come from a similar environment. It is not appropriate to compare manufacturing and service industries against each other since they both have very different objectives and management styles. Some further insights can be gained about DEA from the weights used. DEA assumes equally proportional improvements of all inputs or all outputs. This assumption becomes invalid when a preference structure over the improvement of inputs (outputs) is present in evaluating inefficient DMUs [THAN92]. This leads to the third issue. the unrestricted weights may mean some of the inputs or outputs, especially if the DMU is doing poorly in that dimension may be assigned a weight of zero, where in reality all of the variables contribute in some way to the overall efficiency. This stems from the fact that each unit is assigned weights so that it looks the best it can. To address this problem, the weights can be restricted using analyst and management input. Bounds can be placed on the importance of each of the factors so that the weights assigned are more realistic. Finally, if some of the data points are extremely large when compared to the rest of the variables, these DMUs have potentials to be outliers and may be anomalies in the study. 


\section{Chapter 3 Data Envelopment Analysis}

\subsection{DEA Analysis and Firm Valuation}

The different valuation approaches and the different applications of DEA have been discussed, but so far a discussion of the usefulness of DEA and valuations therefrom has not been covered. The main motivation for this research comes from a Ph.D. dissertation by Simak [SIMA00] on this subject. In this work. Simak examined DEA and private company valuation and proposed a DEA model to identify similar public companies to the one under scrutiny. The resulting peer groups from the DEA analysis identify the similar companies, which when combined with their efficiency scores, the "peer" companies can be found. The model uses data on 51 public manufacturing companies. The peer group for each inefficient company is identified and other companies that have the same peer groups are collected. A difference indicator variable, $d_{i j}$. between company $i$ and $j$ is introduced:

$\mathrm{d}_{\mathrm{ij}}=\sum_{k}(\lambda i k-\lambda j k)^{2}$. where $\mathrm{k}$ is the coefficient of all the efficient companies.

The lower the $d_{i j}$ value. the more similar the companies are. He also examined the closeness of the efficiency scores. By looking at the market capitalization (MC) of these public companies and testing if the DEA analysis found peer companies with similar MCs. the tactors can be combined to reveal the best possible peer(s) for the subjectcompany. The results were encouraging provided adequately similar public companies were availabie for reference.

DEA coupled with valuation will allow multiple inputs and outputs to be used in the same model. The DEA comparable firms model is an extension of the market approach in order to find comparable companies. DEA is otten used to find the most 


\section{Chapter 3 Data Envelopment Analysis}

efficient units but now it can be used to tind proper peer groups. This paper will extend the approach started by Simak [SIMA00], but differs in several respects. The factors used for valuation are different. Also, two new methods are introduced. one to value efficient companies and one to determine upper bounds for the inefficient companies. No estimation of the value of efficient companies has ever been attempted before.

\subsection{Novel Applications of DEA}

Kim and Hendry [KIM98] utilized DEA to assess NATO burden sharing among each member nation in order to determine relative size of their net-burden. This is a novel application of DEA. which examines a net-burden index for each member nation (the ratio between contributions to an alliance and benefits received therefrom). instead of calculating relative etficiencies. In this work, two different models are evaluated and three of the nations appear on the frontier in both models. These nations are given a rank of one. Subsequently, each model is examined individually and the remaining nations are ranked according to descending net burden starting at four. Next, a cluster analysis is applied to both the models to determine the relative position of the DMLs on the frontier. Also, the efficiency score from both the models were graphed against each other to get a simulation of the frontier. The results from the cluster analysis support the frontier found from the plot of the efticiency scores.

Zhu [ZHU00] conducted one of the best studies on DEA and company efficiency. In this work Zhu examines financial performance of Fortune 500 companies using DEA. The data is from the April 1996 issue of Fortune Magazine. The investigation found that the top-ranked companies by revenue do not necessarily perform efficiently. and that only $3 \%$ of these companies were on the best-practice frontier. 


\section{Chapter 3 Data Envelopment Analysis}

Fortune magazine used 8 factors in evaluating companies, mainly revenues, profits, assets, number of employees, stockholders' equity (SE), market value, earnings per share and total return to investors. Zhu did not deem utilizing all of these factors in a single DEA model for performance satisfactory. Instead a different combination of these factors was sought. Zhu tested three models in order to obtain an overall performance index. The first model, called protitability. had three inputs (employees. assets. and stockholders' equity) and two outputs (revenues and protits). The second model. named marketability, had two inputs and three outputs. (namely the outputs from the first model were considered as the inputs into this one), and the new outputs were market value, EPS and total return to investors. The third model combined the tirst two models, it used the inputs from the first model and the outputs from the second model, and thus it had three inputs (employees. assets, and stockholders ${ }^{\circ}$ equity) and three outputs (market value. earnings per share and total return to investors). This third model was meant to represent the overall performance/efficiency. The models are shown in Figure 3-4.

Figure 3-4 Zhu's DEA Model for Company Performance

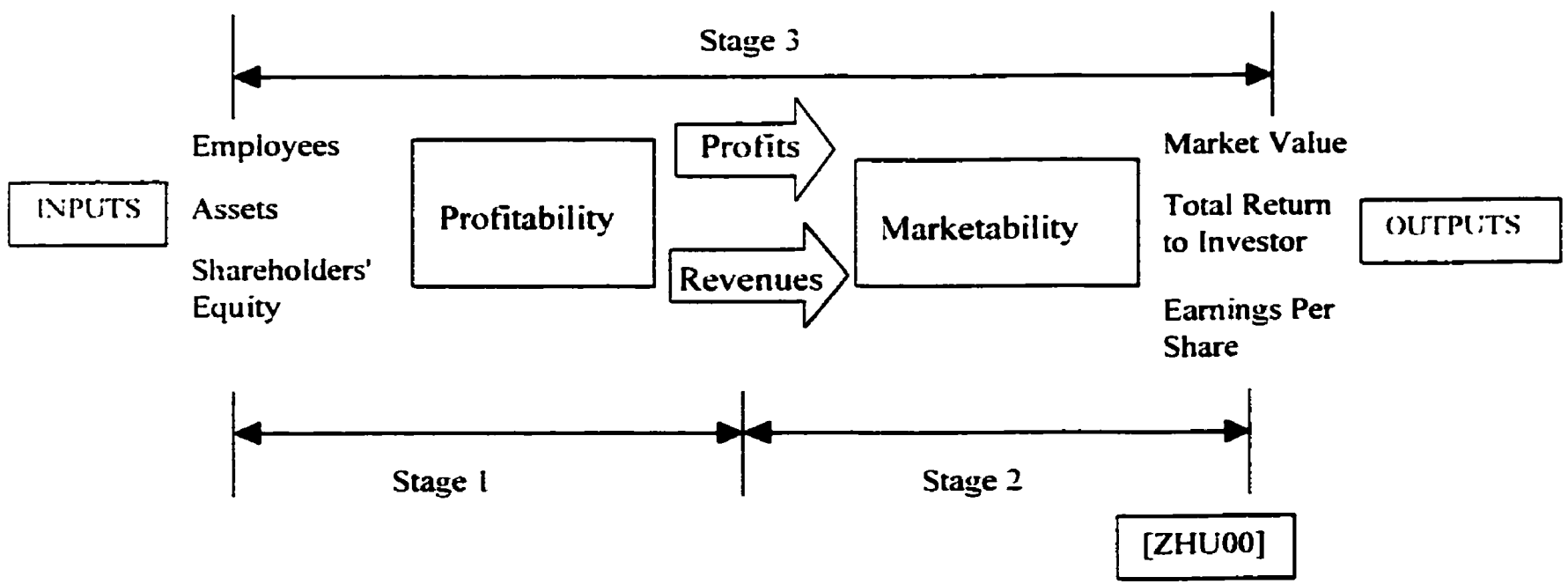




\section{Chapter 3 Data Envelopment Analysis}

Zhu showed, with this DEA analysis, that the larger companies exhibit decreasing returns to scale (DRS). Testing the data for errors using a sensitivity analysis proposed by Seiford and Zhu reveals that the best-practice frontier is reliable [ZHU00]. An inputoriented CRS model was employed in which the DEA methodology was modified to show performance measures that better reflect the way businesses rank against each other. Results showed that substantial input savings could be achieved as evidenced by the distribution of the CRS scores. Most industries performed better with model-1 (protitability) than with model 2 (marketability), and the model 2 scores were better than efficiency scores tor model 3 (overall efficiency).

In addition to the CRS model Zhu also investigated the VRS model in order to examine returns to scale. The VRS version of model 1 revealed an etficiency of 0.46 as opposed to 0.4 for CRS. In model 2 it was 0.29 with CRS and 0.54 with VRS and in model 3 it was 0.25 with CRS and 0.31 with VRS. The $t$-test is applied to the CRSinefficient companies, "the results show that the mean of the paired differences between CRS and VRS scores for the three-model evaluations are significantly greater than zero (the values are equal to $13.5,21.5$ and 14.3 for model 1 , model 2 and model 3 , respectively, at levei 0.01$)^{--}$[ZHU00]. The $t$-test indicated that the ratios were significantly less than $\mathrm{l}$. Therefore serious scale inefficiencies were present in the Fortune 500 companies. A summary of the above results is displayed in Table $3-1$.

Table 3-1 Summary results for $\mathrm{Zhu}$ analysis

\begin{tabular}{|l|l|l|l|}
\hline & VRS & CRS & t-test (0.01) \\
\hline Model I & 0.46 & 0.4 & 13.5 \\
\hline Model 2 & 0.54 & 0.29 & 21.5 \\
\hline Model 3 & 0.31 & 0.25 & 14.3 \\
\hline
\end{tabular}


Upon further investigation into scale efficiency and returns-to-scale. Zhu found that the top-20 companies were not only scale inefficient, but they also operated in a DRS region. while most relatively small companies operated in an IRS region.

For the performance of inetficient companies, "one may use the average factorspecitic scores within each industry to characterize the factor-specific industry efficiency. However, different companies with different sizes may exist in each industry. Therefore arithmetic averages may not necessarily be a good way to characterize the industry's efficiency, usually, one expects bigger input and output levels, from relatively big companies“" [ZHU00].

To summarize, DRS are found mainly among the top ranked companies by revenue. Sensitivity analysis shows which production factor will not affect an efficient company's tinancial performance given that all other production factors are kept at their current levels. This information is useful when a company considers its future policy against other companies. 


\section{DEA-VALUATION MODEL FORMULATION}

This chapter presents the development of the DEA valuation model along with the selection of relevant inputs and outputs. After the appropriate variables are ascertained, the DEA valuation model is constructed. The variables and the model are based on available literature. expert opinion and known valuation criteria. Possible new DEA applications to business are presented as well.

\subsection{Model Criteria}

Due to insufficient amount of knowledge about the geographic locations, social contexts and structures and other qualitative information, this study of the frontier analysis focuses more narrowly on the available financial information. A study of just the financials leads to a much more uniform study and compensates for the different management policies and procedures that may exist among the companies.

\subsection{Identification of Valuation Indicators}

Following the collection of the data, the next requirement in formulating the DEA problem is the specification of the model's inputs and outputs. The three sources of information that will be used for this purpose are available literature, expert opinion and known valuation criteria.

Articles aimed at identifying the most important indicators of value include $Z$ hu. Zhu identifies number of employees, revenues, profits, assets, shareholders equity, market value. EPS. and total return to investors as relevant variabies [ZHU00]. The current study does not have access to some of this information, for example number of employees and total return to investor, but makes use of the remaining variables. Kim [KIM99] makes use of the: preliminary offer price (POP). the offer price (OP). first 


\section{Chapter 4 DEA-Valuation Model Formulation}

market price. proceeds. EPS, preissue book value per share (BPS preissuc $)$, postissue book value per share $\left(\mathrm{BPS}_{\text {postissue }}\right)$, sales, $\mathrm{P} / \mathrm{E}$ (OP/EPS), M/B $\mathrm{B}_{\text {pre }}\left(\mathrm{OP} / \mathrm{BPS}_{\text {preissue }}\right), \mathrm{M} / \mathrm{B}_{\text {post }}$ (OP/postissue), P/S (OP/sales), and $M V_{\text {pustissue }}$ at $\mathrm{OP}$ in his analysis of the value of IPOS [KIM99]. Most of these variables are specific to IPOs and were not available to this study. Many other studies quoted earlier in the literature search section examine similar financial ratios such as $\mathrm{P} / \mathrm{E}$ and $\mathrm{M} / \mathrm{B}$. Investment bankers utilize accounting information. comparable tirms and also market demand, to try and reach a more accurate price. The key accounting variables as determined by them are sales. earnings, operating cash flow and book value [KIM99].

Another source for information regarding value was from communications with professors that teach DCF and M\&A courses. Free cash flow (FCF), 7-year revenue and profits. competing companies were some issues identitied as determinants of value.

There were also some qualitative issues to consider such as the quality of management, strength of market position. quality of products and services, level of customer satisfaction. strength of corporate culture. quality of investor communications, and effectiveness of new product development [HARB97]. The collection and quantification of these types of value indicators will need to be evaluated if they are to be included in the DEA models.

\subsection{DEA Modeling - New DEA Company Valuation Models}

There are different approaches to developing DEA models for companies. One can evaluate the service efticiency of a company and as an added feature the conversion ability of the company, or One can examine issues related to predicting market value or risk. Each of these perspectives require different variables. The choice of inputs and 


\section{Chapter 4 DEA-Valuation Model Formulation}

outputs has to reflect the objectives of the business. In the case of valuation. one wants to examine the variables and factors that optimize the ability of the company to turn its assets into profits.

Borrowing from studies done on DEA and banking efficiency. one can apply the same models to companies with some adjustments. If a bank is measured for service efficiency. i.e. the Production Model. one looks at variables such as labour, office space. loans and deposits. Thus, the cost to produce services is considered as an input and the amounts of services are outputs.

If the bank is more concerned with maximizing protit. the major concern is the Intermediation Model, the key variables being interest expense. deposits, interest income, and loans. Thus all types of costs should be treated as inputs and all types of revenues as outputs.

Tulkens and vanden Eeckaut [BERG98] list five approaches to efficient bank management. The approaches are:

1. Profit maximization

2. Service provision

3. Intermediation

4. Utility provision

5. Risk management

One can adjust the above approaches to reflect the concerns of companies instead of banks. When determining the value of a company, the key variables are not objects such as number of employees. number of offices/stores, square footage of office space, or number of products produced, time to produce and amount of sales. These are more appropriately associated with the service efficiency of a company, and thus will be deemed the Company Model. This measure can identify how good the company is in 


\section{Chapter 4 DEA-Valuation Model Formulation}

marketing and selling their products. For example, this model can be applied to companies such as McDonald's and other fast food restaurants to compare efficiencies.

The Value Model on the other hand, consists of the variables that make a company more profitable, valuable. and competitive. These variables can consist of net income. net sales, total assets. total liabilities. shareholders' equity. cash flow. capital expenditure. retained earnings, working capital and other quantitative and qualitative factors.

Also, risk management is a crucial concern for companies. One can view risk as an input. and the return from the risk as an output. Thus. if given a high risk more income is preferred to less, "minimize risk for a given level of gross revenues" [BERG98]. For a company, the DEA Company Risk Model can utilize the net income and net sales as outputs, and the credit rating, i.e. credit risk, will be the input to the approach.

\subsection{Selection of Factors}

Before the formulation of the DEA model, numerous assumptions regarding inputs and outputs has to be incorporated into the valuation model. Some of the factors involving the valuation model have been stated earlier in this thesis, however. there are a few attributes that need to be discussed. These are variables that are not readily identifiable as being relevant to either inputs or outputs in a financial operation. The characteristics of these items and other factors are discussed in this section.

The following were deemed to be the important factors used to establish the worth of a company: total assets, total liabilities. shareholders' equity, net income, net sales and 


\section{Chapter 4 DEA-Valuation Model Formulation}

cash flow. These were chosen partly based on the literature review and partly because of their significance in a valuation study. Their significance will be described below.

\subsubsection{The Inputs}

\subsubsection{Total Assets \& Total Liabilities}

Total assets and total liabilities are included as inputs to the operation because these are items one wants to minimize. There are some "off-balance sheet" issues with assets that need to be addressed. Total assets are composed of things such as fixed assets and some of these fixed assets may be perceived to distort the study. A separate appraisal may be required for certain fixed assets, for example, real estate. This is due to the fact that the valuation approaches used for the operating entity might not be appropriate for the appraisal of the real estate. Most small businesses and professional practices do not own the real estate they occupy. Real estate should be taken out of the balance sheet so comparisons can be made more readily. Thus. the related items from the income statement should be adjusted and instead a rent value included in the expenses.

Total assets have the characteristics of both inputs and outputs. Total assets consist of items such as cash, receivables, loans. inventories, raw materials, work-inprogress. prepaid expenses, total current assets. fixed assets (plant and equipment. leasehold improvement) and intangible assets. It can be a raw material in providing the funds for investment or collateral, while it can also be seen as a major contributor to liquidity. a highly desirable state for the company. Since the primary objective is to establish company value, it is more important to analyze how one can convert these assets to cash and hence profit. As a result, it is considered an input into the operation. 
Total liabilities are generally regarded as the "cost of doing business" and typically comprise accounts payable, rent. dividends payable, total current liabilities and long term debt. It is considered an "expense" in the financial operation. for that reason this measurement would be considered an input. Placing total liabilities on the input side of the model works well with the primary objective of the DEA analysis, output maximization and input minimization. Since the maximization of it on the output side of the efficiency model is highly undesirable. this item is appropriately defined as input.

\subsubsection{The Outputs}

\subsubsection{Cash flow from operation:}

Cash flow, as defined in a business and tinance sense, is equal to the net income after all cash expenses ignoring the effect of taxes. This means after interest costs but before non-cash items. such as depreciation and amortization. This can include amortization, amortization of deferred financing costs included in interest expense. noncash assets paid for services rendered. and others (minority interests. gain on disposal of capital assets, development costs written off. issuance of shares to settle outstanding debt). Defined another way, it includes items such as amortization of goodwill, amortization of deferred costs. amortization of capital assets and income producing property. Cash flow from operations does not include changes in non-cash working capital items, such as accounts receivable. inventory. income taxes payable. accounts payable, accrued liabilities. prepaid expenses, share proceeds receivable. and deferred revenue. Cash flow from operations is an item that any company would desire to maximize. Accordingly, with the central theory of DEA of output maximization and input minimization. it tits well on the output side of the model. 


\section{Chapter 4 DEA-Valuation Model Formulation}

\subsubsection{Profit and Revenue}

The outputs of the financial operation include net income and net sales. Net income includes revenues, interest and other income. depreciation and amortization, investment income, and income before tax. Net sales are revenue minus cost of goods sold. These two terms are the common items in studying the earnings potential of a company. Generally, the income from these two sources determines whether a business is profitable or not. And. of course. in the formulation of the DEA model, the maximization of these two items indicates a better performance of the business. Moreover, the inclusion of these items also allows the analyst to study the conditions of operations in these corporations and to determine their viability.

\subsubsection{Book Value}

Shareholders' equity. often referred to as book value. typically consists of equity (common and other types of shares), retained earnings. and miscellaneous shareholders equity. To provide shareholders earnings is a paramount goal for all businesses. It can provide information on how efficient these companies are in utilizing their assets to earn profits. However. this value goes down whenever the company pays a dividend, a desirable feature. When measuring return on equity. one wants shareholders equity to go down for a certain level of profit. It could be considered as input into the operation or an output from the operation. In this research. company valuation from the perspective of the company and not the shareholder should be examined: thus it is more appropriate to place shareholders' equity on the output side of the operation. Shareholders' equity is an output as it is desirable to maximize it. 


\section{Chapter 4 DEA-Valuation Model Formulation}

Finally, the model constructed aims to represent the operations of the companies. Inputs and outputs selected for the model are represented in Figure 4-1. This operational representation is the basis for the formulation of the DEA model. The specification of the formulation of the DEA model to measure the relative efficiencies is discussed below.

Figure 4-1 DEA Valuation Model

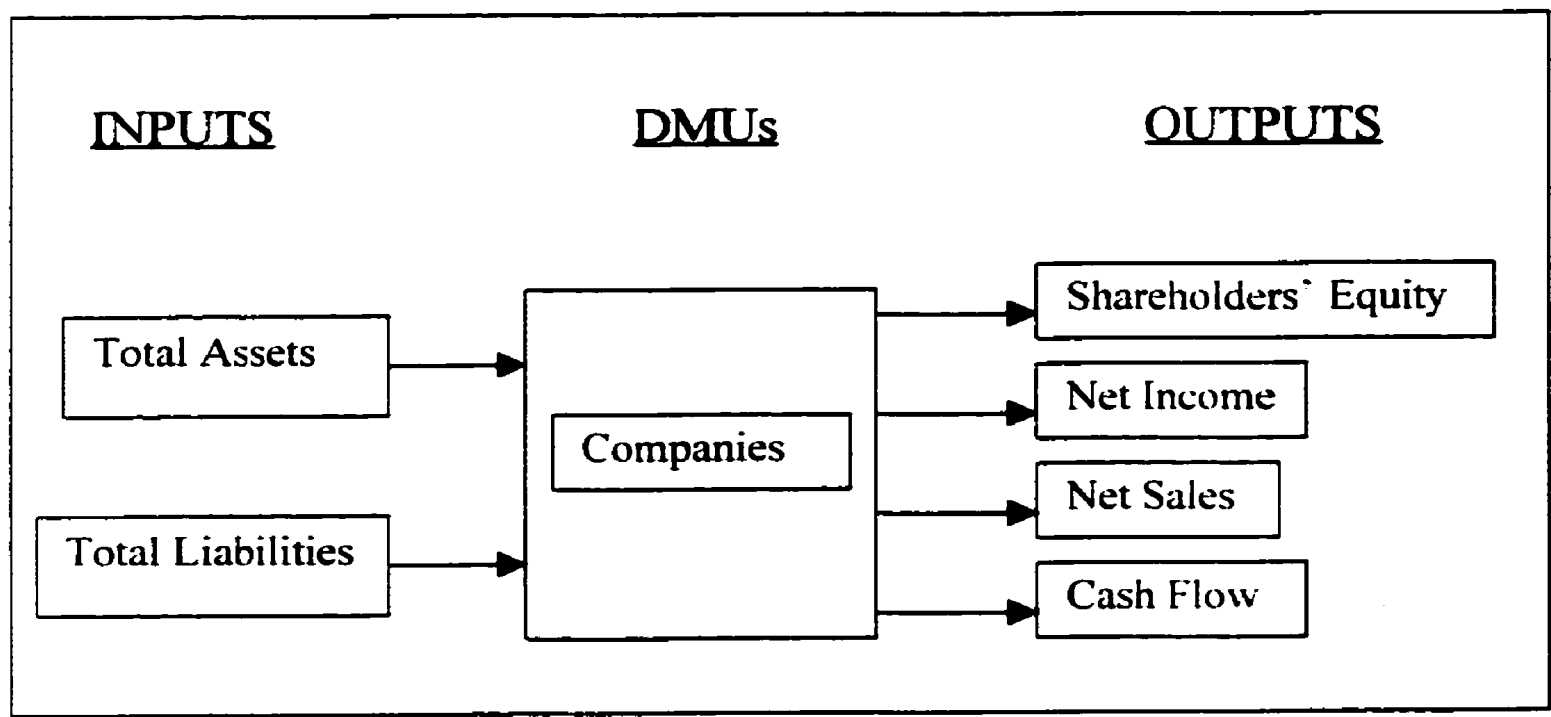

\subsubsection{Variables Not Included}

Items that are important but were not included in this analysis are market value, price to earnings ratio (P/E), retained earnings, and working capital.

Market capitalization was not directly included in the model. It is another key variable that should be examined in a valuation analysis. However. by definition, market value only exists for publicly traded companies. To be able to adapt the model for both public and private companies the variables selected have to exist in both domains. Therefore. market value was not included in the initial analysis. Total assets can be used to account for the size differences among the companies. Market capitalization is added to the analysis after the DEA-Valuation models are run. The market values are used to 
validate the results, by not including them in the analysis they can be used for this purpose.

Financial ratios are often utilized to evaluate corporate performance. The firm's ratios are compared with some benchmark value. Size is ignored and different sized firms are compared. This leads to the issue of the choice of the value to compare with. of the dozens of ratios in existence. which ratios to use. and the choice of the firms to compare with. Companies should preferably operate in the same industry and when constructing the ratio there is an assumption of proportionality among the numerator and the denominator. However, there may be instances where this does not hold [SIMA00], and this leads to problems when comparing different sized companies.

Retained earning is another very important variable in determining value. It represents the reinvested earnings over the years that have not been paid out in dividends. Many corporate raiders bought companies that had a lot of unused retained earnings. then after taking dividends resold the company. In general one wants to use the least amount of cash in the company while maintaining profit levels. Although retained earnings is not directly incorporated. the inclusion of shareholders' equity in the model accounts for it.

Next, firms need cash to pay for all their day-to-day activities. They have to pay for wages. bills. raw materials, and so on. The money available to them to do this is known as the firm's working capital. Working capital consists of current assets; these are the short-term assets that the firm can use to convert into cash. Current liabilities have to be taken into account as well to determine how much working capital a firm has at its disposal. Working capital is therefore current assets less current liabilities. An interesting issue arises when examining the assets of a company. Are the assets owned or 


\section{Chapter \& DEA-Valuation Model Formulation}

leased? Companies with leases may be overvalued, thus more efficient than companies owning their assets. This comes about because assets are located in the denominator of the model, so the smaller it is the better the DEA results. The companies that own their own property will have larger total assets than companies that lease. It is important to know if a company owns land or not. since it inadvertently adds to the value of the company. Thus it is justifiable to use total assets and total liabilities rather than current assets and current liabilities.

\subsection{Formulation of the DEA model}

In this section. the characteristics of the businesses are examined to design a DEA model that would best describe the behaviour of the industry. The available data on these companies will also be evaluated to help determine the most appropriate DEA model for valuation measurement.

A private company is a company that is not a "public $"$ company as defined by the various securities acts. It tends to be smaller in size. and typically has one or few owners. There may be significant differences in the size of the total assets of private companies versus public companies. Actually, a private company may very well have larger assets because it does not have the motivation to use all the accounting tricks available to show a larger por share earnings. Although the market values of these companies are not directly involved in the evaluation of their efficiency scores. their behavior can be inherently different due to differences in size. Applying some banking theory. it was suggested by Piesse [PIES95] that the scale and technical efficiency measurements of financial institutions are inversely proportional. that is. the larger institutions are commonly less scale etficient than their smaller counterparts. This may be due to the 


\section{Chapter 4 DEA-Valuation Model Formulation}

requirement for a significantly larger employee group in the larger units. One assumes the same holds true for companies. With such a significant range of magnitudes in asset values of these companies, it is unwise to assume that they can all operate with the same scale efficiency. Thus, the focus of this thesis will be only on the technical efficiencies of the companies, using VRS technology.

Technical efficiency is concerned with the relationship between inputs and outputs, where the measurement ignores the impact of scale size when comparing DMUs to others on a similar scale. A more detailed description of the concept of technical efficiency can be found in the DEA section. As mentioned above, the inclusion of various sizes of companies in this study requires the assumption of scale efficiency. Banker, Charnes and Cooper's BCC ratio model is used to measure the technical efficiency where the convexity constraint ensures that the unit under consideration is being compared only to other units of similar scale size.

The BCC ratio model, unlike the original CCR ratio model, allows for variable returns to scale where the proportional increase in the input does not translate to a proportional increase in the outputs for the entire range of DMU sizes. The efficient frontier produced by the $\mathrm{BCC}$ ratio model is typically a piece-wise linear surface. The slopes of the frontier representing the ratios of the efficiency scores are different in the various combinations of input and output. But all of the DMUs that are on the frontier are considered to be technically efficient.

After the determination of the appropriate DEA model, its orientation should also be decided. Companies could improve their performance by an increase in their output 


\section{Chapter 4 DEA-Valuation Model Formulation}

levels. or by a decrease in their input levels. It is observed that with the limited information on company performance, industry trends can not be reliably predicted. Financials are available only for a single year, therefore, information regarding the growth of individual companies can not be determined. With this limitation on the data, input-orientation becomes the most appropriate approach. The output-oriented model would project an inefficient unit by increasing its total output. But. the lack of knowledge on whether this is physically possible makes such a projection infeasible.

In the analysis, the CCR model is not examined due to the existence of negative variables in the data set and because it is scale invariant. The BCC model can handle negative data because it is both scale and translation invariant. Scale invariance deals with scaling the inputs or outputs of a DMU by a certain amount where the efficiency scores are not affected. Translation invariance refers to the efficiency scores being invariant to the translation of inputs and outputs by a scalar. The BCC input oriented model is translation invariant in the outputs and vice versa. Thus the efficiency of a DMU will not be affected if the outputs of all the DMUs are translated by a scalar amount. 


\section{Chapter 4 DEA-Valuation Model Formulation}

\section{Summary}

Formulating the DEA model with the available financial information is one of the goals of this thesis. Different articles cite different methodologies and indicators that can be included in a valuation model. The most accurate DEA model was identified along with the corresponding variables. In the analysis of the model no weights will be assigned to the variables since DEA does not require prior knowledge of the importance of each variable and will assign weights in accordance with the company appearing the best it can. 


\section{DATA ANALYSIS}

The data consist of financial statements for 457 Canadian publicly traded companies in the manufacturing sector all having financial records from the year ending in 1998. Each company has a SIC code between 2000-3999, which entails the entire manufacturing sector. The industries range from machine manufacturing to food and kindred products (refer to Table 5-7 for a complete list). Most companies have a different fiscal year-end, however, for this study the year-end was assumed to be standard. As well, data on both private and public companies were collected.

The manufacturing sector was chosen for the purposes of this analysis because of the availability of the data. A substantial number of the companies listed on the TSE are in the manufacturing sector. Service companies, specifically high technology, are hard to monitor since most of these companies have not been in business long enough and reliable financials do not exist or go back far enough.

The data from the year 1998 were chosen because it was the most recent, available and complete. Also, when finding comparable firms for the private companies, the bigger the set of data. the better. According to Booth [BOOT00], it is better to exclude companies that deal in resources such as pulp and paper, since they are very cyciical. and he suggested looking at the 7-year protitability of the companies. Availability of this information is an issue. Perhaps for future research someone can examine only a specific group of companies ( 50 public and one private company, all with the same SIC Code) and get data on the past or future 5 years for these companies. 


\section{Chapter 5 Data Analysis}

\subsection{Stock Prices}

To compute the market capitalization. which is equal to the outstanding shares multiplied by the stock price, historical stock quotes for the public companies had to be obtained. An arbitrary date at the end of November was chosen for this purpose.

\subsection{Public Companies}

The data for the public companies were gathered from a variety of sources. Mainly, Primark $s^{5}$-.Compact D” for December 1999 and January 2000 for Canadian publicly traded companies. The information consisted of total assets, total liabilities, net income, shareholders ${ }^{\circ}$ equity, net sales, date of tiscal year end, SIC codes. and so on. Originally, there were over 700 companies' tinancials available. Unfortunately, due to irregularities in the data. some filings from the late $80^{\circ} \mathrm{s} \&$ early $90^{\circ} \mathrm{s}$ were still included. These companies were omitted from the study and finally 586 companies were left in the data set. Missing and suspicious accounting numbers were checked and corrected if necessary. After resolving the variable selection (inputs and outputs to use in the model), the missing information was collected. Most of the missing information pertained to net sales, shares outstanding, and net income. For the case of a company having two SIC codes, chietly the primary and secondary SIC codes, only the primary was considered. Some of the companies reported in different currencies so everything had to be converted to Canadian Dollars using information on historical exchange rates. This insured that the data were consistent.

\footnotetext{
${ }^{5}$ Primark is one of the leading providers of disclosure information.
} 


\section{Chapter 5 Data Analysis}

The following sources in Table 5-1 were used to find the missing information:

Table 5-1 Financial Information Sources

\begin{tabular}{|c|c|}
\hline Information & Source \\
\hline \multirow{2}{*}{$\begin{array}{l}\text { Financial statements, } \\
\text { annual / financial reports }\end{array}$} & SEDAR homepage whww.sedar.com \\
\hline & TSE homepage www.tse.com \\
\hline \multirow{6}{*}{$\begin{array}{l}\text { The following web sites } \\
\text { were used to find the } \\
\text { closing market price for the } \\
\text { stocks. }\end{array}$} & $\begin{array}{l}\text { CDNX homepage } \\
\text { (Canadian Venture Exchange)www.cdnx.com }\end{array}$ \\
\hline & Yahoo Finance //ca.finance.yahoo.com \\
\hline & FIS Online wrww tisonline.com \\
\hline & Montreal Stock Exchange wrw.me.org \\
\hline & Stockwatch www stockwatch.com \\
\hline & $\begin{array}{l}\text { Microtiche copy of the Globe \& Mail newspaper } \\
\text { from December } 1998\end{array}$ \\
\hline Historical exchange rates & Oanda www.oanda.com \\
\hline
\end{tabular}

\section{$5.3 \quad$ Statistical Testing}

Statistical testing of the data was carried out by calculating the minimum,

maximum, average, standard deviation. and percentiles (25.50. and 75) of the data. This information is recorded in Table 5-2. Total assets (TA), total liabilities (TL), shareholders' equity (SE). net income (NI). net sales (NS). and cash flow (CFI) values are given in millions of dollars.

Table 5-2 Statistical Testing for the Public Companies

\begin{tabular}{|c|c|c|c|c|c|c|c|}
\hline & \multirow{2}{*}{$\begin{array}{l}\text { SIC } \\
\text { code }\end{array}$} & TA & TL & $\mathbf{S E}$ & $\mathbf{N I}$ & NS & CFI \\
\hline & & \multicolumn{6}{|c|}{ S(in millions) } \\
\hline Min. & 2.011 & 0.006 & 0.006 & -367 & $-8+1$ & -0.927 & -225 \\
\hline Max. & 3.999 & 395.298 & 372.286 & 64.175 & 9.718 & 236.541 & 18.969 \\
\hline Mean & 3.153 & 2.368 & 1.717 & 651 & 66 & 1.933 & 180 \\
\hline Stan. Dev. & 572 & 20.934 & 18.530 & 3.993 & 599 & 14.806 & 1.421 \\
\hline Perc. 25 & 2.759 & 5 & 2 & 2 & -2 & 3 & -0.548 \\
\hline Perc. 50 & 3.312 & 33 & 14 & 18 & 0.021 & 28 & 1 \\
\hline Perc. 75 & 3.663 & 231 & 108 & 104 & 5 & 221 & 15 \\
\hline
\end{tabular}


As can be seen from the variation in the standard deviations, across all factors, the data set is large and accounts for a large number of small and large companies, that causes the variation in the data. The data contain negative values since some of the companies had negative earnings. The range in total assets is wide and varied, from a minimum of $\$ 6.000$ (for Primero Industries LTD.) to a maximum of $\$ 395$ billion (for General Motors Corp.). Figure 5-1 represents the distribution of the total assets (log scale is used for the graphs to show a clearer picture):

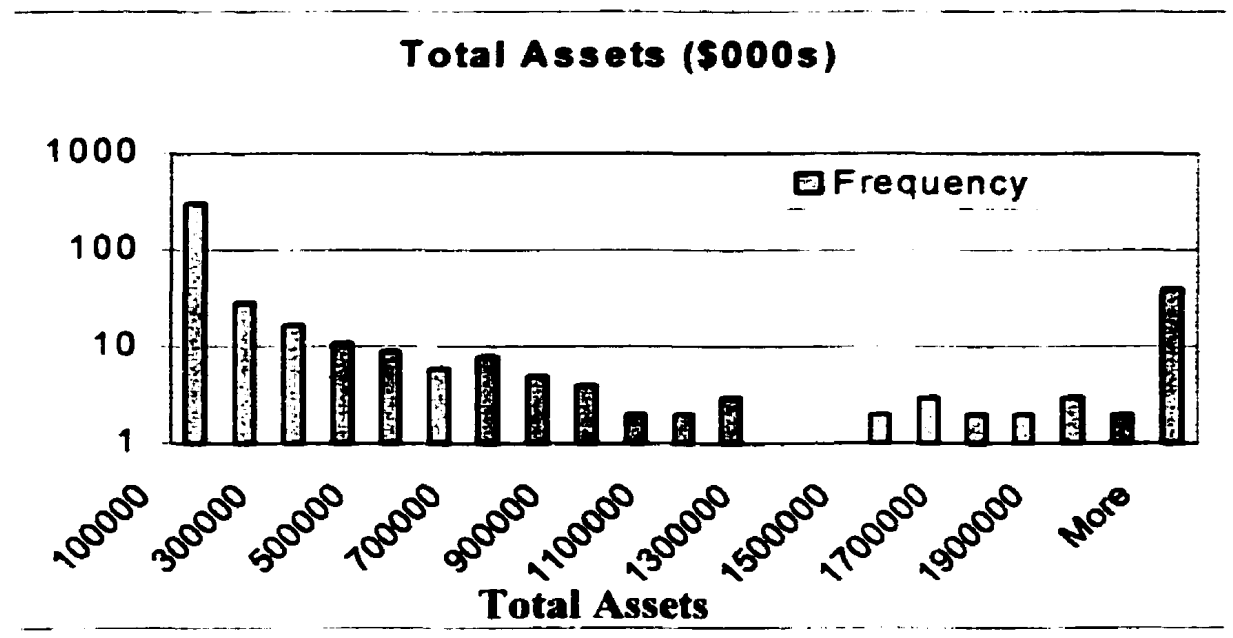

Figure 5-1 Distribution of the Total Assets for the Public Companies

As can be seen from the graph. most of the companies. 305 to be exact, have total assets of less than $\$ 100$ million. Looking more closely at these 305 companies, one can see that 68 companies have total assets of less than $\$ 2$ million and 45 have assets greater than $\$ 56$ million and the rest lie in between, as demonstrated by Figure $5-2$. 
Figure 5-2 Distribution of the Total Assets for the Companies Under \$100,000,000

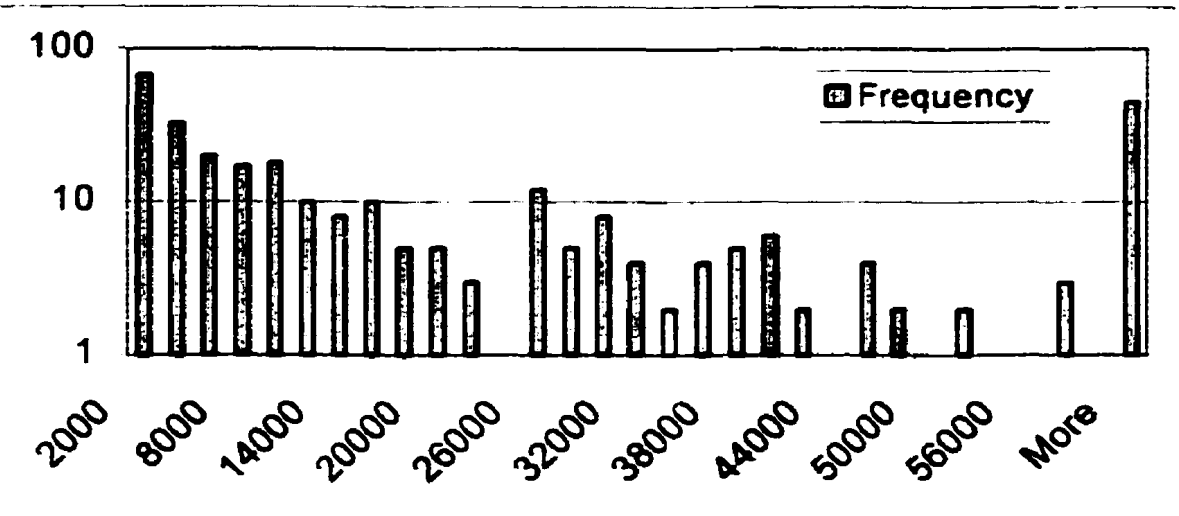

Statistical analysis of the firms ${ }^{*}$ market capitalization(MC) was also carried out, as recorded in Table 5-3. Market capitalization and market value are used interchangeable in this research. Market value consists of the outstanding shares multiplied by the stock price.

Table 5-3 Market Value Statistics

\begin{tabular}{|l|r|r|r|}
\hline & $\begin{array}{l}\text { M.C } \\
\text { (S000s) }\end{array}$ & \multicolumn{1}{|c|}{$\begin{array}{c}\text { CURRENT O/S } \\
\text { SHARES }\end{array}$} & \multicolumn{1}{c|}{$\begin{array}{c}\text { PRICE TSE } \\
\text { Dec-98 }\end{array}$} \\
\hline Minimum & 190 & 246.288 & 0.03 \\
\hline Maximum & 619.712 .000 & 9.683 .000 .000 & 259.4 \\
\hline Mean & 2.985 .071 & $57.656,805$ & 9.512 \\
\hline Standard deviation & 32.045 .700 & $461.969,188$ & 20.75 \\
\hline Percentiles 25 & 5.481 & $\mathbf{8 . 8 2 7 . 6 2 0}$ & 0.45 \\
\hline Percentiles 50 & 27.396 & 15.471 .782 & 2.25 \\
\hline Percentiles 75 & 156.723 & 31.133 .213 & 9.58 \\
\hline
\end{tabular}

The distribution of the market value varies widely from $\$ 190$ thousand to $\$ 619$ billion. The top tive companies by market value are BP Amoco, IBM, Mobil Corp.. GM, and Sony, their market capitalization are \$619. \$240. \$105. \$86 and \$53 billion respectively. Ignoring the top five companies which are multinational conglomerates. the maximum market value in the analysis becomes $\$ 50.5$ billion, which represents Nortel 


\section{Chapter 5 Data Analysis}

followed by Thomson Corp. at $\$ 22$ billion. The five conglomerates will still be included in the DEA analysis because most likely they will be self-evaluators since they are so large and they will thus not have any negative effects on the analysis. Figure $5-3$ shows a graphical representation of the market values.

Figure 5-3 Graphical Representation of the Distribution of Market Value:

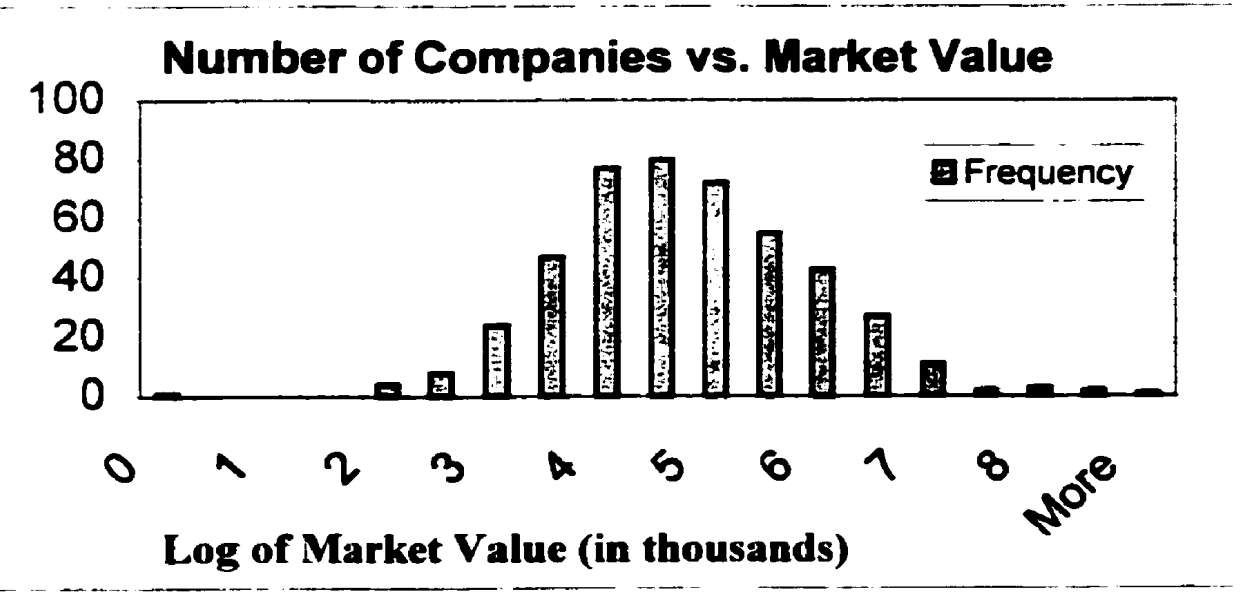

There were 16 companies that have been de-listed by the TSE, CDNX or the other Canadian exchanges. so no stock prices could be found for the year 1998. These data were removed from the analysis. Upon further examination of the market value some anomalies were found. For example, there were tive companies with market values of less than $\$ 100.000$. Subsequent analysis showed that at least one of these companies. Scott Paper. had been bought out by another company in the preceding year (1997 in this case) and still had 100.000 of its shares outstanding. The other four. mainly Consolidated General Diamond Corp. Diffracto Ltd., Lenox Polymers Ltd., and Vendtek Systems. upon further investigation were also excluded from the analysis. 


\section{Chapter 5 Data Analysis}

\subsection{Correlation}

Another important step is the examination of potential correlation among the data items. In a typical DEA analysis. correlation among the data means that some of the variables can be eliminated from the analysis in order to simplify the model. Their inclusion in the analysis may place extra importance on these factors and skew the study.

Table 5-4 Correlation Between the Public Company Data

\begin{tabular}{|c|c|c|c|c|c|}
\hline \multicolumn{6}{|c|}{ Correlation Matrix for $\mathbf{4 5 7}$ Companies } \\
\hline & TA & $\underline{T L}$ & $\underline{\mathrm{SE}}$ & $\underline{N I}$ & $\underline{N S}$ \\
\hline$\underline{\mathrm{TL}}$ & 0.98 & & & & \\
\hline$\underline{\mathrm{SE}}$ & 0.66 & 0.53 & & & \\
\hline$\underline{\mathrm{NI}}$ & 0.71 & 0.63 & 0.78 & & \\
\hline$\underline{N S}$ & $\overline{0.96}$ & 0.92 & 0.79 & 0.81 & \\
\hline$\underline{\mathrm{CF}}$ & $\overline{0.91}$ & 0.84 & 0.85 & 0.89 & 0.97 \\
\hline
\end{tabular}

As is evident from Table $5-4$, there is a high degree of positive correlation among some of the populations of the data. Specifically, total assets to total liabilities have a correlation coefficient of 0.98 . High correlation exists because the data set includes only the manufacturing industry. Manufacturing companies tend to mostly fund their assets through borrowing, thus total assets and liabilities will be highly correlated. Because they are highly correlated, they would have similar correlations with equity. Neither assets nor liabilities tend to be highly correlated with equity. as equity tends to be much smaller. The amount of total assets gives an indication of the credit worthiness/equity of a company. while total liabilities give an indication of the debt of the company. They are both necessary in the valuation scheme. Net sales and cash flow are also highly correlated. This is partly due to the fact that companies cannot have cash tlow unless they have revenues. More notably. cash flow is an indicator of tinancial well being, ignoring the impact of this variable on market value will render an ineffective analysis. 


\section{Chapter 5 Data Analysis}

These variables are essential in company valuation, thus, it is justitiable to use them together in an analysis of this nature. The same argument can be used to contend the use of the other variables in this DEA-Valuation model.

\section{$\underline{5.5 \quad \text { Private Companies }}$}

One of the big major Canadian Banks provided the private company information. It contained statistics on the companies from the year 1988-2003. including financials. SIC codes. statement date. and other financials. From this data. all the information on the companies for the year ending 1998 were extracted. for companies with SIC codes between 2000-3999. No information about the real names of the companies was known. due to the confidentiality of the information. Thus, the companies are listed by number. The data were cleaned and any duplicates eliminated. There were a total of 84 private companies after all anomalies were sorted through. Statistical information about the private companies is located in Table 5-5.

Table 5-5 Private Company Statistical Information

\begin{tabular}{|c|c|c|c|c|c|c|c|}
\hline & \multirow{2}{*}{$\begin{array}{c}\text { SIC } \\
\text { Code }\end{array}$} & $\overline{\mathbf{T A}}$ & TL & $\overline{\mathbf{S E}}$ & NI & NS & CFI \\
\hline & & \multicolumn{6}{|c|}{ (S000s) } \\
\hline Min. & 2013 & 1.760 & $\overline{802}$ & $\mid-3.436$ & -3.242 & 869 & -2.725 \\
\hline Miax. & 3999 & 2.774 .727 & 753.269 & 2.044 .190 & 457.382 & 2.604 .819 & 594,940 \\
\hline Mean & 3169 & 69.031 & 29.134 & 39.897 & 9.035 & 92.066 & 11.248 \\
\hline Stan. Dev. & 537 & 324.739 & 113,326 & 225.914 & 51.298 & 326.308 & 65.855 \\
\hline Perc. 25 & 2821 & 6.929 & 3,258 & 2.344 & 148 & 10.134 & 330 \\
\hline Perc. 50 & 3271 & 13.599 & 7,099 & 5.567 & 595 & 22.614 & 933 \\
\hline Perc. 75 & 3577 & 26.803 & 12.138 & 14.534 & 2.472 & 40.598 & 2.866 \\
\hline
\end{tabular}

As private companies tend to be smaller in size, the data appears to be appropriate with the exception of a few large private companies. The existence of this fairly large private companies will enhance the DEA analysis since there will be ample public peers. The large private firms are namely company \#156 and \#198 with total assets of \$2.8 


\section{Chapter 5 Data Analysis}

billion and $\$ 1.2$ billion respectively, and net sales of $\$ 2.6$ and $\$ 1.5$ billion. Their net income is quite reasonable at $\$ 457$ million and $\$ 103$ million respectively. The next highest values for total assets, total liabilities, shareholders' equity, net income, net sales, and cash flows are smaller at $\$ 145 . \$ 117, \$ 72, \$ 68 . \$ 416$, and $\$ 68$ million respectively. Below in Figure 5.4 is a histogram of the total asset distribution for the private companies.

Figure 5-4 Distribution of the Assets of the Private Companies

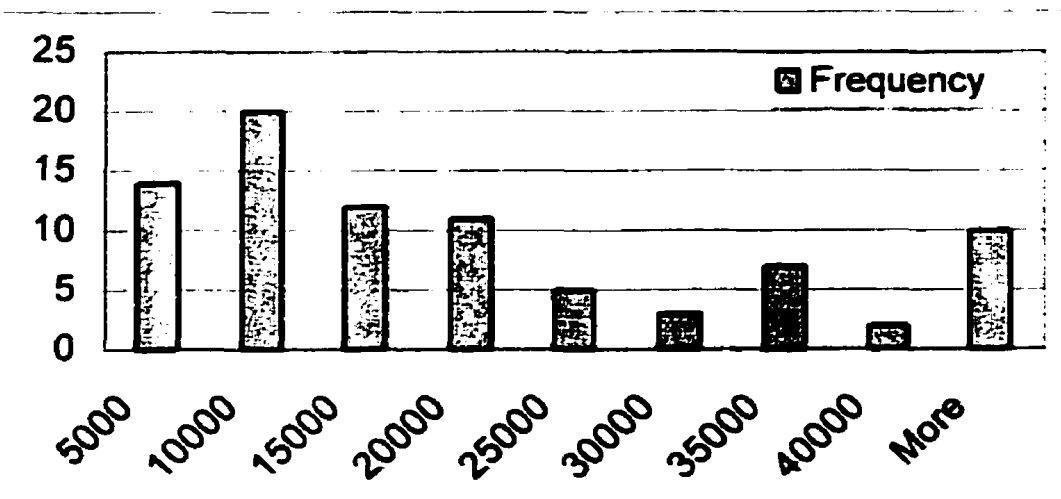

Table 5-6 Correlation Matrix for the Private Companies

\begin{tabular}{|lcllll|}
\hline \multicolumn{1}{l}{ TA } & TL & SE & NI & NS \\
\hline TL & 0.91 & & & & \\
SE & 0.97 & 0.81 & & & \\
NI & 0.97 & 0.82 & 0.99 & & \\
NS & 0.98 & 0.95 & 0.93 & 0.94 & \\
CF & 0.97 & 0.79 & 0.99 & 0.99 & 0.92 \\
\hline
\end{tabular}

A correlation analysis tor the private companies was carried out in Table 5-6 and it shows a high degree of correlation among the variables, especially net income to cash flows $(0.99)$. The preceding section on correlation among public companies pointed out the main reasons for this. Again, the purpose of this analysis is to determine the value of 


\section{Chapter 5 Data Analysis}

the private companies. For the application of the DEA methodology, the private companies must have the same variables as used for the public companies.

\subsection{Public and Private Companies}

The data was sorted by their SIC codes for both the private and the public companies. The first group included companies with SIC codes between 2000-2099; there were 18 other groups, thus aitogether 19 . In the tirst group there were 44 public companies and 4 private ones. Each of the private companies were added one at a time into the DEA model, so in this case there were 45 DML's in the DEA analysis. The companies were analyzed one at a time in the DEA analysis so as not to change the frontier too drastically. Also. one does not want a private company to have another private company in its peer group since this would not yield any useful information. The grouping chart is shown below in Table 5-7: 


\section{Chapter 5 Data Analysis}

Table 5-7 List of the SIC codes and the Corresponding Name of the Industry

\begin{tabular}{|c|c|c|c|}
\hline 510 Code & 1 & $\because$ ol publecos & $\because 011$ \\
\hline $2000-2099$ & Food \& Kindred Products & 44 & 4 \\
\hline 2100-2199 & Tobacco & 0 & 0 \\
\hline 22002299 & 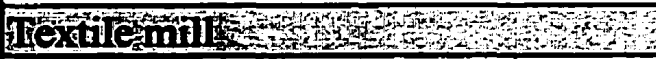 & 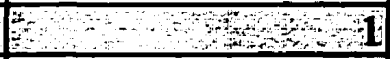 & E \\
\hline 23002399 & 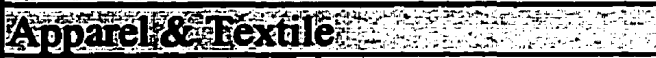 & 6 & 1 \\
\hline $2400-2499$ & Lumber \& Wood & 20 & 2 \\
\hline $2500=2599$ & Eurniture \& E Extures & 8 & 2 \\
\hline $2600-2699$ & Paper \& Allied products & 19 & 3 \\
\hline $2700-2799$ & Printing \& Publishing's & 22 & 5 \\
\hline 2800-2899 & Chemical \& Allied Products & 66 & 12 \\
\hline 29002999 & 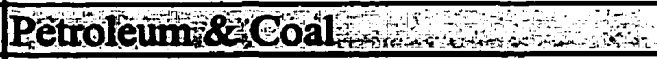 & 10 & 1 \\
\hline 30003099 & 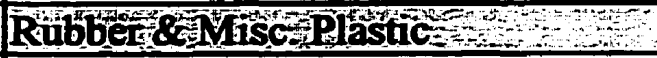 & 13 & 8 \\
\hline $3100 \times 3199$ & 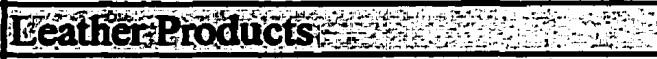 & 1 & 0 \\
\hline 32003299 & Stone olay Glass & $+\quad 13$ & 1 \\
\hline 33003399 & Primany netalifindustresu & $\quad 16$ & 5 \\
\hline $3400=3499$ & Eabricated Netall Poducts & 3 & 9 \\
\hline 3500-3599 & Machinery Except Electrical & 47 & 9 \\
\hline 3600-3699 & Electrical equipment & 85 & 3 \\
\hline 3700-3799 & Transportation & 22 & 5 \\
\hline 3800-3899 & Meas., Analyzing. \& Control. Inst. & 36 & 5 \\
\hline 3900 3999 & Misc.Mfg, (Toy, , Jewelly $/$ etc.) & 9 & 6 \\
\hline & & 452 & 84 \\
\hline
\end{tabular}

Since it is essential in a DEA study to have at least three times the number of

DMUs as the sum of the inputs and outputs ( 6 in this case), some of these private companies can not be investigated for market value. Therefore, one needs at least $(6 * 3)$ 18 DMUs for the DEA models. For the ones with less than 18 DMUs, a DEA analysis could not be carried out, as was the case for 36 of the private companies and 91 of the public companies. The shaded areas in Table 5-7 represent this. There are some models with only 19-22 DMUs. This is rather small but nevertheless a DEA analysis would be able to be carried out. The data on the public companies can be found in Appendix A. 


\section{ANALYSIS \& DISCUSSION}

Based on the models previously discussed, this chapter details the results of the DEA. The analysis is presented in five separate sections. The first section deals with public companies with SIC code 3600 s only. and calculates market values for the companies. Section two is a comprehensive study of the companies that have a SIC code in the 3700 s. Section three reports on companies that have a SIC code in the 2000s. Section four examines an efficient and an inefficient company compared with all 452 companies. Finally, section five examines the methods developed for valuing public companies and applies them to private companies.

The BCC model is run to classify the companies as efficient or inefficient. Then the two classifications are examined separately. For the inefficient companies, peers are found based on the other companies having the same efficient companies as their peers. The distance equation is applied and a range for the market value for the subject company is revealed. An upper bound is found for the inefficient companies as well. The upper bound is based on the lambda relations of the inefficient company to the efficient companies multiplied by the market values of the efficient companies. For the efficient companies, a lower bound can be tound by finding all the companies using it as a peer. summing these values and normalizing them then multiplying these by the market values and summing them to get the lower bound.

Since there are negative variables in the data, the most negative variable is found and one plus this value is added to all the outputs in the BCC model, making them positive. This can be done since $\mathrm{BCC}$ is both scale and translation invariant. 


\subsection{BCC Analysis of Companies with SIC Code 3600s}

In this section, public company analysis was carried out using the results of the DEA BCC model. The BCC model was run for the 452 companies grouped by their SIC; thus 9 models were run in total, one for each SIC grouping. The first analysis was conducted on only companies with SIC codes in the 3600 s (3600-3699) and consisted of 85 DMUs. The data for these companies can be found in Appendix B. For each company one now has their associated efficiency. lambda, slack and multiplier values. The market capitalization is incorporated back into the model to validate the findings. Once a value is estimated for the company, it can be compared back to the known market capitalization of the company to see if the results are realistic. In this grouping, there are also three private companies with the same SIC code. These are added one by one into the analysis and their results are discussed in section five.

\subsubsection{Summary Statistics}

The average efficiency of the companies is 0.73 with a standard deviation of 0.27 and a median of 0.79 . There were 23 efficient DMUs and the efficiency scores ranged

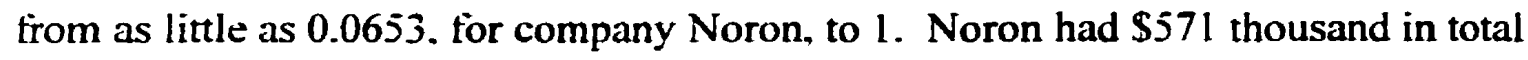
assets and \$4.4 million in total liabilities along with $-\$ 1.3$ millions in net income and $-\$ 1.2$ million in cash flow. These account for why its efficiency was so poor.

\subsubsection{Inefficient Company Analysis}

\subsubsection{Subset Hammond}

A subset of the 85 DMUs was chosen for this analysis. The peer group for company, Hammond was found. The peer group consisted of all the efficient companies Hammond was being compared to as well as all the inefficient companies that were being 
compared to the same combination of efficient companies. In the case for Hammond the peer companies were LG Technologies, Camco Inc, TS Telecom, Calian, Primetech. and Electrohome. Table 6-1 illustrates the subset group along with efficiency scores and lambda values.

Table 6-1 Hammond Subset Statistics

\begin{tabular}{|c|c|c|c|c|c|c|}
\hline \multicolumn{2}{|l|}{$\overline{\text { DMU }}$} & \multirow[t]{2}{*}{ Score } & \multirow{2}{*}{$\begin{array}{l}\text { Market } \\
\text { Cap. } \\
\text { S(000s) }\end{array}$} & \multicolumn{3}{|c|}{ Efficient Peers $(\lambda)$ : } \\
\hline$\#$ & Name & & & 7-Camco & 32-TS Tel. & 67-Prime. \\
\hline & HA.MMOND & 0.7567 & 18.426 & 0.2217 & 0.4467 & 0.3315 \\
\hline & LG TECH & 0.5865 & 27.707 & $6.03 \mathrm{E}-03$ & 0.7302 & 0.2637 \\
\hline & $\mathrm{CAMCO}$ & 1 & 100.000 & 1 & 0 & $\overline{0}$ \\
\hline 321 & TS TELECOM & 1 & 11.832 & 0 & I & () \\
\hline 340 & CALIAN & 0.8001 & 33.191 & $5.99 \mathrm{E}-02$ & 0.5935 & 0.3466 \\
\hline 67 & PRIMETECH & $\overline{1}$ & $1+3.365$ & 0 & 0 & 1 \\
\hline $7+1$ & ELECTROHOM & 0.6733 & 11.398 & 7.52E-02 & 0.4257 & 0.499 \\
\hline
\end{tabular}

Camco. TS Telecom and Primetech were on the efficient frontier and thus had a score of 1 . The inefticient companies had scores ranging from as low as 0.59 to 0.8 . The lambda values going across the table for each DMU should sum to unity in the BCC model; this is not the case with the CCR model. In the BCC model, this is due to the convexity constraint. the CCR model does not have this constraint so its lambda values have to be adjusted: refer to section two for an explanation of the adjustment. This subset was then analyzed with the Simak [SIMA00] distance equation. The distance for Hammond to LG Technologies is computed as:

$$
\begin{gathered}
\mathrm{d}_{\mathrm{ij}}=\sum_{k}(\lambda i k-\lambda j k)^{2} \\
\mathbf{d}_{\mathrm{ij}}=\sum(0.2217-0.006)^{2}+(0.4467-0.7302)^{2}+(0.3315-0.2637)^{2}=0.1315
\end{gathered}
$$




\section{Chapter 6 Analysis and Discussion}

In a similar manner the remaining distances are computed for Hammond's six peers, Table 6-2.

Table 6-2 Distances to Hammond

\begin{tabular}{|c|c|}
\hline DMU\# & $\begin{array}{l}\text { Distance } \\
\text { (from DMU } U_{\text {liammond) }}\end{array}$ \\
\hline Hammond & 0 \\
\hline LG Technologies & 0.1315 \\
\hline Camco & 0.9152 \\
\hline TS Telecom & 0.4652 \\
\hline Calian & 0.048 \\
\hline Primetech & 0.6956 \\
\hline Electrohome & 0.0499 \\
\hline
\end{tabular}

All the companies that had a distance of less than 1.0 from Hammond were then compared in terms of their efficiency scores and market capitalizations. Calian was the closest company with a distance of 0.048 followed by Electrohome, LG Tech., TS Telecom. Primetech and Camco. Calian and Electrohome were also closest in terms of efficiency score. 0.80 and 0.67 respectively, compared with Hammond's efficiency of 0.76. Electrohome was second closest by market value. $\$ 11.4$ million, followed by TS Telecom at \$1 1.8 million. Although Primetech and Camco had a distance of less than one in relation to Hammond. they were greatly different from Hammond in terms of their efficiency scores and market values and thus can be ignored as peers. The analysis determined a range for Hammond's market value based on its peers of $\$ 11.4$ to $\$ 33$ million. Hammond's real market capitalization of $\$ 18.4$ million is in this range.

\subsubsection{Upper Bound for Subset Hammond}

In this part. a new method of determining value based on the reference units for the inefficient companies is introduced and it is argued that this is an upper bound for the inefficient company. To calculate an upper bound for Hammond one uses the market 
values of the efficient companies that it was being compared to. namely, Camco, TS Telecom, and Primetech, multiplied by the lambda values of Hammond in relation to these efficient peers. The lambda values can be found in Table 6-1. This formula is exemplified by:

$$
\begin{gathered}
=(0.2217 * 100,000,000)+(0.4467 * 11,832,000)+(0.3315 * 143,365,000) \\
=\$ 74,988,000
\end{gathered}
$$

The $\$ 75$ million value thus found is considered as an upper bound on the market capitalization of Hammond. since it is based on the market values of the efficient companies. Similar analysis is carried out on the rest of the inefficient companies in this subset. The results are summarized in Table 6-3:

Table 6-3 - Subset Hammond and the Predicted Market Values

\begin{tabular}{|l|c|l|r|r|}
\hline \multicolumn{5}{|c|}{ For the Inefircient Public Companies(\$) } \\
\hline \multicolumn{1}{|c|}{ Company } & $\begin{array}{c}\text { Real Market } \\
\text { Cap }\end{array}$ & Minimum & Maximum & $\begin{array}{c}\text { Predicted Upper } \\
\text { Bound }\end{array}$ \\
\hline Hammond & $18.426 .(000$ & 11.398 .000 & 33.191 .000 & 74.988 .000 \\
\hline LG Tech & 27.707 .000 & $11,398.000$ & 33.191 .000 & 47.055 .000 \\
\hline Calian & 33.191 .000 & $11.398,000$ & 27.707 .000 & 62.705 .000 \\
\hline Electrohome & $11.398 .(000$ & $11,832.000$ & 33.191 .000 & $\mathbf{8 4 . 1 0 3 . 0 0 0}$ \\
\hline
\end{tabular}

The first two companies ${ }^{*}$ actual market values falls within the predicted range, so the model appears to work well. Calian on the other hand is not within the predicted range with a difference of $\$ 5.5$ million from its predicted upper range value. so it could be overpriced, but it is less than its predicted upper bound. Electrohome seems to be undervalued, but again it is less than the predicted upper bound. It is only $\$ 434,000$ less than its predicted minimum range value. 


\section{Chapter 6 Analysis and Discussion}

\subsubsection{Subset 2 - Company Inverpower}

The next subset in the 3600s group consists of Inverpower and its peers, which are Avante. RIM, TS telecom, Advantedge, Fifty-Plus, Kasten Chase, Wi-Lan. Plaintree, Nextron. WE XL. In total there are 11 companies in this subset. RIM. TS telecom and Fifty-Plus are the efficient companies. Table 6-4 represents this set.

Table 6-4 Company Inverpower and Distance to other peers

\begin{tabular}{|c|c|c|c|c|c|c|c|}
\hline \multicolumn{2}{|c|}{$\overline{\mathbf{D M U}}$} & \multirow[t]{2}{*}{ Score } & \multirow{2}{*}{$\begin{array}{l}\text { Market } \\
\text { Cap. } \\
\text { S(000s) }\end{array}$} & \multicolumn{3}{|c|}{ Efricient Peers $(\lambda)$ : } & \multirow{2}{*}{$\begin{array}{l}\text { Distance } \\
\text { (from } \\
\text { DMU } \text { Inver.) }\end{array}$} \\
\hline$\#$ & Name & & & 30-RIM & 32-TS Tel. & 42-Fifty & \\
\hline & INVERPOWER & 0.545 & 7.179 & $1.16 \mathrm{E}-02$ & 0.920842 & $6.76 \mathrm{E}-02$ & 0 \\
\hline & AVANTE & $0 . \overline{583}$ & 2.302 & $2.76 \mathrm{E}-03$ & $2.10 \mathrm{E}-02$ & 0.976265 & 1.635 \\
\hline 30 & RESEARCIH IN MOTION & $T$ & 585.308 & I & 0 & $6.18 E-16$ & 1.829 \\
\hline 32 & TS ГELECOM & $T$ & 11.832 & 0 & 1 & $2.78 E-17$ & 0.0109 \\
\hline 33 & ADVANTEDGE & 0.180 & 19.928 & $1.17 \mathrm{E}-02$ & $8.91 E-02$ & 0.899219 & 1.383 \\
\hline+2 & FIFTY-PLLS & & 2.404 & 0 & 0 & & 1.717 \\
\hline 45 & KASTEN CHASE & $\overline{0.995}$ & 23.569 & 0.112999 & 0.761709 & 0.125291 & 0.0389 \\
\hline 65 & WI-LAN INC & 0.873 & 329.339 & $3.59 E-02$ & 0.15989 & $0.80+195$ & 1.122 \\
\hline 77 & PLAINTREE & 0.866 & 14.946 & $8.84 \mathrm{E}-02$ & 0.495785 & 0.415858 & 0.308 \\
\hline$\overline{83}$ & NEXTRON & 0.534 & 2.426 & 3.22E-03 & $4.52 \mathrm{E}-02$ & 0.95158 & 1.548 \\
\hline 85 & WE X.L. & 0.944 & 17.083 & 8.79E-03 & $5.95 \mathrm{E}-03$ & 0.985255 & 1.679 \\
\hline
\end{tabular}

Table 6-5 shows the predicted market values for these companies.

Table 6-5 Subset Inverpower and the Predicted Market Values

\begin{tabular}{|c|c|c|c|c|c|}
\hline \multicolumn{6}{|c|}{ For the inefficient Public Companies(S) } \\
\hline & & \multicolumn{2}{|c|}{ Predicted Market Cap Range } & \multirow[b]{2}{*}{$\begin{array}{l}\text { Predicted } \\
\text { upper bound }\end{array}$} & \multirow[b]{2}{*}{$\begin{array}{l}\text { Market Value } \\
2000 \text { (march) }\end{array}$} \\
\hline Company & $\begin{array}{l}\text { Real Market } \\
\text { Cap (1998) }\end{array}$ & Minimum & Maximum & & \\
\hline Inverpower & 7.179 .000 & $11.832,000$ & 23.569 .000 & $17.848 .(900)$ & 3.793 .725 \\
\hline Avante & 2.302 .000 & 2.404 .000 & 329.339 .000 & 4.211 .000 & 2.281 .016 \\
\hline Advantedge & 19.928 .000 & 2.302 .000 & 329.339 .000 & 10.064 .000 & 11.385 .000 \\
\hline Kasten Chase & 23.569 .000 & 7.179 .000 & 329.339 .000 & 75.454 .000 & 322.862 .069 \\
\hline Wi-Lan & 329.339 .000 & $2.302,000$ & 23.569 .000 & 24.838 .000 & 707.841 .877 \\
\hline Plaintree & 14.946 .000 & 2.302 .000 & 329.339 .000 & 58.607 .000 & 126.612 .983 \\
\hline Nextron & $2 .+26,000$ & 2.302 .000 & 329.339 .000 & 4.707 .000 & 1.320 .900 \\
\hline $\mathrm{WE} \mathrm{XL}$ & 17.083 .000 & 2.302 .000 & $329.339,000$ & 7.548 .000 & $1,755.287$ \\
\hline
\end{tabular}

Inverpower falls short of the predicted range for its market value, this could mean it is undervalued. It is also very inetficient and an improvement in efficiency score may 


\section{Chapter 6 Analysis and Discussion}

enhance its market value. The predicted upper bound is 2.5 times as great as

Inverpower's real market value. Avante's market value falls below the predicted range, however, DEA found two very similar peers to it. namely, Nextron and Fifty-Plus. Especially Nextron. which had a similar score and market capitalization. Avante does seem slightly undervalued, but again it is highly inefficient an increase in efficiency might help Avante improve its market value. The predicted upper bound is 1.8 times greater than the real market value of Avante. Ignoring Wi-Lan. which was greatly different from Avante in terms of the efficiency score and its market value. one can find a more appropriate range tor Avante of $\$ 2.3$ to $\$ 20$ million. The same is true for Advantedge; if one ignores the effect of Wi-Lan. which was not even close in terms of efficiency or market value. Its range becomes $\$ 2.3$ to $\$ 17$ million. Also, there are closer companies like Avante. Nextron. and WE XL in terms of distance. Advantedge had the lowest efficiency score in the group at 0.18 , so this seems to be a very poor company in terms of turning its assets into profits. That also explains why the upper bound is so low. By all accounts, Advantedge is overvalued. It is just 0.5 times less than its upper bound. Kasten Chase, too is not very similar to Wi-Lan, in terms of distance, efficiency score, and market value. The closest peers are TS Telecom and Plaintree. Thus, ignoring WiLan the upper range becomes $\$ 14.9$ million. Kasten Chase then becomes overvalued, but it is still operating less than its upper bound and it is highly efficient at 0.994 . The predicted upper bound is $\mathbf{3 . 2}$ times greater than Kasten's real market capitalization.

In all, 62 inefficient companies were examined and a range for market values predicted as displayed in Table 6-6. Subsequently. it was found that eleven of the companies did not yield any information due to too few peers. Of the remaining 51 
companies DEA predicted a suitable range $59 \%$ of the time, although some of these ranges were quite large. Another $16 \%$ were within $25 \%$ of their actual market value, either slightly above or below. There is evidence that DEA works better when there is a bigger peer group. 
Chapter 6 Analysis and Discussion

Table 6-6 Inefficient DMUs and Predicted Market Values

\begin{tabular}{|c|c|c|c|c|c|c|}
\hline & \multirow[t]{2}{*}{ Company Name } & \multirow[t]{2}{*}{ Score } & \multirow{2}{*}{$\begin{array}{l}\text { Market Cap } \\
1998\end{array}$} & \multicolumn{2}{|l|}{ Predicted Range } & \multirow{2}{*}{$\begin{array}{l}\text { Upper } \\
\text { Bound }\end{array}$} \\
\hline & & & & Minimum & Maximum & \\
\hline 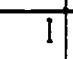 & HAMMOND & 0.757 & 18.426 .080 & II.397.939 & 33.191 .018 & 74.988 .000 \\
\hline & INVERPOWER & $0.5+5$ & 7.179 .058 & 11.832 .000 & 23.569 .233 & 17.848 .000 \\
\hline & UNITEC & 0.435 & 5.570 .707 & 2.404 .000 & one peer & 5.057 .000 \\
\hline & LG TECH & 0.587 & 27.706 .969 & 11.397 .939 & 33.191 .018 & 47.055 .000 \\
\hline 8 & NORON & 0.065 & 7.029 .310 & 2.404 .000 & one peer & 2.383 .000 \\
\hline 9 & AVA.VTE & 0.583 & 2.302 .425 & 2.404 .000 & 329.339 .322 & +.211 .000 \\
\hline 10 & SEMII-TECH & 0.215 & 10.025 .976 & 100.000 .000 & one peer & 720.885 .000 \\
\hline 11 & DANBEL & 0.755 & 5.797 .576 & 289.000 & 46.091 .000 & 30.156 .000 \\
\hline 12 & AVVA & $0.8+7$ & 2.429 .279 & 1.710 .000 & $13.382 .000)$ & 2.669 .000 \\
\hline 13 & TIR & 0.656 & 1.709 .641 & 1.956 .000 & 13.382 .000 & 3.537 .000 \\
\hline 14 & DIGITAL PROC & 0.884 & 28.123 .144 & {$[1.832 .000$} & one peer & 154.005 .000 \\
\hline 18 & $\overline{A B L}$ & 0.309 & 13.381 .932 & 1.710 .000 & 11.832 .000 & 7.609 .000 \\
\hline 19 & BCS TECH & 0.677 & 1.026 .687 & 622.999 & 15.697 .570 & 2.376 .000 \\
\hline 20 & BELL CAN & 0.254 & 1.371 .119 .948 & 1.031 .559 .000 & 3.608 .271 .000 & $2 .+48.639 .000$ \\
\hline 21 & CIRCA & 0.859 & 6.600 .985 & 3.855 .000 & 46.091 .090 & 22.797 .000 \\
\hline 22 & DBA & $0.6+0$ & 1.956 .000 & 1.710 .000 & 13.382 .000 & 3.782 .000 \\
\hline 23 & EIGER & 0.815 & 8.289 .000 & 2.404 .000 & 3.878 .000 & 5.512 .000 \\
\hline 24 & KING & 0.472 & 7.738 .941 & 307.000 & 2.854 .080 & 1.072 .000 \\
\hline 25 & MEMOTEC & 0.649 & 4.952 .521 & 11.832 .000 & 76.678 .291 & $\$ 8.488 .000$ \\
\hline 26 & MICROCELL & 0.066 & 307.086 .660 & 3.878 .432 & one peer & 21.615 .000 \\
\hline 28 & NHC & 0.671 & 7.317 .082 & 2.404 .000 & seer & $+4 .+11.000$ \\
\hline 31 & TRADE WIND & 0.676 & $9.699 .54 \mathrm{I}$ & 307.000 & 15.697 .570 & 2.485 .000 \\
\hline 33 & ADVANTEDGE & 0.180 & 19.927 .644 & 2.302 .425 & 329.339 .322 & 10.064 .000 \\
\hline 34 & CALIAN & 0.800 & 33.191 .018 & 11.397 .939 & 27.706 .969 & 62.705 .000 \\
\hline 36 & CELL-LOC & 0.980 & 28.669 .000 & 1.969 .999 & 2.404 .000 & 23.996 .000 \\
\hline 37 & COM DEV & 0.863 & 252.315 .304 & 112.896 .710 & 1.031 .559 .000 & 851.037 .000 \\
\hline 39 & CYGNAL & 0.589 & 8.637 .474 & 11.832 .000 & 32.734 .620 & 50.650 .000 \\
\hline 40 & DIMENSIONS & 0.110 & 1.969 .999 & 2.404 .000 & 28.669 .000 & 12.241 .000 \\
\hline $4 !$ & DYNAMIC & 0.939 & 110.353 .695 & 80.615 .000 & on & 89.291 .000 \\
\hline 43 & GEMSTAR & 0.232 & 4.887 .873 & 1.729 .263 & 61.220 .528 & 3.327 .000 \\
\hline 45 & KASTEN CHASE & 0.995 & 23.569 .233 & 7.179 .058 & 329.339 .322 & $75 .+5+.000$ \\
\hline 46 & MARATHON & 0.604 & 622.999 & 717.010 & 15.697 .570 & 2.447 .000 \\
\hline 48 & SENSE & 0.374 & 61.220 .528 & 1.729 .263 & 4.887 .873 & 15.085 .000 \\
\hline 49 & SIMMONDS & 0.766 & $2.85+.080$ & 3.878 .000 & $7 . \overline{738.941}$ & 3.334 .000 \\
\hline 50 & SPECTRUM & 0.787 & 38.637 .268 & 4.952 .521 & 76.678 .291 & 100.858 .000 \\
\hline 51 & SR TEL & 0.447 & 112.896 .710 & 44.404 .112 & 1.031 .559 .000 & 532.269 .000 \\
\hline 52 & STRATEGIC & 0.983 & 3.943 .154 & 2.404 .000 & 13.222 .000 & 6.597 .000 \\
\hline 53 & SYSCAN & 0.657 & 7.259 .505 & 2.404 .000 & 3.855 .000 & 5.654 .000 \\
\hline 54 & TEKLOGIX & 0.810 & 243.501 .458 & 44.404 .112 & 143.365 .000 & 179.974 .000 \\
\hline 55 & TRIPLE CROWN & 0.520 & $4.978 .95 !$ & 1.710 .000 & 13.382 .000 & 4.818 .000 \\
\hline
\end{tabular}


Chapter 6 Analysis and Discussion

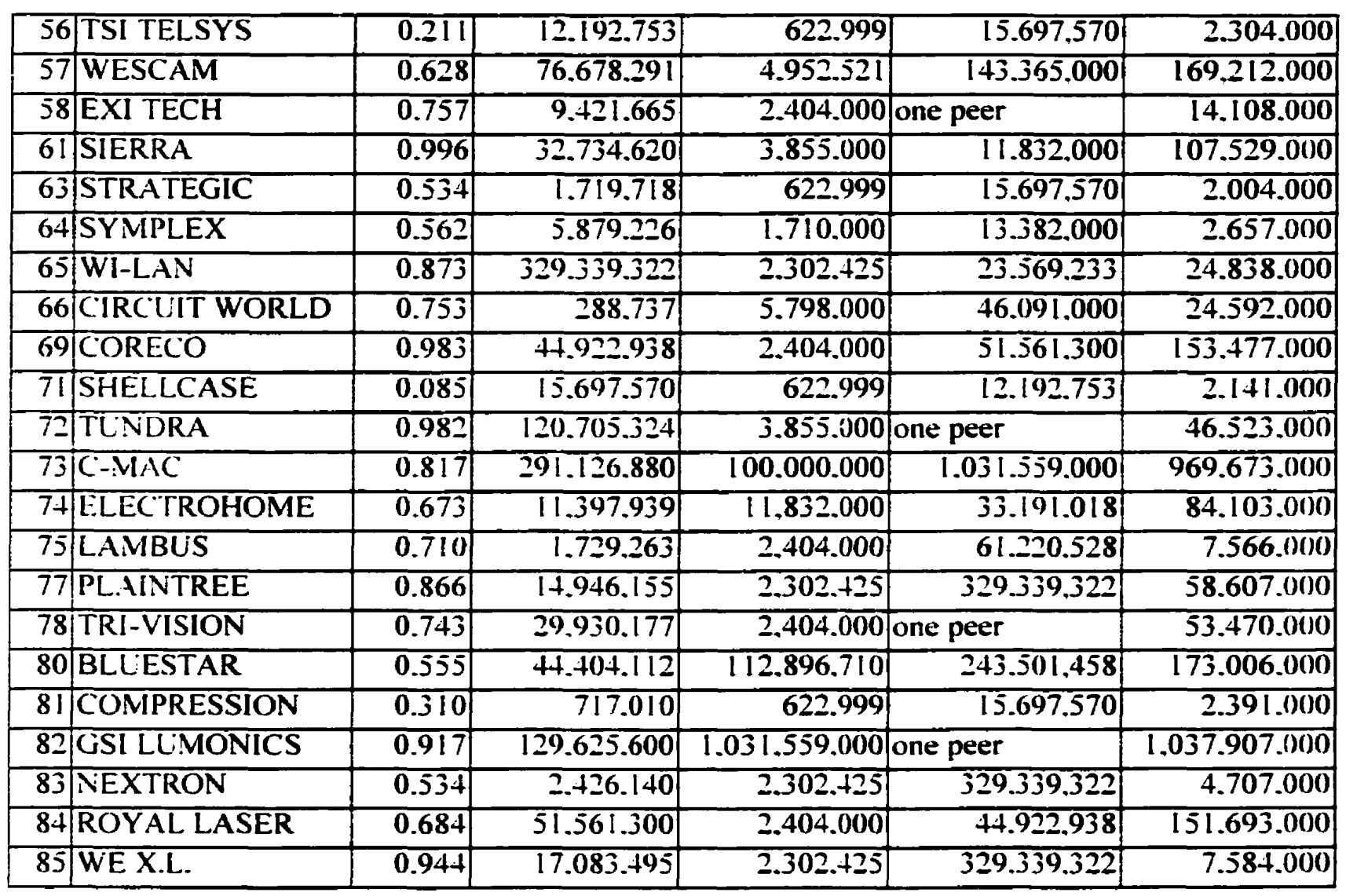




\section{Chapter 6 Analysis and Discussion}

Figure 6-1 demonstrates the predicted and the actual market values:

Figure 6-1 Inefifieient Companies and their Predicted and Actual Market Values

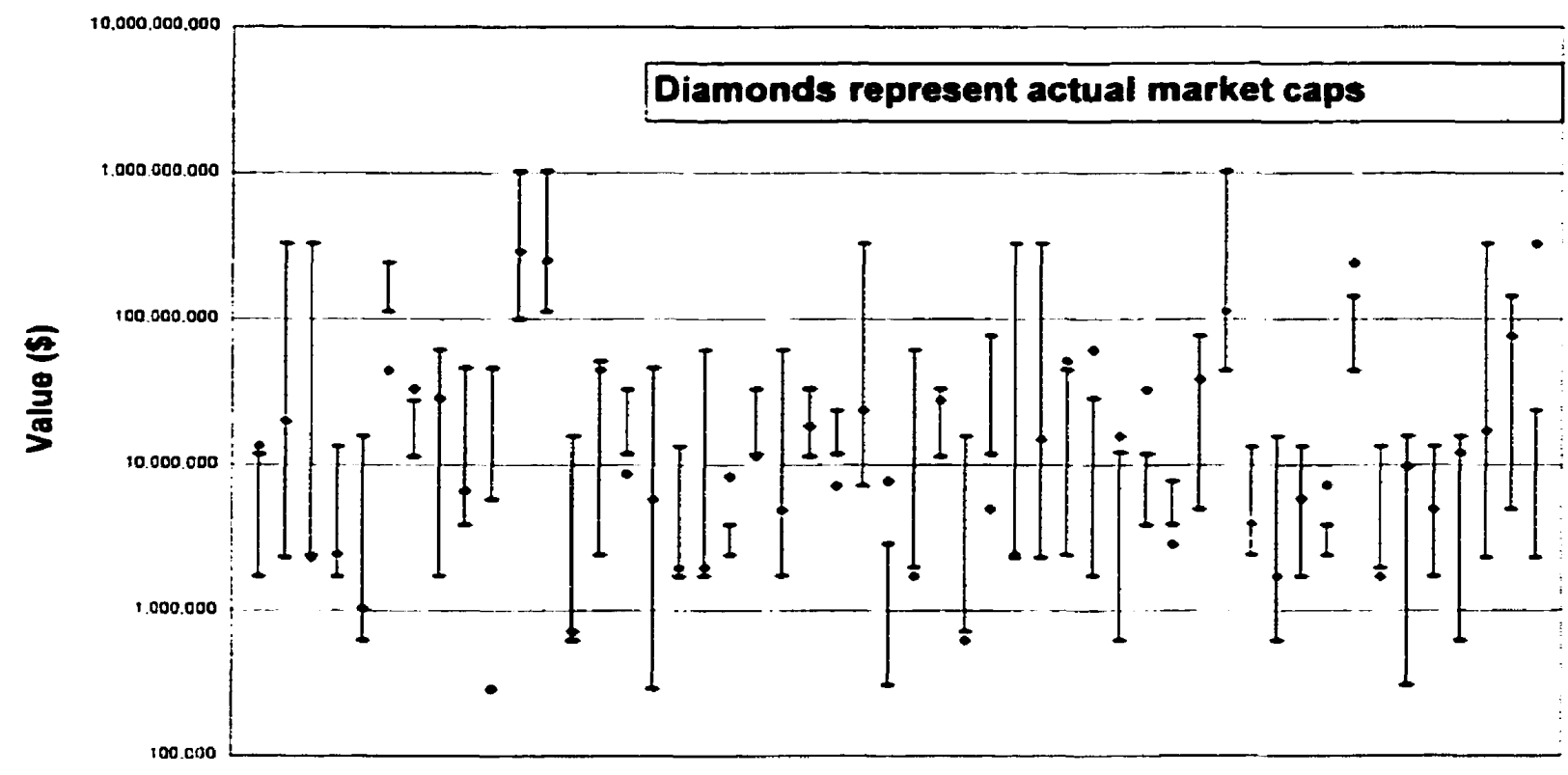

The real market values were also graphed against the predicted upper bound. Of the total 62 companies, 41 companies had real market caps that were less than the predicted upper market capitalization. thus DEA is correct $66 \%$ of the time in predicting an upper market cap that is truly higher than the market cap of the company. This is the result one would hope for since the upper market value is based on the efficient companies. and intuitively, the market caps of the inefficient companies should be below these values. Another $13 \%$ of companies were within $35 \%$ of their predicted upper bound.

Figure 6-2 represents the predicted upper bound versus the actual market capitalizations. 


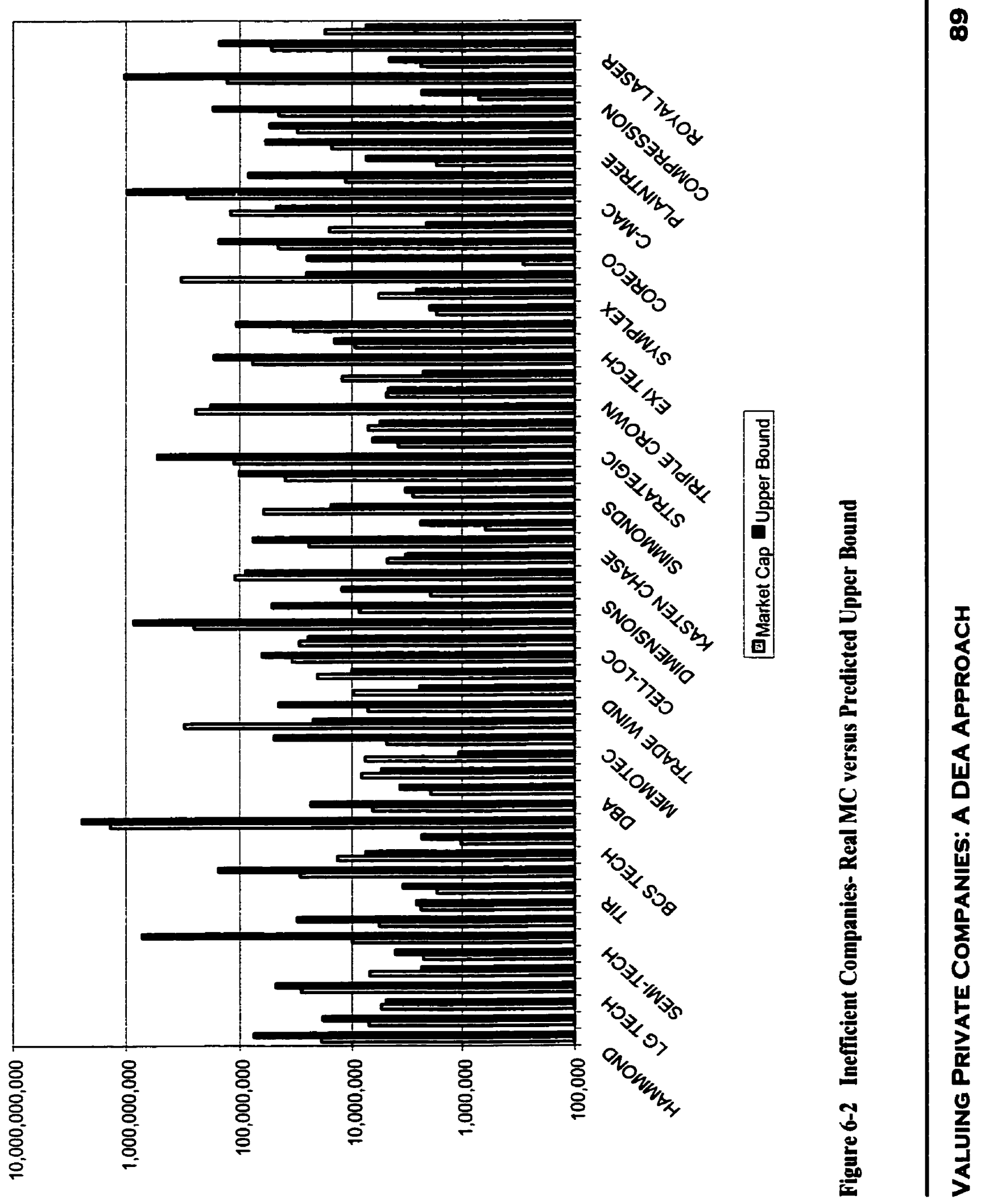




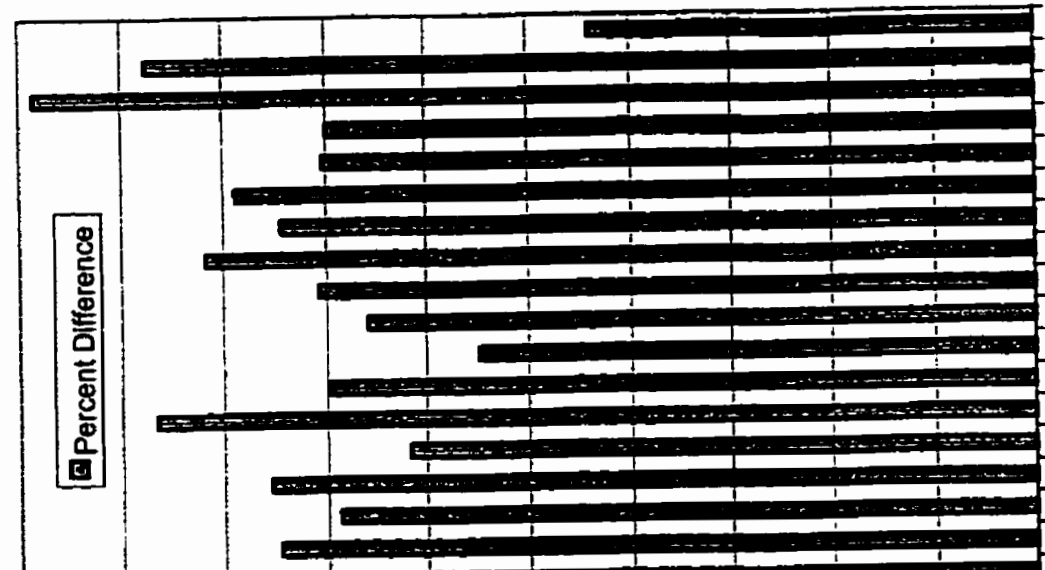

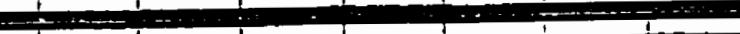

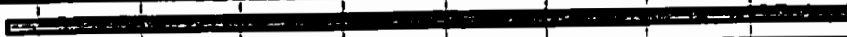

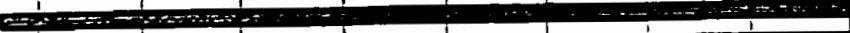

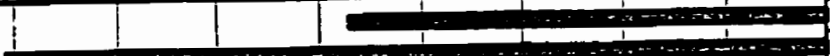

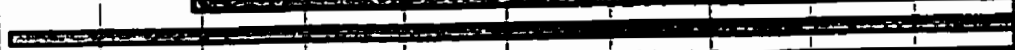

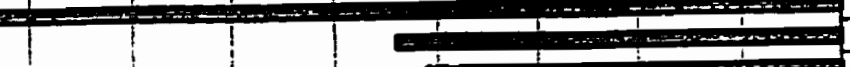

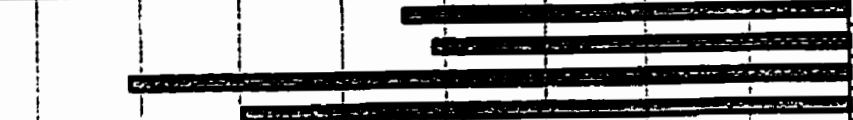
$1 \quad$ | 1 1 C

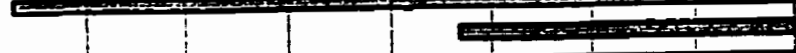

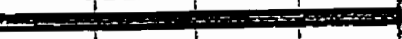
1

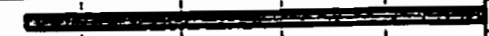
ind

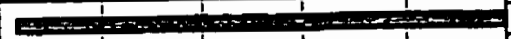

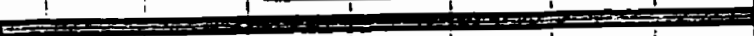

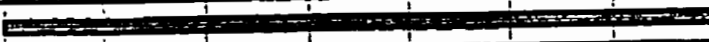

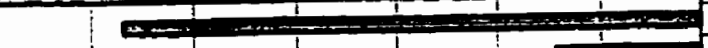
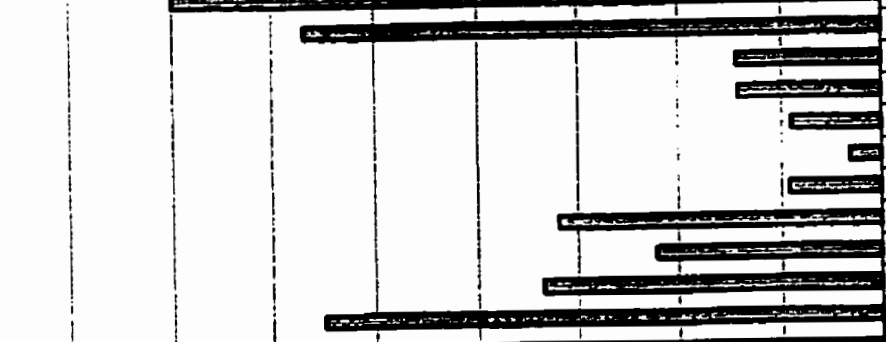
1 1 (1)

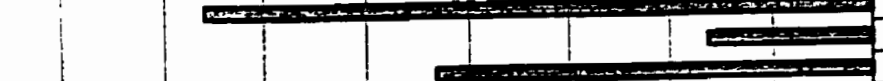
1 1 1010 E. 1 $E=D_{-1}^{1}=0$ -

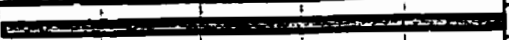
$1=01$ con $1+1$ | | | | |

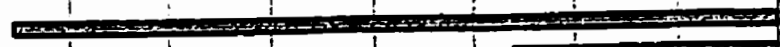

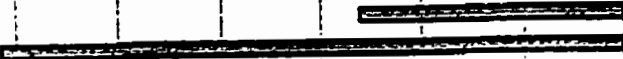

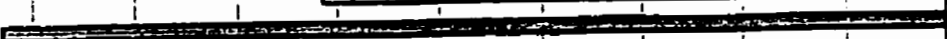
$\frac{1}{1} \frac{1}{1}=\frac{1}{1}=0$ 


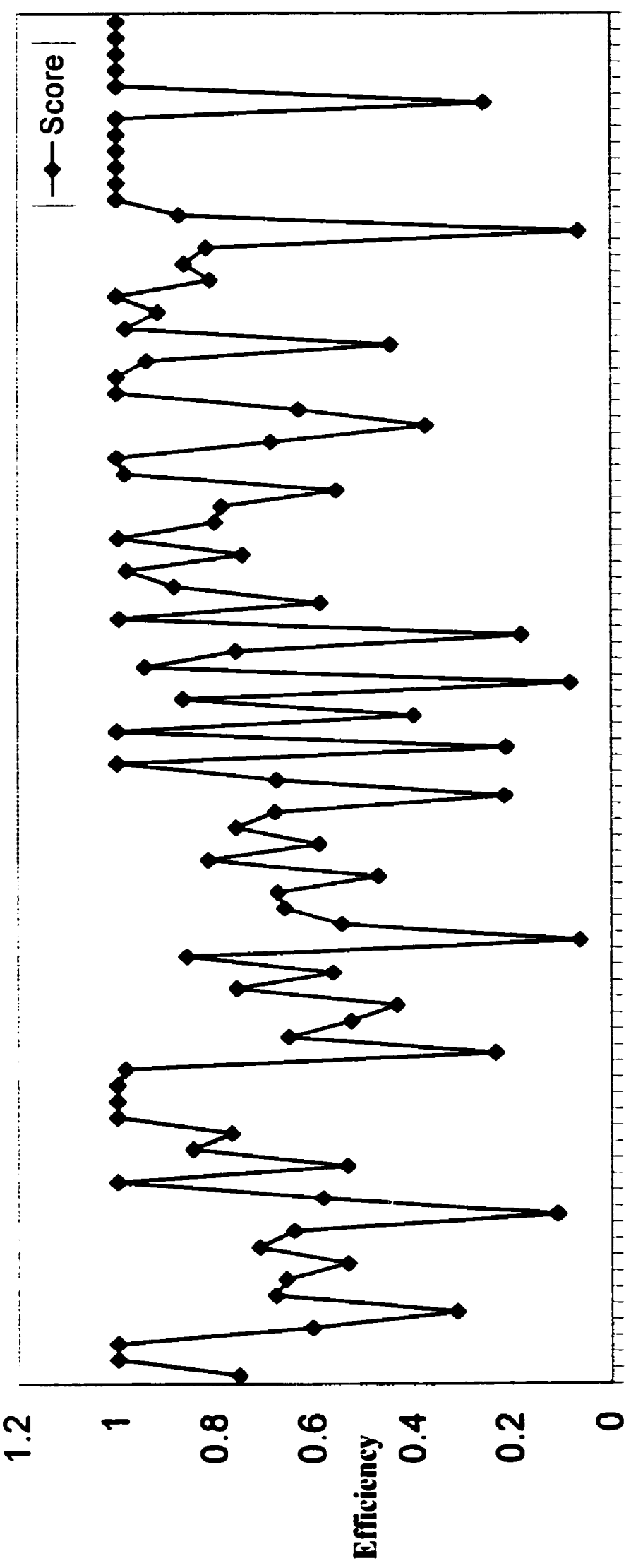

$\frac{6}{2 / 2} \pi_{3}$<smiles>OC1CC1[18O]</smiles>

4

$4_{0}^{2 / 2}$

$d_{2} s_{2}$

${ }_{0} \Omega_{2}$

$0_{0 / 3}^{2}{ }^{2}{ }^{\frac{3}{x}}$

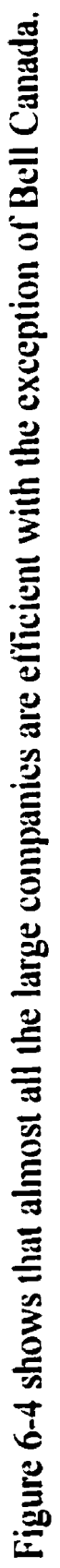




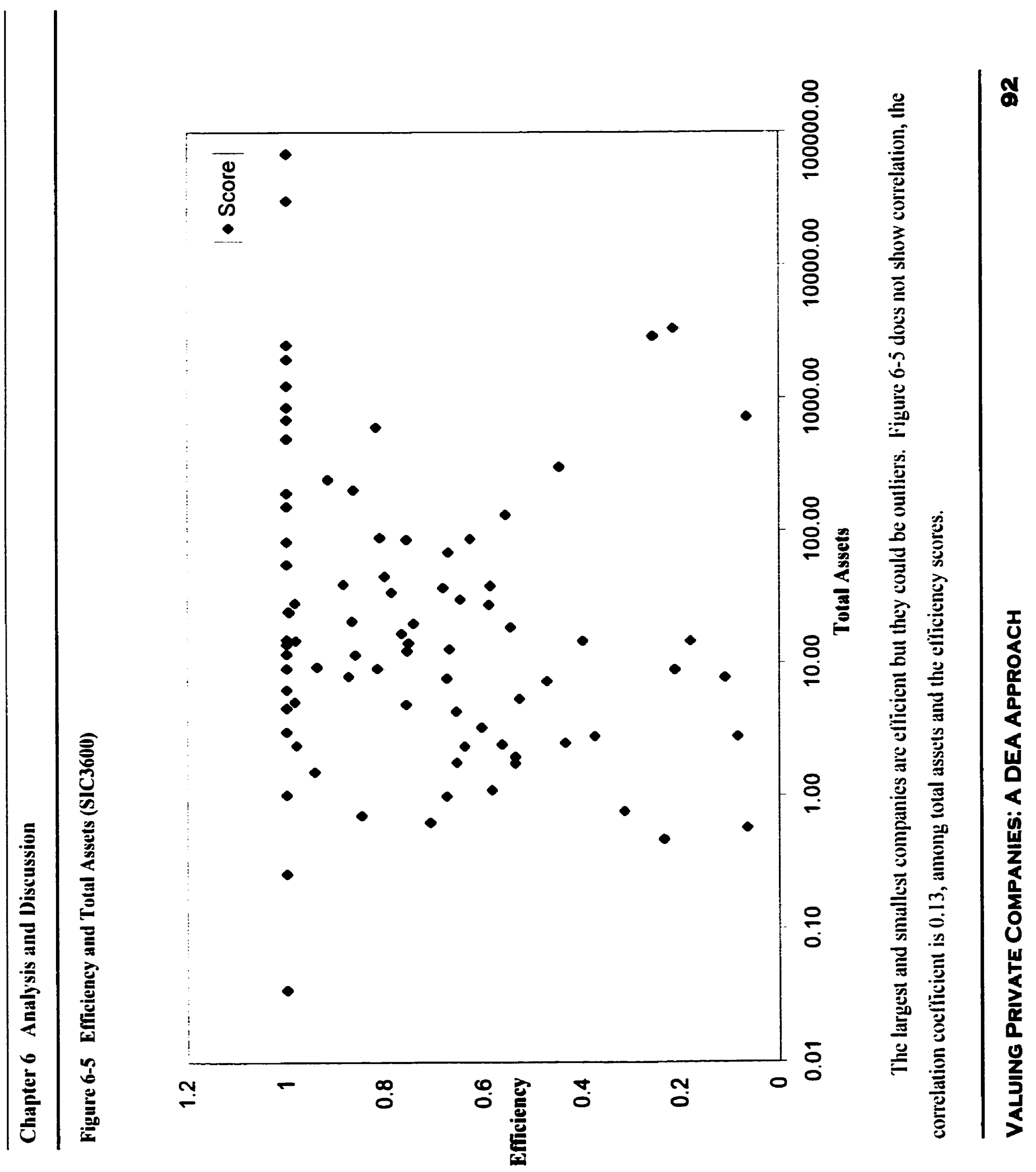




\section{Chapter 6 Analysis and Discussion}

\subsubsection{Efficient Companies}

In this part. a new way to analyze efficient companies is introduced. The analysis for the efficient companies was carried out in a different manner than for the inefticient companies. Since these efficient companies are rarely compared to other companies. one has to calculate the market value from the companies being compared to them, whether they are inefficient or efficient. One can hypothesize that this way a lower bound on the market values can be found. Since it is an efficient company, it should presumably be doing better than the market value calculated from the inefficient companies in its peer group. The lower bound was calculated based on the lambda values of the inefticient companies being compared to the efficient company. Adjustments must be made for the fact that the lambda values on the column of the matrix do not sum to unity.

\subsubsection{Lower bound for Efficient Company Camco}

Camco was analyzed first; it had 17 companies being compared to it. The lambda values of the inefficient companies in relation to Camco were summed then this sum was used to divide each lambda value to get a new normalized lambda $(\lambda / \Sigma \lambda)$. For example. Hammond has a lambda relation of 0.222 to Camco, the sum of all the lambda relations to Camco equaled 1.961. Hammond's new lambda score is equal to $(0.2217 / 1.9605) 0.113$ in relation to Camco. This same procedure was repeated for all the other companies' lambda values, thus the new sum of the lambda values equals one. The new, normalized lambda's of the firms were then multiplied by their market values and summed. The results are shown in Table 6-7: 
Chapter 6 Analysis and Discussion

Table 6-7 Efficient Company Camco Inc (\#7)

\begin{tabular}{|c|c|c|c|c|c|}
\hline $\begin{array}{l}\mathbf{D M U} \\
\#\end{array}$ & Score & \begin{tabular}{|} 
Market Cap \\
$\mathbf{S ( 0 0 0 )}$
\end{tabular} & $\begin{array}{l}\text { DMU \#7 } \\
(\text { old } \lambda)\end{array}$ & $\begin{array}{l}\text { Normalized } \\
\text { New } \lambda(\lambda / \Sigma \lambda)\end{array}$ & $\begin{array}{l}\text { M.C. S(000s) } \\
\text { Calculation }\end{array}$ \\
\hline I/HAMMOND & 0.7568 & $\overline{18426}$ & 0.2217 & 0.1131 & 2083.92 \\
\hline 6| $\overline{\mathrm{LG} \text { TECH }}$ & 0.5866 & 27707 & $\overline{0.006}$ & 0.0031 & 85.22 \\
\hline 10|SEMI-TECH & 0.2145 & 10026 & $\overline{0.7746}$ & 0.3951 & 3961.35 \\
\hline $15 \mid$ SONY CORP & $T$ & $5.3 E \div 07$ & $3.1 \mathrm{E}-15$ & $1.6 \mathrm{E}-1 \overline{5}$ & $8.343 E-08$ \\
\hline \begin{tabular}{l|l}
17 & AASTRA TECH
\end{tabular} & T & 46091 & $6.3 \mathrm{E}-18$ & $3.2 \mathrm{E}-18$ & $1.483 \mathrm{E}-13$ \\
\hline \begin{tabular}{l|l}
23 & EIGER TECH \\
\end{tabular} & 0.8151 & 8289 & 0.0107 & 0.0055 & 45.24 \\
\hline \begin{tabular}{l|l}
26 & MICROCELL
\end{tabular} & 0.0664 & $\overline{307087}$ & 0.1845 & 0.0941 & 28902.05 \\
\hline I+ CALIAN TECH & 0.8001 & 33191 & 0.0599 & 0.0305 & 1014.08 \\
\hline \begin{tabular}{l|l}
37 COM DEV \\
\end{tabular} & 0.8633 & 252315 & 0.0824 & 0.042 & 10604.66 \\
\hline 5I|SR TELECOM & 0.447 & 112897 & $0.13 \overline{63}$ & 0.0695 & 7845.93 \\
\hline \begin{tabular}{l|l}
52 & STRATEGIC
\end{tabular} & 0.9832 & $\overline{3943}$ & 0.0012 & 0.0006 & 2.45 \\
\hline \begin{tabular}{l|l}
54 & TEKLOGIX \\
\end{tabular} & 0.8099 & 243501 & 0.0755 & 0.0385 & 9377.23 \\
\hline \begin{tabular}{l|l|}
68 & CELESTICA INC
\end{tabular} & I & $28 \overline{85867}$ & $2.8 \mathrm{E}-16$ & $1.4 \mathrm{E}-16$ & $4.092 \mathrm{E}-10$ \\
\hline $73 \mid$ C-MAC & $0.817 !$ & 291127 & 0.2202 & 0.1124 & 32707.43 \\
\hline \begin{tabular}{l|l}
74 & ELECTROHOME
\end{tabular} & 0.6733 & 11398 & 0.0752 & 0.0384 & 437.19 \\
\hline \begin{tabular}{l|l|l|} 
80 & BLUESTAR \\
\end{tabular} & 0.5547 & 44404 & 0.0926 & $0 . \overline{0472}$ & 2097.3 \\
\hline 8:GSI LL'MONICS & 0.9167 & 129626 & 0.0196 & 0.01 & 1295.9 \\
\hline \multicolumn{3}{|c|}{ SUM: } & 1.96053 & $\mathbf{1}$ & $\$ 100,460$ \\
\hline
\end{tabular}

For Camco, the predicted market capitalization is $\$ 100.459 .000$; its real market value is $\$ 100.000,000$. DEA did an exceptional job at predicting the value of the public company. Similar analyses were carried out on the remaining 22 efficient companies and are recorded in Table 6-8. A complete analysis can be found in Appendix C. 
Table 6-8 - Efficient DMUs \& Number of Peers (SIC 3600s)

\begin{tabular}{|c|c|c|c|c|c|}
\hline \multicolumn{6}{|c|}{ For the Efficient Public Companies (\$) } \\
\hline DMU\# & Company & $\begin{array}{c}\text { Real Market Cap } \\
\text { (S) }\end{array}$ & $\begin{array}{l}\text { Predicted Market Cap } \\
\text { (Lower Bound) (S) }\end{array}$ & Comment & $\begin{array}{c}\text { \# of } \\
\text { Peers }\end{array}$ \\
\hline 2 & Turbo Genset & 80.615 .000 & 79.412 .730 & Above lower & 6 \\
\hline 5 & Global Therm & 13.222 .000 & 2.358 .240 & Above lower & 4 \\
\hline 7 & Camco & 100.000 .000 & 100.459 .949 & Above lower & 17 \\
\hline 15 & Sony & 52.935 .385 .000 & Self evaluator & no info & $\mathbf{0}$ \\
\hline 16 & Cinram & 1.075 .691 .000 & Selt evaluator & no info & $\overline{0}$ \\
\hline 17 & Aastra Tech & +6.091 .000 & 4.427 .000 & Above lower & 5 \\
\hline 27 & Mitel & 1.257 .378 .000 & Self evaluator & no info & 2 \\
\hline 29 & Nortel & 50.495 .406 .000 & Self evaluator & no info & $\overline{0}$ \\
\hline 30 & Res. In Motion & 585.308 .000 & 48.895 .000 & Above lower & 18 \\
\hline 32 & TS Telecom & 11.832 .000 & 25.878 .000 & Lndervalued & 29 \\
\hline 35 & Cdn Marconi & +26.808 .000 & Self evaluator & No info & 0 \\
\hline 38 & Comm. Sys & 3.855 .000 & 43.170 .000 & Endervalued & 9 \\
\hline 42 & Fifty-Plus & 2.404 .000 & 21.030 .000 & Undervalued & $\overline{45}$ \\
\hline 44 & Int. Datacast. & 3.893 .000 & 5.074 .000 & Undervalued & 4 \\
\hline 47 & Newbridge & 8.125 .481 .000 & 51.858 .075 .000 & Lindervalued & 2 \\
\hline 59 & Jemtec & 330.000 & 3.943 .000 & Lndervalued & 1 \\
\hline 60 & Pacitic E-link & 3.878 .000 & 86.216 .000 & Undervalued & 18 \\
\hline 62 & Snif Security & 307.000 & 7.164 .000 & Lindervalued & 11 \\
\hline 67 & Primetech & 143.365 .000 & 73.681 .000 & Above lower & 15 \\
\hline 68 & Celestica & 2.854 .867 .000 & 487.320 .000 & Above lower & 6 \\
\hline 70 & Gennum & 576.578 .000 & 50.868 .000 & Above lower & 5 \\
\hline 76 & Leitch & 1.031 .559 .000 & 287.982 .000 & Above lower & 21 \\
\hline 79 & Ballard & 3.608 .271 .000 & 1.371 .119 .000 & Above lower & 2 \\
\hline
\end{tabular}

Excluding the tive self-evaluators, DEA does a fairly good job of tinding a reasonable or appropriate lower bound for the companies. as evidenced by the majority of companies having real market values higher than the predicted lower market value. DEA finds a lower bound that is less than the true market value $56 \%$ of the time. In some cases, there are too few peers and the calculation maybe exaggerated or the peers may be vastly different from the company under analysis. The seven companies that had market caps below the predicted lower bound can be classitied as undervalued, since according to the 
analysis their value can be greater. Efficient company Snif Security was the most

undervalued. It had a predicted lower market cap of $\$ 7$ million when in reality it only had a market cap of $\$ 307,000$. It had a $2234 \%$ difference between its predicted and real market value. Figure 6-6 displays the real market values compared to the predicted lower bound, and Figure 6-7 shows the percentage difference between the real market value and the lower bound. 
Efficient Co's - Real vs Predicted Lower Bound M.C. (\$)

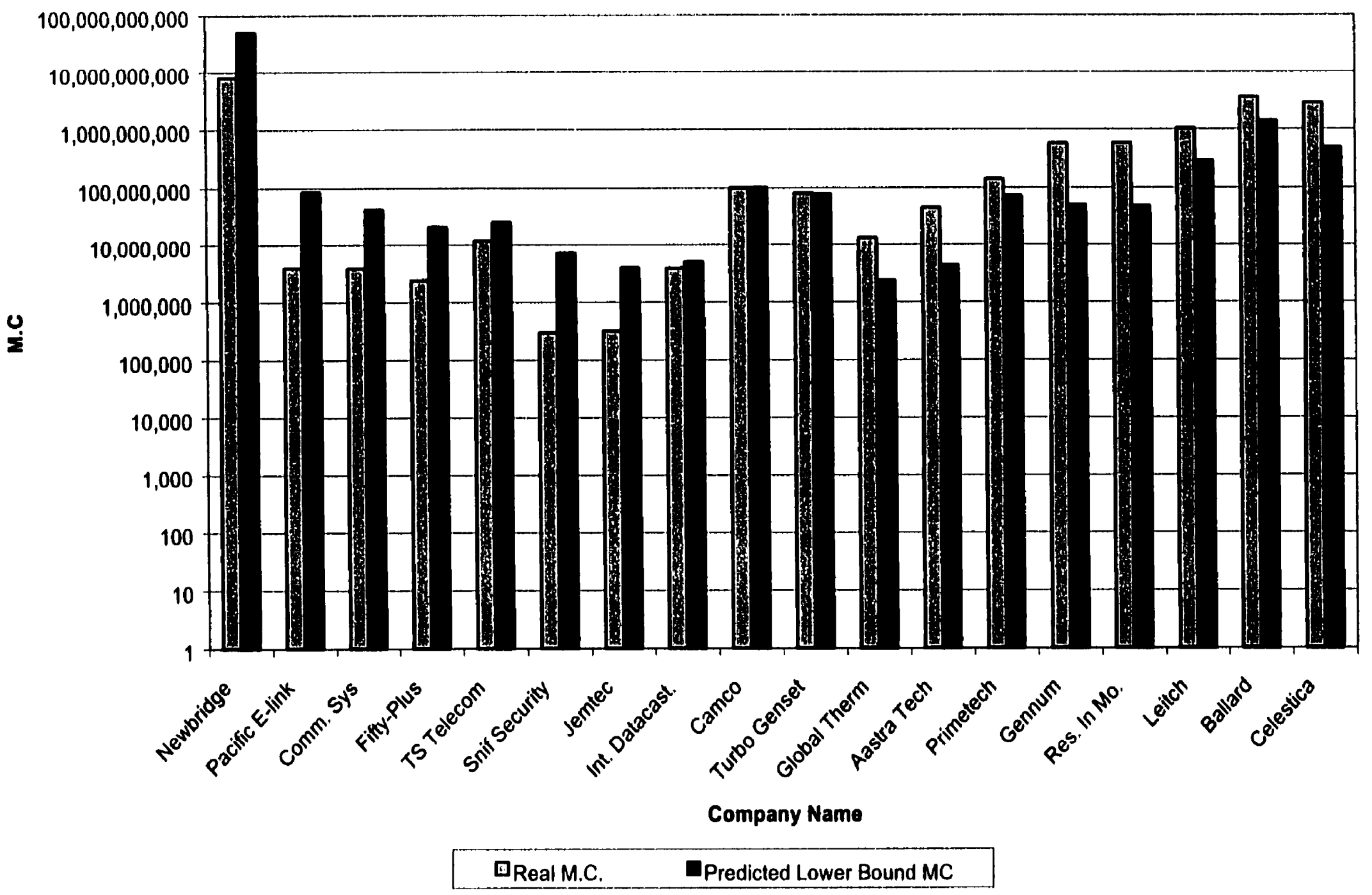

Figure 6-6 Efficient Companies-Real MC versus the Predicted Lower Bound 


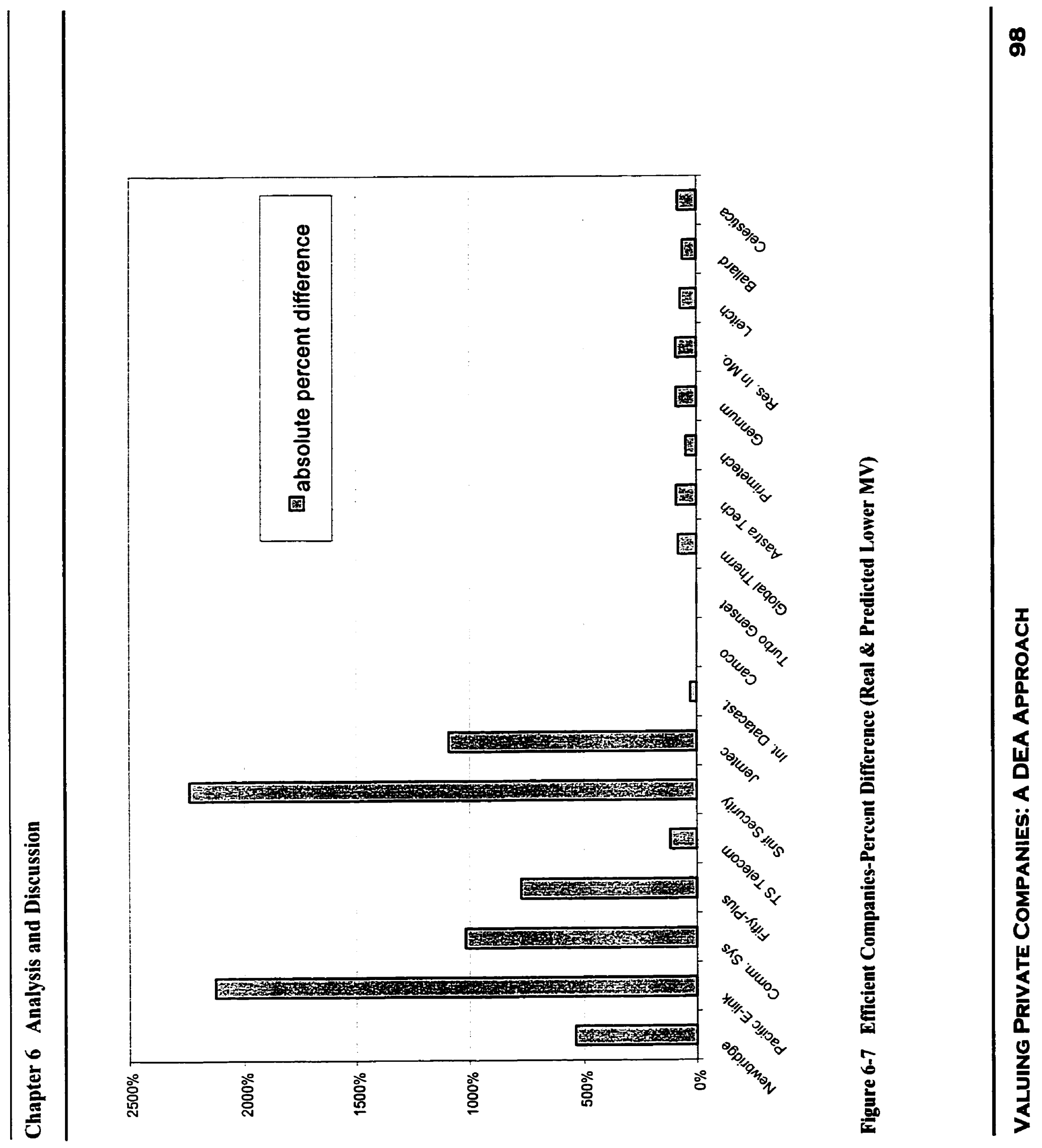




\subsection{Analysis of the Companies with SIC Code 3700s}

A similar analysis as for SIC 3600 was carried out on the companies with a SIC code in the $3700 \mathrm{~s}$. This group consisted of 22 DMUs. This group was tested to see if the number of DMUs in the analysis really has an effect on the number of peers that DEA finds. All 22 DMUs were analyzed. The average efficiency of the BCC model was 0.81 with 8 efficient DMUs. The efficient DMUs are listed in Table 6-9.

Table 6-9 Efficient DMUs SIC3700s

\begin{tabular}{|c|c|c|}
\hline$\#$ & DMU & \# of Peers \\
\hline 2 & GM & 0 \\
\hline 5 & Budd Canada & 12 \\
\hline 6 & Linamar & 6 \\
\hline 7 & Magna & 1 \\
\hline 11 & Spectra & 6 \\
\hline 14 & Wescast & $\mathbf{8}$ \\
\hline 21 & Templar & 11 \\
\hline 22 & Bombardier & 0 \\
\hline
\end{tabular}

DMUs Budd and Templar are the most employed peers with 12 and 11 peers respectively, however Templar has a higher degree of influence over its peers. DMUs GM, Magna and Bombardier do not act a reference unit for any of the inetficient units. This could mean they are either efficient in a very narrow sector or that they possess a very uncommon input/output mix or they are just very different. The complete efficiency scores and lambda values are shown in Table 6-10: 
Table 6-10 DMU 3700s Statistics

\begin{tabular}{|c|c|c|c|c|c|c|c|c|c|c|c|c|}
\hline \multirow[t]{2}{*}{$\#$} & \multirow[t]{2}{*}{ DMU } & \multirow[t]{2}{*}{ Score } & \multirow[t]{2}{*}{ SIC } & \multirow{2}{*}{$\begin{array}{l}\text { Market } \\
\text { Cap. } \\
\text { S(000s) }\end{array}$} & \multicolumn{8}{|c|}{ Efficient Peers ( $\lambda$ s): } \\
\hline & & & & & $\overline{1}$ & 3 & 6 & 7 & 11 & 14 & 21 & 22 \\
\hline 1 & $G$ & 1.00 & 3711 & 86.392 .582 & 1 & 0 & 0 & $2.5 \mathrm{E}-15$ & 0 & 0 & 0 & 0 \\
\hline 2 & A.E. VENT. & 0.80 & $\longdiv { 3 7 1 4 }$ & 627 & 0 & 0.0036 & 0 & 0 & 0.0146 & 0 & 0.9818 & 0 \\
\hline 3 & BUDD CAN & 1.00 & 3714 & 116.772 & 0 & 1 & (0) & 0 & 0 & 0 & 0 & 0 \\
\hline 4 & DECOMA & 0.58 & 3714 & 560.656 & 0 & 0.4576 & 0.4793 & 0 & 0 & 0.0631 & 0 & 0 \\
\hline 5 & DEVTEK & 0.67 & $\longdiv { 3 7 1 4 }$ & 99,709 & 0 & 0.8818 & $0.118 \mid$ & 0 & 0 & 0 & 0 & 0 \\
\hline 6 & LINAMAR & 1.00 & $37[4$ & 1.792 .517 & (1) & 0 & 1 & 0 & 0 & 0 & 0 & 10 \\
\hline 7 & MAGNA & 1.00 & 3714 & 7.374 .103 & 10 & 0 & 0 & I & 0 & $6.6 \mathrm{E}-17$ & 0 & 0 \\
\hline 8 & MERCH & 0.65 & 3714 & 2.869 & (1) & (1) & 0 & 0 & 0.0195 & 0 & 0.9805 & 0 \\
\hline 9 & NORTHSIDE & 0.90 & 3714 & 14.056 & 11 & 0.0906 & 0.0227 & 0 & 0 & 0 & 0.8867 & 0 \\
\hline 10 & ROSE & 0.71 & 3714 & 25.150 & 0 & 0 & 0 & 0 & 0.5985 & 0 & 0.4015 & 0 \\
\hline II & SPECTRA & 1.00 & 3714 & 525,280 & 0 & $7.4 \mathrm{E}-18$ & 0 & 0 & 1 & $1.7 \mathrm{E}-17$ & $9.8 \mathrm{E}-19$ & 0 \\
\hline 12 & STACKPOLE & 0.63 & 3714 & 131,497 & 0 & 0.2442 & 0 & o & 0.5083 & 0.2475 & 0 & 0 \\
\hline 13 & TESMA & 1.00 & 3714 & 570,124 & 0 & 0.4037 & 0.4697 & $\mathbf{0}$ & 0 & 0.1266 & 0 & 0 \\
\hline 14 & WESCAST & 1.00 & 3714 & 574,300 & 0 & 0 & $9.3 \mathrm{E}-17$ & 0 & 0 & 1 & $1.5 \mathrm{E}-16$ & 0 \\
\hline 15 & TRAILMOB. & 0.97 & 3715 & 14.342 & 0 & 0.3072 & 0 & 0 & 0 & 0 & 0.6928 & 0 \\
\hline 16 & GLENDALE & 0.52 & 3716 & 47,948 & 0 & 0.4337 & 0 & 0 & 0 & 0.0132 & 0.5531 & 0 \\
\hline 17 & AVCORP & 0.50 & 3728 & 45,730 & (1) & 0.1315 & 0 & 0 & 0.4154 & 0 & 0.4531 & 0 \\
\hline 18 & HEROUX & 0.59 & 3728 & 62,462 & 0 & 0.2724 & 0 & 0 & 0.4183 & 0.0145 & 0.2948 & 0 \\
\hline 19 & MAGELLAN & 0.63 & 3728 & 496,389 & 0 & 0.5206 & 0.1523 & 0 & 0 & 0.3271 & 0 & 0 \\
\hline 20 & SERENA & 0.73 & 3731 & 572 & 0 & 0 & 0 & 0 & 0 & 0 & 1 & 0 \\
\hline 21 & TEMPLAR & 1.00 & 3732 & 4.576 & 0 & 0 & 0 & 0 & 0 & 0 & 1 & 0 \\
\hline 22 & BOMBARD. & 1.00 & 3743 & 7.502 .049 & 0 & 0 & 0 & 0 & 0 & 0 & 0 & 1 \\
\hline
\end{tabular}

\subsubsection{Efficiency and Market Value}

Figure 6-8 shows the efficiency for all the DMUs in the analysis ordered by their market capitalization. It is evident from this figure that the larger companies, the ones with the white points, are all efficient or nearly so. The correlation coefticient is 0.26 . 
Chapter 6 Analysis and Discussion

Figure 6-8 Efficiency and Market Value (SIC3700)

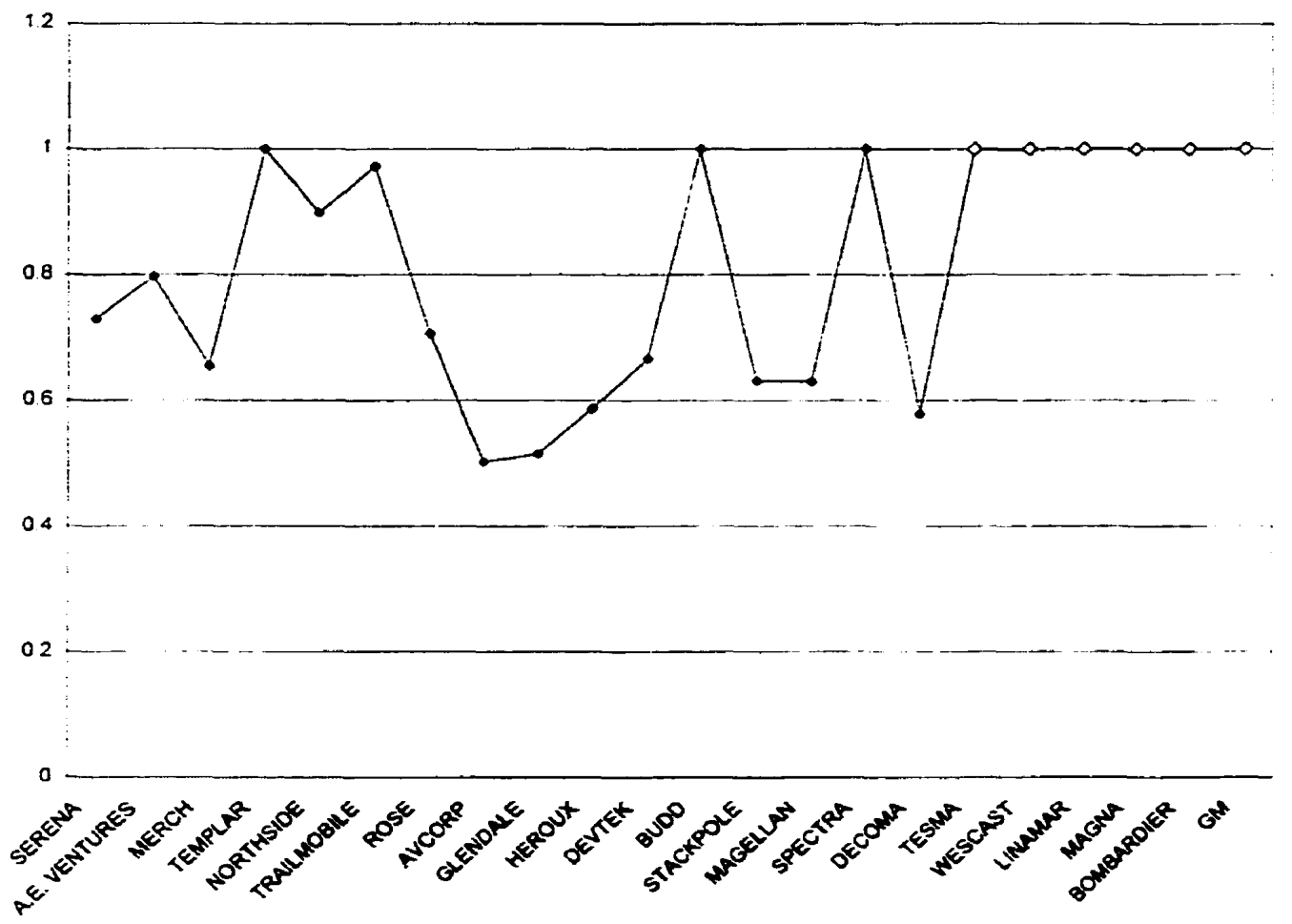

\subsubsection{Efficiency and Total Assets}

The correlation coefficient between efficiency and total assets of the DMUs is 0.15 , illustrated in Figure 6-9. Thus there is great difference between the total assets of the various companies. 
Figure 6-9 Efficiency and Total Assets (SIC3700)

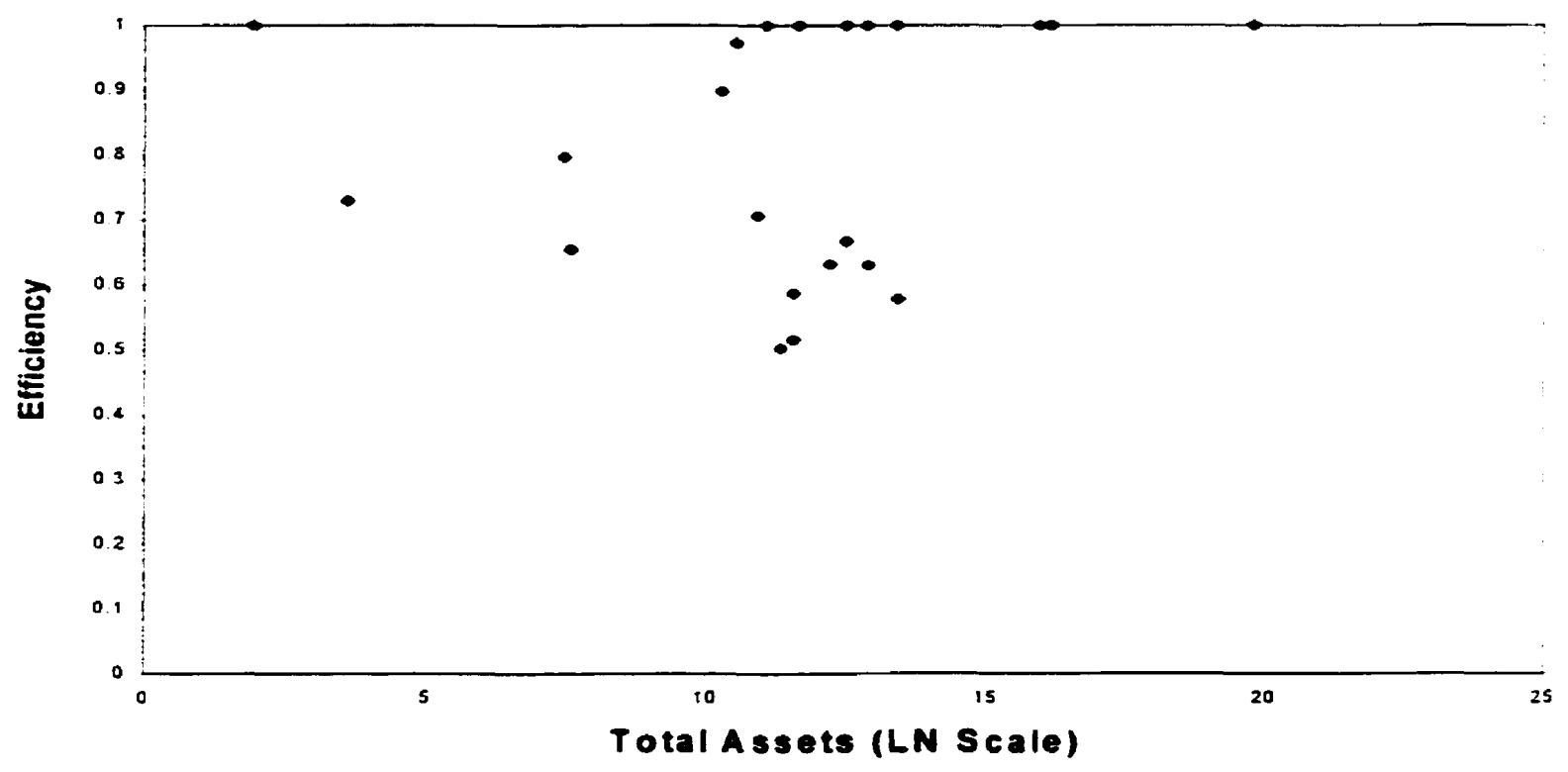

\subsubsection{Graph of Virtual Outputs}

A virtual output is simply the product of a given output and its weight. Its value indicates the importance attached to a given output. In the case of the CCR model. the sum of the virtual outputs is equal to the unit's efficiency score. In the BCC model, the sum of the virtual outputs plus the measure of scale efficiency, $u_{0}$. is equal to the unit's efticiency score. For each DMU, a stacked column that has the unit's virtual outputs as its series is plotted in Figure 6-10. It displays the relative amount that each output factor contributes. It is interesting to note that company 21 has no contribution from its outputs. It is solely made up of the contribution trom its input. namely total liability. Figure 6-10 also shows that the factor shareholders ${ }^{\circ}$ equity is the most influential output. 

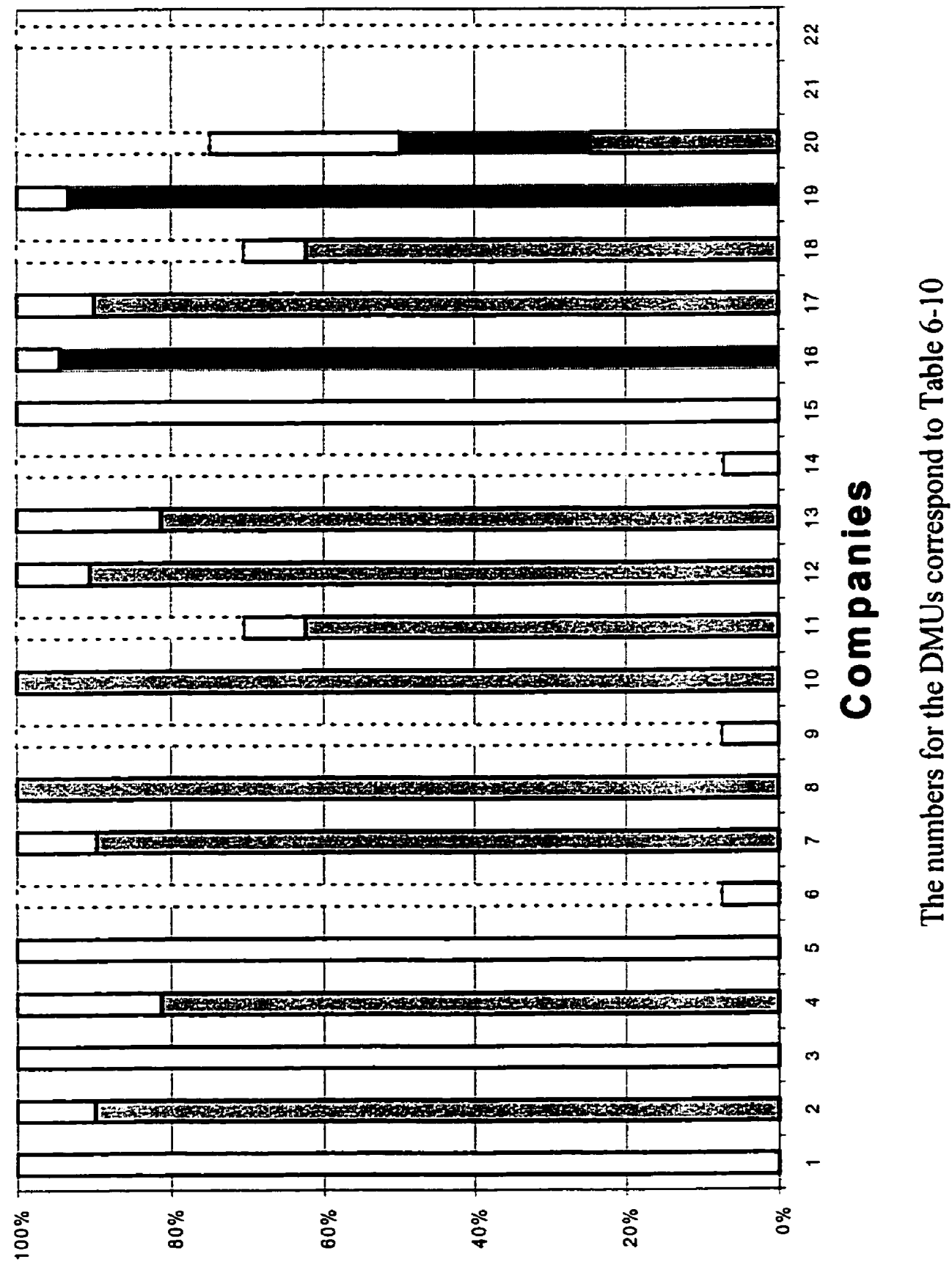


\subsubsection{Valuation of SIC 3700s}

Table 6-11 summarizes the predicted values for the companies with SICs in the 3700 s and Figure 6-11 shows the predicted ranges. There were 10 peer groups in total with some companies only being compared to efficient companies. For most DMUs there were at least three peers. with the exception of Trailmobile and Devtek. which only had two peers. and Serena which only had one.

Table 6-11 Range for Market Values (SIC3700)

\begin{tabular}{|c|c|c|c|c|}
\hline \multicolumn{5}{|c|}{ For the Inefficient Public Companies(\$) } \\
\hline & & \multicolumn{2}{|c|}{ Predicted Market Cap Range } & \multirow[b]{2}{*}{$\begin{array}{l}\text { Predicted upper } \\
\text { bound }\end{array}$} \\
\hline Company & $\begin{array}{l}\text { Real Market } \\
\text { Cap }\end{array}$ & Minimum & Maximum & \\
\hline A.E Ventures & 627.000 & $4.576,000$ & 45.730 .000 & 12.581 .000 \\
\hline Avcorp & 45.730 .000 & 627.000 & 525.280 .000 & 235.632 .000 \\
\hline Merch & 2.869 .000 & 4.576 .000 & 25.150 .000 & 14.730 .000 \\
\hline$\overline{R o s e}$ & 25.150 .000 & 2.869 .000 & 525.280 .000 & 316.213 .000 \\
\hline Stackpole & 131.497 .000 & 116.772 .000 & $574,300.000$ & 437.638 .000 \\
\hline Glendale & +7.948 .000 & $4.576,000$ & T16.772.000 & 60.753 .000 \\
\hline Trailmobile & 14.342 .000 & $4,576,000$ & 116.772 .000 & 39.042 .000 \\
\hline Northside & $\mid 4.056 .000$ & 4.576 .000 & & $55.327,000$ \\
\hline Heroux & 62.462 .000 & 4.576 .000 & 525.280 .000 & 261.222 .000 \\
\hline Serena & 572.000 & $4.576,000$ & -1.2- & One peer \\
\hline Magellan & 496.389 .000 & 116.772 .000 & 574.300 .000 & 521.651 .000 \\
\hline Devtek & 99.709 .000 & $116.772,000$ & $\ldots$ & 314.710 .000 \\
\hline$\overline{\text { Decoma }}$ & 560.656 .000 & \16.772.000 & $1,792.517 .000$ & 948.802 .000 \\
\hline Tesma & 570.124 & 116.772 .000 & $1,792.517 .000$ & 961.817 .000 \\
\hline \multicolumn{5}{|c|}{ For the Efficient Public Companies(\$) } \\
\hline & Real M.C. & \multicolumn{3}{|c|}{\begin{tabular}{|l|l|} 
Predicted Market Cap. Lower Bound Comment \\
\end{tabular}} \\
\hline Budd Canada & 116.772 .000 & & 244.116 .00 & Undervalued \\
\hline Linamar & 1.792 .517 .000 & & 502.534 .00 & Above lower \\
\hline Spectra & 525.280 .000 & & 64.357 .00 & Above lower \\
\hline Wescast & 574.300 .000 & & 383.838 .00 & Above lower \\
\hline Templar & 4.576 .000 & & $16.359,00$ & Undervalued \\
\hline$\overline{\mathrm{GM}}$ & 86.392 .582 .000 & & Self Evaluato & No info \\
\hline Magna & 7.374 .103 .000 & & Self Evaluato & No info \\
\hline Bombardier & 7.502 .049 .000 & & Self Evaluato & No info \\
\hline
\end{tabular}


Figure 6-11 Range for Predicted Market Values and the Real Value (SIC3700)

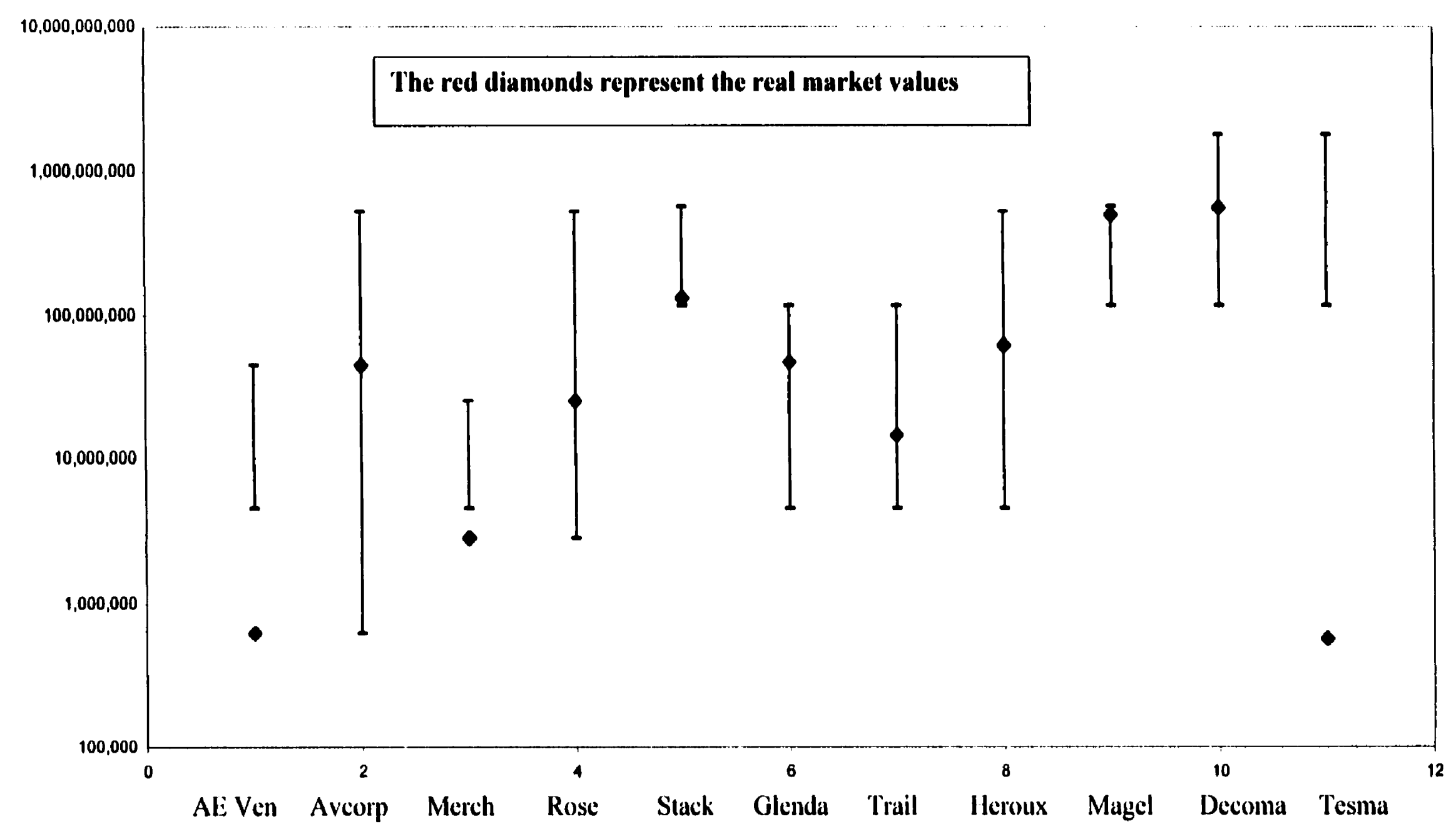


Figure 6-12 Inefficient Company-Real \& Predicted Upper Market Value (SIC3700)

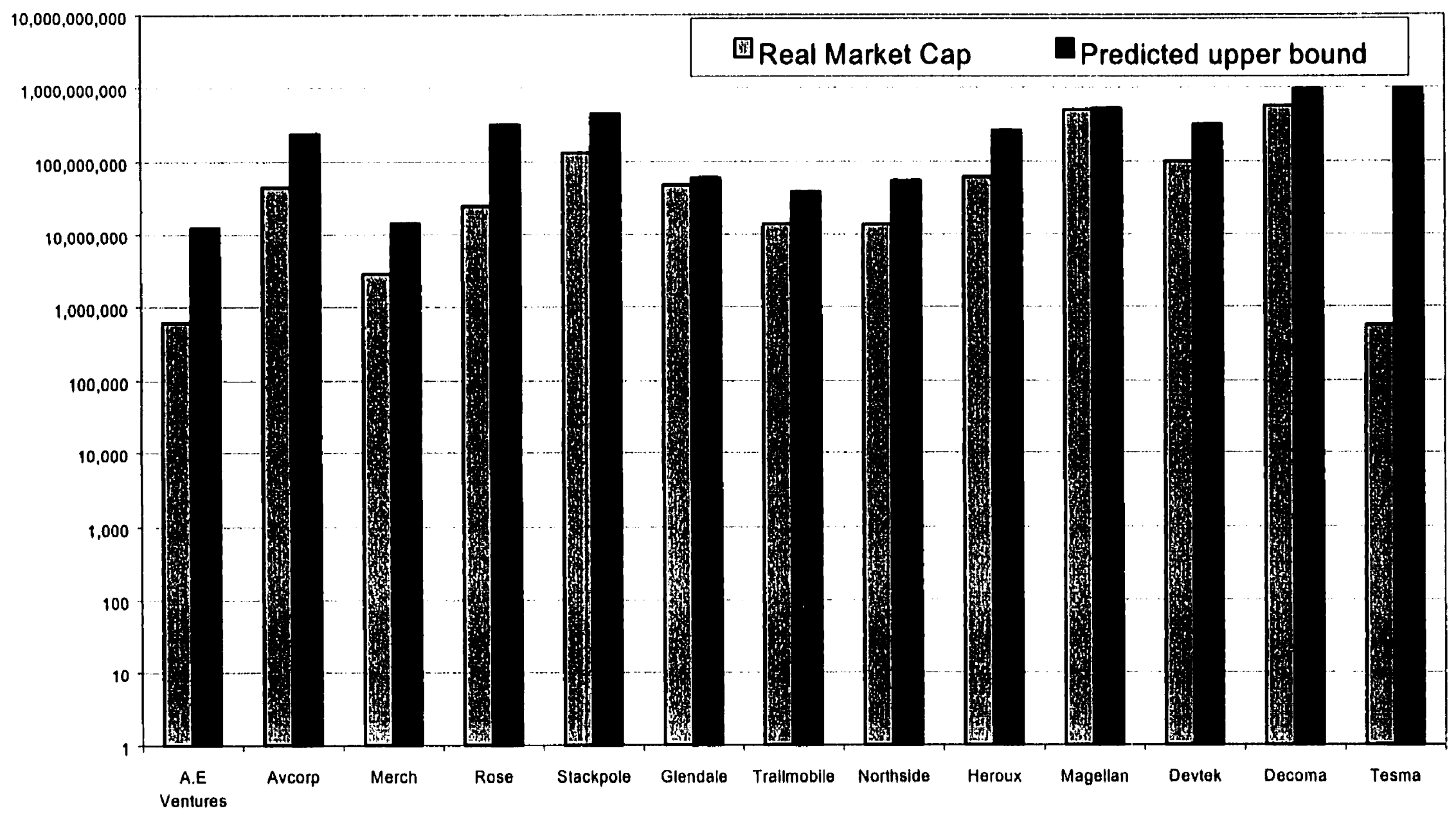




\section{Chapter 6 Analysis and Discussion}

Figure 6-13 Efficient Firms-Real and Predicted Upper Bound(SIC3700)

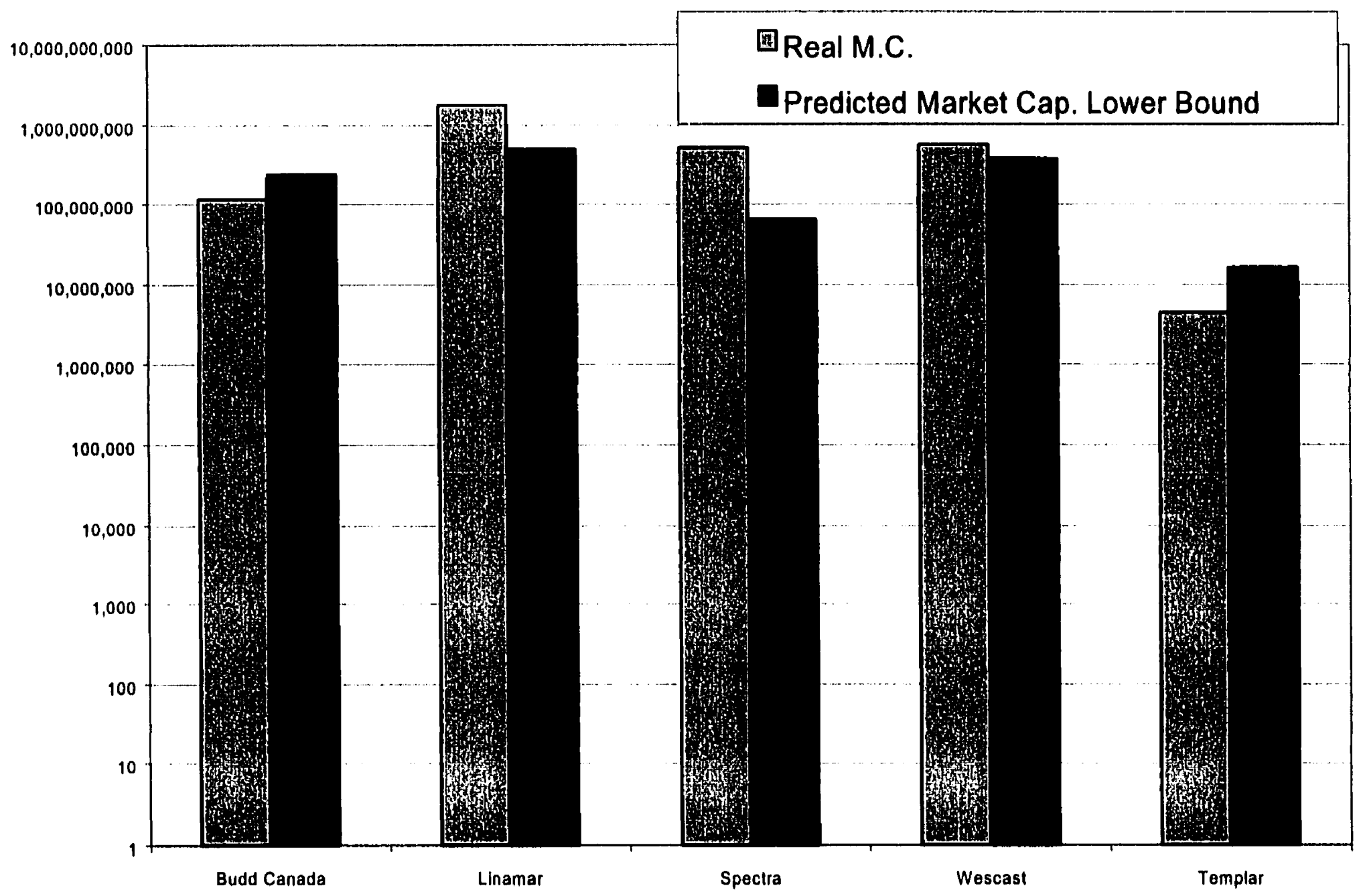


Chapter 6 Analysis and Discussion

In the case of the inefficient companies. in Figure 6-12. DEA accurately classifies $64 \%$ of the companies, but without exception the range from the minimum to the maximum value is very large. In the instances when DEA cannot classify the companies, it is due to there being not enough similar peers. DEA correctly finds an appropriate lower bound $60 \%$ of the time for the efficient companies. Figure $6-13$. with a SIC of 3700. Appendix D contains the information on the companies with a SIC in the 3700 s.

\subsection{Analysis of the Companies (SIC2000)}

A similar analysis for companies with SIC in the 2000s was also performed. This group represented food and kindred products. There were 44 DMUs in this subset, with 15 on the efficiency frontier and an average efficiency of 0.81 . The most popular efficient peers are A. L. Van Houtte Ltd. with 21 peers followed by AMT Fine Foods Ltd. with 19. Analysis of the lower bounds of the efficient companies shows that $67 \%$ of the companies are found to be undervalued, they have actual market value less than the predicted lower bound. Canada Bread Company Ltd., Seagram and Petroreal Oil Corporation are found to be self-evaluators. For the 29 inetficient companies, 10 of them do not reveal any information due to the fact they have one or no peers. The remaining 19 companies have a correct predicted market range $68 \%$ of the time. Also, $86 \%$ of the time the inefficient companies have an actual market value less than the predicted upper bound. Table 6-12 shows the range of market values for the inetticient companies and Table 6-13 demonstrates the market values for the etficient firms. 
Chapter 6 Analysis and Discussion

Table 6-12 Range for Market Values -Ineficient Companies(SIC2000)

\begin{tabular}{|c|c|c|c|c|c|}
\hline \multicolumn{6}{|c|}{ For the Inefficient Public Companies(\$) } \\
\hline & & & Predicted Ma & Irket Cap Range & \\
\hline Company & $\begin{array}{l}\text { Efificient } \\
\text { Peers }\end{array}$ & \begin{tabular}{|l} 
Real \\
Market Cap
\end{tabular} & Minimum & Maximum & \begin{tabular}{|l|} 
Predicted \\
Upper Bound
\end{tabular} \\
\hline 3 SEPP'S & 4.5 .12 & 27.532 .000 & 11.173 .015 & one peer & 18.937 .000 \\
\hline 6 T:ML FOODS & 4.33 & 1.782 .000 & 11.173 .015 & one peer & 10.684 .000 \\
\hline 7 SAPUTO & 2.24 .43 & 2.107 .819 .000 & 632.441 .262 & one peer & 586.998 .000 \\
\hline 8 DELICIOUS & $+1 .+3$ & 17.246 .000 & 302.000 & 38.002 .000 & 19.742 .000 \\
\hline 10 LASSONDE & 2.9 .43 & 17.825 .000 & 55.889 .000 & $632 .+41.000$ & 328.512 .000 \\
\hline II GLOBAL COMM & $16 .+1.43$ & 14.410 .000 & 1.917 .000 & 3.938 .000 & 5.567 .000 \\
\hline I4 AGRO PACIFIC & $2 .+.5$ & 10.874 .000 & 8.570 .000 & 11.173 .000 & 19.654 .000 \\
\hline 15 RIDLEY & 2.9 .24 .43 & 160.050 .000 & no peers & no peers & 481.981 .000 \\
\hline 18 BETA BRANDS & 2.4 & 47.999 .000 & 11.173 .000 & one peer & 19.408 .000 \\
\hline 19 SMALL FRY & 2.4 .9 & 26.740 .000 & 11.173 .000 & 15.889 .000 & 29.793 .000 \\
\hline 20 AFRICAN & $16 .+1 .+3$ & 683.000 & 302.000 & 1.917 .000 & 2.537 .000 \\
\hline $21 \overline{B A N F F}$ & 16.33 .41 & 1.378 .000 & 2.879 .000 & 3.938 .000 & 2.881 .000 \\
\hline 22 BIG ROCK &.++1.43 & 19.445 .000 & 11.173 .000 & 12.878 .000 & 71.738 .000 \\
\hline 23 BRICK BREWING & +.12 .43 & 15.421 .000 & 11.173 .000 & one peer & 52.811 .000 \\
\hline 25 SLEEMAN & +.24 .43 & 126.836 .000 & 11.173 .000 & 632.441 .000 & 205.764 .000 \\
\hline 26 TREE & 16.41 .43 & 1.917 .000 & 302.000 & $1 4 . 4 \longdiv { 0 . 0 0 0 }$ & 2.368 .000 \\
\hline 27 UNIBROUE & +.24 .43 & 33.828 .000 & 11.173 .000 & 126.836 .000 & 84.632 .000 \\
\hline 28 ANDRES & +.9 .24 .43 & 79.826 .000 & 11.173 .000 & 632.441 .000 & 139.259 .000 \\
\hline 29 MAGNOTTA & 4.24 .43 & 13.310 .000 & 11.173 .000 & 126.836 .000 & 49.850 .000 \\
\hline 31 VINCOR & 2.9 .13 .24 .43 & 192.114 .000 & $15,889.000$ & 632.441 .000 & 288.746 .000 \\
\hline 32 HIGHWOOD & 4.16 .41 .43 & 2.373 .000 & 3.938 .000 & one peer & 6.517 .000 \\
\hline 34 ARROWHEAD & +.16 .43 & 962.000 & 11.173 .000 & one peer & 13.002 .000 \\
\hline$\overline{35 \text { CLEARLY CDN }}$ & 41.43 & 5.135 .000 & 302.000 & $632.4+1.000$ & 188.943 .000 \\
\hline $36 \mathrm{COTT}$ & 1.2 .24 & 330.647 .000 & 139.628 .000 & 1.374 .236 .000 & 552.839 .000 \\
\hline 37 LEADING BRAND & 2.4 .5 & 8.570 .000 & 10.874 .000 & 11.173 .000 & 10.947 .000 \\
\hline 39 URBAN JUICE & 4.41 .43 & 12.878 .000 & 11.173 .000 & 19.445 .000 & 14.834 .000 \\
\hline 40 VIVANT & 33 & 876.000 & 2.879 .000 & Similar to Aqua & 2.879 .000 \\
\hline 42 LEF MCLEAN & +.5 .9 .12 & 3.381 .000 & 11.173 .000 & one peer & 14.939 .000 \\
\hline 44 ARCTIC GROUP & 41.43 & 38.002 .000 & 302.000 & $17.2+6.000$ & 66.865 .000 \\
\hline
\end{tabular}


Table 6-13 Range for Market Values -Eficient Companies(SIC2000)

\begin{tabular}{|c|c|c|c|c|}
\hline \multicolumn{5}{|c|}{ For the Efficient Public Companies(\$) } \\
\hline & Real M.C. & $\begin{array}{l}\text { Predicted. } \\
\text { Lower Bound }\end{array}$ & $\begin{array}{l}\text { Number of } \\
\text { Peers }\end{array}$ & Comment \\
\hline 1 MAPLE LEAF & 1.374 .236 .000 & 95.217 .210 & 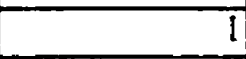 & Above lower \\
\hline 2 SCHNEIDER & 139.628 .000 & 321.064 .000 & TI & Undervalued \\
\hline 4 A.MT FINE & 11.173 .000 & 24.079 .000 & 19 & Undervalued \\
\hline 5 FLETCHER'S & 5.936 .000 & 12.038 .000 & 5 & Undervalued \\
\hline 9 SLN-RYPE & 15.889 .000 & 75.881 .000 & 9 & Undervalued \\
\hline 12 DOVER & 53.129 .000 & 20.133 .000 & $\overline{3}$ & Above lower \\
\hline 13 MIRRM & 21.548 .000 & 192.114 .000 & 2 & Undervalued \\
\hline 16 SENTEX & 3.938 .000 & 5.918 .000 & 7 & Undervalued \\
\hline 17 CAN BREAD & 449.753 .000 & self evaluator & $\overline{0}$ & No into \\
\hline 24 FOSTER'S & 556.622 .000 & 1.060 .747 .000 & 10 & Undervalued \\
\hline 30 SEAGRAM & $19,977.447 .000$ & self evaluator & 0 & No info \\
\hline $33 \mathrm{AQUA} \mathrm{I}$ & 2.879 .000 & 1.085 .000 & 3 & Above lower \\
\hline 38 PETROREAL & $5,304.000$ & selt evaluator & 1 & No info \\
\hline 41 EVEREST & 302.000 & 13.971 .000 & 11 & Undervalued \\
\hline 43 A. L. VAN & 632.441 .000 & 528.193 .000 & 21 & Above lower \\
\hline
\end{tabular}

Appendix E contains the information on the companies with a SIC in the 2000s.

\subsection{Analysis Utilizing All 452 Companies}

Some may argue that using different SIC codes in the same analysis is incorrect.

However. there are studies that do in fact use companies with different 4-digit SIC codes in a valuation analysis, such as Renaissance Capital [ZHUO0]. To test the theory that a relevant peer group would be found when all $\$ 52$ companies were included in the valuation analysis. an efficient and an inefficient DMU were analyzed with all 452 companies.

\subsubsection{Inefficient Hammond compared to all 452 Companies}

Comparing DMU Hammond to all of the companies resulted in Hammond having 21 peers of which 4 were efficient. The range for its market value based on these 
Chapter 6 Analysis and Discussion

companies was between $\$ 3.4$ to $\$ 142.8$ million. with a predicted upper bound of $\$ 57.5$ million. Hammond's real market value is $\$ 18.4$ million. The most similar companies were Patheon. Sico, and Lassonde with SIC codes of 2834,2851 and 2034 respectively and market values of $\$ 142.8, \$ 71$, and $\$ 17.8$ million. respectively. The only other company with the same SIC code in the 21 peers thus found was Aastra. Even though this analysis resulted in a bigger peer group for Hammond. the results did not conclusively find a better. tighter range for its market capitalization.

\subsubsection{Efficient Company Wescast Compared to all 452 Companies}

An efficient company. Wescast, was also tested with all 452 companies. This time around Wescast had 97 companies utilizing it as a peer. The lower bound calculated based on these peers was $\$ 408$ million, with Wescast having a real market value of $\$ 574$ million. This amount was better than the $\$ 383$ million predicted as a lower bound for Wescast when it was compared only to companies with an SIC code in the 3700s just like itself. In this comparison, the peer group consisted of companies with SIC codes ranging from 2000 to 3900 . The most comparative group were companies with SIC in the $3500^{\circ}$ s, numbering 15 in total. There were also 8 companies with SIC in the 3700 s compared to Wescast. including 6 that had the same identical SIC code. Appendix F contains the information on this analysis.

\subsection{Private Companies}

The private companies were analyzed by adding one at a time and re-running the DEA BCC model with the 85 DMUs. Once similar reference peer units are found, the private companies can be assumed to have the market values of these reference DMUs; thus one has found a market value for the private companies based on the similar public 


\section{Chapter 6 Analysis and Discussion}

companies. The private companies were analyzed in the same manner as the efficient and inefficient public companies. As mentioned, there are three private companies having a SIC code in the 3600s, namely, company \#55, 85, and 220.

\subsubsection{Inefficient Private Companies}

After the initial DEA analysis, private company $\# 55$ was found to have an efticiency score of 0.77 in BCC. It was then analyzed using the procedure applied for public companies above. Unfortunately. the company had a very unique definition of peer groups, consisting only of 4 other companies. all efficient. The peer group included Aastra Technologies. Ts Telecom, Communication Systems Internat. and Fifty-Plus.Net International. After the analysis, it was found to be most similar in terms of distance and efticiency score to TS Telecom. The actual values found are listed in Table 6-14.

Private Company \#220, coincidentally, had the same peer grouping as subset Hammond above. In its peer group were LG Technologies, Camco Inc, TS Telecom, Calian, Primetech, Electrohome and Hammond. It was found to be most similar to TS Telecom. which had a market cap of $\$ 11.8$ million.

Table 6-14 Ineficient-Range for Market Values (Private Companies)

\begin{tabular}{|l|l|l|l|l|}
\hline \multicolumn{5}{|l|}{ For Inefficient Private Companies (\$) } \\
\hline & Predicted Market Cap Range (\$) & \\
\hline Company & Minimum & Maximum & Closest to: & $\begin{array}{l}\text { Predicted } \\
\text { Upper Bound }\end{array}$ \\
\hline Company \#55 & 2.400 .000 & 46.000 .000 & $11,832.000$ & $17,700,000$ \\
\hline Company \#220 & 11.832 .000 & $33.191,000$ & $11,832,000$ & $37,414,000$ \\
\hline
\end{tabular}

\subsubsection{Efficient Private Companies}

For the efficient private companies the same analysis as for efficient public companies was conducted, the lower range found is listed in Table 6-15. 


\section{Chapter 6 Analysis and Discussion}

Table 6-15 Efficient-Range for Market Values (Private Companies)

\begin{tabular}{|l|c|}
\hline \multicolumn{2}{|c|}{ For Efficient Private Companies } \\
\hline Company & Predicted lower bound (\$) \\
\hline Company $\# 85$ & $48,822.000$ \\
\hline
\end{tabular}

\section{Analysis Summary}

To summarize. the DEA-Valuation model is a way to identify a set of similar public companies that can be used to estimate the market value of a private company. DEA is traditionally used to measure relative efficiencies and this novel application expands its function. DEA does a fairly good job in determining appropriate peers for the companies when utilizing the BCC model. The CCR model was not employed due to the existence of negative variables in the model. The DEA-Valuation approach works better with more DMUs. There must be more than 22 DMUs for DEA to find a correct range for the company under analysis. Private companies are valued by tinding suitable public peers and inferring their market values onto the private companies.

Although the range specified by the peers is sometimes quite wide, the method still does an above average job of classifying market value. For companies that have only one peer or none (the self-evaluators), the results are not binding. A larger data set, if possible. should be collected. This will increase the likelihood of correct classifications. 


\section{CONCLUSIONS \& RECOMMENDATIONS}

With a global increase in mergers and acquisitions and the number of companies going public, the need for valuation tools and methodologies increases. Determining value is a significant part of any business. be it for selling a business, divorce settlements or for mergers. Value estimates can vary widely and to insure a fair value for the business a number of issues need to be addressed.

Valuation is oftentimes a subjective task performed by valuators, business analysts. accountants, lawyers and investment bankers. The existing methods for determining this value consist of forecasting growth and future cash flows, or optimizing the value of owned assets by liquidation or finding similar companies and adjusting their forecasts and growth expectations to arrive at a value. The goal of this thesis is to develop a methodology that evaluates the market value of corporations utilizing Data Envelopment Analysis to find comparable firms and to apply this methodology to assess the worth of private companies.

A DEA analysis of manufacturing companies was studied. Valuation models for predicting market ranges were developed. Different approaches were constructed based on the performance of the company in the DEA model. Inetficient companies had their most similar peers identified which lead to a predicting of the market value range. An upper bound for their market value was determined as well. For the efficient companies, a lower bound market value predicting approach was constructed.

The results were encouraging when a highly comparable peer group existed. In total over 200 companies were examined with the DEA-Valuation method. Results showed that overall $70 \%$ of the inefficient companies were within the range predicted by 


\section{Chapter 7 Conclusions and Recommendations}

the DEA-Valuation method, and quite a number of companies were scarcely outside of their individual predicted range. Overall, the calculated upper bounds were greater than the real market value for the inefficient companies $75 \%$ of the time. For the efficient companies the lower bound was less than the real market value $50 \%$ of the time. however there were instances where it was not and this could mean that the companies are undervalued.

In summary, the DEA-Valuation model was tairly adequate in predicting appropriate market ranges. As with all valuations, this is another tool that valuators have at their disposal. and a combination of the different valuation methods will give better ranges of value.

\subsection{CONTRIBUTIONS}

The contributions of this thesis include novel ways to predict lower bounds for market value for efficient companies and upper bounds for inefficient ones. This work expands on the use of DEA for finding peer groups instead of its traditional role of finding efficiency measures. Valuation models were developed for both private and public companies and efticiency scores, difference indicators. market value ranges. and comparative peers were provided where appropriate. DEA was able to handle the multidimensional nature of companies because it allows multiple inputs and outputs. The work consists of a group of data, more than 500 companies all together, which can be used to determine the peer groups.

\subsection{LIMITATIONS OF THE DEA APPROACH}

In order to apply the DEA-Valuation Methodology there has to be a sufficient number of firms in the peer group. The number of DMUs in the analysis varied from 22- 


\section{Chapter 7 Conclusions and Recommendations}

85. The number of similar peers should at least be three in order to conduct an appropriate analysis. Increasing the number of firms in the analysis mav improve and tighten the ranges for predicted market values. Ideally one wants a set with many DMUs but with very similar DMUs. Having more DMUs would not guarantee more peers however a bigger group would increase the probability of having more similar companies.

\subsection{AREAS OF FUTURE WORK}

The methods discussed in this thesis to determine market values represent an excellent start and show encouraging results. The above methodology can be enhanced and made stronger by applying it to different areas and comparing its results with other methods. In the following list, areas of future research are addressed and examined to advance the DEA-Valuation methodology.

- Obtain data on five-year growth forecasts for companies and run a DEA analysis

- Analyze different sectors rather than just manufacturing to see if the results hold for the other industries.

- Attempt to analyze Internet company valuation, need to somehow rank key-men and technology contributions, and it is necessary to look at other qualitative and quantitative factors. Although information of this nature was not available for this analysis, if it were, the possible models would consist of the important quantitative factors that Internet start-ups rely on. These include their burn-rate of cash and the amount of cash or investments on hand. While one wants to increase the amount of cash investments in the business, and thus maximize it, it has to be in balance with 
the burn-rate. Internet companies go through an exorbitant amount of cash, called the "burn-rate". This would be an important factor to minimize in a DEA study. Other factors to consider are supplier relations, marketability, "killer apps" or unique technology, and customer base to make up for the fact that most Internet companies scarcely have revenue and typically, no profits.

- The weights in this study were not restricted. DEA chose the weights according to the company under analysis allowing it to appear the best it could. With expert opinion, these weights can be restricted and analyzed to test the change in market value ranges.

- Accurding to Renaissance Capital (a research boutique) a valuation analysis can be carried out without using all the companies from the same 4-digit SIC code. The argument is that some present day public companies are so large and diversified into many forms of businesses that four digit SIC codes are no longer of significance. For example, Molson`s Canada is a brewer, i.e. Manufacturing, but at the same time it owns the Montreal Canadians Hockey Club, i.c. Non-manufacturing. This might lead to an interesting study if a lot of companies with varying SIC codes can be included in the same study.

- A complete valuation using different methodologies such as DCF, CF, asset valuation, with all the appropriate discounts applied would be the best study. As well as being the best way to compare all the methods against each other

- Find and set optimal cut-off values for the distance and the efficiency similarity when analyzing the minimum and maximum of the inefficient companies. Right now the distance is set to 1 , and only companies that have a distance of less than 1 


\section{Chapter 7 Conclusions and Recommendations}

are analyzed as peers. For the efficiency scores, try to determine a percentage range that is appropriate for peer companies. For example, if the subject company has an efficiency score of 0.75 only examine other companies that are within $10 \%$ of this score.

\subsubsection{New Applications for DEA}

- The ranking of the reputation of the underwriters are based on pricing, selling of their allotment, post-issue price stability, market making, analyst coverage/publicity, ability to underwrite subsequent debt/equity issues. The DEA approach can be used to study IPO performance and also to determine the best underwriters based on the above factors.

- Also, as previously mentioned. DEA can be used just to find the best comparable firms, and instead of trying to estimate a market value range based on the found comparable peers, the known $\mathrm{P} / \mathrm{E}$ ratios, growth forecasts and discount rates of the peers should be used in the estimation of value of the private ones. 


\section{REFERENCES:}

[BANK84] Banker. R.D., Charnes, A., Cooper. W.W., "Some Models for Estimating Technical and Scale Efficiency in Data Envelopment Analysis." Management Science. (1984). 30(9): 1078-1092.

[BERG98] Bergendahl. G., "DEA and benchmarks - an application to Nordic Banks," Annals of Operational Research. (1998), 82: 233-249

[BOAT81] Boatsman. J., Baskin. E.. “Asset Valuation with Incomplete Markets," The Accounting Review, (1981) 56:38-53.

[BOOT00] Booth, L., Class Notes on Mergers and Acquisitions. (2000).

[BOOT98] Booth. L., "What Drives Shareholder Value." Federated Press-Creating Shareholder Value Conference. October 28. 1998.

[BOOT98a] Booth, L., "The Capital Asset Pricing Model: Equity Risk Premiums And The Privately Held Business," Journal of Business Valuation- Proceedings of the $3^{\text {rd }}$ Joint Business Valuation Conference of the Canadian Institute of Chartered Business Valuators (CICBV) and the American Society of Appraisers (ASA). Montreal, (1998), 1-36.

[BYRN94] Byrne. A., Rees, W., "The Time Series Behaviour of Initial Returns on U.K. IPOs.“ Journal Of International Financial Markets, Institutions \& Money," (1994), 4(3-4): 81-100.

[CAMP92] Campbell, I.R., "Business Valuation a Canadian Author's Perspective," Journal of Business Valuation - Proceedings of the $11^{\text {th }}$ Business Valuation Conference. Quebec City, (1992). 135-159.

[CBC00] CBC Newsworld Broadcast, July 22, (2000)

[CDNX00] www.cdnx.com

[CHAF93] Chaffe. D., "Option Pricing As A Proxy For Discount For Lack Of Marketability In Private Company Valuations: A Working Paper," Business Valuation Review, December (1993).

[CHAR78] Charnes, A., Cooper, W.W., Rhodes, E.L., "Measuring the Efficiency of Decision Making Units," European Journal of Operational Research, (1978), 2(6):429-444.

[CHAR94] Charnes, A., Cooper, W.W., Lewin, A.Y., Seiford, L.M., Data Envelopment Analysis: Theory, Methodology and Applications, Boston: Kluwer Academic Publishers (1994) 
[CSI89] C.S.I.. How to read tinancial statements, Toronto: The Canadian Securities Institute (CSI) (1989).

[DENN00] Dennis, R., "Question and Answer on Selling A Business," The Washington Post, February 21, 2000.

[ETT097] Ettore, B.. "Too Much of a Bad Thing," Management Review. December 1997.

[FARR57] Farrell. M.J.. “The Measurement of Productive Efficiency." Journal of the Royal Statistical Society, Series A. (1957), 120(3):253-290.

[FIRT97] Firth. M.. Liau-Tan. C.K.. "Signaling Models and the Valuation of New Issues: an Examination of IPOs in Singapore," Pacitic-Basin Finance Journal. (1997). $5(5): 511-526$.

[FISO00] www.tisonline.com

[FITC88] Fitchett. G.A, "Financing Closely-Held Businesses" Journal of Business Valuation- Proceedings of the 9th Biennial Conference of the CICBV, Toronto. (1988), 11-20.

[HARB97] Harbert. T.. “Intangibles Count in a Company”s Valuation.” Electronic Business. November 1997.

[HEND88] Henderson, A.R., “Key Strategies in Selling a Privately-Held Business," Journal of Business Valuation- Proceedings of the 9th Biennial Conference of the CICBV Toronto, (1988), 39-65.

[HUNT75] Hunt. P.. “Funds Position: Keystone in Financial Planning,“ Harvard Business Review, May-June 1975.

[IBBO94] Ibbotson. R., Sindelar, J.L.. Ritter, J.R., "The Market's Problems With The Pricing of IPOs." Journal of Applied Corporate Finance, (1994), 7:66-74.

[JAIN99] Jain, B.A., Kini, O., "On Investment Banker Monitoring In The New Issues Market," Journal of Banking \& Finance. (1999) 23:49-84.

[JENS76] Jensen. M., Meckling W., "Theory Of The Firm: Managerial Behavior, Agency Costs And Ownership Structure," Journal of Financial Economics, (1976) 3:305-360.

[KAPL95] Kaplan. S.N., Ruback, R.S., "The valuation of cash flow forecasts: an empirical analysis," Journal of Finance, (1995), 50:1059-1093. 
[KIM95] Kim, J-B., Krinsky, I., Lee, J., :The Role Of Financial Variables In The Pricing Of Korean Initial Public Offerings,“ Pacific-Basin Finance Journal. (1995), 3(4):449-464.

[KIM98] Kim, I., Hendry, L.C., "Using DEA To Assess NATO Burden-Sharing," Journal of the Operational Research Society. (1998). 49:228-236.

[KIM99] Kim, M.. Ritter J.R., "Valuing IPOs," Journal of Financial Economics, (1999). 53:409-437.

[KLEI96] Klein. A.. - The Association between the information contained in the prospectus and the price of initial public offerings," Journal of Financial Statement Analysis. (1996), 2:23-40.

[LELA77] Leland. H.. Pyle. D.. "Informational Asymmetries. Financial Structure And Financial Intermediation," Journal of Finance, (1977). 32:371-387.

[LEV195] Levis, M.. Thomas, D.C., "Investment Trust IPOs: Issuing Behaviour And Price Performance. Evidence From The London Stock Exchange," Journal of Banking \& Finance, (1995), 19(8): 1437-1458.

[LITT59] Little, A.J.. "Valuation of Goodwill." The Valuation of Private Business and Professional Practice, Toronto: Canadian Institute of Chartered Accountants (1959), 1-6.

[L.JUN97] Ljungqvist, A., "-Pricing Initial Public Offerings: Further Evidence From Germany." European Economic Review, (1997), 41:1309-1320.

[LYON89] Lyons, R.P., Wilczynski, M.J., “Discounting Intrinsic Value." Trusts and Estates. February (1989), 22-27.

[ME00] www.me.org

[MERC97] Mercer. C.. Quantifying Marketability Discounts, @city: Peabody Publishing (1997), 345-370.

[MORR92] Morris, I.T., "Valuation Perspectives of a Venture Capitalist," Journal of Business Valuation - Proceedings of the $11^{\text {th }}$ Business Valuation Conference, Quebec City, (1992), 83-90.

[MULL90] Mullen, M., "What is a Brand Name or Trademark Really Worth - How Can that Value be Measured?" Journal of Business Valuation- Proceedings of the 2nd Joint Business Valuation Conference of the CICBV and the ASA, Vancouver, (1990), 203-212. 
[NEED86] Needham. J., Young, A., “-The Leading Edge In Mergers And Acquisitions." Mergers \& Acquisitions, November / December 1986.

[OAND00] www.oanda.com

[OVEN59] Ovens. G., "Valuing a Privately Owned Business." The Valuation of Private Business and Professional Practice, Toronto: Canadian Institute of Chartered Accountants (CICA) (1959), $11-18$.

[OVEN72] Ovens, G., "Introduction to the Business Valuation Field." Solving the Valuation Problem, Toronto: The CICA (1972). 7-9.

[PIES95] Piesse. J.. Townsend. R.. - The Measurement of Productive Efficiency in UK Building Societies." Applied Financial Economics. (1995), 5:397-407.

[PRAT93] Pratt. S.. Valuing Small Businesses And Professional Practices, $2^{\text {nd }} \mathrm{ed.}$ Homewood: Dow Jones-Irwin (1993).

[PRAT96] Pratt, S.. Valuing A Business: The Analysis and Appraisal of Closely Held Companies, $3^{\text {rd }}$ ed., Homewood: Dow Jones-Irwin (1996).

[RITT84] Ritter, J.R., "Signaling And The Valuation Of Unseasoned New Issues: A Comment," Journal of Finance, (1984), 39:1231-1237.

[RUBA96] Ruback. S.N.. Richard, S., --The Market Pricing Of Cash Flow Forecasts: Discounted Cash Flow vs. The Method Of Comparables." The Bank of America Journal of Applied Corporate Finance. (1996) 8(4):45-57.

[SEDA00] www.sedar.com

[SEGU97] Seguin, P.J., Smoller. M.M., “-Share Price and Mortality: An Empirical Evaluation of Newly Listed NASDAQ Stocks,“'Journal of Financial Economics, (1997). 45:333-363.

[SIMA00] Simak, P.C., Paradi. J.C., "How To Estimate The Market Value Of A Private Company - A DEA Approach.“ University of Toronto working paper (1999).

[STOC00] www.stockwatch.com

[STOU98] Stoughton, N.M., Zechner, J., "IPO Mechanisms. Monitoring And Ownership Structure," Journal of Financial Economics, (1998), 49:45-77.

[THAN92] Thanassoulis, E., Dyson, R.G., "Estimating Preferred Target Input Output Levels Using Data Envelopment Analysis," European Journal of Operational Research, (1992), 56:80-97. 


\section{References}

[TSEO0] www.tse.com

[WEAV98] Weaver, W.C., "Discounts And Other Adjustments To Fair Market Value Estimates," Orlando: William C. Weaver (1998), 1-16.

[WISE90] Wise, R.M., "Discounts in Arriving at Share Values of Closely-Held Corporations" Journal of Business Valuation- Proceedings of the 2nd Joint Business Valuation Conference of the CICBV and the ASA, Vancouver, (1990), 127-148.

[YAHO00] ca.tinance.yahoo.com

[ZHU00] Zhu. J., "Multi-Factor Performance Measure Model With An Application To Fortune 500 Companies." European Journal of Operational Research, (2000) 123:105-124. 


\section{BIBLIOGRAPHY:}

[ALI95] Ali, A.I., Lerme, C.S., Seiford, L.M., "Components of Efficiency Evaluation in DEA.“ European Journal of Operational Research, (1995), 80:462-473

[BERG97] Berger. A.N.. Humphrey, D.B., “Efficiency of Financial Institutions:

International Survey and Directions for Future Research." European Journal of Operational Research. (1997), 98: 175-212

[BROC97] Brockett. P.L.. Charnes, A., Cooper, W.W.. Huang. Z.M., Sun. D.B.. “Data Transformation in DEA Cone Ratio Envelopment Approaches for Monitoring Bank Performances,“' European Journal of Operational Research, (1997), 98: 250-268.

[CAMP90] Campbell. I.R.. Low. R.B., Murrant, N.V.. The Valuation \& Pricing of Privatelv-Held Business Interests, Toronto: Canadian Institute of Chartered Accountants (1990).

[CHIL95] Chilingerian. J.A., "Evaluating Physician Efficiency in Hospitals: A Multivariate Analysis of Best Practice," European Journal of Operational Research, (1995), 80:548-574.

[COOK90] Cook. W., Roll, Y., Kazakov, A., -A DEA model for Measuring the Relative Efficiency of Highway Maintenance Patrols.“ Journal of Information. (1990), 28(2):113-124.

[DAUD87] Dauderis. H.. Financial Accounting: An intro to decision making, Toronto: Holt, Rinehart and Winston of Canada, Ltd. (1987).

[DROM98] Droms. W.G.. Finance \& Accounting for Nonfinancial Managers, all the basics vou need to know, $4^{\text {th }}$ ed., Reading: Addison Wesley Longman Inc. (1998).

[ELMA95] El-Mahgary. S., "Data Envelopment Analysis: Visualizing the Results," European Journal of Operational Research. (1995), 85:700-710.

[ELMA95a] El-Mahgary. S., "Data Envelopment Analysis - A Basic Glossary,” Journal of Operational Research Society, (1995), 8(4):15-22.

[MIKK97] Mikkelson, W.H., Partch, M.M., Shah, K., "Ownership And Operating Pertormance Of Companies That Go Public," Journal of Financial Economics, (1997) 44:281-307.

[MORC88] Morck, R., Shleifer, A., Vishny, R., "Management Ownership And Market Valuation: An Empirical Analysis," Journal of Financial Economics, (1988) 20:293-316. 
Bibliography

[PAPA97] Papagapoou, A., Mingers, J., Thanassoulis, E., "Would You Buy A Used Car With DEA?" Journal of Operational Research Society, (1997), 10(1):13-19.

[PAST97] Pastor, J..M.. Perez, F., Quesada, J., "Efficiency Analysis in Banking Firms: An International Comparison," European Journal of Operational Research. (1997), 98: 395-407.

[TATJ97] Tatje, E.F., Lovell, C.A.K., "The Sources of Productivity Change in Spanish Banking," European Journal of Operational Research. (1997), 98: 364-380.

[TRAC99] Tracy. J.A. How To Read A Financial Report. For Managers. Entrepreneurs. Lenders. Lawyers \& Investors, $5^{\text {th }}$ ed., New York: John Wiley \& Sons Inc. (1999). 


\section{GLOSSARY}

Aggregate

Efficiency

Appraisal

BCC Model

Beta

Binomial

Model

Binomial Tree

Black-Scholes

Model

BPS

Business

Enterprise

Business

Valuation

Call Option

Capitalization

Rate

CAPM
Another name for the efficiency measure as obtained from the CCR model, also known as efficiency

The act or process of determining the value of something

This model measures technical efficiency as the convexity constraint ensures that the composite unit is of similar scale size as the unit being measured; unlike the CCR model. the $\mathrm{BCC}$ allows variable returns to scale

A measure of the systematic risk of an asset. Compares the price volatility of a particular issue to the movement of the market in general. If the difference is great. security has a high beta; if low. has a low beta.

A model where the price of an asset is monitored over successive short periods of time. In each short period it is assumed that only two price movements are possible

A tree that represents how an asset price can evolve under the binomial model

A model for pricing European options on stocks, developed by Fischer Black, Myron Scholes, and Robert Merton

Book value per share

An organization pursuing an economic activity on a 'for profit' basis

The act of determining the value of, or the estimated value of, a business enterprise, or an interest therein

A financial instrument that gives the owner the option to buy an asset at a certain price by a certain date

The required rate of return that is used to convert income/cash flow into value. The inverse of the cap. Rate is referred to as the multiple or multiplier.

The capital asset pricing model is a model relating the expected return on an asset to its beta. 
CCR Model

Closely-Held Corporation

Comparable

Firms

Constant

Returns to

Scale (CRS)

DEA

Depreciation

Discount Rate

Discounted Cash Flow

Dividend

DMU

DRS

EBIT

EBITDA
The CCR ratio model calculates an overall efficiency for the unit in which both its pure technical efficiency and scale efficiency are aggregated into a single value. The obtained efficiency is never absolute as it is always measured relative to the field

A term used to describe a corporation whose shares are neither listed for trading on a recognized stock exchange nor traded in an over-the-counter market. Technically it has less than 51 shareholders (Canada).

Public companies that are similar in nature to private companies or other companies.

A unit operates under constant returns to scale if an increase in inputs results in a proportionate increase in the output levels. If the inputs values for a unit are all doubled, then the unit must produce twice as much outputs

Data Envelopment Analysis is a decision making tool based on linear programming for measuring the relative efficiencies of a set of comparable units

The systematic assignment of the cost of tangible assets to expense

The annualized dollar return on a treasury bill or similar instrument expressed as a percentage of the final face value. Or, a rate of return used to convert a monetary sum, payable or receivable in the future, into present value

An accounting technique for estimating the present value of anticipated future income and expenditures. such as earnings from loan principal and interest payments, and income from investment securities. It is calculated as either net present value, which expresses future cash flows in terms of current money by applying a discount rate to future receipts, or internal rate of return, which figures the average annual yield or return on capital of an investment or a bank loan over its expected lifetime

A cash payment made to the owner of a stock

Decision Making Unit. This term emphasizes the fact that the focus was not on profit generating enterprises. but rather on decision making entities

Decreasing returns to scale

Earnings Before Interest and Tax

Earnings Before Interest, Tax, Depreciation, and Amortization 
Economies of The decreases in combined operating expenses and/or increases in Scale combined revenues, which result following the merging of two or more business operations. They are created by factors such as the elimination of duplicate overhead costs, the acquisition of a secured source of supply or enhanced combined purchasing power. more effective utilization of operating facilities, and so on.

Efficiency

A general term often associated with performing activities as well as possible.

Efficient

Frontier

A frontier or surface determined from the best-observed or best practice DMUs.

Enterprise

The market value of equity plus its book value of cash minus cash.

Value

Envelopment Please see Efficient Frontier

Surface

EPS Earnings per share

Exogeneously

Fixed Factor

An input or output that is beyond the control of the DMU manager

Fair market value

The highest price available in an open and unrestricted market between informed and prudent parties, acting at arm 's length and under no compulsion to act, expressed in terms of cash.

Financial Ratio Usually a ratio of financial information, aiming to capture a single dimension of corporate performance

Financial Risk The portion of overall business risk associated with the financial structure of a business

Forced

Liquidation

The sale of the assets where an immediate cessation of the business and disposition of assets is assumed on an 'as is/where is' basis. The forced liquidation of assets at auction.

Going Concern A business enterprise that is both conducting operations at a given date, and has every reasonable expectation of doing so for the foreseeable future after that date. An accounting term used to indicate that a company is operating normally.

Going Concern The present value of all future benefits expected to accrue from ownership, Value where a business operation is expected to continue to operate either for a finite period, or indefinitely into the future 
Goodwill

Homogeneity

Input-oriented Model

Intrinsic Value

IPO

IRS

Lambda Values

Liquidation

Liquidation

Value

Liquidity

Market

Capitalization

Market to Book Value (M/B)

Marketability Discount

Minority

Discount
The difference between going concern value and the sum of the net tangible assets and identifiable intangible assets

\section{Degree of similarity between the units in the field}

Indicates that an inefficient unit is made efficient through the proportional reduction of its inputs while its output proportions are held constant. The CCR model yields the same efficiency regardless of whether it is input or output-oriented. this is not the case with the BCC model

A notional market value, based upon rates of return required by investors given economic and business conditions existing at the valuation date. without consideration of possible synergistic benefits that might accrue in differing degrees to arm's length purchasers

Initial public offering

Increasing returns to scale

Results from a DEA analysis that indicate the level of contribution of efficient firms to the virtual DMU created by the projection of an efficient of an inefficient DMU onto the frontier

The process of converting assets into cash.

The net amount of money, if any, available to equity owners following a voluntary liquidation. a reorganization of a business pursuant either to a proposal to creditors, or a liquidation of a business pursuant to a receivership or other proceeding under The Bankruptcy Act.

The relative ease of converting non-cash assets into cash.

The total value of a company, derived by the price of a share multiplied by the number of shares the company has outstanding

Ratio of the market value of a security to its book value. An indication of performance of common stock equity, after accounting for such factors as dilution of stock value after a merger and market reaction to unexpected gains or losses and changes in operating income

An amount deducted from what would otherwise be the value of a shareholding in a company to reflect illiquidity, or lack of marketability

The reduction from the pro rata portion of the en bloc value of the assets or ownership interests of a business as a whole to reflect the disadvantages of owning a non-controlling interest 
Multipliers Please refer to definition for Weights

Net Book

Value

With respect to a business enterprise, the difference between total assets (net of depreciation, depletion, and amortization), and total liabilities of an enterprise as they appear on the balance sheet. The term is synonymous with each of the term's book value, net worth and shareholders' equity.

Nominal Rate

A discount rate, or capitalization rate, that includes both an inflation of Return component and a real rate of return.

Notional

Market

A term used to describe circumstances where it is necessary to determine fair market value. fair value. or some other value in the absence of open market negotiations

Open Market

A term used to describe the market in which arm 's length, negotiated transactions take place.

Output-

An inefficient unit is made efficient through the proportional increase of its oriented Model outputs, while the inputs proportions remain unchanged

Over-thecounter Market

The trading of securities or commodities not listed on an established stock exchange

Peer Group

The set of efficient DMUs against which inefficient units are compared. The efficient targets are a linear combination of these peers.

Piecewise

Linearity

Price

An efficient frontier is piecewise linear when the underlying production function is approximated through interconnected linear segments

The consideration paid in a negotiated open market transaction involving the purchase and sale of an asset

Price to Earnings Ratio (P/E)

The relationship between the current price of a stock to the earnings over any earnings period. The $\mathrm{P} / \mathrm{E}$ is calculated by dividing the current stock price by the earnings per share or dividing the market value by earnings per share for the most recent 12-month period. It is used by investors to gauge the market demand for stocks. Companies with a high $\mathrm{P} / \mathrm{E}$ have greater earnings potential than low $\mathrm{P} / \mathrm{E}$ stocks, but also are more volatile and somewhat riskier

Privately-Held Business Interest

An en bloc, control, or minority shareholding in a private company, or all of part of the business of a private company represented by its net operating assets or all or one or more partnership interests in a partnership or a proprietorship 
Privately-Held

Company

Public

Company

Put Option

Rate of Return

Real Rate of

Research

Boutique

Risk Free Rate of Return
Return

A business that is incorporated. has less than 51 shareholders (Canada), and does not offer its shares to the public

A company whose equity shares and/or issued debt are traded on an established stock exchange or in an over-the-counter market.

An option to sell an asset for a certain price by a certain date

An amount of income realized or expected on an investment, expressed as a percentage of that investment

A discount rate, or cap. Rate. that excludes consideration of intlation, as contrasted with a nominal rate of return

Company that specializes in tinding comparable companies

The prevailing rate of return on money market investments such as long term government bonds, conventional first mortgages, and high quality long term corporate bonds. These are investments which are generally free from substantial credit risk, are priced to reflect a relatively long term holding period, and hence, aside from inflation related purchasing power risk, put the investor at relatively little risk. These securities typically are fixed in income as well as in principal and, hence, generally do not offer any potential for capital growth.

\section{RTS Returns to scale}

Rules of

Thumb

Scale

Efficiency

Shareholders' Equity

Slack Variable

Technical Efficiency
Commonly used criteria within a specific industry to gauge an element of business value

A unit is said to be scale efficient when its size of operations is optimal so that any modifications on its size will render the unit less efficient; value obtained by dividing the aggregate efficiency by the technical efficiency

The aggregation of a company ${ }^{\circ}$ paid-in capital, retained earnings, contributed, appraisal and other surpluses.

Result form a DEA analysis and indicates the level of input minimization or output augmentation that is required for the inefficient firm to reach the envelopment surface following the proportional change indicated by the efficiency score

An efficiency measure that ignores the impact of scale-size by comparing a DMU only to other units of similar scale, computed using the BCC model 
Threshold Rate A benchmark, point in time related. predetermined rate of return on equity of Return criteria that is applied to a projected after tax cash flow that includes both inflation and real growth, where leverage and related interest bearing debt considerations are excluded. and where purchaser perceived net economic value-added is taken into account

Treasury Bill A short-term non-coupon bearing instrument issued by the government to tinance its debt

Valuation

The act or process of determining the value of something

Valuation Day The date proclaimed in the Income Tax Act (Canada) on which capital (V-Day) gains taxation in Canada came into effect. With respect to privately held business interests, this date is December 31,1971 .

Value

A return or equivalent in goods, services, or money for something exchanged

Variable

An input or output included in a DEA model

Variable

Returns to

Scale (VRS)

Can be increasing, decreasing, or constant. A proportionate increase in inputs can result in the non-proportionate increase in outputs

Warrant

An option issued by a company or a financial institution. Call warrants are frequently issued by companies on their own stock

Weighted Average Cost of Capital A discount rate that is applied to a projected after tax (generally discretionary) cash flow that includes both intlation and 'real' growth. It is determined by the appropriate capital structure (i.e. interest bearing debt/equity structure) for a given business. It weighs the cost of said appropriate indebtedness and the cost of equity capital, where the cost of equity capital is taken to be equal to the threshold rate of return. It assumes an ability to deduct interest expense when calculating taxable income.

Weights

Results from a DEA analysis and indicates the level of contribution each variable has in the determination of the DMU's efficiency score.

Working Capital

The amount by which current assets exceeds current liabilities 


\section{LIST OF ABBREVIATIONS}

BPS Book Value Per Share

Capex Capital Expenditure

CAPM Capital Asset Pricing Model

CDNX Canadian Venture Exchange

CF Comparable Firm

CFI Cash Flow

CFO Cash Flow from Operations

CICA Canadian Institute of Chartered Accountants

CICBV Canadian Institute of Chartered Business Valuators

CRS Constant Returns to Scale

CSI Canadian Securities Institute

DCF Discounted Cash Flow

DEA Data Envelopment Analysis

DMU Decision Making Unit

DRS Decreasing Returns to Scale

EBITDA Earnings Before Interest, Tax, Depreciation, and Amortization

EPS Earnings Per Share

ESOP Employee Stock Ownership Plan

EV Enterprise Value

FCF Free Cash Flow

GAAP Generally Accepted Accounting Principles

IPO Initial Public Offering 
IRS Increasing Returns to Scale

M\&A Mergers and Acquisitions

M/B Market to Book

MC Market Capitalization

NI Net Income

NS Net Sales

NwC Net Working Capital

OP Offer Price

P/E Price to Earnings

PER Price Earnings Multiple

POP Preliminary Offer Price

PPA Pure Play Approach

RA Redundant Assets

RFR Risk Free Rate

SE Shareholders' Equity

SEC Securities Exchange Commission

SIC Standard Industrial Classification

TA Total Assets

TL Total Liabilities

TSE Toronto Stock Exchange

VRS Variable Returns to Scale

WACC Weighted Average Cost of Capital 


\section{APPENDIX A}

\section{Public Companies DATA 1998 SIC 2000-3999}




\begin{tabular}{|c|c|c|c|c|c|c|c|c|c|}
\hline & & & Market & TOTAL & \multirow{2}{*}{\begin{tabular}{|l|} 
TOTAL \\
LABIITI \\
\end{tabular}} & \multicolumn{2}{|c|}{ SHAREHONET } & \multicolumn{2}{|c|}{ NET SALES|CASH } \\
\hline & COMPANY & PRIN & Capitalizati: & ASSETS & & EQUITY & INCOME & /REVENUE & FLOWS \\
\hline & NAME & SIC & & & (in thousand & & & & \\
\hline 1 & A. L. VAN HOUTTE L & 2095 & 632,441 & 206,480 & 40,532 & 165,948 & 13,952 & 207,067 & 30,512 \\
\hline 2 & A.E. VENTURES LTD & 3714 & 627 & 1,779 & 1,181 & 598 & -283 & 1,995 & 11 \\
\hline 3 & AASTRA TECHNOLO & 3661 & 46,091 & 14,014 & 6,827 & 7,187 & 1,343 & 37,173 & 1,957 \\
\hline 4 & ABITIBI-CONSOLIDA & 2621 & $2,609,850$ & $6,835,000$ & $3,829,000$ & $3,006,000$ & $-31,000$ & $3,657,000$ & 316,000 \\
\hline 5 & ABL CANADA INC & 3661 & 13,382 & 14,690 & 11,174 & 3,516 & $-3,992$ & 16,712 & $-3,254$ \\
\hline 6 & ACETEX CORPORAT & 2869 & 84,226 & 441,481 & 397653.94 & 43,827 & $-31,954$ & 344.449 & 1,026 \\
\hline 7 & ADVANTEDGE INTE & 3663 & 19,928 & 14,666 & 12,391 & 2.275 & $-4,137$ & 2.809 & $-2,640$ \\
\hline 8 & AFRICAN GEMSTON & 2066 & 683 & 2,649 & 755 & 1,895 & $-1,372$ & 237 & .906 \\
\hline 9 & AGRIUM INC & 2873 & $1,541,000$ & $2,796,692$ & $1.686,308$ & $1,110,383$ & 185,832 & $2,772,119$ & 319,446 \\
\hline 10 & AGRO PACIFIC INDU & 2048 & 10,874 & 40,980 & 26,882 & 14,098 & -704 & 97,128 & 1,383 \\
\hline 11 & AIMGLOBAL TECHN & 3829 & 155,617 & 87,112 & 10.887 & 76,225 & 4.625 & 78.478 & 7,621 \\
\hline 12 & AINSWORTH LUMBE & 2411 & 44,467 & 434,862 & 357.966 & 76,896 & $-9,479$ & 349.056 & 24,354 \\
\hline 13 & ALCAN ALUMINIUM & 3353 & $9,435,500$ & $5.205,956$ & $6,729.876$ & $8,476,080$ & 612.784 & $11,962,346$ & $1,297,751$ \\
\hline 14 & ALGO GROUP INC & 2329 & 9,266 & 84,550 & 63.220 & 21.330 & $-15,700$ & 196,136 & $-3,467$ \\
\hline 15 & ALGOMA STEEL INC & 3312 & 108,383 & $1,521,000$ & $1,185,000$ & 336,000 & $-59,000$ & $1,272,000$ & 74,000 \\
\hline 16 & ALLIANCE FOREST & 2611 & 563,100 & $1,771,800$ & 814,000 & $\mathbf{9 5 7 , 8 0 0}$ & 25,900 & 1,08 & 138,200 \\
\hline 17 & ALPHA COMMUNIC & 2731 & 3,019 & 1,238 & 886 & 352 & -308 & 1,927 & -227 \\
\hline 18 & ALTA NATU & 2833 & 6,577 & 1,956 & 613 & 1,343 & -110 & 3,123 & 107 \\
\hline 19 & ALTAREX CORP & 2834 & 7,100 & 15,160 & 2.513 & 12,647 & $-13,116$ & 50 & $-12,736$ \\
\hline 20 & ALTERRA RESOURC & 3841 & 340 & 2,146 & 1.945 & 201 & -667 & 0 & -618 \\
\hline 21 & AMR TECHNOLOGIE & 2819 & 76,024 & 75,913 & 33.760 & 42,153 & 596 & 49.655 & 3,609 \\
\hline 22 & AMT FINE FOODS LT & 2013 & 11,173 & 1,592 & 696 & 896 & 164 & 6,188 & 251 \\
\hline 23 & ANDRES WINES LTD & 2084 & 79,826 & 126.085 & 72.581 & 53.504 & 6.732 & 118,668 & 11,078 \\
\hline 24 & ANGIOTECH PHARM & 2834 & 140,743 & 27,508 & 767 & 26.741 & $-6,731$ & 2.277 & -6.325 \\
\hline 25 & AQUA 1 BEVERAGE & 2086 & 2,879 & 210 & 97 & 113 & -501 & 387 & -485 \\
\hline 26 & AQUA-PURE VENTU & 2899 & 895 & 1.655 & 42 & .613 & -316 & 14 & -307 \\
\hline 27 & AQUARIUS COATIND & 3479 & 2,115 & 2,091 & 613 & .522 & $-2,395$ & 374 & $-1,868$ \\
\hline 28 & ARCTIC GROUP INC & 2097 & 38,002 & 36.157 & 17.425 & 32 & $-1,016$ & 74 & -367 \\
\hline 29 & ARROWHEAD WATE & 2086 & 962 & 2,542 & 1.144 & 398 & 118 & 2,060 & 342 \\
\hline 30 & ASIA PACIFIC CONC & 3273 & 1,888 & 2,743 & 246 & 2,497 & -803 & 769 & -84 \\
\hline 31 & ASTAWAI & 2741 & 3,178 & 1,385 & 214 & 1,171 & $-1,881$ & 469 & $-1,651$ \\
\hline 32 & AT PLASTICS INC & 2821 & 153,632 & $505,62 \mathrm{l}$ & 317,913 & 187,708 & 10,768 & 229,976 & 27,984 \\
\hline 33 & ATS AUTOMATION 1 & 3569 & 995.530 & 423,519 & 155.313 & 268,206 & 27,362 & 402,920 & 50,659 \\
\hline 34 & AVANTE TECHNOLO & 3634 & 2.302 & 1,115 & 592 & 523 & .625 & 777 & -563 \\
\hline 35 & AVCORP INDUSTRIE & 3728 & 45,730 & 86,856 & 51,803 & 35,053 & 2,810 & 66,903 & 5,032 \\
\hline 36 & AVVA TECHNOLOGI & 3646 & 2,429 & 716 & 476 & 240 & -374 & $1, \overline{875}$ & -311 \\
\hline 37 & AXCAN PHARMA IN & 2834 & 165,498 & 88,823 & 18.819 & 70,004 & 1,540 & 43,404 & 2,240 \\
\hline 38 & B.C. REPORT MAGAA & 2721 & 284 & 235 & 2,053 & $-1,818$ & 1,885 & 2,498 & -100 \\
\hline 39 & BALLARD POWER SY & 3691 & $3,608,271$ & 0.348 & 62.656 & 27,692 & 765 & 25.078 & $-18,826$ \\
\hline 40 & BANFF BREWERY CQ & 2082 & 1,378 & 937 & 332 & 605 & -432 & 179 & -372 \\
\hline 41 & BCS TECHNOLOGY I & 3661 & 1,027 & 996 & 914 & 82 & $-1,211$ & 2,176 & -913 \\
\hline 42 & BELL CANADA INTE & 3661 & $1,371,120$ & $2,923,589$ & $2,385,264$ & 538,325 & -65.611 & 771,506 & $-71,291$ \\
\hline 43 & BESTAR INC & 2511 & 23,108 & 35,495 & 26.096 & 9,399 & 5,432 & 69,155 & 6,808 \\
\hline 44 & BESTAR INTERNATI & 2836 & 1,488 & 10,769 & 3.532 & 7.237 & .697 & 6,280 & -157 \\
\hline 45 & BETA BRANDS INCO & 2064 & 47,999 & 63,737 & 59,541 & 4,196 & $-3,460$ & 63,870 & -116 \\
\hline 46 & BIG ROCK BREWERY & 2082 & 19,445 & 31,993 & {$[4.262$} & 17,731 & 289 & 25,185 & 2,384 \\
\hline 47 & BIOCHEM PHARMA & 2835 & $4,708,260$ & 629,990 & 151.369 & 478,621 & 114,774 & 335,221 & 129,087 \\
\hline 48 & BIOTECH HOLDNNGS & 2834 & $22,80 \mathrm{I}$ & 7,987 & 3.778 & 4,209 & $-3,014$ & 1,356 & $-1,723$ \\
\hline 49 & BIOVAIL CORPORAT & 2834 & $1,404,647$ & 307,036 & 228,416 & 78,619 & 69,755 & 173,294 & 77.367 \\
\hline 50 & BIT DNTEGRATION T & 3577 & 5,486 & 10,771 & 8,254 & 2,517 & $.5,143$ & 2,955 & $-1,319$ \\
\hline
\end{tabular}

Valuing Private Companies: A dea Approach 


\begin{tabular}{|c|c|c|c|c|c|c|c|c|c|}
\hline 51 & BLUESTAR BATTER & 3692 & 44,404 & 133,332 & 83.377 & 49,955 & $-8,816$ & 135,366 & $-3,628$ \\
\hline 52 & BOLIDEN LIMITED & 3339 & 401.312 & $2,831,270$ & $1,828,276$ & $1,002.994$ & $-116,239$ & $1,618.176$ & 4,199 \\
\hline 531 & BOMBARDIER INC & 3743 & $7,502,049$ & $10,575,200$ & $7,685,900$ & $2,889,300$ & 420,200 & $8,508,900$ & 919,700 \\
\hline 54 & BORDER CHEMICAL & 2819 & 3,725 & 10,174 & 1,515 & 8,659 & 352 & 14,387 & 790 \\
\hline 55 & BP AMOCO P.L.C & 2911 & $619,712,000$ & $129.775,100$ & $65,600,161$ & 64,174.939 & $5,006,708$ & $28,595,606$ & $14.722,179$ \\
\hline 56 & BRAMPTON BRICK L & $325 \mathrm{I}$ & 33,466 & 64,523 & 20,389 & 44,134 & 7,042 & 34,949 & 10,335 \\
\hline 57 & BRICK BREWING CO & 2082 & $\mid 5,421$ & 19,835 & $\overline{7,775}$ & 12,060 & 694 & 19,923 & 1,570 \\
\hline 58 & BUDD CANADA INC & 3714 & $\mid 16,772$ & 121,603 & 40,977 & 80,626 & 7,359 & 349,036 & 13,728 \\
\hline 59 & BUHLER INDUSTRIE & 3523 & 66.665 & 61,139 & 16,349 & 44,790 & 7,113 & 89,194 & 11,194 \\
\hline 60 & CAE INC & 3812 & 917,070 & 928,179 & 651,726 & 276,453 & 70,236 & 922,369 & 87,541 \\
\hline 61 & CALLAN TECHNOLO & 3663 & 33,191 & 45,533 & 22.936 & 22.597 & 1,408 & 79,928 & 3,007 \\
\hline 62 & CAMCC INC & 3631 & 100,000 & 192,375 & 117,134 & 75.241 & 8,979 & 565,305 & 24.119 \\
\hline & CANADA BREAD CO & 2051 & 449,753 & 338.272 & 107.736 & 230.536 & 2,896 & 508,445 & 28,883 \\
\hline & CANADLAN BANK N & 2796 & 46.898 & 97.932 & 30,659 & 67.273 & $1.3 \hat{32}$ & 100.589 & 8.503 \\
\hline $65 i$ & ¿CANADLAN MANOIR & 3433 & 3,5111 & 11.815 & 9,474 & 2.341 & 370 & 10,155 & 581 \\
\hline $66 !$ & CANADIAN MARCOI & 3663 & 426.808 & 495.928 & 113,940 & 381,988 & 28,003 & 291,544 & 39.501 \\
\hline 67 & CANAM MANAC GRO & 344 & 177.740 & 645.753 & 445,882 & $\mid 99.871$ & 26,066 & .000 .700 & 52.013 \\
\hline 68 & CANFIBRE GR & 2631 & 91,809 & 362.265 & 331,515 & 30.749 & -6.334 & 284 & -3.564 \\
\hline $69 !$ & CANFOR COR & 2421 & 274.251 & .864 .295 & $1,438,247$ & 426,048 & -203.731 & 1.632 .273 & 21,928 \\
\hline 70 & CANGENE CORPORA & 2836 & 221,802 & 45.784 & $15,60\rfloor$ & 30,183 & 11,000 & 28.300 & 10,159 \\
\hline $71 \mathrm{i}$ & ¿CANHORN CHEMICA & 2869 & 1,792 & 6.382 & 4,858 & 1,524 & -2.701 & $4,155 \mid$ & $-1,827$ \\
\hline 72 & CANTOL LIMITED & 2842 & 2,108 & 6.508 & 1,683 & 4,825 & -46 & 8.490 & 85 \\
\hline $73 !$ & CARBITE & 3949 & 9,240 & 12.271 & 1,034 & 11.237 & 367 & 24.054 & 1.424 \\
\hline 74 & SOLU & 3841 & 2.065 & 279 & 67 & 212 & -2.515 & 78 & $-2,401$ \\
\hline 75 & $\overline{\text { CASC }}$ & 2611 & 595,430 & 5,000 & $1,867,000$ & $6 ́ 18,000$ & 45.000 & 2.527 .000 & 85.000 \\
\hline $76 !$ & CCL INDUSTRIES IN & 2844 & 698,733 & $1,428,531$ & 857,114 & 571.417 & 44,394 & 1.469 .195 & 132.418 \\
\hline 77 & CD ROM NETWORK & $27 \hat{3} I$ & 471 & 296 & 109 & 186 & -206 & 289 & -110 \\
\hline $78:$ & CEAPRO INC & 2844 & 10,546 & 479 & 1,567 & $-1,088$ & $-14,260$ & 400 & -1.654 \\
\hline 79 & CELESTICA INC & 3674 & 854,867 & 13.222 & $1,193,561$ & 1.319 .661 & $-74,442$ & $4.990,121$ & 130.326 \\
\hline $80 t$ & ICELL-LOC INC & 3663 & 28,669 & 413 & 142 & 2,271 & $-1,441$ & 308 & -1.403 \\
\hline 81 & CERAMIC PROT & 3259 & 2.765 & 10 & 2,898 & 4.212 & $-|9|$ & 3.835 & 281 \\
\hline $82 !$ & CFE NND & 3999 & 7,887 & 53 & 186 & -133 & -518 & 0 & -79 \\
\hline $83 !$ & $\mathrm{CHAl}$ & 2331 & 45,927 & 007 & 22,465 & 42,542 & 5,368 & 150,241 & 10,106 \\
\hline 84 & ND LIMITEI & 2891 & 2,917 & 9.898 & 8,792 & 1,106 & -150 & $15,001\}$ & -150 \\
\hline $85:$ & CIE-NERGY PLY-FOI & 3086 & 918 & 542 & 528 & 14 & -873 & 2.066 & -436 \\
\hline $86:$ & CIMATEC ENVIRONI & 3564 & 4,040 & 910 & 283 & 1,627 & 148 & 1.493 & 232 \\
\hline $87 !$ & CIN] & 3652 & $1,075,691$ & 774 & 423,711 & 433,063 & 42.303 & 642.714 & 11,912 \\
\hline $88 !$ & ICIR & $366 i$ & 6,601 & 60 & 113 & 6.547 & 1,031 & 21,464 & 1,472 \\
\hline 891 & $\overline{C I R C}$ & 3672 & 289 & 92 & 62 & 5.330 & 1,561 & 22.001 & 1,942 \\
\hline 901 & ICLEARLY CANADLA & 2086 & 5,135 & 775 & 5,267 & 50,508 & 476 & 61.320 & 3.841 \\
\hline $91:$ & C-MAC INDUSTRIES & 3679 & 291,127 & 607.831 & 347,514 & 260.317 & 25,418 & 642.983 & $+7,363$ \\
\hline $92 !$ & CME TELEMETRIX I & 3841 & 27,749 & 5.024 & 1,295 & 3.729 & $-4,139$ & 1.250 & -3.826 \\
\hline $93 !$ & CMI INDUSTRIES LT & 2621 & 7,109 & 02 & 12,224 & 7,478 & 21 & 33.152 & 2.159 \\
\hline 941 & ICOM DEV INTERNAI & 3663 & 252,315 & 205.496 & 56,673 & 48,823 & 8.439 & 175,298 & $-1,511$ \\
\hline $95 !$ & COMMUNICATION S & 3663 & 3,855 & 4.635 & 1,110 & 3,525 & 424 & 8.350 & 717 \\
\hline 96 & COMPRESSION \& EN & 3695 & 717 & 763 & 753 & 10 & $-1,288$ & 791 & -278 \\
\hline $97 !$ & CONCERT INDUSTRI & 2621 & 48,917 & 57,951 & 35,977 & 21,974 & 1,461 & 12.672 & 2.271 \\
\hline $98 !$ & CONSOLIDATED ECd & 2844 & 936 & 636 & 708 & -71 & -538 & 36 & -460 \\
\hline $99 i$ & CONSOLDATED EN & 2875 & 5,178 & 22,317 & 14,193 & 8,124 & $-2,984$ & 24,780 & 1,974 \\
\hline 100 & CONSUMERS PACKA & 3221 & 204,373 & 631,982 & $1,447,727$ & 184,255 & -47.985 & $1,368.150$ & 97,730 \\
\hline 1011 & CORECO INC & 3674 & 44,923 & 28.618 & 3,830 & 24,788 & 2,778 & 14.349 & 4.379 \\
\hline 102 & COREL CORPORATIC & 3575 & 362,816 & 214,724 & $\mid 70,934$ & 43,789 & $-46,646$ & 378.139 & $-2,781$ \\
\hline 103 & COSGROVE-MOORE & 2789 & 3,375 & 6,377 & 3,927 & 2,450 & 291 & 9,403 & 765 \\
\hline
\end{tabular}




\begin{tabular}{|c|c|c|c|c|c|c|c|c|}
\hline 104|CO-STEEL NNC & 3312 & 385,413 & $1,705,264$ & $1,032,327$ & 672.937 & -80.745 & $1,511,432$ & 107,310 \\
\hline 105|COTT CORPORATIOA & 2086 & 330,647 & $1,829,043$ & $1,333,121$ & 495.922 & $-11,198$ & 2.152 .266 & 67,969 \\
\hline \begin{tabular}{l|l|}
106 & CPI PLASTICS GROU \\
\end{tabular} & 3089 & 60,851 & 31.709 & 21.973 & 9.736 & 2,726 & 46,501 & 4,160 \\
\hline \begin{tabular}{|l|l|}
107 & CRS ROBOTICS COR \\
\end{tabular} & 3569 & 3,765 & 9,222 & 5,636 & 3,586 & 1,952 & 13.507 & 865 \\
\hline 108 CSI CREDIT SYSTEM & 3577 & 7.616 & 1,732 & 672 & 1,060 & -513 & 2.214 & $\overline{-319}$ \\
\hline I09|CV TECHNOLOGIES & 2835 & 12.657 & 3,608 & 1,094 & 2,514 & -849 & 2,585 & -791 \\
\hline 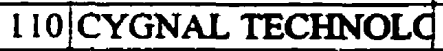 & 3663 & 8,637 & 27,797 & $\mid 4,563$ & 13,234 & -824 & 24.553 & 717 \\
\hline $11 \|$ DANBEL INDUSTRIE & 3645 & 5.798 & 12,460 & 9,024 & 3.436 & 1,048 & 24,099 & 1.322 \\
\hline I12|DATAMARK SYSTEN & 2761 & 35.889 & 45,511 & 18,897 & 26,614 & 3,049 & 82.783 & 4.685 \\
\hline 113 DBA TELECOM COR & 3661 & 1.956 & 2,369 & 1,468 & 901 & -722 & 4,336 & -2.461 \\
\hline 114 DECOMA INTERNAT & 3714 & 560.656 & 681,894 & 427,116 & 254,778 & 29,307 & 656,1751 & 73.649 \\
\hline $115 \mid$ DELICIOUS ALTERN & 2024 & 17.246 & 14,581 & 8,115 & 6,466 & $-2,956$ & 3.8911 & -2.664 \\
\hline \begin{tabular}{l|l|l|}
116 & DEVTEK CORPORAT \\
\end{tabular} & 3714 & 99.709 & 279,474 & 178,330 & 101,144 & 7.810 & 425.728 & 24.756 \\
\hline I17IDIAGNOCURE INC & 2835 & 13.124 & 13,304 & 5,159 & 8.145 & $-6,052$ & 664 & -5.460 \\
\hline 118 DIGITAL PROCESSIN & 3651 & 28.123 & 39,615 & 10.309 & 29,306 & -1.487 & 42.464 & -382 \\
\hline I19!DIMENSIONS WEST I & 3663 & 1.970 & 7,806 & 7,011 & 795 & $-1,637$ & 2 & -229 \\
\hline IFIED INVES & 2899 & 13,328 & 5,076 & 1,260 & 3.816 & 1,338 & 3.105 & 1.566 \\
\hline $121 /$ DIVERSITY CORPOR & 2899 & 1,096 & 1,143 & 470 & 673 & $-3,167$ & 983 & -484 \\
\hline 122! íDOFASCO INC & 3312 & 1.603 .890 & $3,377,100$ & $|.548 .600|$ & $1,828.500$ & 175.700 & 2.982 .200 & 416.100 \\
\hline 123 DOMAN INDUSTRIES & 2411 & 123,195 & $1,528,587$ & 1.239 .034 & 289.553 & $-74,752$ & 779.241 & -30.297 \\
\hline 124 DOMCO TARKETT IN & 3996 & 207.110 & 329,101 & 113.908 & 215,193 & 14.725 & 350,798 & 34.170 \\
\hline $125 \mid$ DOMTAR INC & 2611 & $1,568.323$ & $4,030,000$ & $2,342,000$ & $1,688.000$ & 74,000 & $2,348,000$ & 258.000 \\
\hline 126|DONOHUE INC & 2421 & $2.604,005$ & $3,456,865$ & $2.068,543$ & $1,388,322$ & 229.249 & 2.295 .805 & 450,728 \\
\hline 127 DOREL INDUSTRIES & $2512 !$ & 682.294 & 460,790 & 208 & 223.582 & 26.985 & 766.607 & 47.477 \\
\hline \begin{tabular}{|l|l|}
128 & DOVER INDUSTRIES \\
\end{tabular} & 2041 & 53,129 & 74.312 & 19.766 & 54.546 & 4,270 & 132,987 & 8.011 \\
\hline 129 DUPONT CANADA IN & 2819 & $4,081,770$ & $1,831,645$ & 621,977 & 1.209 .668 & 298.772 & $2,025,072$ & 282,480 \\
\hline \begin{tabular}{|l|l|}
30 & DYNAMIC DIGITAL \\
\end{tabular} & 3663 & 110.354 & 9,433 & 7821 & 8,651 & -2.062 & 368 & $-1,750$ \\
\hline 131 EAGLE PRECISION T & 3542 & 57,395 & 80,655 & 43,411 & 37.244 & 4.364 & 136.618 & 7.508 \\
\hline \begin{tabular}{|l|l|} 
I32 & EI ENVIRONMENTAI \\
\end{tabular} & 3585 & 592. & 996. & 635 & 361 & 189 & 3.766 & 236 \\
\hline 133 |EIGER TECHNOLOG & 36611 & 8,289 & 9,221 & 6.157 & 3.064 & 84 & 22,734 & 360 \\
\hline 134 ELECTR & 3679 & 11,398 & 68,916 & $775 !$ & 29.141 & 5,116 & 97,873 & -4.342 \\
\hline 135 ENERCHE & 2911 & 19.094 & 16,867 & 38 & 7,229 & 1.817 & 16.447 & 3,208 \\
\hline 136|ENERFLEX SYSTEMS & 3563 & 420.532 & $\mid 59,506$ & 59,450 & 100.056 & 22.568 & $314.496 \mid$ & 26.042 \\
\hline 137|ENERSHARE TECHN & 3823 & 9,416 & 9,051 & $7.870 \mid$ & 1.181 & 93 & 3.330 & 161 \\
\hline 138 EPIC DATA INTERNA & $3571_{1}^{1}$ & 149,403 & 64,302 & 14.012 & 50.290 & 6.512 & 53.174 & 8.627 \\
\hline 139|EUROPEAN TECHNO & 3596 & 6,067 & 5,085 & $587 !$ & 4,498 & $-1,096$ & 928 & -337 \\
\hline 140|EVEREST MINES AN] & 2092 & 302 & 1.570 & $163 \mathrm{i}$ & 1.406 & -1.559 & 0! & -527 \\
\hline $141 \mathrm{EXCO} \mathrm{TEC}$ & 3544 & 138.406 & 125,405 &, 763 & 77.642 & 11.115 & 118,045 & 21.238 \\
\hline 142!EXI & 3669 & 9,422 & 4,907 & 1,615 & 3,292 & 99 & 3,027 & 311 \\
\hline 143 EYELOGIC SYSTEMS & 3841 & 1,059 & 1,888 & 883 & 1.005 & $5 !$ & 958 & 220 \\
\hline I44:FANTOM TECHNOLd & 3589 & 137,839 & 83,206 & 38,193 & $45,013 j$ & 10.318 & 177.585 & 13.185 \\
\hline 145|FAR WEST INDUSTR & $2329 !$ & 3,692 & 9,080 & 4,407 & 4.674 & 147! & 11.789 & 412 \\
\hline 146:FIFTY-PLUS.NET INT & 3663 & 2,404 & 35 & $52 !$ & -17 & -18 & 151 & -17 \\
\hline 147!FLETCHER CHALLES & 26111 & $2,111.217$ & $2,530,700$ & 000 & 175,700 & 98.600 & 284.100 & 5.000 \\
\hline 148!FLETCHER'S FINE FQ & 2013 & 5,936 & 147,365 & 64,204 & 83.1611 & 3.656 & 394.015 & 11.377 \\
\hline 149!FLOTEK INDUSTRIES & 3533 & 4.750 & 3,658 & 2,608 & 1.050 & $-3,457$ & $4.522 i$ & $-1,762$ \\
\hline 150|FOREMOST RNDUSTH & 3533 & 20,332 & 51,999 & 20,732 & 31.267 & $-4,597$ & 44.948 & -4.371 \\
\hline 15I:FOSTER'S BREWDNG & 2082 & 556,622 & $4,419,800$ & $1,900,900$ & $2.518 .900 \mid$ & 446.600 & 4.970 .900 & 323.800 \\
\hline 152:FOUNTAIN HOUSE H & 3585 & 1,799 & 500 & $77 !$ & 423 & -300 & 0 & -259 \\
\hline 153 |FYTOKEM PRODUCT & 2833 & 2,996 & 399 & 149 & 250 & -746 & 97 & -727 \\
\hline 154|G.T.C. TRANSCONTZ & 2759 & 559,473 & $1,153,587$ & 728,641 & 424.946 & 42,104 & $1,336.756$ & 127.333 \\
\hline 155 GARNEAU NC & 3499 & 19,557 & 29,250 & 6,044 & 23.206 & 2.012 & 22.477 & 3.163 \\
\hline 156 GEAC COMPUTER C & 3575 & $2,425,988$ & 702,572 & 424,815 & 277,757 & 168,685 & 641,731 & 223,762 \\
\hline
\end{tabular}




\begin{tabular}{|c|c|c|c|c|c|c|c|c|}
\hline I57/GEMSTAR COMMUN & 3663 & 4.888 & $470 \mid$ & $4|4|$ & 56 & -469 & $\mid I I$ & -462 \\
\hline 158 GENERAL MOTORS & $\mid 3711$ & $86.392,582$ & $395,298,026$ & 372.285 .5991 & 23.012 .427 & $4,539,825$ & \multicolumn{2}{|c|}{$236.540 .844 ![8.968 .666$} \\
\hline 159|GENNUM CORPORA & $\mid 3674$ & 576.578 & 82,972 & 24.310 & 58.662 & 16,177 & 83.497 & 19,735 \\
\hline I60 GENOMICS ONE COA & 2835 & 20.562 & $771:$ & 151 & 6201 & -237 & $1 !$ & -222 \\
\hline \begin{tabular}{|l|l|}
161 & GENSCI REGENERA \\
\end{tabular} & 3842 & 67,127 & 39.695 & 12.150 & $27.545 !$ & -10.772 & $16.304 !$ & -7.360 \\
\hline 162|GILDAN ACTIVEWEd & 2329 & $\mid 16.913$ & 165,678 & 112.348 & 53.330 & 13,168 & 215.428 & 18,826 \\
\hline 163 GLENDALE INTERNA & 3716 & 47,948 & 109,606 & 85.247 & 24.359 & 3.773 & 155.141 & 5,967 \\
\hline I64!GLOBAL COMMERC & 2038 & $\mid 4,410$ & 4,204 & 2.340 & 1,864 & -130 & $1.736 !$ & 20 \\
\hline 165 GLOBAL THERMOEL & 3629 & 13,222 & 11,804 & 4.892 & 6.912 & 2.115 & 16.273 & 2,806 \\
\hline 166:GOODFELLOW INC & 2421 & 35.1361 & $\mid 14,590$ & 70.322 & 44.268 & 6,364 & 335.696 & 5,284 \\
\hline 167 GROUPE BOCENOR II & 3442 & 27.022 & 28,241 & 18.960 & 9.281 & 3,122 & 68.803 & 3,251 \\
\hline 168 GROUPE LAPERRIER & 3569 & 31.2181 & 100.557 & 57.961 & +2.596 & $3.653 !$ & 156.206 & 7.403 \\
\hline \begin{tabular}{|l|l}
69 GSI LUMONICS INC \\
\end{tabular} & 3699 & 129.626 & $245.344 i$ & 59.720 & 185.624 & $-12.260 \mid$ & 221.4501 & $-5,159$ \\
\hline 170 GST TELECOMMUNI & 3357 & 241.954 & 1.151 .283 & 1.223 .029 & -71.746 & $-154,690$ & 163.317 & $-18,978$ \\
\hline 171 H. PAULIN \& CO., LII & $3452 i$ & 23.100 & 52,152 & 29.003 & 23.149 & 2,970 & 96.068 & 4,305 \\
\hline 172 HAEMACURE CORPC & $283+$ & 55.116 & $29,968 i$ & 16.157 & 13.811 & -13.656 & 318 & $-12,289$ \\
\hline 173 HALEY INDUSTRIES & 3365 & +4.829 & 64,645 & 40.234 & 24.4111 & 3.714 & 75.851 & 7,992 \\
\hline 174! HALLMARK TECHNO & 3544 & 21.547 & $65.289 !$ & $32.369 !$ & 32.920 & 2,504 & $+3.810 !$ & 4,226 \\
\hline 175 HAMMOND MANUFA & 3612 & 18.426 & 86.384 & $53.121 !$ & 33.263 & 3.591 & 166.3151 & 7.496 \\
\hline 176 HANKIN ATLAS IND & 3589 & 3.315 & 9,237 & $7.882 !$ & 1.356 & 199 & 11.115 & 986 \\
\hline \begin{tabular}{|l|l|}
177 & HEDLEY TECHNOLO \\
\end{tabular} & 2879 & 936 & 1.581 & $477 \mid$ & 1,104 & $-1,108$ & $701 !$ & -941 \\
\hline \begin{tabular}{|l|l|l|}
178 & HEROUX INC \\
\end{tabular} & 3728 & 62.462 & 110,753 & 60.627 & 50.126 & 3,047 & 120.370 & 10.198 \\
\hline \begin{tabular}{|l|l|}
$179 \mid$ HIGHWOOD DISTILL \\
\end{tabular} & 2085 & 2.373 & 2,948 & $1.437 !$ & 1.511 & 1441 & 3.708 & 164 \\
\hline \begin{tabular}{|l|l|} 
I 80 & HIGHWOOD RESOUR \\
\end{tabular} & 3295 & 13.017 & 25,035 & 6.232 & 18.803 & $-5,498$ & 13.870 & 1,852 \\
\hline \begin{tabular}{|l|l|}
181 & HILLESTAD PHARMA \\
\end{tabular} & 2834 & 1.294 & 2,116 & 2.017 & 99 & -60 & 2.809 & -20 \\
\hline \begin{tabular}{|l|l|}
$182 \mid$ HOLLINGER CANAD \\
\end{tabular} & 2711 & $1.218,657$ & 2.862 .252 & $\mid, 780.534$ & $1,081,718$ & 85.506 & 1.569 .297 & 234.701 \\
\hline \begin{tabular}{|l|l|l|} 
I83 & HUSKY INJECTION N \\
\end{tabular} & 3089 & $1 .+23,935$ & 870.049 & 539.475 & 330.574 & 69,258 & 1.148 .7201 & 99.757 \\
\hline 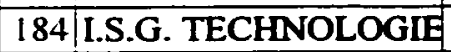 & 3841 & 63.025 & 46,307 & 10.804 & 35,503 & 498 & 36.055 & 2,770 \\
\hline \begin{tabular}{|l|l|}
185 & IBEX TECHNOLOGIE \\
\end{tabular} & 2835 & 10.029 & 25,063 & 3.8511 & 21,212 & $-\mid 4,075$ & 387 & $-13,713$ \\
\hline I86 IDS NNTELLIGENT DI & 3829 & 45.265 & 60.385 & 6.255 & 54,130 & -1.280 & 21.984 & 701 \\
\hline I87 IMARK CORPORATIO & 2731 & 7,524 & 11,372 & 2.128 & 9,244 & -238 & 4.499 & 399 \\
\hline \begin{tabular}{|l|l|l|}
188 & IMAX CORPORATIO \\
\end{tabular} & 3861 & 1.314 .736 & 770,176 & 628.545 & 41,631 & -375 & $300.542 !$ & 98,652 \\
\hline I89/LMI INTERNATIONAI & 2835 & 11.881 & 1,768 & 121 & 1,647 & -784 & 193 & -728 \\
\hline 190 IMPERIAL PLASTEC & 3084 & 9,283 & 6,8391 & 4.088 & 2,751 & 595 & $12.332 !$ & 1.044 \\
\hline \begin{tabular}{|l|l|}
191 & INCO LIMITED \\
\end{tabular} & 3339 & 151,308 & $11,275,844$ & 4.582 .827 & $6.693 .016 \mid$ & $-116,721 !$ & $2.712 .223 i$ & 39.931 \\
\hline 192 INEX PHARMACEUT & 2834 & 18,596 & 24,363 & 2.162 & 22,201 & $-13,470$ & $851 !$ & $-11,947$ \\
\hline \begin{tabular}{|l|l|}
193 & INTEPAC INC \\
\end{tabular} & 3089 & 4.916 & 973 & 491 & 482 & 546 & 550 & -344 \\
\hline \begin{tabular}{|l|l|}
194 & INTERGOLD LTD \\
\end{tabular} & 3911 & 23.762 & 4,422 & 2.802 & 1,620 & -376 & $8.663 !$ & 134 \\
\hline 195 INTERNATIONAL BU & 3571 & 40.429 .832 & $132,232,380$ & 102.387 .179 & 29.845 .201 & $9.718,542$ & $|25,424,179| 1$ & .508 .508 \\
\hline 196|INTERNATIONAL CQ & 3585 & +40.175 & 657,015 & 509.118 & 147.898 & 54,060 & $1,126,509 !$ & 76.483 \\
\hline I97!INTERNATIONAL DA & 3663 & 3.893 & 3,043 & 3.494 & -450 & 7,556 & $4.599:$ & -3.277 \\
\hline 198|INTERNATIONAL FO & 2421 & $\mid 19,643$ & 550,098 & 268.594 & 281.504 & -58.747 & 597.094 & $-17,498$ \\
\hline 199|INTERNATIONAL HI- & 2439 & +1.177 & 19,900 & 5,408 & 14.492 & -1.454 & $3.319 !$ & -665 \\
\hline 200 INTERNATIONAL RQ & 3829 & 12.350 & 17,807 & 11,066 & 6,741 & $-3,072$ & 20.495 & 109 \\
\hline 201 INTERNATIONAL UT & 3449 & +3.555 & 241,336 & 238.327 & 3,009 & $-13,364$ & 158.965 & -2.843 \\
\hline $\begin{array}{|l:l|}202 & \text { INTERNATIONAL W/ } \\
\end{array}$ & 2621 & 21.998 & 75,952 & 120,151 & $-44,199$ & $-153.626 \mid$ & 139.1271 & 1.329 \\
\hline 203 INTERNATIONAL WA & 3589 & 4.698 & 646 & 670 & -24 & -298 & 1.646 & -275 \\
\hline 204 INTERTAPE POLYME & 2295 & 982.579 & 952,204 & 654,906 & 297.298 & 44,003 & 578.575 & 88,648 \\
\hline 205 INTRACOASTAL SYS & 3823 & 4.030 & 799 & 879 & -80 & $-1,105$ & $129 !$ & -1.032 \\
\hline \begin{tabular}{|l|l|}
206 & INVENTRONICS LIM \\
\end{tabular} & 3444 & 6,838 & 11,551 & 5,549 & 6.002 & -217 & 17.254 & 385 \\
\hline \begin{tabular}{|l|l|}
207 & INVERPOWER CONT \\
\end{tabular} & 3625 & 7.179 & 18.796 & 11.548 & 7.248 & $-16,238$ & 24.016 & -4.096 \\
\hline \begin{tabular}{|l|l|}
208 & INVESPRINT CORPO \\
\end{tabular} & 2752 & 39,825 & 86,229 & 56,610 & 29.619 & $-1,504$ & 74.269 & 4,453 \\
\hline \begin{tabular}{|l|l|}
209 & IPEC LTD \\
\end{tabular} & 3533 & 26,958 & 32,605 & 20,128 & 12,477 & 2,092 & 58,017 & 4,536 \\
\hline
\end{tabular}




\begin{tabular}{|c|c|c|c|c|c|c|c|c|c|}
\hline 210 & IPL INC & 3081 & 80,755 & 95,087 & 40,721 & 54,366 & 7,034 & 113,775 & 15,050 \\
\hline 211 & IPSCO INC & 3317 & $1,098,993$ & $1,936,237$ & 723,248 & $1,212,989$ & 113,241 & $1,099,320$ & 144,040 \\
\hline 212 & IRWIN TOY LIMITED & 3944 & 14,586 & 70,913 & 47,929 & 22,984 & $\mid-1,015$ & 103.658 & 1.558 \\
\hline 213 & IVACO INC & 3312 & 122,952 & $1,312,530$ & 906,244 & 406,286 & $-17,988$ & $1,194,563$ & 46.311 \\
\hline 214 & IVI CHECKMATE CO & 3578 & 143,572 & $\overline{127,209}$ & $\overline{42,714}$ & 84,495 & $-7,634$ & {$[64.518$} & 1.124 \\
\hline 215 & JANNOCK LIMITED & 3251 & 503,302 & $1,015,800$ & 506,900 & 508,900 & 44.900 & $1,405,300$ & 99,000 \\
\hline 216 & JEMTEC INC & 3669 & 330 & 1,023 & 579 & 444 & -246 & 640 & 284 \\
\hline 217 & KAFUS INDUSTRIES & 2493 & 144,464 & 554,206 & 525,999 & 28.207 & -18.282 & 577 & $-17,646$ \\
\hline 218 & KASTEN CHASE APP & 3663 & 23,569 & 24,457 & 2.942 & 21,515 & -5.311 & 23,306 & $-3,382$ \\
\hline 219 & KELMAN TECHNOLD & 2911 & 15,111 & 26,578 & 10,550 & 16,028 & $-1.071 \mid$ & 17,668 & 3.697 \\
\hline 220 & KING PRODUCTS ANd & 3661 & 7,739 & 7,309 & 12,801 & $-5,492$ & $-5,441$ & 11,018 & -4.961 \\
\hline 221 & KRYSTAL BOND INC & 2891 & 1,398 & 8,099 & 2.463 & 5.636 & $-5,108$ & 3,070 & -2.556 \\
\hline 222 & LABOPHARM INC & 2834 & 44,269 & 20,896 & 2,974 & 17.922 & $-6.027 !$ & 1,301 & -4.039 \\
\hline 223 & LAFARGE CORPORA & 3241 & $4,330,770$ & $4,461,187$ & $2,287, \overline{763}$ & $2,173,424$ & $361,681 !$ & $3,759,953$ & 614,467 \\
\hline 224 & LAMBUS ENTERPRIS & 3679 & 1,729 & 6344 & 243 & 391 & $-473 \mid$ & 88 & -179 \\
\hline 225 & LANDOVER ENERGY & 2869 & 2,846 & 316 & 6 & 310 & -152 & 7 & -47 \\
\hline 226 & LASSONDE INDUSTR & 2034 & 17,825 & 137.251 & 66.296 & 70.955 & 5,877 & 82.434 & 18.555 \\
\hline 227 & LBL SKYSYSTEMS C & 3231 & 7,113 & 24.018 & 17.627 & 6,391 & 3041 & 40,142 & 951 \\
\hline 228 & LE PRINT EXPRESS I & 2759 & 8,776 & 4,799 & 1,423 & 3,376 & -4.108 & 4,742 & -3.640 \\
\hline 229 & LEADER INDUSTRIE & 3851 & 13,556 & 14,625 & 10.629 & 3.996 & 1,417 & 22,106 & 2.822 \\
\hline 230 & LEADING BRANDS, I & 2086 & 8,570 & 27,899 & 20.858 & 7,041 & -7.722 & 35,667 & -1.239 \\
\hline 231 & LEF MCLEAN BROTH & 2092 & $\overline{3,381}$ & 17.037 & 8.881 & 8.156 & 604 & 31.232 & 1,570 \\
\hline 232 & LEITCH TECHNOLOQ & 3679 & $1,031,559$ & 193,542 & 21.556 & $|71.986|$ & $23,393 \mid$ & 147,743 & 29,672 \\
\hline 233 & LG TECHNOLOGIES & 3629 & 27,707 & 38,659 & 22.771 & 15,888 & $-9,463 \mid$ & 45,616 & 916 \\
\hline 234 & LINAMAR CORPORA & 3714 & $1,792,517$ & 669,641 & 246.351 & 423,290 & 84.385 & 998,312 & 150.854 \\
\hline 235 & LITHOS CORPORATI & 2819 & 10,733 & 8.212 & 4.430 & 3.782 & $-21,878$ & 1,686 & $-1,146$ \\
\hline 236 & LOGICSYS INC & 3823 & 3,337 & 1.210 & 1.092 & 118 & -338 & 5,868 & -232 \\
\hline 237 & LUXELL TECHNOLO & 3575 & 24,493 & 5,596 & 2.637 & 2,959 & $-2,548$ & 1,372 & $-2,096$ \\
\hline 238 & MAAX INC & 3088 & 307,970 & 168,735 & 84.927 & 83,808 & 12,224 & 174,841 & 20.084 \\
\hline 239 & MAGELLAN AEROSP & 3728 & 496,389 & 407,960 & 231.548 & $|76,412|$ & 32.336 & 426,942 & 41.918 \\
\hline 240 & MAGNA INTERNATIO & 3714 & $7,374,103$ & $8,620,700$ & $3,675.300$ & $4.945,400$ & 506,200 & $9,190,800$ & 803,498 \\
\hline 241 & MAGNIFOAM TECHN & 2821 & 20,940 & 24,131 & 5.532 & [8.599| & -4.289 & 6,640 & $-2,898$ \\
\hline 242 & MAGNOTTA WINER & 2084 & 13,310 & 26.530 & 17.764 & 8,766 & 1.432 & {$[6,537 \mid$} & 2,415 \\
\hline 243 & MALETTE QUEBEC I & 2672 & 56,024 & 187,413 & 91.403 & 96,010 & $2.80 \mathrm{I}$ & 111,829 & 13,498 \\
\hline 244 & MAPLE LEAF FOODS & 2011 & $1,374,236$ & $1,406,595$ & 1.007 .339 & 399.256 & -23.257 & $3.281,464$ & 44,280 \\
\hline 245 & MARATHON FOODS & 3663 & 623 & 3,296 & 2.862 & 434 & -464 & 6,350 & -277 \\
\hline 246 & MARINE BIOPRODUC & 2833 & 19,046 & 6.518 & 2.581 & 3,937 & -2.171 & 46 & $-1,942$ \\
\hline 247 & MARSHALL-BARWIO & 3441 & 23,227 & 41,445 & 9.428 & 32,017 & 2,093 & 51,589 & $-1,117$ \\
\hline 248 & MAXILL INC & 3991 & 1,570 & {$[, 797$} & 922 & 874 & $2 \mid$ & 1,166 & 134 \\
\hline 249 & MCCARTHY CORPOF & 2731 & 29,396 & 69,530 & 50.470 & 19,060 & -21.559 & 5,278 & -14 \\
\hline 250 & MCGRAW-HILL RYE & 2731 & 39,533 & 62.348 & 21.193 & 41,155 & 5.207 & 68.356 & 8,094 \\
\hline 251 & MDC CORPORATION & 2759 & 242,559 & 740,013 & 541.869 & 198,144 & 14.108: & 476,727 & 45,072 \\
\hline 252 & MEMOTEC COMMUN & 3661 & 4,953 & 30.281 & 15.913 & 14.368 & -2.360 & 37,926 & 864 \\
\hline 253 & MERCER INTERNAT) & 2611 & 138,461 & 333.284 & 180.265 & 153.019 & $9.012 !$ & 174,896 & 15,009 \\
\hline 254 & MERCH PERFORMAN & 3714 & 2,869 & 1,991 & 1.394 & 597 & $-754 !$ & 498 & -642 \\
\hline 255 & METHANEX CORPOF & 2869 & $1,370,334$ & $2,762,996$ & $1,061.960$ & $1,701,037$ & -105.1221 & $1.107,126$ & 75,783 \\
\hline 256 & MICROCELL TELECO & 3661 & 307,087 & 720,969 & $1,087.657$ & $-366,688$ & $-408,920$ & 143,412 & 224,510 \\
\hline 257 & MILLTRONICS LTD & 3823 & 222,793 & 105,188 & 15.320 & 89.868 & 10,006 & 125,053 & 14,499 \\
\hline 258 & MITEC TELECOM IN & 3571 & 56,401 & 35.958 & 6.456 & $29,502 !$ & 2.638 & 34,343 & 4,619 \\
\hline 259 & MITEL CORPORATIO & 3661 & $1,257,378$ & $1,237,700$ & 802.200 & 435,500 & 91,900 & 888.500 & 125,600 \\
\hline 260 & MOBIL CORPORATIG & 2911 & $105,489,100$ & $65,661,593$ & $37,448,947$ & $28,212,646$ & $2,617.003$ & $80.076,612$ & $8,145,883$ \\
\hline 261 & MOBILE CLIMATE C & 3585 & 33,407 & 31,158 & 17,796 & 13.362 & 2,865 & 29,118 & 3,922 \\
\hline 262 & MOORE CORPORATI & 2761 & $1,4 \overline{28,580}$ & $2,650,998$ & $1,713,937$ & 937,061 & $-841,413$ & $4,173,847$ & 133,682 \\
\hline
\end{tabular}




\begin{tabular}{|c|c|c|c|c|c|c|c|c|c|}
\hline 263 & MRRM INC & 2044 & 21,548 & 25,062 & 6,696 & 18,366 & 2,030 & 42,797 & 1,784 \\
\hline 264 & MULTIMEDLA WTM & 2711 & 223 & 6,162 & 4,489 & 1,673 & 314 & 4,019 & $\overline{470}$ \\
\hline 265 & MURPHY OIL CORPC & 2911 & $2,968,466$ & $3,324,115$ & $1,821,744$ & $1,502.370$ & $-22,106$ & $2,602,367$ & 506,135 \\
\hline 266 & NAPIER INTERNATIC & 2879 & 32,776 & 2,012 & 324 & 1,688 & -854 & 524 & -813 \\
\hline 267 & NATION WIDE RESO & 2951 & 796 & 1.035 & 156 & 879 & 186 & 1,045 & 105 \\
\hline 268 & NATRACEUTICALS I & 2834 & 8,108 & 10,425 & 10,639 & -214 & $-2,437$ & 23,453 & $-1,759$ \\
\hline 269 & NAVITRAK INTERNA & 2752 & 9,541 & 1,497 & 2,132 & -635 & $-1,555$ & 281 & $-1,278$ \\
\hline 270 & NEWBRIDGE NETWC & 3663 & $8,125,481$ & $1,966,825$ & 733,205 & $1,233,620$ & $-18,318$ & $1,620,620$ & 323,961 \\
\hline $27 \mathrm{I}$ & NEXFOR INC & 2426 & 929,923 & $2,775,000$ & $1,493,000$ & $1,282,000$ & 48,000 & $2,426,000$ & 260,000 \\
\hline 272 & NEXTRON CORPORA & 3699 & 2,426 & 1,764 & 1,026 & 738 & -581 & 1,410 & -188 \\
\hline 273 & NHC COMMUNICAT & 3661 & 7,317 & 12,791 & 5,116 & 7,675 & 979 & 5,620 & .385 \\
\hline 274 & NORDEX EXPLOSIVE & 2892 & 530 & 2,177 & 738 & 1,439 & -441 & 1,247 & -366 \\
\hline 275 & NORON TECH LTD & 3631 & 7,029 & 571 & 4.450 & -3.879 & $-1,317$ & 159 & $-1,201$ \\
\hline 276 & |NORTEL NETWORKS & $366 \mathrm{I}$ & $50,495,406$ & $30,304,406$ & 12.542 .879 & $17,761.527$ & $-824,725$ & $26.991,685$ & $1,397,578$ \\
\hline 277 & NORTH AMERICAN & 3829 & 7,036 & 25,060 & $11.00 \mathrm{I}$ & 14.059 & 333 & 17.704 & 851 \\
\hline 278 & NORTH AMERICAN & 3841 & 7.100 & 2,467 & 2,698 & -231 & -591 & 2.306 & $\overline{6}$ \\
\hline 279 & NORTHSIDE GROUP & 3714 & 14,056 & 29.179 & 21,295 & 7.884 & 2,115 & 54,256 & 4.581 \\
\hline 280 & NORTHSIDE MINERA & 3533 & 4,066 & 560 & 693 & -133 & $-2,192$ & 2.195 & .396 \\
\hline 281 & NORWALL GROUP I & 2621 & 10,959 & 69,109 & 43,268 & 25.841 & 1,387 & 82.761 & 7,388 \\
\hline 282 & NOVA CHEMICALS O & 2821 & $1,838,447$ & $3,580,000$ & $2.068,000$ & $1,512.000$ & {$[8,000$} & $2,075,000$ & 170,000 \\
\hline 283 & NQL DRILLING TOOI & 3533 & 71,671 & 102,082 & 34,350 & 67.732 & 9.807 & 61.289 & 16.033 \\
\hline 284 & NTS COMPUTER SYS & 3571 & 48,091 & 38,093 & 18.551 & 19,542 & 3,593 & 34,030 & 5,266 \\
\hline 285 & $\overline{\mathrm{COR}}$ & 2879 & 41,449 & 61,530 & 36,407 & 25.123 & 4.763 & 91,653 & 8,033 \\
\hline 286 & TY & 2521 & 286.013 & 82,129 & 12.242 & 69.887 & 16,039 & 94,565 & 16,869 \\
\hline 287 & OMNI-LITE INDUSTR & 3297 & 23,659 & 3,007 & 683 & 2.324 & 801 & 1,701 & 997 \\
\hline 288 & ORALIFE GROUP. IN & 2834 & 2,931 & 8,169 & 341 & 7.828 & $-3,003$ & 158 & $-2,745$ \\
\hline 289 & OTATCO INC & 3533 & 40.576 & 9,778 & 4,544 & 5,234 & $-3,286$ & 20,186 & 2.247 \\
\hline 290 & PACIFIC E-LINK COR & 3669 & 3,878 & 15,142 & 10,375 & 4.767 & -882 & 47,950 & 784 \\
\hline 291 & IFIC RANGER PE & 3443 & 771 & 6,048 & 4.558 & $1 .+90$ & -59 & 10,611 & 213 \\
\hline 292 & IC SAFETY PRO & 3842 & 5,040 & 9,117 & 5,772 & 3.345 & -522 & 9,312 & -380 \\
\hline 293 & PALLET PALLET INC & 2448 & 5,466 & 38,736 & 34.364 & 4,373 & -39.299 & 96,915 & $-4,412$ \\
\hline 294 & PAPERBOARD INDUS & 2631 & 95,201 & $1,010,933$ & 759.556 & 251.377 & -13.284 & 840,418 & 26,530 \\
\hline 295 & $\mathrm{PA}$ & 2911 & 51,484 & 95,561 & 44,671 & 50.890 & 3,554 & 255,374 & 9,709 \\
\hline 296 & PATHEON INC & $28 \hat{3} 4$ & 142,814 & 62,244 & 35.379 & 26.865 & 3,982 & 70,473 & 6,485 \\
\hline 297 & PEARL RIVER HOLD & 3089 & 1,942 & 12,287 & 3,247 & 9.040 & -724 & 14,831 & 684 \\
\hline 298 & PELORUS NAVIGATI & 3812 & 8,812 & 7,413 & 917 & 6.496 & $-2,471$ & 2.069 & $-1,227$ \\
\hline 299 & T FRY CORPY & 3589 & 1,925 & 2,302 & 472 & 1.831 & -127 & 1,681 & 33 \\
\hline 300 & PERKINS PAPERS LT & 2676 & 293,634 & 95,686 & 2,233 & 33.453 & 27,235 & 281,807 & 52.292 \\
\hline 301 & PETROREAL OIL COI & 2086 & 5,304 & 626 & 294 & 332 & -126 & 42 & -153 \\
\hline 302 & PFB CORPORATION & 2821 & 24,080 & 28,549 & 6,065 & 22.484 & 3.085 & 11.967 & 6,030 \\
\hline 303 & PHARMEX INDUSTR & 2834 & 4,651 & 1.781 & 1,995 & $-2|4|$ & -927 & -927 & -140 \\
\hline 304 & PIH PACIFIC INTERN & 2421 & 2,384 & 7,352 & 167 & 3,185 & -487 & 2.069 & -464 \\
\hline 305 & TREE SYSTEM & 3679 & 14,946 & 20,915 & 4,695 & 16.220 & $-24,147$ & 15.711 & $-20,259$ \\
\hline 306 & PLC SYSTEMS INC & 3845 & 3,356 & 24,968 & 8.594 & {$[6.373$} & $-25,499$ & 8.743 & -20.630 \\
\hline 307 & PLM GROUP LTD & 2759 & 40,707 & 83,089 & 66,044 & $|7,045|$ & 2.828 & 91.559 & 9,796 \\
\hline 308 & POLYAIR NTER PAC & 3086 & 27,260 & 72.331 & 49,663 & $22,668 !$ & 2,132 & 101.408 & 6,052 \\
\hline 309 & POLYCORP INC & 3061 & 28,084 & 9,891 & 4,226 & 5.665 & 1,338 & 14,274 & 1,943 \\
\hline 310 & POLYMER SOLUTIO & 2851 & 3,207 & 3,271 & 3,478 & -207 & -870 & 7,329 & -756 \\
\hline 311 & POLY-PACIFIC INTE & 2821 & 1,251 & 1,968 & 800 & 1.168 & 394 & 2,247 & 493 \\
\hline 312 & POLYPHALT INC & 2951 & 2,796 & 3,013 & I35 & 2.878 & 2,035 & 532 & $-1,365$ \\
\hline 313 & POPI GROUP INC & 2369 & 602 & 6,424 & 2,334 & 4,090 & -21 & 4,627 & 450 \\
\hline 314 & POTASH CORPORAT & 2873 & $5,261,648$ & $6,963,712$ & $3,195,226$ & $3,768,486$ & 400,848 & $3,544,262$ & 853.651 \\
\hline 315 & PREMDOR INC & 2431 & 646,260 & 887,934 & 484,907 & 403,026 & 47,290 & $1,462,734$ & 78,532 \\
\hline
\end{tabular}




\begin{tabular}{|c|c|c|c|c|c|c|c|c|c|}
\hline 316 & PRICE MANUFACTU & 2515 & 2,339 & 4,214 & 2,178 & 2.036 & $-4,015$ & 6,650 & -3.216 \\
\hline 317 & PRIMERO INDUSTRU & 3822 & 498 & 6 & 142 & -136 & -707 & 0 & -94 \\
\hline 318 & PRMMETECH ELECTR & 3672 & 143,365 & 56,143 & 14,201 & 41.942 & 11,074 & 89,013 & 11.208 \\
\hline 319 & PRIMEX FOREST PRC & 2421 & 56,925 & 99,053 & 33,341 & 65,712 & 6,447 & 168.079 & 12.450 \\
\hline 320 & PROCESS CAPITAL & 2911 & 5,667 & 3,455 & 1,810 & 1,645 & -877 & 150 & 571 \\
\hline 321 & PROFAB ENERGY SE & 3533 & 2,980 & 3,929 & 1,737 & 2,192 & 122 & 6,766 & 190 \\
\hline 322 & PROMATEK INDUST & 3841 & 10,374 & 2,876 & 402 & 2.474 & 936 & 3,144 & 966 \\
\hline 323 & PROMETIC LIFE SCIF & 2833 & 78.451 & 36,374 & 16,463 & 19,911 & -7.497 & 10,586 & $-6,807$ \\
\hline 324 & PRUDENTIAL STEEL & 3498 & 205,602 & 154,315 & 26,004 & 128,311 & 12,886 & $\mid 75,656$ & $16, \overline{766}$ \\
\hline 325 & QLT PHOTOTHERAP & 2834 & 974,676 & 103,223 & 8,145 & 95.078 & $-24,071$ & 2,004 & $-22 . \overline{859}$ \\
\hline 326 & QSOUND LABS, INC & 3846 & 92.229 & 7,372 & 331.7328 & 7.039 & $-1,900$ & 3,244 & $-1, \overline{729}$ \\
\hline 327 & QUEBECOR PRINTIN & 2759 & $3,821,070$ & $5,900.722$ & $3,497,957$ & 2.402 .765 & 245,052 & $5,848,564$ & 653,148 \\
\hline 328 & R.P.M. TECH INC & 3531 & 6.266 & 24.369 & 15,507 & 8.862 & 851 & 36,090 & 1,474 \\
\hline 329 & RAINBOW GROUP O & 3812 & 11.864 & 4.147 & 1,067 & 3.080 & -631 & 0 & -548 \\
\hline 330 & RE-CON BUILDNNG $P$ & 3272 & 1.974 & 25.055 & 17,683 & 7.372 & 899 & 11,908 & $-3,222$ \\
\hline 331 & |REKO INTERNATION & 3544 & 38,558 & 89.410 & 41,474 & 47.936 & 5.247 & $67,927 !$ & 9.654 \\
\hline 332 & RESEARCH IN MOTI & 3661 & 585.308 & 153.347 & 3,292 & 150.054 & 540 & 33,159 & 2,732 \\
\hline 333 & REX DLAMOND MIN & 3915 & 47,331 & 79.183 & 22,551 & 56.632 & -6.216 & 11.362 & -2.538 \\
\hline 334 & RIDLEY INC & 2048 & 160.050 & 230.838 & 124,222 & 106.616 & 13.479 & 398,004 & 27.007 \\
\hline 335 & RIVERSIDE FOREST & 2421 & 75.896 & 371.272 & 240.418 & 130.854 & $-7,845$ & 450.942 & 14.783 \\
\hline 336 & RT MITCHELL & 3535 & 19.851 & 55.849 & 10,636 & 45.213 & 378 & 78,722 & 2.788 \\
\hline $337 !$ & ROLLAND INC & 2621 & $\mid 49.295$ & 309.616 & 197,876 & 111,740 & 18,817 & 670,669 & 31.292 \\
\hline$\overline{3381}$ & |ROSE CORPORATIOY & 3714 & 25,150 & 56,382 & 21,009 & 35.373 & 1,144 & 5,799 & 1,944 \\
\hline 339 & ROYAL GROUP TECL & 3089 & $2,920,250$ & 551,652 & 736,578 & 815.074 & 120.024 & $1,050,103$ & 196.819 \\
\hline 340 & ROYAL LASER TECH & 3699 & 51,561 & 37.376 & 16,244 & 21.132 & 3,301 & 19,361 & 4.616 \\
\hline 341 & DSMARTVISION & 3861 & 59.149 & 94,451 & 70,716 & 23,735 & $-20,785$ & $70,184 \mid$ & 3.333 \\
\hline $\overrightarrow{342 !}$ & SADDLERO & 2449 & 570 & 569 & 88 & 481 & $\mid-74$ & II & -38 \\
\hline 343 & SALIX PHARMACEU & 2834 & 14,803 & 12,680 & 2,196 & 10.483 & -11.379 & 2,394 & -11.239 \\
\hline 344 & SAMUEL MANU-TEC & 3316 & 310,901 & 524.402 & 319,020 & 205,382 & 23,393 & 735.475 & 46.800 \\
\hline 345 & SAPUTO GROUP INC & 2022 & 2.107 .819 & 896,662 & 526,769 & 369.893 & 45.745 & 817.255 & 63,972 \\
\hline 346 & SCHNEIDER CORPOR & 2011 & 139,628 & 278.877 & 175,296 & 103,581 & 10,524 & 905,908 & 18.180 \\
\hline 347 & SCI INCOME TRUST & 2515 & 75.019 & 89,371 & 18.542 & 70.829 & 9,714 & 104,803 & 14,047 \\
\hline 348 & SCI-TEC INSTRUMEN & 3826 & 5,721 & 11,174 & 6,437 & 4.737 & $-1,460$ & $|2,595|$ & -573 \\
\hline 349 & ISEAGRAM COMPAN & 2084 & $9,977.447$ & 22.179 .000 & $12,863,000$ & 9.316 .000 & 946,000 & $9,7|4.000|$ & 90.000 \\
\hline 350 & ISEMI-TECH CORPOR & 3639 & 10,026 & $3.335,258$ & $3,064,548$ & 270,711 & $-659,573$ & 1.562 .558 & -212.843 \\
\hline 351 & SENCO SENSORS INO & 3823 & 26.212 & 1.757 & 178 & 1.579 & -2.469 & 4391 & -2.421 \\
\hline 352 & |SENSE TECHNOLOG & 3663 & 61.221 & 2.820 & $1, \overline{834}$ & 986 & -671 & $0 \mid$ & -511 \\
\hline 353 & SENTEX SYSTEMS L & 2048 & 3,938 & 1,671 & 462 & 1,209 & 159 & 2.702 & 165 \\
\hline 354 & SEPP'S GOURMET FC & 2011 & 27,532 & 34.064 & 20,260 & 13.804 & 331 & $43.175 !$ & 1.509 \\
\hline 355 & SEPROTECH SYSTEM & 3569 & 1,589 & 2.331 & 931 & 1.400 & -334 & 3,357 & -177 \\
\hline 356 & SERENA RESOURCE & 3731 & 572 & 37 & 795 & -758 & -755 & 0 & -289 \\
\hline 357 & ISHAW INDUSTRIES 1 & 2899 & 767.740 & 556.897 & 237,363 & 319.534 & $69.624 \mid$ & 769,017 & 95.051 \\
\hline 358 & SHELLCASE LTD & 3674 & $\mid 5,698$ & 2.792 & 6.040 & -3.248 & $-2,954$ & 799 & -2.587 \\
\hline 3591 & SHERMAG INC & 2511 & 185.957 & 109.171 & 51,509 & 57.662 & 9,507 & 109.438 & 12.252 \\
\hline 360 & SICO INC & 2851 & 71,059 & 102.844 & 59,751 & 43,093 & 6.156 & 206.086 & 11.067 \\
\hline 361 & SIERRA WIRELESS, I & 3669 & 32.735 & 24.812 & 3,723 & 21.089 & 2.529 & 26.400 & 3,192 \\
\hline 362 & SIGNALGENE INC & 2836 & 17,484 & 4,340 & 1,103 & 3,237 & $-5,782$ & 25 & -4.301 \\
\hline 363 & SIMMONDS CAPITAI & 3663 & $2.854 \mid$ & 16.802 & 33,825 & $-17,023$ & -12.245 & $40.791 !$ & -8.175 \\
\hline 3641 & ISINO-FOREST CORPO & 2411 & 119.484 & 154,349 & 23,544 & 130.806 & 32.811 & 142.384 & 21.678 \\
\hline 365 & SIRIT TECHNOLOGIE & 3829 & 2,977 & 12.296 & 3,250 & 9.046 & $-1,428$ & $\mid 11.466$ & $-1,112$ \\
\hline 366 & SKYJACK INC & 3537 & 192.829 & 104.140 & 42,537 & 61.603 & 8,155 & 199,433 & 10.407 \\
\hline 367 & SLATER STEEL INC & 3316 & 84,802 & 414.209 & 203,572 & 210.637 & $-7,507$ & 509.610 & 10.927 \\
\hline 368 & |SLEEMAN BREWERI & 2082 & 126,836 & 105,655 & 54,240 & 51,415 & 6,755 & 76,023 & 11,283 \\
\hline
\end{tabular}




\begin{tabular}{|c|c|c|c|c|c|c|c|c|}
\hline $369 \mid$ SMALL FRY SNACK & 2064 & 26,740 & 70,175 & 50,468 & 19,707 & $-4,708$ & 159.810 & 5,268 \\
\hline 370 SMARTIRE SYSTEMS & 3823 & 81,369 & 14,186 & 802 & 13,384 & $-6,693$ & 2.057 & $-5,840$ \\
\hline 371 SMARTOR PRODUCT & 3822 & 524 & 3,398 & 3,179 & 219 & -895 & 2.686 & -715 \\
\hline 372|SMED INTERNATION & 2522 & 87.643 & 208,794 & 102,963 & 105.831 & 8,169 & $1,835,770$ & 18.576 \\
\hline \begin{tabular}{|l|l|}
373 & SNIF SECURITY INC \\
\end{tabular} & 3669 & 307 & 261 & 2,622 & $-2,361$ & -324 & 947 & -190 \\
\hline \begin{tabular}{|l|l|}
374 & SOFAME TECHNOLO \\
\end{tabular} & 3433 & 6,843 & 1,721 & 434 & 1,287 & -143 & 3,028 & $\overline{85}$ \\
\hline 375 SONY CORPORATIOI & 3651 & $52,935,385$ & $68,454,933$ & $49,044,834$ & $19,410,099$ & $2,374,129$ & $72,222,944$ & $6,324,079$ \\
\hline \begin{tabular}{|l|l|}
376 & SPECTRA PREMIUM \\
\end{tabular} & 3714 & 525,280 & 66,530 & 7,042 & 59,488 & 11,146 & 50.577 & 13.174 \\
\hline \begin{tabular}{|l|l|}
377 & SPECTRUM GAMES \\
\end{tabular} & 3944 & 327 & 6 & 516 & -510 & -106 & 0 & -105 \\
\hline 378 SPECTRUM SIGNAL & 3663 & 38.637 & 34,379 & 12,793 & 21.586 & $-1,863$ & 39.931 & 1.226 \\
\hline \begin{tabular}{l|l}
379 & SR TELECOM INC
\end{tabular} & 3663 & 112.897 & 303.790 & $\mid 99,505$ & 104,285 & 3,229 & 180,014 & 7,210 \\
\hline \begin{tabular}{|c|l|}
380 & ST. LAURENT PAPER \\
\end{tabular} & 2631 & 529.380 & $1,613,224$ & 728,433 & 884,791 & -35.727 & $1,216,211$ & 64,938 \\
\hline $381 !$ ST. LA WRENCE CEM & 3241 & 714.241 & 738,856 & 319.950 & 418,906 & 65.090 & 850.410 & 103.188 \\
\hline 382:STACKPOLE LIMITE & 3714 & 131,497 & 210,530 & 101.756 & 108.774 & 3.528 & 181.455 & 21.755 \\
\hline 383 STELCO INC & 3312 & 841,840 & $2,833,000$ & $1,394.000$ & $1,439.000$ & {$[19,000$} & $3,168.000$ & 276.000 \\
\hline 384: STELLA-JONES INC & 2491 & 19.540 & 51,234 & 24.069 & 27.165 & 3,821 & 82.014 & $\overline{5.37 \mathrm{I}}$ \\
\hline 385 STRATEGIC TECHNC & 3663 & 3.943 & 5,156 & 2.269 & 2.887 & 382 & 7.318 & 1.171 \\
\hline 386|STRATEGIC VISTA If & 3669 & 1.720 & 1,981 & 2.473 & -492 & $-1,778$ & 3.408 & -1.373 \\
\hline 387 STRESSGEN BIOTEC & 2836 & 44.932 & 33,477 & 6.678 & 26.799 & $-14,209$ & 2.626 & -13.494 \\
\hline 388!SUN ICE LIMITED & 2329 & 190 & 1,368 & 3,764 & -2.3961 & -1.221 & 5.064 & -1.362 \\
\hline $389 \mid$ SUN-RYPE PRODUC] & 2033 & 15,889 & 36,678 & 22.529 & 14.149 & 1.814 & 83.811 & 5.556 \\
\hline 390 SYMPLEX COMMUN & 3669 & 5,879 & 2,452 & 1,999 & 453 & $-1,323$ & 4.352 & -+25 \\
\hline 391 SYNSORB BIOTECH & 2836 & 77.292 & 29,441 & 15,438 & 14.003 & $-13,487$ & 633 & -13.016 \\
\hline 392 SYSCAN INTERNATI & 3663 & 7.260 & 4,340 & 2,376 & 1.964 & 159 & 5.778 & +25 \\
\hline \begin{tabular}{l:l|l}
393 & TANBRIDGE CORPOI \\
\end{tabular} & 3111 & 9.639 & 45,351 & 19.938 & 25.413 & 2,880 & 78.064 & 4.711 \\
\hline 394 TECHMIRE LTD & 3542 & 2,698 & 8,951 & 5,531 & 3.419 & 821 & 16.517 & 1.555 \\
\hline 395:TECHNILAB PHARM & 2834 & 107,756 & 66,571 & 21.146 & 45.425 & 4,422 & 53.624 & 9.388 \\
\hline 396: TEKLOGLX INTERNA & 3663 & 243,501 & 89,633 & 39.342 & 50.291 & $-8,238$ & 127.613 & 360 \\
\hline 397 TEKNION CORPORA & 2521 & 977,251 & 204,952 & 89,6011 & 115.351 & 56,015 & 483,695 & 62.094 \\
\hline 398 TELEPANEL SYSTEM & 3571 & 10,082 & 9,450 & 12,806 & -3.357 & $-8,958$ & 9.577 & $-5,789$ \\
\hline 399 TEMBEC INC & 2611 & 583.665 & $2,496,900$ & $1,535,200$ & $96 ! .700$ & 61,100 & $1,422,900$ & 207.000 \\
\hline 4()0!TEMPLAR RESOURC & 3732 & 4.576 & 7 & 580 & -573 & -94 & 2 & -94 \\
\hline 401 TERRA INDUSTRIES & 2873 & 716.918 & $3,555,603$ & $2,407,052$ & 1.148 .551 & $-40,313$ & $3,797,974$ & 217.142 \\
\hline 402:TESMA INTERNATIC & 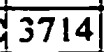 & 570.124 & 399,331 & 137.858 & 261.473 & 29,654 & 645,894 & 58.310 \\
\hline 403 THERATECHNOLOG] & 2834 & 57.159 & 19,085 & 2,325 & 16.760 & $-5,146$ & 708 & -5.036 \\
\hline 404!THERMAL ENERGY & 3564 & 1,327 & 434 & 1.407 & -973 & -390 & 1.196 & -321 \\
\hline 405:THOMSON CORPORA & 92711 & $21,769.346$ & $19,116,103$ & $8.757,132 !$ & 10.358 .971 & $2.835,087$ & $9,627.930$ & 1.893 .641 \\
\hline 4)6 TIMBERWEST FORES & 2411 & 616.034 & $1,144,600$ & 425,800 & 718,800 & 21,800 & 399.800 & 53,000 \\
\hline 407! TIMMINCO LIMITED & 3356 & 54,968 & 118,143 & 72.651 & 45.492 & 3,125 & 95.162 & 8.276 \\
\hline 408!TIR SYSTEMS LTD & 3648 & 1.710 & 1.787 & 1,072 & 715 & $-1,079$ & 3.333 & -960 \\
\hline 409:TML FOODS INC & 2013 & 1.782 & 5,876 & 6.297 & -421 & $-1,498$ & 5.846 & -1.207 \\
\hline+10 TOROMONT INDUST! & 3585 & 456.602 & 442.972 & $259.376 !$ & 183,596 & 38,188 & 683.482 & 43,386 \\
\hline 411:TRADE WIND COMM & 3661 & 9,700 & 7.708 & 6,569 & 1,139 & $-1,201$ & 16.548 & -528 \\
\hline 412:TRAILMOBILE CANA & 3715 & 14.342 & 38.434 & $45,884 !$ & -7.450 & $-7,905$ & 107.224 & -6.525 \\
\hline 413 ITREE BREWING CON & 2082 & 1.917 & 1,986 & 656 & 1.330 & -634 & 1,144 & -832 \\
\hline 4I4!TRINORTH CAPITAL & 3011 & 3,313 & 70.210 & 52,409 & 17,801 & $-29,271$ & 59,796 & -4.106 \\
\hline 415 TRIPLE CROWN ELE & 3663 & 4,979 & 5,405 & 3,754 & 1.651 & $-1,494$ & 8.167 & -1.406 \\
\hline 4I6! TRITECH PRECISION & 3369 & 194.222 & 347,339 & 220,883 & 126.456 & $\mid 4,455$ & 328.565 & 37.472 \\
\hline 417 TRI-VISION INTERNA & 3679 & 29,930 & 20,026 & 6,044 & 13,983 & 62 & 7,463 & 233 \\
\hline 418|TROJAN TECHNOLO & $\mid 3826$ & 594.264 & 106,845 & 47.662 & $59,183 !$ & 2,828 & 26,767 & 6.670 \\
\hline \begin{tabular}{l|l|}
419 & TS TELECOM LTD \\
\end{tabular} & 3661 & 11.832 & 9,189 & 3,201 & 5.988 & 2.281 & 25.653 & -470 \\
\hline \begin{tabular}{l|l|}
420 & TSI TELSYS CORPOR \\
\end{tabular} & 3663 & 12,193 & 8,912 & 8,662 & 249 & $-9,313$ & 6,006 & $-8,949$ \\
\hline \begin{tabular}{|l|l|}
421 & TUNDRA SEMICOND \\
\end{tabular} & 3674 & 120,705 & 14,889 & 3,156 & 11,733 & 473 & 20,142 & 2,242 \\
\hline
\end{tabular}




\begin{tabular}{|c|c|c|c|c|c|c|c|c|c|}
\hline 422 & TURBO GENSET INC & 3621 & 80,615 & 6,325 & 156 & 6,169 & $-1,919$ & 35 & $-1,743$ \\
\hline 423 & ULTRAMAR DIAMOI & 2911 & $3,323,827$ & $8,162,777$ & $6,037,230$ & $2,125,547$ & $-119,946$ & $17,100,519$ & 374.735 \\
\hline 424 & UNIBROUE INC & 2082 & 33,828 & 29,284 & 9,219 & 20.065 & 2,113 & 21,814 & 4,047 \\
\hline 425 & UNIFORET INC & 2421 & 136,498 & 409,914 & 281,618 & 128,296 & -22.244 & 292,357 & $-8,208$ \\
\hline 426 & UNILENS VISION INd & 3851 & 199 & 3,016 & 7,038 & $-4,022$ & -979 & 4,905 & -256 \\
\hline 427 & UNIROM TECHNOLO & 3825 & 441 & 402 & 680 & -278 & $-3,096$ & 0 & -108 \\
\hline 428 & UNITEC INTERNATId & 3625 & 5,571 & 2,513 & 1,933 & 580 & 17 & 2.474 & 166 \\
\hline 429 & UNITED DOMINION & 3325 & $1,258,176$ & $3,245,637$ & $1,867,593$ & $1,378.044$ & 153,101 & $3,102,890$ & 220,582 \\
\hline 430 & UPLAND GLOBAL CD & 2834 & 11,221 & 12,415 & 3,672 & 8,743 & 171] & 13.753 & $1 . \overline{774}$ \\
\hline 431 & URBAN JUICE AND S & 2086 & 12,878 & 4,055 & 1.728 & 2,327 & $-2,342$ & 7,0111 & $-1,904$ \\
\hline 432 & VELAN INC & 3494 & 793,613 & 256,957 & $89, \overline{449}$ & 167,508 & 34,156 & 284,483 & 42.370 \\
\hline 433 & VENTRA GR & 3465 & 159,396 & 350,343 & 233,907 & 436 & 13,294 & 467,340 & 38,419 \\
\hline 434 & VICE & 2452 & 29,840 & 47,082 & 4.129 & 953 & 833 & 44.425 & 1,316 \\
\hline 435 & VINCOR INTERNATI & 2084 & 192,114 & 203,096 & 100.753 & 102,343 & 10,825 & 204.810 & 18,956 \\
\hline 4361 & VISIBLE GENETICS I & 3826 & 155,833 & 42,669 & 20,279 & 22.390 & -22.870 & 16.702 & $-19,190$ \\
\hline $437 !$ & PITAL & 3291 & 914 & 5,385 & 2,865 & 2,520 & 230 & 5,017 & 460 \\
\hline 438 & GROUP INC & 2086 & 876 & 956 & 1,432 & -476 & $-1,61 \mathrm{II}$ & $284 !$ & -1.517 \\
\hline $439 !$ & WAJA & 3569 & 120,082 & 637,973 & 36,146 & 1,827 & 9,469 & 92,248 & 20.213 \\
\hline 440 & WARWICK COMMUN & 2731 & 240 & 1,301 & 505 & 796 & 36 & $1 .\lfloor 90 !$ & 79 \\
\hline+41 & L. HOL & 3699 & 17,083 & 1.523 & [85! & 1,338 & $-1,647$ & $593 !$ & $-1,624$ \\
\hline+42 & WESCAM INC & 3663 & 76,678 & 87,312 & $44,893 !$ & 42.419 & 2,865 & 79,904 & 8.494 \\
\hline+431 & WESCAST INDUSTRI & 3714 & 574,300 & 280.367 & 42,594 & 237,773 & 47,856 & 284.861 & 67,277 \\
\hline+44 & WEST FRASER TIMB & $26 \mathrm{II}$ & 880,003 & $2,108,930$ & $1,211,299$ & 897.631 & 5,625 & $1.863,399$ & 161,198 \\
\hline+45 & WFI I & 3567 & 9,697 & 37.881 & 16.541 & 21,338 & $-1,017$ & 53.595 & -119 \\
\hline $446 !$ & WI-LAN INC & 3669 & 329,339 & 8.022 & $1.689 !$ & 6.333 & $-6,292$ & 5.414 & $-5,220$ \\
\hline $447 !$ & WINPAK LTD & 2656 & 318,500 & 254.737 & 122,150 & $\mid 32.587$ & 16,138 & 336.397 & 37,018 \\
\hline$\$ 48 !$ & WOOD COMPOSITE 1 & 3089 & 9,334 & 4,504 & 2.733 & 1.771 & -732 & 85 & -688 \\
\hline 449 & WORLD SPORTS MEI & 3949 & 4,932 & 538 & 1.075 & -536 & $-1,838$ & 123 & $-1,814$ \\
\hline 450 & XEROX C & 3579 & $2,561,066$ & 575,618 & $2,061,952$ & 513.666 & 69,826 & $1,550,412$ & 158.732 \\
\hline 451 & XILLIX TECHNOLOG & 3841 & 22,149 & 16,596 & & 15,196 & $-2,984$ & 5,602 & $-2,511$ \\
\hline 452 & ZEMEX CORPORATIC & 3299 & 86,904 & 228,628 & 102,849 & 125,779 & 8,240 & 159,560 & 7,128 \\
\hline
\end{tabular}




\section{APPENDIX B}

\section{DEA Model Results and Market Value Analysis of the Inefficient Companies-SIC 3600}




\section{APPENDIX B Efficient and Inefficient Companies (SIC3600)}

No. DMU

1 HAMMOND

2 TURBO

3 Inverpower

4 UNITEC

5 GLOBAL

6 LG TECH

7 CAMCO

8 NORON

9 AVANTE

10 SEMI-TECH

11 DANBEL

12 AWA

13 TIR SYS

14 DIGITAL

15 SONY

16 CINRAM

17 AASTRA

$18 \mathrm{ABL}$

19 BCS TECH

20 BELL

21 CIRCA

22 DBA TEL

23 EIGER

24 KING

25 MEMOTEC

26 MICROCELL

27 MITEL

$28 \mathrm{NHC}$

29 NORTEL

30 RIM

31 TRADE WINC

32 TS TEL

33 ADVANTEDC

34 CALIAN

35 CDN marcon

36 CELL-LOC

37 COM DEV

38 COMM

39 CYGNAL

40 DIMENSIONS

41 DYNAMIC

42 FIFTY-PLUS
Score Reference set (lambda)

0.7568 CAMCO I 0.2217 TS TELE 1.0000 TURBO C 1.0000

0.5446 RESEARI 0.0116 TS TELEI 0.4349 GLOBAL 0.0217 AASTRA 1.0000 GLOBAL 1.0000

0.5866 CAMCO I 0.0060 TS TELEI

1.0000 CAMCOI 1.0000

0.0653 FIFTY-PL 0.9899 SNIF SEC

0.5830 RESEAR! 0.0028 TS TELEI

0.2145 CAMCO I 0.7746 CELESTI

0.7553 GLOBAL 0.0556 AASTRA

0.8473 TS TELEI 0.0245 FIFTY-PL

0.6557 TS TELEI 0.1198 FIFTY-PL

0.8843 RESEARI 0.0034 TS TELEI

1.0000 SONY CC 1.0000

1.0000 CINRAM 1.0000

1.0000 AASTRA 1.0000

0.3991 TS TELEI 0.5432 FIFTY-PL

0.6766 FIFTY-PL 0.9156 PACIFIC

0.2541 CELESTI 0.1402 LEITCH 7

0.8595 AASTRA 0.2780 TS TELE

0.6399 TS TELEI 0.1446 FIFTY-PL

0.8151 CAMCO I 0.0107 TS TELEI

0.4719 PACIFIC 0.2143 SNIF SEC

0.6492 TS TELEI 0.8199 PRIMETE

0.0664 CAMCO I 0.1845 PACIFIC

1.0000 MITEL C 1.0000

0.6709 RESEARI 0.0132 FIFTY-PL

1.0000 NORTEL 1.0000

1.0000 RESEAR! 1.0000

1.0000 TS TELEI 1.0000

0.1804 RESEARI 0.0117 TS TELEI

0.8001 CAMCO 10.0599 TS TELEI

i.0000 CANADIF 1.0000

0.9803 TURBO C 0.2345 RESEAR!

0.8633 CAMCO I 0.0824 PRIMETE

1.0000 COMMUP 1.0000

0.5892 RESEAR' 0.0242 TS TELEI

\$ 0.1103 TURBO C 0.1233 RESEAR!

0.9394 TURBO C 0.9828 RESEARI

0.3397 SNIF SEC $\quad 0.2002$

0.0891 FIFTY-PL $\quad 0.8992$

0.5935 PRIMETE 0.3466

0.0056 FIFTY-PL $\quad 0.7599$

0.1168 LEITCH $7 \quad 0.8008$

0.6881 COMMUP $\quad 0.2612$ LEITCH TE $\quad 0.0265$ 0.0003 FIFTY-PL $\quad 0.8763$

0.0172
0.4001 PACIFIC

0.0417 SNIF SEC

0.4090 BALLARL

0.0737 COMMUP

0.8450 PACIFIC

0.1798 FIFTY-PL

0.7857

0.1655 LEITCH $1 \quad 0.0146$

0.8155

0.9257 INTERNA

0.0279 LEITCH TE

0.0333

$\begin{array}{lll}0.9208 \text { FIFTY-PL } & 0.0676 \\ 0.0472 \text { FIFTY-PL } & 0.9285 \text { PRIMETEC } & 0.0025\end{array}$

0.0474

0.2501

0.0428

0.4507

0.0104

0.5594 PACIFIC E.

0.2501

0.0333
0.0135
0210 FIFTY-PL $\quad 0.9763$
. 0210 FIFTY-PL 0.3099
0.8776 PACIFIC 0.0027
0.8591 LEITCH $1 \quad 0.1375$

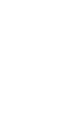

\section{5

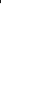




\section{APPENDIX B Efficient and Inefficient Companies (SIC3600)}

43 GEMSTAR 0.2324 TURBO C 0.0118 FIFTY-PL 44 INTER DATA 1.0000 INTERNA 1.0000

45 Kasten chase 0.9949 RESEARı 0.1130 TS TELEI 46 MARATHON 0.6045 FIFTY-PL 0.8016 PACIFIC 47 NEWBRIDGE 1.0000 NEWBR\| 1.0000

48 SENSE TECF 0.3741 TURBO C 0.1621 FIFTY-PL 49 SIMMONDS 0.7663 PACIFIC 0.8477 SNIF SEC 50 SPECTRUM 0.7867 TS TELEI 0.8465 PRIMETE 51 SR TEL 0.4470 CAMCO I 0.1363 PRIMETE 52 STRATEGIC 0.9832 GLOBAL 0.3983 CAMCO I 53 SYSCAN 0.6574 AASTRA 0.0522 COMMUP 54 TEKLOGIX 0.8099 CAMCO I 0.0755 PRIMETE 55 Triple crown 0.5260 TS TELEI 0.2507 FIFTY-PL 56 TSI 0.2112 FIFTY-PL 0.7477 PACIFIC 57 WESCAM $58 \mathrm{EXI}$ 59 JEMTEC 60 PACIFIC

- 61 SIERRA 62 SNIF 0.6285 TS TELEI 0.1979 PRIMETE 0.7569 RESEARI 0.0117 COMMUP 1.0000 JEMTEC 1.0000 1.0000 PACIFIC 1.0000 0.9963 RESEARI 0.0052 TS TELEI 1.0000 SNIF SEC 1.0000

63 STRATEGIC 0.5342 FIFTY-PL 0.6999 PACIFIC 64 SYMPLEX 0.5622 TS TELEI 0.0143 FIFTY-PL 65 WI-LAN 0.8732 RESEARI 0.0359 TS TELEI 66 CIRCUIT 0.7525 GLOBAL 0.4312 AASTRA 67 PRIMETECH 1.0000 PRIMETE 1.0000

68 CELESTICA 1.0000 CELESTI 1.0000

69 CORECO 0.9834 FIFTY-PL 0.8480 GENNUN 70 GENNUM 1.0000 GENNUN 1.0000

71 SHELLCASE 0.0847 FIFTY-PL 0.8555 PACIFIC 72 TUNDRA 0.9817 TS TELEI 0.1004 COMMUP 73 C-MAC $\quad 0.8171$ CAMCO 0.2203 MITEL CC 74 Electrohome 0.6733 CAMCO 10.0752 TS TELEI 75 LAMBUS 76 LEITCH 0.7096 TURBO C 0.0660 FIFTY-PL 1.0000 LEITCH 11.0000

77 PLAINTREE 0.8663 RESEARI 0.0884 TS TELEI 78 TRI-VISION 0.7426 RESEARI 0.0850 TS TELEI 79 BALLARD 1.0000 BALLAR[ 1.0000 80 BLUESTAR 0.5548 CAMCO I 0.0926 PRIMETE 81 COMPRES 0.3105 FIFTY.PL 0.9716 PACIFIC 82 GSI LUmonic: 0.9167 CAMCO 10.0196 CELESTI 83 NEXTRON 0.5345 RESEARI 0.0032 TS TELEI 84 ROYAL LASE 0.6837 FIFTY-PL 0.8098 GENNUN 85 WE X.L. $\quad 0.9437$ RESEARı 0.0088 TS TELEI
0.9882

0.7617 FIFTY-PL $\quad 0.1253$

0.1285 SNIF SEC $\quad 0.0699$

0.8379

0.1523

0.0760 LEITCH $7 \quad 0.0775$

0.4192 LEITCH $7 \quad 0.4445$

0.0012 FIFTY-PL 0.4871 JEMTEC IN

0.1133

0.5220 PRIMETEC

0.0025

0.8796 LEITCH $7 \quad 0.0449$

0.7153 PACIFIC $\quad 0.0339$

0.1203 SNIF SEC 0.1320

0.7437 LEITCH $1 \quad 0.0584$

0.2240 FIFTY-PL

0.7599 LEITCH TE

0.0044

0.2631 COMMUP

0.6358 LEITCH TE

0.0959

0.0642 SNIF SEC

0.9054 PACIFIC

0.1599 FIFTY-PL

0.2359

0.0802

0.8042

0.4006 FIFTY-PL

0.1531 INTERNAT

0.0151

0.0119 LEITCH 1

0.1402

0.0113 SNIF SEC

0.1332

0.7976 PRIMETE

0.1599 CELESTI

0.4257 PRIMETE

0.0710 LEITCH TE

0.0311

0.0588 LEITCH TE $\quad 0.5610$

0.9340

0.4990

0.4958 FIFTY-PL

0.4159

0.1415 COMMUP

0.1094 FIFTY-PLU

0.6641

0.8695 LEITCH $1 \quad 0.0379$

0.0131 SNIF SEC 0.0153

0.0135 LEITCH $7 \quad 0.9669$

0.0452 FIFTY-PL 0.9516

0.1021 LEITCH $1 \quad 0.0881$

0.0060 FIFTY-PL $\quad 0.9853$ 


\begin{tabular}{|c|c|c|c|c|c|c|}
\hline DMU & Score & Market Cap & Distane & Efricient & Peers & \\
\hline \# & & $\$(000 s)$ & & 32 & 42 & 60 \\
\hline $18 \mathrm{ABL}$ CAN & 0.399 & 13,382 & 0.0000 & 0.5432 & 0.4001 & 0.0567 \\
\hline 13 TIR SYS & 0.656 & 1,710 & 0.4101 & 0.1198 & 0.8776 & 0.0027 \\
\hline 12 AWA TE & 0.847 & 2,429 & 0.5753 & 0.0245 & 0.9525 & 0.0230 \\
\hline 22 DBA TEL & 0.64 & 1,956 & 0.3590 & 0.1446 & 0.8450 & 0.0104 \\
\hline 55 TRIPLE C & 0.526 & 4.979 & 0.1854 & 0.2507 & 0.7153 & 0.0339 \\
\hline 64 SYMPLE & 0.562 & 5,879 & 0.5356 & 0.0143 & 0.9054 & 0.0802 \\
\hline 32 TS TELE & 1 & 11,832 & 0.3720 & 1.0000 & 0.0000 & 0.0000 \\
\hline 42 FIFTY-PI & 1 & 2,404 & 0.6581 & 0.0000 & 1.0000 & 0.0000 \\
\hline 60 PACIFIC & 1 & 3,878 & 1.3450 & 0.0000 & 0.0000 & 1.0000 \\
\hline
\end{tabular}

Ranking, according to the distances that are less than 1 (for ABL CANADA):

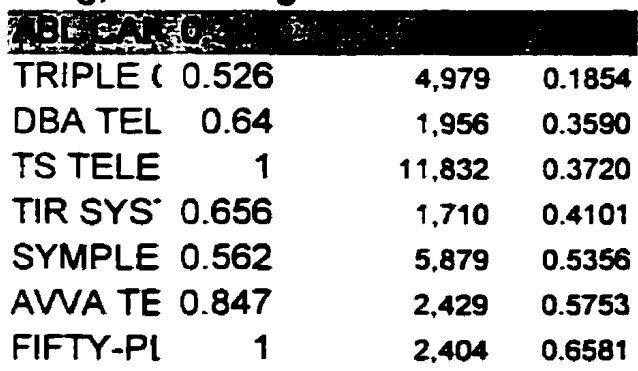

Similarity of the eficiency scores (difference between ABL CANADA's score):

\begin{tabular}{|c|c|c|c|}
\hline \multicolumn{4}{|c|}{ TEJU } \\
\hline TRIPLE ( & 0.526 & 4.979 & 0.1854 \\
\hline SYMPLE & 0.562 & 5,879 & 0.5356 \\
\hline DBA TEL & 0.64 & 1,956 & 0.3590 \\
\hline TIR SYS & 0.656 & 1.710 & 0.4101 \\
\hline AWA TE & 0.847 & 2,429 & 0.5753 \\
\hline TS TELE & 1 & 11,832 & 0.3720 \\
\hline FIFTY-PI & 1 & 2.404 & 0.6581 \\
\hline
\end{tabular}

Similarity of the Market Cap. (difference between ABL CANADA's market cap.):

\begin{tabular}{lrrr} 
TIR SYS & 0.656 & 1.710 & 0.4101 \\
DBA TEL & 0.64 & 1.956 & 0.3590 \\
FIFTY-PI & 1 & 2.404 & 0.6581 \\
AWVA TE & 0.847 & 2.429 & 0.5753 \\
TRIPLE & 0.526 & 4.979 & 0.1854 \\
SYMPLE & 0.562 & 5.879 & 0.5356 \\
TS TELE & 1 & 11.832 & 0.3720 \\
\hline & & &
\end{tabular}

Range for ABL CANADA's market cap. based on peer group is $\$ 1,710,000$ and $\$ 11,832,000$ $A B L$ is a little bit overvalued

Market Capitalization of ABL CANADA based on EFFICIENT PEERS $\$ 7,609$ thousand 


\begin{tabular}{|c|c|c|c|c|c|c|c|}
\hline $\begin{array}{l}\text { DMU } \\
\#\end{array}$ & Score & $\begin{array}{l}\text { Market C. } \\
\$(000 s)\end{array}$ & $\begin{array}{l}\text { Distance } \\
\text { (displayee }\end{array}$ & $\begin{array}{c}\text { Efficient } \\
30\end{array}$ & $\begin{array}{r}\text { Peers } \\
32\end{array}$ & 42 & $\begin{array}{l}\text { Dis } \\
\text { Fon }\end{array}$ \\
\hline NTEDG & 0.180379 & 19. & 0.00000 & 0.0117 & 0.0891 & 0.8992 & 00 \\
\hline 9 AVANTE TEC & 0.582956 & 2.302 & 0.01065 & 0.0028 & 0.0210 & 0.9763 & 0.0107 \\
\hline 3 INVERPOWE & 0.544648 & 7,179 & 1.38 & 0.0116 & 0.9208 & 0.0676 & 1.3834 \\
\hline ARCH & 1 & 585.308 & & 1.0000 & 0.0000 & 0.0000 & 933 \\
\hline ECON & 1 & 11,832 & 1.63847 & 0.0000 & 1.0000 & 0.0000 & 1.6385 \\
\hline -PLUS. & 1 & 2.404 & 0.01823 & 0.0000 & 0.0000 & 1.0000 & 0.0182 \\
\hline 5 KASTEN CH, & 0.994883 & 23,569 & 1.06163 & 0.1130 & 0.7617 & 0.1253 & 1.0616 \\
\hline 5 WI-LAN INC & 0.87321 & 329.339 & 0.01463 & 0.0359 & 0.1599 & 0.8042 & 0.0146 \\
\hline 77 PLAINTREE : & 0.866344 & 14.946 & 0.40491 & 0.0884 & 0.4958 & 0.4159 & 0.4049 \\
\hline 3 & 0.53 & 2,426 & & 0.0032 & 0.0452 & 0.9516 & 0.0047 \\
\hline 5 WE X.L. HOL & 0.94369 & 17,083 & 0.01432 & 0.0088 & 0.0060 & 0.9853 & 0.0143 \\
\hline
\end{tabular}

Ranking, according to the distances that are less than 1 (for ADVANTEDGE TECHNOLOGIES I

$\begin{array}{ll}\text { Nextron } & 0.00474 \\ \text { Avante } & 0.01065 \\ \text { WE X.L. Hold } & 0.01432 \\ \text { Wi-Lan } & 0.01463 \\ \text { Fifty-plus } & 0.01823 \\ \text { Plaintree } & 0.40491\end{array}$

Similarity of the efficiency scores (difference between ADVANTEDGE score (0.18):

Nextron $\quad-0.354072$

Avante $\quad-0.402577$

WE X.L. Hold -0.763311

Wi-Lan $\quad-0.692832$

Fifty-plus $\quad-0.819621$

Plaintree $\quad-0.685966$

ADVANTEDGE's efficiency score is not close to any of the others, the closest is Nextron at ( Similarity of the Market Cap. (difference between ADVANTEDGE's market cap. (\$19,92

$\begin{array}{lrr}\text { Nextron } & 17,502(19,928-2 & 2,426 \\ \text { Avante } & 17,625 & 2,302 \\ \text { WE X.L. Hold } & 2,844 & 17,083 \\ \text { Wi-Lan } & -309,412 & 329,339 \\ \text { Fifty-plus } & 17,524 & 2,404 \\ \text { Plaintree } & 4,981 & 14,946\end{array}$

Range for ADVANTEDGE's market cap. based on peer group is $\$ 2,302,000-\$ 329,339,000$ ADVANTEDGE's real market cap of $\$ 19,928,000$ falls between this range.

Market Capitalization of ADVANTEDGE based on EFFICIENT PEERS

$[(0.012 * 585,308)+(0.089 * 11,832)+(0.90 * 2,404)$

is $\$ 10,064$ thousand 


\section{AVANTE TECHNOLOGIES INC (SIC 3600)}

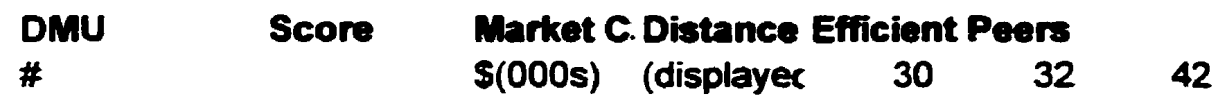

$\begin{array}{lrrrrrr}9 \text { AVANTE T } & 0.5829556 & 2,302 & 0.00000 & 0.0028 & 0.0210 & 0.9763 \\ 3 \text { INVERPOI } & 0.5446483 & 7.179 & 1.63547 & 0.0116 & 0.9208 & 0.0676 \\ 30 \text { RESEARC } & 1 & 585,308 & 1.94802 & 1.0000 & 0.0000 & 0.0000 \\ 32 \text { TS TELEC } & 1 & 11,832 & 1.91154 & 0.0000 & 1.0000 & 0.0000 \\ 33 \text { ADVANTE } & 0.1803789 & 19.928 & 0.01065 & 0.0117 & 0.0891 & 0.8992 \\ 42 \text { FIFTY-PLL } & 1 & 2.404 & 0.00101 & 0.0000 & 0.0000 & 1.0000 \\ 45 \text { KASTEN C } & 0.994883 & 23,569 & 1.28496 & 0.1130 & 0.7617 & 0.1253 \\ 65 \text { WI-LAN IN } & 0.8732104 & 329,339 & 0.05000 & 0.0359 & 0.1599 & 0.8042 \\ \text { 77 PLAINTRE } & 0.8663444 & 14,946 & 0.54681 & 0.0884 & 0.4958 & 0.4159 \\ 83 \text { NEXTRON } & 0.5344511 & 2.426 & 0.00120 & 0.0032 & 0.0452 & 0.9516 \\ \text { 85 WE X.L. H } & 0.9436897 & 17,083 & 0.00034 & 0.0088 & 0.0060 & 0.9853\end{array}$

Ranking, according to the distances that are less than 1 (for AVANTE TECHNOLOGIES INC):

WE X.L. $H_{1} \quad 0.00034$

Fifty-plus $\quad 0.001$

Nextron $\quad 0.0012$

Advantedg $\quad 0.0106$

Wi-Lan $\quad 0.05$

Plaintree $\quad 0.5468$

Similarity of the efficiency scores (difference between AVANTE's score (0.583):

WE X.L. H -0.360734

Fifty-plus $\quad-0.417044$

Nextron 0.0485045

Advantedg 0.4025768

Wi-Lan $\quad-0.290255$

Plaintree $\quad-0.283389$

AVANTE's efficiency score is very close to Nextron's than Plaintree

Similarity of the Market Cap. (difference between AVANTE's market cap. $(\$ 2,302,000)$ :

WE X.L. $H_{1} \quad-14,781(2,302-17,083)$

Fifty-plus $\quad-101(2,302-2,404)$

Nextron $\quad-124$

Advantedg $\quad-17,625$

Wi-Lan $\quad-327,037$

Plaintree $\quad-12,644$

Range for AVANTE's market cap. based on peer group is between $\$ 2,404,000$ and $\$ 329,339,000$

AVANTE's real market cap of $\$ 2,302,000$ falls below this range.

Market Capitalization of AVANTE based on EFFICIENT PEERS

$[(0.0028 * 585,308)+(0.021 * 11,832)+(0.98 * 2,404)$

is $\$ 4,21$ thousand 


\section{AVVA (SIC 3600)}

\begin{tabular}{|c|c|c|c|c|c|c|c|}
\hline $\begin{array}{l}\text { DMU } \\
\text { \# }\end{array}$ & Score & \multicolumn{2}{|c|}{$\begin{array}{l}\text { Market Cas Diatance } \\
\$(000 s)\end{array}$} & \multicolumn{2}{|c|}{$\begin{array}{l}\text { Efiricient Peers: } \\
32\end{array}$} & \multicolumn{2}{|c|}{60 Distance } \\
\hline 12 AWA TECH & 0.84726 & 2,429 & 0.0000 & 0.0245 & 0.9525 & 0.0230 & 0.0000 \\
\hline 32 TS TELECO & 1 & 11,832 & 1.8594 & 1.0000 & 0.0000 & 0.0000 & 1.8594 \\
\hline 18 ABL CANAD & 0.39914 & 13,382 & 0.5753 & 0.5432 & 0.4001 & 0.0567 & 0.5753 \\
\hline 55 TRIPLE CRC & 0.52596 & 4,979 & 0.1076 & 0.2507 & 0.7153 & 0.0339 & 0.1076 \\
\hline 22 DBA TELEC & 0.63987 & 1,956 & 0.0261 & 0.1446 & 0.8450 & 0.0104 & 0.0261 \\
\hline 13 TIR S & 0.65569 & 1,710 & 0.0151 & 0.1198 & 0.8776 & 0.0027 & 0.0151 \\
\hline 64 SYMPLEX C & 0.56217 & 5,879 & 0.0056 & 0.0143 & 0.9054 & 0.0802 & 0.0056 \\
\hline 42 FIFTY-PLUS & 1 & 2,404 & 0.0034 & 0.0000 & 1.0000 & 0.0000 & 0.0034 \\
\hline 60 PACIFIC E-L & 1 & 3,878 & 1.8624 & 0.0000 & 0.0000 & 1.0000 & 1.8624 \\
\hline
\end{tabular}

Ranking, according to the distances that are leas than 1 (for AWA):

$\begin{array}{lrrr}\text { AWNA TECH } & 0.84726 & 2,429 & 0.0000 \\ \text { FIFTY-PLUS } & 1 & 2,404 & 0.0034 \\ \text { SYMPLEX C } & 0.56217 & 5,879 & 0.0056 \\ \text { TIR SYSTEA } & 0.65569 & 1,710 & 0.0151 \\ \text { DBA TELEC } & 0.63987 & 1,956 & 0.0261 \\ \text { TRIPLE CRC } & 0.52596 & 4,979 & 0.1076 \\ \text { ABL CANAD } & 0.39914 & 13,382 & 0.5753\end{array}$

Similarity of the efficiency scores (difference between AWA's score):

$\begin{array}{lrrr}\text { ABL CANAD } & 0.39914 & 13,382 & 0.5753 \\ \text { TRIPLE CRC } & 0.52596 & 4,979 & 0.1076 \\ \text { SYMPLEX C } & 0.56217 & 5,879 & 0.0056 \\ \text { DBA TELEC } & 0.63987 & 1,956 & 0.0261 \\ \text { TIR SYSTEA } & 0.65569 & 1,710 & 0.0151 \\ \text { AWNA TECH } & 0.84726 & 2,429 & 0.0000 \\ \text { FIFTY-PLUS } & 1 & 2,404 & 0.0034\end{array}$

Similarity of the Market Cap. (difference between AWA's market cap.):

$\begin{array}{lrrr}\text { TIR SYSTEA } & 0.65569 & 1,710 & 0.0151 \\ \text { DBA TELEC } & 0.63987 & 1,956 & 0.0261 \\ \text { FIFTY-PLUS } & 1 & 2,404 & 0.0034 \\ \text { AWNA TECH } & 0.84726 & 2.429 & 0.0000 \\ \text { TRIPLE CRC } & 0.52596 & 4,979 & 0.1076 \\ \text { SYMPLEX C } & 0.56217 & 5,879 & 0.0056 \\ \text { ABL CANAD } & 0.39914 & 13,382 & 0.5753\end{array}$

Range for AWA's market cap. based on peer group is $\$ 1,710,000$ and $\$ 13,382,000$ AVVA's real market cap of $\$ 2,429,000$ is right in this range

\section{Market Capitalization of AVVA based on EFFICIENT PEERS \\ $\$ 2,669$ thousand}




\section{BCS TECH (SIC 3600)}

\begin{tabular}{|c|c|c|c|c|c|c|}
\hline Score & Market Cap & & Eficien & I Peers (I & lambdas & \\
\hline \# & $s(000 s) b$ & & 42 & 60 & 62 & distence \\
\hline 19 BCS TECH 0.6766 & 1,027 & 0.0000 & 0.9156 & 0.0417 & 0.0428 & 0.0000 \\
\hline 31 TRADE W 0.6762 & 9,700 & 0.3210 & 0.4601 & 0.3397 & 0.2002 & 0.3210 \\
\hline 46 MARATHC 0.6045 & 623 & 0.0213 & 0.8016 & 0.1285 & 0.0699 & 0.0213 \\
\hline 56 TSI TELSY 0.2112 & 12,193 & 0.0423 & 0.7477 & 0.1203 & 0.1320 & 0.0423 \\
\hline 63 STRATEG 0.5342 & 1,720 & 0.0843 & 0.6999 & 0.0642 & 0.2359 & 0.0843 \\
\hline 71 SHELLCA! 0.0847 & 15,698 & 0.0127 & 0.8555 & 0.0113 & 0.1332 & 0.0127 \\
\hline 81 COMPRES 0.3105 & 717 & 0.0047 & 0.9716 & 0.0131 & 0.0153 & 0.0047 \\
\hline 42 FIFTY-PLL 1.0000 & 2.404 & 0.0107 & 1.0000 & 0.0000 & 0.0000 & 0.0107 \\
\hline 60 PACIFIC E 1.0000 & 3,878 & 1.7584 & 0.0000 & 1.0000 & 0.0000 & 1.7584 \\
\hline 62 SNIF SECI 1.0000 & 307 & 1.7562 & 0.0000 & 0.0000 & 1.0000 & 1.7562 \\
\hline Ranking, according to & o the distane & we that & are les & than 11 & for BCS & ; TECH): \\
\hline BCS TECH 0.6766 & 1,027 & 0.0000 & & & & \\
\hline COMPRES 0.3105 & 717 & 0.0047 & & & & \\
\hline FIFTY-PLL 1.0000 & 2,404 & 0.0107 & & & & \\
\hline SHELLCA: 0.0847 & 15,698 & 0.0127 & & & & \\
\hline MARATHC 0.6045 & 623 & 0.0213 & & & & \\
\hline TSI TELSY 0.2112 & 12,193 & 0.0423 & & & & \\
\hline STRATEG 0.5342 & 1,720 & 0.0843 & & & & \\
\hline TRADE W 0.6762 & 9,700 & 0.3210 & & & & \\
\hline Similarity of the of & finciency sc & res (dif & eren & atwe & & $=010$ \\
\hline SHELLCA: 0.0847 & 15,698 & 0.0127 & & & & \\
\hline TSI TELSY 0.2112 & 12,193 & 0.0423 & & & & \\
\hline COMPRES 0.3105 & 717 & 0.0047 & & & & \\
\hline STRATEG 0.5342 & 1,720 & 0.0843 & & & & \\
\hline MARATHC 0.6045 & 623 & 0.0213 & & & & \\
\hline TRADE W 0.6762 & 9,700 & 0.3210 & & & & \\
\hline BCS TECP 0.6766 & 1,027 & 0.0000 & & & & \\
\hline FIFTY-PLL 1.0000 & 2,404 & 0.0107 & & & & \\
\hline
\end{tabular}

Similarity of the Market Cap. (difference between BCS TECH's market cap.):
MARATHC 0.6045
$623 \quad 0.0213$
COMPRES 0.3105
$717 \quad 0.0047$
BCS TECP 0.6766
$1,027 \quad 0.0000$
STRATEG 0.5342
$1,720 \quad 0.0843$
FIFTY-PLL 1.0000
$2,404 \quad 0.0107$
TRADE W 0.6762
$9,700 \quad 0.3210$
TSI TELSY 0.2112
$12,193 \quad 0.0423$
SHELLCA: 0.0847
$15,698 \quad 0.0127$

Range for BCS TECH's market cap. based on peer group is $\$ 623,000$ to $\$ 15,698,000$

Market Capitalization of BCS TECH based on EFFICIENT PEERS

$\$ 2,376$ thousand 


\section{VALUATION ANALYSIS - BELL CANADA INTERN (SIC3600)}

\begin{tabular}{lrrrrrr} 
DMU & Score & \multicolumn{6}{c}{ Market Caj Efficient Peers } \\
\# & S(000s) & 68 & 76 & 79 distance \\
20 BELL CANADA II & 0.25406 & $1,371,120$ & 0.14023 & 0.40904 & 0.45073 & 0.0000 \\
68 CELESTICA INC & 1 & $2,854,867$ & $13.97 E-16$ & 0 & 1.1097 \\
76 LEITCH TECHNC & 1 & $1,031,559$ & 0 & 1 & 0 & 0.5721 \\
79 BALLARD POWE & 1 & $3,608,271$ & 0 & 0 & 1 & 0.4887
\end{tabular}

Bell is similar to Leitch and Ballard

Therefore, Market Value range of \$1,031,559,000 to $\$ 3,608,271,000$

Upper bound

$\$ 2,448,639,000$

\section{BLUESTAR BATTERY SYSTEMS INTER. (SIC3600)}

$\begin{array}{lllcl}\text { DMU } & \text { Score } & \text { Market Cal Efriciont Peers: } & \\ \text { \# } & \$(000 s) & 7 & 67 & 76 \text { distance }\end{array}$

80 BLUESTAR BAT 0.55479

51 SR TELECOM IN 0.44695

37 COM DEV INTEF 0.86326

54 TEKLOGIX INTE 0.80991

7 CAMCO INC

67 PRIMETECH ELI

76 LEITCH TECHNC

$\begin{array}{rrrrr}44,404 & 9.26 E-02 & 0.86946 & 3.79 E-02 & 0.00000 \\ 112,897 & 0.13625 & 0.41924 & 0.44451 & 0.36994 \\ 252.315 & 8.24 E-02 & 0.1168 & 0.80078 & 1.14858 \\ 243.501 & 7.55 E-02 & 0.87962 & 4.49 E-02 & 0.00044 \\ 100.000 & 1 & 0 & 0 & 1.58077 \\ 143,365 & 0 & 1 & 0 & 0.02705 \\ 1,031,559 & 0 & 0 & 1 & 1.69017\end{array}$

44.404 9.26E-02 $0.869463 .79 E-02 \quad 0.00000$ $\begin{array}{llllll}112,897 & 0.13625 & 0.41924 & 0.44451 & 0.36994\end{array}$ $\begin{array}{lllll}252.315 & 8.24 E-02 & 0.1168 & 0.80078 & 1.14858\end{array}$ 243.501 7.55E-02 0.87962 4.49E-02 0.00044 $\begin{array}{lllll}100.000 & 1 & 0 & 0 & 1.58077\end{array}$ $1,031,559$

$44,404 \quad 0$

$243.501 \quad 0.00044$

$143,365 \quad 0.02705$

$112,897 \quad 0.36994$

Market value range: $\$ 112,897,000$ to $\$ 243,501,000$

It appears to be undervalued.

Upper bound

\$173,006 thousand 


\section{VALUATION ANALYSIS FOR CALIAN TECHNOLOGY LTD (34)}

\begin{tabular}{|c|c|c|c|c|c|c|c|}
\hline $\begin{array}{l}\text { DMU } \\
\text { \# }\end{array}$ & Score & $\begin{array}{l}\text { Market Cal } \\
\text { S(000s) }\end{array}$ & $\begin{array}{l}\text { Distance } \\
\text { (displaye }\end{array}$ & $\begin{array}{r}\text { ient Pee } \\
7\end{array}$ & 32 & & $\begin{array}{l}\text { istance } \\
\text { formula) }\end{array}$ \\
\hline 34 CALIAN TECHI & 0.80014 & 33,191 & 0.00000 & 0.0599 & 0.5935 & 0.3466 & 0.0000 \\
\hline 6 LG TECHNOLC & 0.58659 & 27,707 & 0.02846 & 0.0060 & 0.7302 & 0.2637 & 0.0285 \\
\hline 1 HAMMOND MA & 0.75677 & 18,426 & 0.04795 & 0.2217 & 0.4467 & 0.3315 & 0.0480 \\
\hline 7 CAMCO INC & 1 & 100,000 & 1.35618 & 1.0000 & 0.0000 & 0.0000 & 1.3562 \\
\hline 32 TS TELECOM I & 1 & 11,832 & 0.28897 & 0.0000 & 1.0000 & 0.0000 & 0.2890 \\
\hline 67 PRIMETECH E & 1 & 143,365 & 0.78275 & 0.0000 & 0.0000 & 1.0000 & 0.7827 \\
\hline 74 ELECTROHON & 0.67333 & 11,398 & 0.05162 & 0.0752 & 0.4257 & 0.4990 & 0.0516 \\
\hline
\end{tabular}

Accordingly, Calian is closest to (in distance):

CALIAN TECHI 0.00000

LG TECHNOLC 0.02846

HAMMOND MA 0.04795

ELECTROHON 0.05162

TS TELECOM I 0.28897

PRIMETECH E 0.78275

Similarity of efficiency scores (Distance of Calian. to):

LG tech $\quad 0.21356$

Hammond $\quad 0.04337$

Electrohome $\quad 0.12681$

TS telecom $\quad-0.19986$

Primetech $\quad-0.19986$

Similarity in Market Caps (Calian- M.C. minus):

LG tech $\quad 5,484$

Hammond $\quad \mathbf{1 4 , 7 6 5}$

Electrohome $\quad 21,793$

TS telecom 21,359

Primetech $\quad-110,174$

Range for Calian's market cap based on peer groups is $\$ 11,398,000$ to $\$ 27,707,000$

By adding Primetech we can increase this range to a max of $\$ 143,365,000$

But, Primetech is the most different from Calian in terms of efficiency score, distance, and $m . v$.

Calian's real market cap. of $\$ 33,191,000$ falls just out of this range

\section{UPPER BOUND CALCULATION:}

Based on lambda relation of CALIAN to efficient peers

Looks like: $[(0.0599 * 100,000)+(0.59 * 11,832)+(0.35 * 143,365)]$

$\$ 62,705$ thousand 


\begin{tabular}{|c|c|c|c|c|c|c|c|}
\hline \multirow{2}{*}{$\begin{array}{l}\text { DMU } \\
\begin{array}{l}\text { \# } \\
36 \text { CELL-LOC IN }\end{array}\end{array}$} & \multirow{2}{*}{$\begin{array}{l}\text { Score } \\
0.9803\end{array}$} & \multicolumn{2}{|c|}{$\begin{array}{l}\text { Market Cal Distance } \\
\$(000 s)\end{array}$} & \multicolumn{2}{|c|}{$\begin{array}{cc}\text { Efficient Peers } \\
2 & 30\end{array}$} & \multicolumn{2}{|c|}{42 Distance } \\
\hline & & 28,669 & 0.0000 & 0.2345 & 0.0056 & 0.7599 & 0.0000 \\
\hline 40 DIMENSIONS & 0.11029 & 1.970 & 0.0259 & 0.1233 & 0.0003 & 0.8763 & 0.0259 \\
\hline 2 TURBO GENS & 1 & 80,615 & 1.1635 & 1.0000 & 0.0000 & 0.0000 & 1.1635 \\
\hline 30 RESEARCH II & 1 & 585,308 & 1.6214 & 0.0000 & 1.0000 & 0.0000 & 1.6214 \\
\hline $\begin{array}{l}42 \text { FIFTY-PLUS.I } \\
\text { Distance }\end{array}$ & 1 & 2,404 & 0.1126 & 0.0000 & 0.0000 & 1.0000 & 0.1126 \\
\hline CELL-LOC INI & 0.9803 & 28,669 & 0.0000 & & & & \\
\hline DIMENSIONS & 0.11029 & 1,970 & 0.0259 & & & & \\
\hline $\begin{array}{l}\text { FIFTY-PLUS.P } \\
\text { Efficiency: }\end{array}$ & 1 & 2,404 & 0.1126 & & & & \\
\hline DIMENSIONS & 0.11029 & 1,970 & 0.0259 & & & & \\
\hline CELL-LOC INI & 1 0.9803 & 28,669 & 0.0000 & & & & \\
\hline $\begin{array}{l}\text { FIFTY-PLUS.I } \\
\text { Market Value }\end{array}$ & 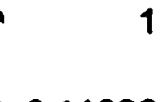 & 2,404 & 0.1126 & & & & \\
\hline DIMENSIONS & 0.11029 & 1,970 & 0.0259 & & & & \\
\hline FIFTY-PLUS.P & 1 & 2.404 & 0.1126 & & & & \\
\hline CELL-LOC INI & 0.9803 & 28,669 & 0.0000 & & & & \\
\hline
\end{tabular}

Range for market value $\$ 1,970,000$ to $\$ 2,404,000$

Upper Range

$\$ 23,996$ thousand

\section{CIRCA}

\begin{tabular}{|c|c|c|c|c|c|c|c|}
\hline $\begin{array}{l}\text { DMU } \\
\text { \# }\end{array}$ & Score & $\begin{array}{l}\text { Market Cap } \\
\$(000 s)\end{array}$ & 17 & 32 & 38 & 67 & \\
\hline 21 CIRCA ENTEF & 0.85947 & 6,601 & 0.2780 & 0.0737 & 0.6009 & 0.0474 & 0.0000 \\
\hline 17 AASTRA TEC & 1 & 46,091 & 1.0000 & 0.0000 & 0.0000 & 0.0000 & 0.8900 \\
\hline 32 TS TELECOM & 1 & 11,832 & 0.0000 & 1.0000 & 0.0000 & 0.0000 & 1.2986 \\
\hline 38 COMMUNICA & 1 & 3,855 & 0.0000 & 0.0000 & 1.0000 & 0.0000 & 0.2442 \\
\hline 67 PRIMETECH I & 1 & 143,365 & 0.0000 & 0.0000 & 0.0000 & 1.0000 & 1.3512 \\
\hline
\end{tabular}

Similar to Aastra and Communication, therefore

range for market value of $\$ 3,855,000$ to $\$ 46,091,000$

Upper bound

$\$ 22,797$ thousand

$\$ 22,797,000$ 


\section{CIRCUIT WORLD CORPORATION \& C MAC (SIC3600)}

\begin{tabular}{|c|c|c|c|c|c|c|c|}
\hline \multirow{2}{*}{$\begin{array}{l}\text { DMU } \\
\#\end{array}$} & \multirow[t]{2}{*}{ Score } & \multicolumn{6}{|c|}{ Market Cał Efiicient Peers: } \\
\hline & & $\$(000 s)$ & 5 & 17 & 42 & 44 & listance \\
\hline 66 CIRCUIT WK & 0.75253 & 289 & 0.4312 & 0.4006 & 0.1531 & 0.0151 & 0.0000 \\
\hline 11 DANBEL INE & 0.75534 & 5,798 & 0.0556 & 0.6210 & 0.3099 & 0.0135 & 0.2142 \\
\hline 5 GLOBAL TH & 1 & 13,222 & 1.0000 & 0.0000 & 0.0000 & 0.0000 & 0.5077 \\
\hline 17 AASTRA TE & 1 & 46,091 & 0.0000 & 1.0000 & 0.0000 & 0.0000 & 0.5689 \\
\hline 42 FIFTY-PLUS & 1 & 2,404 & 0.0000 & 0.0000 & 1.0000 & 0.0000 & 1.0638 \\
\hline 44 INTERNATIC & 1 & 3,893 & 0.0000 & 0.0000 & 0.0000 & 1.0000 & 1.3399 \\
\hline
\end{tabular}

In terms of distance, Circuit is closest to Danbel, then Global, then Aastra In terms of efficiency score it is closest to Danbel

Range for market cap. $\$ 5,798,000$ to $\$ 46,091,000$

\section{Market Capitalization of Circuit World based on EFFICIENT PEERS $\$ 24,592$ thousand}

Thus it seems that Circuit World is undervalued

\section{VALUATION ANALYSIS FOR C-MAC INDUSTRIES INC (SIC3600)}

\begin{tabular}{|c|c|c|c|c|c|c|c|}
\hline $\begin{array}{l}\text { DMU } \\
\#\end{array}$ & Score & $\begin{array}{l}\text { Market Cap } \\
\$(000 s)\end{array}$ & 7 & 27 & 68 & \multicolumn{2}{|c|}{76 distance } \\
\hline 73 C-MAC INDI & 0.81714 & 291 & 0.2203 & 0.1599 & 0.0588 & 0.5610 & 0.0000 \\
\hline 7 CAMCO INC & 1 & 100,000 & 1.0000 & 0.0000 & 0.0000 & 0.0000 & 0.9518 \\
\hline 27 MITEL CORI & 1 & $1,257,378$ & 0.0000 & 1.0000 & 0.0000 & 0.0000 & 1.0725 \\
\hline 68 CELESTICA & 1 & $2,854,867$ & 0.0000 & 0.0000 & 1.0000 & 0.0000 & 1.2747 \\
\hline 76 LEITCH TEC & 1 & $1,031,559$ & 0.0000 & 0.0000 & 0.0000 & 1.0000 & 0.2702 \\
\hline
\end{tabular}

MV range $\$ 100$ million to $\$ 1$ billion, based on peers Leitch and Camco

Upper bound:

$\$ 969,673$ thousand 


\section{COM DEV INTERNATIONAL LTD \& DANBEL (SIC3600)}

\begin{tabular}{|c|c|c|c|c|c|c|}
\hline \multirow{2}{*}{$\begin{array}{l}\text { DMU } \\
\text { \# }\end{array}$} & \multirow[t]{2}{*}{ Score } & \multicolumn{5}{|c|}{ Market Ca| Efiicient Peers } \\
\hline & & $\$(000 s)$ & 7 & 67 & & Jistance \\
\hline 37 COM DEV & 0.86326 & 252,315 & 0.0824 & 0.1168 & 0.8008 & 0.0000 \\
\hline 51 SR TELECO & 0.44695 & 112,897 & 0.1363 & 0.4192 & 0.4445 & 0.2213 \\
\hline 80 BLUESTAR & 0.55479 & 44,404 & 0.0926 & 0.8695 & 0.0379 & 1.1486 \\
\hline 54 TEKLOGIX I & 0.80991 & 243,501 & 0.0755 & 0.8796 & 0.0449 & 1.1533 \\
\hline 7 CAMCO INC & 1 & 100,000 & 1.0000 & 0.0000 & 0.0000 & 1.4969 \\
\hline 67 PRIMETECr & 1 & 143,365 & 0.0000 & 1.0000 & 0.0000 & 1.4281 \\
\hline 76 LEITCH TEC & 1 & $1,031,559$ & 0.0000 & 0.0000 & 1.0000 & 0.0601 \\
\hline
\end{tabular}

Two peers: Leitch and SR Tel

Market value range: $\$ 112,897,000$ to $\$ 1,031,559,000$

Upper bound estimate:

$\$ 851,037$ thousand

\section{DANBEL INDUSTRIES CORPORATION (SIC3600)}

\begin{tabular}{|c|c|c|c|c|c|c|c|}
\hline \multirow{2}{*}{$\begin{array}{l}\text { DMU } \\
\#\end{array}$} & \multirow[t]{2}{*}{ Score } & \multicolumn{6}{|c|}{ Market Cał Efricient Peers } \\
\hline & & $\$(000 s)$ & 5 & 17 & 42 & \multicolumn{2}{|c|}{44 distance } \\
\hline 11 DANBEL INI & 0.75534 & 5,798 & 0.0556 & 0.6210 & 0.3099 & 0.0135 & 0.0000 \\
\hline 5 GLOBAL TH & 1 & 13,222 & 1.0000 & 0.0000 & 0.0000 & 0.0000 & 1.3737 \\
\hline 66 CIRCUIT WK & 0.75253 & 289 & 0.4312 & 0.4006 & 0.1531 & 0.0151 & 0.2142 \\
\hline 17 AASTRA TE & 1 & 46,091 & 0.0000 & 1.0000 & 0.0000 & 0.0000 & 0.2429 \\
\hline 42 FIFTY-PLUS & 1 & 2,404 & 0.0000 & 0.0000 & 1.0000 & 0.0000 & 0.8652 \\
\hline 44 INTERNATIC & 1 & 3,893 & 0.0000 & 0.0000 & 0.0000 & 1.0000 & 1.4579 \\
\hline
\end{tabular}

In terms of distance, Danbel is nearest Circuit, then Aastra, then Fifty In terms of efficiency score it is closest to Circuit

Range for market cap. $\$ 289,000$ to $\$ 46,091,000$

Market Capitalization of DANBEL based on EFFICIENT PEERS $\$ 30,156$ thousand 


\section{COMPRESSION \& ENCRYPTION TECH (SIC3600)}

\begin{tabular}{|c|c|c|c|c|c|c|c|}
\hline $\begin{array}{l}\text { DMU } \\
\#\end{array}$ & Score & $\begin{array}{l}\text { Market CaI } \\
\$(000 s)\end{array}$ & ance & $\begin{array}{r}\text { ient } \\
42\end{array}$ & 60 & 62 & 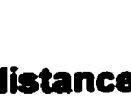 \\
\hline 81 COMPRESS & 0.31046 & 717 & 0.0000 & 0.9716 & 0.0131 & 0.0153 & 0.0000 \\
\hline 71 SHELLCASE & $8.47 E-02$ & 15,698 & 0.0274 & & 0.0113 & 0.1332 & 0.0274 \\
\hline 63 STRATEGIC & 0.53425 & 1,720 & 0.1251 & & & 0.2359 & \\
\hline 56 & 0.21119 & 12,193 & 0.0752 & .7477 & & 0.1320 & 0.0752 \\
\hline 46 MARATHON & 0.6045 & 623 & 0.0452 & 0.8016 & & 0.0699 & 0.045 \\
\hline 31 TRAD & 0.67621 & 9,700 & 0.4024 & 0.4601 & 0. & 0.2002 & 0.4024 \\
\hline TECHA & 0.67662 & 1,027 & 0.0047 & 0.9156 & 0.0 & 0.0428 & 0.0047 \\
\hline 42 FIFTY-PLUS & 1 & 2.404 & 0.0012 & 1.0000 & 0.0000 & 0.0000 & 0.001 \\
\hline 60 PACIFIC E-L & 1 & 3,878 & 1.9182 & 0.0000 & 1.0000 & 0.0000 & 1.91 \\
\hline 62 SNIF SECUI & 1 & 307 & 1.9138 & 0.0000 & 0.0000 & 1.0000 & 1.913 \\
\hline
\end{tabular}

Ranking, according to the distances that are less than 1 (for COMPRESSION):

$\begin{array}{lrrr}\text { COMPRESS } & 0.31046 & 717 & 0.0000 \\ \text { FIFTY-PLUS } & 1 & 2,404 & 0.0012 \\ \text { BCS TECHN } & 0.67662 & 1.027 & 0.0047 \\ \text { SHELLCASE } 8.47 E-02 & 15,698 & 0.0274 \\ \text { MARATHON } & 0.6045 & 623 & 0.0452 \\ \text { TSI TELSYS } & 0.21119 & 12,193 & 0.0752 \\ \text { STRATEGIC } & 0.53425 & 1,720 & 0.1251 \\ \text { TRADE WN } & 0.67621 & 9,700 & 0.4024\end{array}$

Similarity of the efficiency scores (difierence between COMPRESSION's score):

$\begin{array}{lrrr}\text { SHELLCASE 8.47E-02 } & 15,698 & 0.0274 \\ \text { TSI TELSYS } & 0.21119 & 12,193 & 0.0752 \\ \text { COMPRESS } & 0.31046 & 717 & 0.0000 \\ \text { STRATEGIC } & 0.53425 & 1,720 & 0.1251 \\ \text { MARATHON } & 0.6045 & 623 & 0.0452 \\ \text { TRADE WNN } & 0.67621 & 9.700 & 0.4024 \\ \text { BCS TECHN } & 0.67662 & 1.027 & 0.0047 \\ \text { FIFTY-PLUS } & 1 & 2,404 & 0.0012\end{array}$

Similarity of the Market Cap. (difference between COMPRESSION's market cap.):

$\begin{array}{lrrr}\text { MARATHON } & 0.6045 & 623 & 0.0452 \\ \text { COMPRESS } & 0.31046 & 717 & 0.0000 \\ \text { BCS TECHN } & 0.67662 & 1,027 & 0.0047 \\ \text { STRATEGIC } & 0.53425 & 1,720 & 0.1251 \\ \text { FIFTY-PLUS } & 1 & 2,404 & 0.0012 \\ \text { TRADE WIN } & 0.67621 & 9,700 & 0.4024 \\ \text { TSI TELSYS } & 0.21119 & 12,193 & 0.0752 \\ \text { SHELLCASE8.47E-02 } & 15,698 & 0.0274\end{array}$

Range for COMPRESSION's market cap. based on peer group is $\$ 623,000$ to $\$ 15,698,000$

Market Capitalization of COMPRESSION based on EFFICIENT PEERS $\$ 2,391$ thousand 


\section{VALUATION ANALYSIS FOR CORECO INC (SIC3600)}

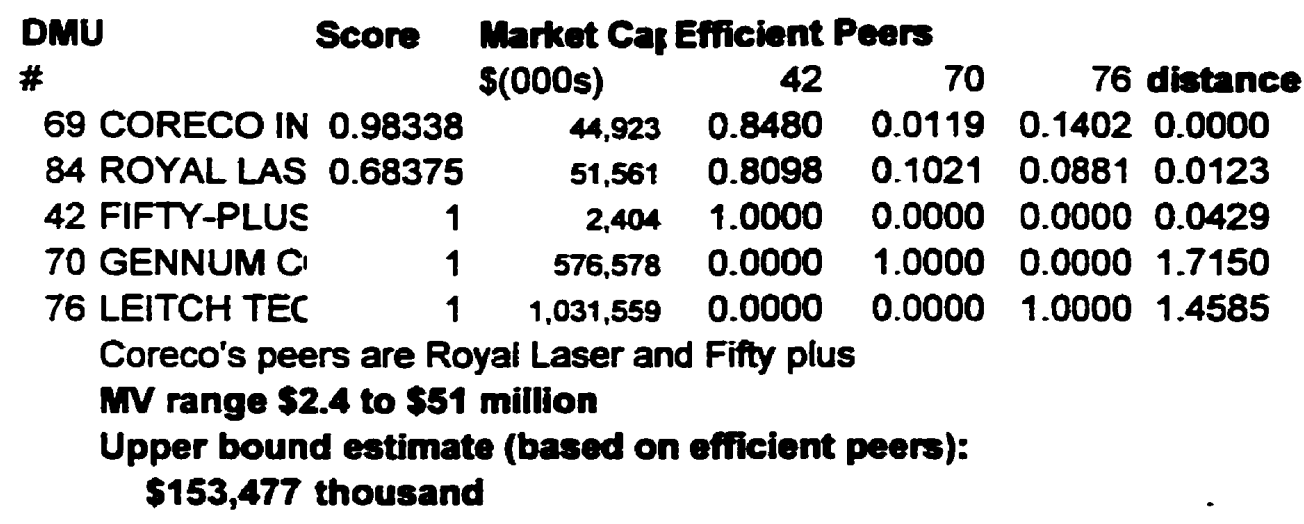

\begin{tabular}{|c|c|c|c|c|c|c|}
\hline \\
\hline \multicolumn{7}{|c|}{$\begin{array}{l}\text { ROYAL LASER TECH CORP (SIC3600) } \\
\text { DMU Score Market Caf Efficient Pe }\end{array}$} \\
\hline \# & & $\$(000 s)$ & 42 & 70 & 76 & distance \\
\hline 84 ROYAL LAS & 0.68375 & 51,561 & 0.8098 & 0.1021 & 0.0881 & 0.0000 \\
\hline 69 CORECO IN & 0.98338 & 44,923 & 0.8480 & 0.0119 & 0.1402 & 0.0123 \\
\hline 42 FIFTY-PLUS & 1 & 2.404 & 1.0000 & 0.0000 & 0.0000 & 0.0544 \\
\hline 70 GENNUM C & 1 & 576,578 & 0.0000 & 1.0000 & 0.0000 & 1.4697 \\
\hline 76 LEITCH TEC & 1 & $1,031,559$ & 0.0000 & 0.0000 & 1.0000 & 1.4977 \\
\hline
\end{tabular}

\begin{tabular}{|c|c|c|c|c|c|c|c|}
\hline DMU & Score & Market Ca: & ficient & iers: & & & ygnal \\
\hline \# & & $\$(000 s)$ & 30 & 32 & 38 & 76 & dista \\
\hline 39 CYGNAL TE & 0.58919 & 8,637 & 0.0242 & 0.6881 & 0.2612 & 0.0265 & 0.0000 \\
\hline 61 SIERRA WIF & 0.99635 & 32,735 & 0.0052 & 0.2631 & 0.6358 & 0.0959 & 0.3260 \\
\hline 30 RESEARCH & 1 & 585,308 & 1.0000 & 0.0000 & 0.0000 & 0.0000 & 1.4945 \\
\hline 32 TS TELECO & 1 & 11,832 & 0.0000 & 1.0000 & 0.0000 & 0.0000 & 0.1668 \\
\hline 38 & 1 & 3,855 & 0.0000 & 0.0000 & 1.0000 & 0.0000 & 1.0205 \\
\hline 76 LEITCH TEC & 1 & $1,031,559$ & 0.0000 & 0.0000 & 0.0000 & 1.0000 & 1.4899 \\
\hline
\end{tabular}

Cygnal is similar to Sierra and TS telecom in terms of distance

Therefore, market value range: $\$ 11,832,000$ to $\$ 32,735,000$

UPPER BOUND:

Market Capitalization of CYGNAL based on EFFICIENT PEERS $\$ 50,650$ thousand

Sierra

distance

SIERRA WIRELESS, INC (SIC3600)

0.32603

Sierra is similar to Comm, Cygnal and TS telecom

Market range $\$ 3,855,000$ to $\$ 11,832,000$

1.47229

UPPER BOUND:

0.9564

Market Capitalization of SIERRA based on EFFICIENT F 0.21112 $\$ 107,529$ thousand

1.29087 


\section{DBA (SIC 3600)}

\begin{tabular}{|c|c|c|c|c|c|c|c|}
\hline \multirow{2}{*}{$\begin{array}{l}\text { DMU } \\
\text { \# } \\
22 \text { DBA TELEC }\end{array}$} & \multirow{2}{*}{$\begin{array}{l}\text { Score } \\
0.63987\end{array}$} & \multicolumn{2}{|c|}{$\begin{array}{l}\text { Market Ca! Distance } \\
\$(000 s)\end{array}$} & \multicolumn{2}{|c|}{ Efficient Peers: } & \multicolumn{2}{|c|}{60 Distance } \\
\hline & & 1,956 & 0.0000 & 1457 & 4501 & 0.01040 & 0.00000 \\
\hline 18 ABL CANAD & & 13. & 0.3590 & & 14 & & \\
\hline 13 & & 0 & 017 & 77 & 56 & & \\
\hline 12 & & 9 & .0261 & & & & \\
\hline SRC & & 4.979 & 0.0286 & & & & \\
\hline $64 s$ & 0.56217 & 5,879 & 0.0255 & 0.01430 & 0.9 & 0.08020 & 0.02549 \\
\hline 32 TS TELECO & 1 & 11,832 & 1.4459 & 1.00000 & 0.00000 & 0.00000 & 1.44591 \\
\hline 42 & 1 & & & 0.00000 & 1.00000 & 0.00000 & 0.04503 \\
\hline E-L & 1 & 3,878 & 1.7142 & 0.00000 & 0.00000 & 1.00000 & 1.71425 \\
\hline
\end{tabular}

Ranking, according to the distances that are less than 1 (for DBA):

$\begin{array}{lrrr}\text { DBA TELEC } & 0.63987 & 1,956 & 0.0000 \\ \text { TIR SYSTEN } & 0.65569 & 1,710 & 0.0017 \\ \text { SYMPLEX C } & 0.56217 & 5,879 & 0.0255 \\ \text { AWNA TECH } & 0.84726 & 2,429 & 0.0261 \\ \text { TRIPLE CRC } & 0.52596 & 4,979 & 0.0286 \\ \text { FIFIY-PLUS } & 1 & 2,404 & 0.0450 \\ \text { ABL CANAD } & 0.39914 & 13,382 & 0.3590\end{array}$

Similarity of the efficiency scores (difference between DBA's score):

$\begin{array}{lrrr}\text { ABL CANAD } & 0.39914 & 13,382 & 0.3590 \\ \text { TRIPLE CRC } & 0.52596 & 4,979 & 0.0286 \\ \text { SYMPLEX C } & 0.56217 & 5,879 & 0.0255 \\ \text { DBA TELEC } & 0.63987 & 1,956 & 0.0000 \\ \text { TIR SYSTEN } & 0.65569 & 1,710 & 0.0017 \\ \text { AWVA TECH } & 0.84726 & 2,429 & 0.0261 \\ \text { FIFTY-PLUS } & 1 & 2,404 & 0.0450\end{array}$

Similarity of the Market Cap. (difference between DBA's market cap.):

$\begin{array}{lrrr}\text { TIR SYSTEA } & 0.65569 & 1,710 & 0.0017 \\ \text { DBA TELEC } & 0.63987 & 1,956 & 0.0000 \\ \text { FIFTY-PLUS } & 1 & 2,404 & 0.0450 \\ \text { AWNA TECH } & 0.84726 & 2,429 & 0.0261 \\ \text { TRIPLE CRC } & 0.52596 & 4,979 & 0.0286 \\ \text { SYMPLEX C } & 0.56217 & 5,879 & 0.0255 \\ \text { ABL CANAD } & 0.39914 & 13,382 & 0.3590\end{array}$

Range for DBA's market cap. based on peer group is $\$ 1,710,000$ and $\$ 13,382,000$

\section{Market Capitalization of DBA based on EFFICIENT PEERS $\$ 3,782$ thousand}




\section{DIGITAL PROCESSING SYSTEMS INC (SIC3600)}

\begin{tabular}{lrrrrrr}
$\begin{array}{l}\text { DMU } \\
\text { \# }\end{array}$ & Score & $\begin{array}{l}\text { Market Cap } \\
\text { S(000s) }\end{array}$ & 30 & 32 & 76 & \\
& \multicolumn{1}{c}{30} & & & & \\
14 DIGITAL PR & 0.88428 & 28,123 & $3.45 E-03$ & 0.85907 & 0.13748 & 0.00000 \\
30 RESEARCH & 1 & 585,308 & 1 & 0 & 0 & 1.75002 \\
32 TS TELECO & 1 & 11,832 & 0 & 1 & 0 & 0.03877 \\
76 LEITCH TEC & 1 & $1,031.559$ & 0 & 0 & 1 & 1.48196
\end{tabular}

Digital is only similar to TS telecom, minimum of $\$ 11.8$ million

UPPER BOUND:

Market Capitalization of DIGITAL based on EFFICIENT PEERS $\$ 154,005$ thousand

\section{DIMENSIONS WEST ENERGY INC (SIC 3600)}

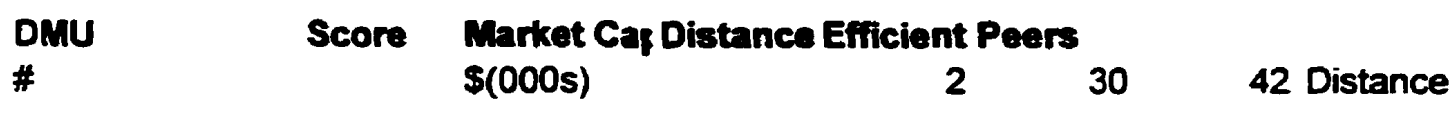

\begin{tabular}{|c|c|c|c|c|c|c|c|}
\hline 40 DIMENSION & 29 & 1,970 & 0.0000 & 0.12335 & 0.00033 & 0.87633 & 1.32805 \\
\hline 36 CELL-LOC II & 0.9803 & 28 & 0.0259 & 0.23449 & 0.00558 & 0.75993 & $0.985 c$ \\
\hline 2 TURBO GEP & 1 & 80,615 & 1.5365 & 1.00000 & 0.00000 & 0.00000 & 0.0387 \\
\hline 30 RESEARCH & 1 & 585,308 & 1.7825 & 0.00000 & 1.00000 & 0.00000 & 1.481 \\
\hline 42 FIFTY-PLUS & 1 & 2,404 & 0.0305 & 0.00000 & 0.00000 & 1.00000 & 1.756 \\
\hline
\end{tabular}

Distance

$\begin{array}{lrrr}\text { DIMENSION } & 0.11029 & 1,970 & 0.0000 \\ \text { CELL-LOC II } & 0.9803 & 28,669 & 0.0259\end{array}$

$\begin{array}{llll}\text { FIFTY-PLUS } & 1 & 2,404 & 0.0305\end{array}$

Efficiency:

DIMENSION $0.11029 \quad 1,970 \quad 0.0000$

CELL-LOC I! $0.9803 \quad 28,669 \quad 0.0259$

$\begin{array}{llll}\text { FIFTY-PLUS } & 1 & 2,404 & 0.0305\end{array}$

Market Value

DIMENSION $0.11029 \quad 1,970 \quad 0.0000$

$\begin{array}{llll}\text { FIFTY-PLUS } & 1 & 2,404 & 0.0305\end{array}$

$\begin{array}{llll}\text { CELL-LOC \| } & 0.9803 & 28,669 & 0.0259\end{array}$

Range for market value $\$ 2,404,000$ to $\$ 28,669,000$

Upper Range

$\$ 12,241$ thousand 


\section{DYNAMIC SIC 3600}

\begin{tabular}{|c|c|c|c|c|c|c|}
\hline $\begin{array}{l}\text { DMU } \\
\#\end{array}$ & \multicolumn{3}{|c|}{$\begin{array}{l}\text { Score Market Caß Distance } \\
\$(000 s)\end{array}$} & \multicolumn{2}{|c|}{$\begin{array}{c}\text { Efficient Peers } \\
2\end{array}$} & 30 Distance \\
\hline 41 DYNAMII & 0.939 & 110.354 & 0.0000 & 0.98275 & 0.01720 & 0.00000 \\
\hline 2 TURBO & 1 & 80,615 & 0.0006 & 1.00000 & 0.00000 & 0.00059 \\
\hline $\begin{array}{l}30 \text { RESEAR } \\
\text { Distance }\end{array}$ & 1 & 585,308 & 1.9317 & 0.00000 & 1.00000 & 1.93169 \\
\hline DYNAMII & 0.939 & 110,354 & 0.0000 & & & \\
\hline TURBO 6 & 1 & 80.615 & 0.0006 & & & \\
\hline $\begin{array}{l}\text { Minimum n } \\
\text { Upper Rar } \\
\$ 89,291 \mathrm{t}\end{array}$ & market & $e$ is $\$ 80$ & 5,000 & & & - \\
\hline
\end{tabular}

\section{VALUATION ANALYSIS FOR EIGER TECHNOLOGY INC (SIC3600)}

\begin{tabular}{|c|c|c|c|c|c|c|c|}
\hline MU & 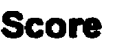 & & Che & & & & \\
\hline \# & & \$(000s) & 7 & 32 & 42 & 60 & Distan \\
\hline 23 EIGER T & 0.815 & $\mathbf{8 , 2 8 9}$ & 0.01070 & 0.17981 & 0.55943 & 0.25006 & 0.00000 \\
\hline 7 CAMCO & 1 & 100,000 & 1.00000 & 0.00000 & 0.00000 & 0.00000 & 1.38654 \\
\hline 32 TS TELE & 1 & 11,832 & 0.00000 & 1.00000 & 0.00000 & 0.0 & 1.04832 \\
\hline 42 FIFTY-PI & 1 & 2,404 & 0.00000 & 0.00000 & 1.00000 & 0.00000 & 0.28908 \\
\hline 60 PACIFIC & 1 & 3,878 & 0.00000 & 0.00000 & 0.00000 & 1.00000 & 0.90782 \\
\hline
\end{tabular}

Eiger is similar to Fifty-plus and Pacific Edink, therefore its market value is between $\$ 2.4$ to 3.9 million

Eiger seems overvalued at $\$ 8$ million

Upper Bound

$\$ 5,512$ thousand

\section{Valuation Analysis for EXI TECHNOLOGIES INC (SIC3600)}

\begin{tabular}{|c|c|c|c|c|c|c|c|}
\hline MU & $s$ & lactot cas & ent $P$ & & & & \\
\hline \# & & $\mathbf{s ( 0 0 0 s )}$ & 30 & 38 & 42 & & Distanc \\
\hline 58 EXI TEC & 0.757 & 9,422 & 0.01170 & 0.22403 & 0.75986 & 0.00443 & 0.00000 \\
\hline SEAR & 1 & 585,308 & 1.00000 & 0.00000 & 0.00000 & 0.00000 & 1.60433 \\
\hline MMUI & 1 & 3,855 & 0.00000 & 1.00000 & 0.00000 & 0.00000 & 1.17967 \\
\hline TY-PI & 1 & 2,404 & 0.00000 & 0.00000 & 1.00000 & 0.00000 & 0.10802 \\
\hline 76 LEITCH $^{-}$ & 1 & $1,031,559$ & 0.00000 & 0.00000 & 0.00000 & 1.00000 & 1.61887 \\
\hline
\end{tabular}

Minimum mv of $\$ 2,404,000$ (one peer)

UPPER BOUND:

Market Capitalization of EXI based on EFFICIENT PEERS

$\$ 14,108$ thousand 


\section{VALUATION ANALYSIS FOR ELECTROHOME LIMITED (SIC3600)}

\begin{tabular}{|c|c|c|c|c|c|c|c|}
\hline $\begin{array}{l}\text { DMU } \\
\text { \# }\end{array}$ & Score & $\begin{array}{l}\text { Market Ca } \\
\text { S(000s) }\end{array}$ & $\begin{array}{l}\text { distance } \\
\text { displayed }\end{array}$ & $\begin{array}{r}\text { Efficient P } \\
7\end{array}$ & cers & & $\begin{array}{l}\text { Distance } \\
\text { (formula) }\end{array}$ \\
\hline 74 ELECTROHC & 0.67333 & 11,398 & 0.00000 & 0.0752 & 0.4257 & 0.4990 & 0.0000 \\
\hline 6 LG TECHNO & 0.586585 & 27,707 & 0.15288 & 0.0060 & 0.7302 & 0.2637 & 0.1529 \\
\hline 1 HAMMOND I & 0.756773 & 18,426 & 0.04998 & 0.2217 & 0.4467 & 0.3315 & 0.0500 \\
\hline 7 CAMCO INC & 1 & 100,000 & 1.28554 & 1.0000 & 0.0000 & 0.0000 & 1.2855 \\
\hline 32 TS TELECOI & 1 & 11,832 & 0.58451 & 0.0000 & 1.0000 & 0.0000 & 0.5845 \\
\hline 34 CALIAN TEC & 0.800142 & 33,191 & 0.05162 & 0.0599 & 0.5935 & 0.3466 & 0.0516 \\
\hline 67 PRIMETECH & 1 & 143,365 & 0.43784 & 0.0000 & 0.0000 & 1.0000 & 0.4378 \\
\hline
\end{tabular}

Similarity of efiiciency scores (Distance of Electrohoome. to):

hammond $\quad-0.083443$

calian $\quad-0.126813$

LG Tech $\quad 0.086745$

prime tech $\quad-0.32667$

TS telecom $\quad-0.32667$

similarity in Market Caps (Electrohome- M.C. minus):

hammond $\quad-7,028$

calian $\quad-21,793$

LG Tech $\quad-16,309$

prime tech $-131,967$

TS telecom $\quad-435$

Range for Electrohome market cap based on peer groups is $\$ 11,832,000$ to $\$ 33,191,000$ And Electrohomes real market cap. of $\$ 11,398,000$ falls below this range

UPPER BOUND:

Market Capitalization of ELECTROHOME based on EFFICIENT PEERS Looks like:[(0.075*100,000)+(0.43*11,832)+(0.5*143,365)]

$\$ 84,103$ thousand 


\section{GEMSTAR COMMUNICATIONS INC (SIC 3600)}

\begin{tabular}{|c|c|c|c|}
\hline Score & Market C. & stance & ifficient Peers \\
\hline$\#$ & $S(000 s)$ & & 42 Distance \\
\hline 43 GEMSTAR CC 0.2324 & 4,888 & 0.0000 & 0.01180 .98820 .0000 \\
\hline 48 SENSE TECH 0.3741 & 61,221 & 0.0452 & $\begin{array}{lll}0.1621 & 0.8379 & 0.0452\end{array}$ \\
\hline 75 LAMBUS EN 0.7096 & 1,729 & 0.0059 & 0.06600 .93400 .0059 \\
\hline 2 TURBO GEN! & 80,615 & 1.9531 & 1.00000 .00001 .9531 \\
\hline $\begin{array}{l}42 \text { FIFTY-PLUS.I } \\
\text { Distance }\end{array}$ & 2,404 & 0.0003 & 0.00001 .00000 .0003 \\
\hline GEMSTAR CC 0.2324 & 4.888 & 0.0000 & \\
\hline FIFTY-PLUS.I & 2,404 & 0.0003 & \\
\hline LAMBUS EN 0.7096 & 1,729 & 0.0059 & \\
\hline $\begin{array}{l}\text { SENSE TECH } 0.3741 \\
\text { Efficiency: }\end{array}$ & 61,221 & 0.0452 & \\
\hline GEMSTAR CC 0.2324 & 4,888 & 0.0000 & \\
\hline SENSE TECH 0.3741 & 61,221 & 0.0452 & \\
\hline LAMBUS EN 0.7096 & 1,729 & 0.0059 & \\
\hline $\begin{array}{l}\text { FIFTY-PLUS.I } \\
\text { Market Value }\end{array}$ & 2,404 & 0.0003 & \\
\hline LAMBUS EN 0.7096 & 1,729 & 0.0059 & \\
\hline FIFTY-PLUS.I & 2,404 & 0.0003 & \\
\hline GEMSTAR CC 0.2324 & 4,888 & 0.0000 & \\
\hline SENSE TECH 0.3741 & 61.221 & 0.0452 & \\
\hline
\end{tabular}

Range for market value $\$ 1,729,000$ to $\$ 61,221,000$

Upper Range

$\$ 3,327$ thousand

\section{VALUATION ANALYSIS FOR GSI LUMONICS INC (SIC3600)}

\begin{tabular}{|c|c|c|}
\hline $\begin{array}{l}\text { DMU } \\
\text { \# }\end{array}$ & Score & $\begin{array}{l}\text { Market Cap } \\
\text { S(000s) }\end{array}$ \\
\hline
\end{tabular}

$\begin{array}{crrrrrr}82 \text { CSI LUMONII } & 0.9167 & 129,626 & 0.0196 & 0.0135 & 0.9669 & 0.0000 \\ 7 \text { CAMCO INC } & 1 & 100,000 & 1.0000 & 0.0000 & 0.0000 & 1.8962 \\ 68 \text { CELESTICA II } & 1 & 2,854,867 & 0.0000 & 1.0000 & 0.0000 & 1.9084 \\ 76 \text { LEITCH TECI } & 1 & 1.031,559 & 0.0000 & 0.0000 & 1.0000 & 0.0017\end{array}$

Minimum market value of $\$ 1,031,559,000$, based on one peer

Upper bound:

$\$ 1,037,907$ thousand 


\section{VALUATION ANALYSIS - HAMMOND MANUFACTURING (SIC 3600) Based on BCC-I}

\begin{tabular}{|c|c|c|c|c|c|c|c|}
\hline \multirow{2}{*}{$\begin{array}{l}\text { DMU } \\
\#\end{array}$} & \multirow[t]{2}{*}{ Score } & \multirow{2}{*}{\multicolumn{2}{|c|}{$\begin{array}{l}\text { Market I Distance } \\
\text { S(000s) (displayed better) }\end{array}$}} & \multirow{2}{*}{\multicolumn{2}{|c|}{$\begin{array}{c}\text { Efiriciont Peers } \\
7\end{array}$}} & \multirow{2}{*}{\multicolumn{2}{|c|}{$\begin{array}{l}\text { Distance } \\
67 \text { (formula) }\end{array}$}} \\
\hline & & & & & & & \\
\hline 1 HAMMONL & 0.7568 & 18,426 & 0.0000 & 0.2217 & 0.4467 & 0.3315 & 0.0000 \\
\hline 6 LG TECHN & 0.5866 & 27.707 & 0.1315 & 0.0060 & 0.7302 & 0.2637 & 0.1315 \\
\hline 7 CAMCO IN & 1.0000 & 100,000 & 0.9152 & 1.0000 & 0.0000 & 0.0000 & 0.9152 \\
\hline 32 TS TELECI & 1.0000 & 11,832 & 0.4652 & 0.0000 & 1.0000 & 0.0000 & 0.4652 \\
\hline 34 CALIAN TE & 0.8001 & 33,191 & 0.0480 & 0.0599 & 0.5935 & 0.3466 & 0.0480 \\
\hline 67 PRIMETEC & 1.0000 & 143,365 & 0.6956 & 0.0000 & 0.0000 & 1.0000 & 0.6956 \\
\hline 74 ELECTROI & 0.6733 & 11,398 & 0.0500 & 0.0752 & 0.4257 & 0.4990 & 0.0500 \\
\hline
\end{tabular}

Accordingly, Hammond is closest to (in distance):
CALIAN TE $\quad 0.0480$
ELECTROI $\quad 0.0500$
LG TECHN $\quad 0.1315$
TS TELECI $\quad 0.4652$
PRIMETEC $\quad 0.6956$
CAMCO IN $\quad 0.9152$

Similarity of efficiency scores (Hammond to):

Calian $\quad-0.0434$

Electrohorr $\quad 0.0834$

LG Tech $\quad 0.1702$

TS $\quad-0.2432$

Primetech $\quad-0.2432$

Camco $\quad-0.2432$

Similarity in Market Caps (Hammond M.C. minus):

$\begin{array}{lr}\text { Calian } & -14,765 \\ \text { Electrohor } & 7,028 \\ \text { LG Tech } & -9,281 \\ \text { TS } & 6,594 \\ \text { Primetech } & -124,939 \\ \text { Camco } & -81,574\end{array}$

Range for Hammonds market cap based on peer groups is $\$ 11,398,000$ to $\$ 143,365,000$

Ignoring the two biggest companies, which are least similar to Hammond in terms of distance and efficiency score, the range for Hammonds market cap is $\$ 11,398,000$ to $\$ 33,191,000$ Hammond's real market cap. of $\$ 18,426,000$ falls right between this range

\section{UPPER BOUND CALCULATION:}

Looks like: $[(0.22 * 100,000)+(0.45 * 11,832)+(0.33 * 143,365)]$

$\$ 74,988$ thousand 


\section{Valuation Analysis of INVERPOWER (SIC 3600)}

\begin{tabular}{|c|c|c|c|c|c|c|c|}
\hline DMU & Score & Market & istan & sien & ars & & nietane \\
\hline \# & & $\$(000 s)$ & $\begin{array}{l}\text { (displayex } \\
\text { better) }\end{array}$ & 30 & 32 & 12 & ? \\
\hline 3 & 0 & 7,179 & 0.00000 & 0.0116 & 0.9208 & 0.0676 & 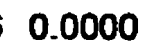 \\
\hline 9 AVANTE T & 0.583 & 2,302 & 1.63547 & 0.0028 & 0.0210 & 0.9763 & 1.6355 \\
\hline 30 RESEARC & 1 & 85,308 & 1.82945 & 1.0000 & 0.0000 & 0.0000 & 1.8295 \\
\hline 32 TS TELEC & 1 & .832 & 197 & 0.0000 & 1.0000 & 0.0000 & 0.0110 \\
\hline 33 ADVANTE & 04 & 19,928 & 1.38339 & 0.0117 & 0.0891 & 0.8992 & 1.3834 \\
\hline 42 FIFTY-PLL & 1 & 2,404 & 1.71745 & 0.0000 & 0.0000 & 1.0000 & 1.7175 \\
\hline $45 K$ & 949 & 23,569 & 0.03893 & 0.1130 & 0.7617 & 0.1253 & 0.0389 \\
\hline 65 WI-LAN IN & 0.8732 & 329,339 & 1.12221 & 0.0359 & 0.1599 & 0.8042 & 1.1222 \\
\hline 77 PLAII & & 14,946 & 0.30786 & 0.0884 & 0.4958 & 0.4159 & 0.3079 \\
\hline & & 2,426 & 1.54824 & 0.0032 & & & 1.5482 \\
\hline 851 & 0 & 17,083 & 1.67913 & 0.0088 & 0.0060 & 0.9853 & 1.6791 \\
\hline
\end{tabular}

Ranking, according to the distances that are less than 1 (for INVERPOWER):

TS Telecor 0.011

Kasten $\quad 0.039$

Plaintree $\quad 0.31$

Similarity of the efficiency scores (difference between INVERPOWER's score (0.545):

TS Telecol -0.455

Kasten $\quad-0.45$

Plaintree $\quad-0.322$

INVERPOWER CONTROLS LTD's efficiency score is not close to the efficiency score of it's peers

Similarity of the Market Cap. (difference between INVERPOWER's market cap.):

TS Telecol $4,653(7,179-11,832)$

Kasten $\quad-16,390(7,179-23,569)$

Plaintree $\quad-7,767(7,179-14,946)$

Range for INVERPOWER's market cap. based on peer group is $\$ 11,832,000$ to $\$ 23,569,000$ INVERPOWER CONTROLS LTD real market cap of $\$ 7,179,000$ falls below this range

\section{Market Capitalization of INVERPOWER based on EFFICIENT PEERS}

$\left[\left(0.0116^{*} 585,308\right)+(0.92 * 11,832)+(0.0676 * 2,404)\right.$

is $\$ 17,8<$ thousand 


\section{KASTEN CHASE APPLIED RESEARCH INC (SIC 3600)}

\section{Based on BCC-I for public company}

\begin{tabular}{|c|c|c|c|c|c|c|c|}
\hline DMu & Score & arket & tar & Efficien & eers & & stance \\
\hline \# & & $\$(000 s)$ & displayec & 30 & 32 & 42 & Formula \\
\hline 45 KASTEN CHA & 0.9949 & 23,569 & 0.00000 & 0.1130 & 0.7617 & 0.1253 & 0.0000 \\
\hline 33 ADVANTEDG & 0.1804 & 19,928 & 1.06163 & 0.0117 & 0.0891 & 0.8992 & 1.0616 \\
\hline 9 AVANTE TEC & 0.5830 & 2.302 & 1.28496 & 0.0028 & 0.0210 & 0.9763 & 1.2850 \\
\hline 3 INVERPOWEI & 0.5446 & 7.179 & 0.03893 & 0.0116 & 0.9208 & 0.0676 & 0.0389 \\
\hline 30 RESEARCH II & 1.0000 & 585,308 & 1.38267 & 1.0000 & 0.0000 & 0.0000 & 1.3827 \\
\hline 32 TS TELECOM & 1.0000 & 11.832 & 0.08525 & 0.0000 & 1.0000 & 0.0000 & 0.0852 \\
\hline 42 FIFTY-PLUS.l & 1.0000 & 2,404 & 1.35809 & 0.0000 & 0.0000 & 1.0000 & 1.3581 \\
\hline 65 W-LAN INC & 0.8732 & 329,339 & 0.82904 & 0.0359 & 0.1599 & 0.8042 & 0.8290 \\
\hline 77 PLAINTREE $\subseteq$ & 0.8663 & 14.946 & 0.15575 & 0.0884 & 0.4958 & 0.4159 & 0.1557 \\
\hline 83 NEXTRON CC & 0.5345 & 2,426 & 1.20819 & 0.0032 & 0.0452 & 0.9516 & 1.2082 \\
\hline 85 WE X.L. HOLI & 0.9437 & 17,083 & 9.32157 & 0.0088 & 0.0060 & 0.9853 & 1.3216 \\
\hline
\end{tabular}

Ranking, according to the distances that are less than 1 (for KASTEN):

$\begin{array}{ll}\text { Inverpower } & 0.0389 \\ \text { Ts Telecom } & 0.0852 \\ \text { Plaintree } & 0.1557 \\ \text { Wi-Lan } & 0.8290\end{array}$

Similarity of the efficiency scores (difference between KASTEN score (0.18):

$\begin{array}{lr}\text { Inverpower } & 0.4502 \\ \text { Ts Telecom } & -0.0051 \\ \text { Plaintree } & 0.1285 \\ \text { Wi-Lan } & 0.1217\end{array}$

KASTEN's efficiency score is very close to that of TS telecom

Similarity of the Market Cap. (difference between KASTEN's market cap. $(\$ 19,928,000)$ :

Inverpower $\quad 16390.18$

Ts Telecom $\quad 11736.78$

Plaintree $\quad 8623.08$

Wi-Lan $\quad-305770.09$

Range for KASTEN's market cap. based on peer group is between $\$ 7,179,000$ and $\$ 329,339,000$ KASTEN's real market cap of $\$ 23,569,000$ falls between this range. Ignoring the biggest market cap. company in the peer group (Wi-Lan), the range is between $\$ 7,179$ and $\$ 14,946$ million

KASTEN seems either slightly overvalued when one examines the market cap., however it is perform near the efficient frontier, with an efficiency score of 0.99 , thus it may well be undervalued

Market Capitalization of KASTEN based on EFFICIENT PEERS

$\left[(0.11 * 585,308)+\left(0.76^{* 11}, 832\right)+(0.13 * 2,404)\right.$

is $\$ 75,454$ thousand 


\section{Valuation Analysis of KING PRODUCTS INC (SIC3600)}

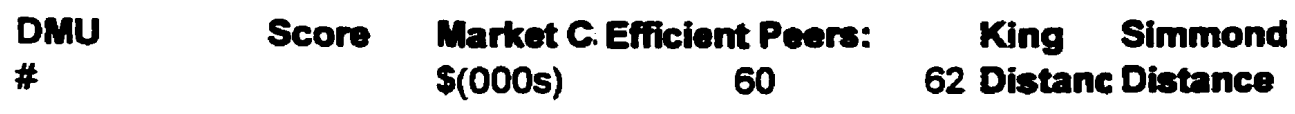

$\begin{array}{lrrrrrr}24 \text { KING PRC } & 0.47195 & 7.739 & 0.214263 & 0.785737 & 0 & 0.8025 \\ \text { 60 PACIFICE } & 1 & 3,878 & 1 & 7.15 E-16 & 1.2348 & 0.0464 \\ \text { 49 SIMMOND } & 0.76631 & 2,854 & 0.847691 & 0.152309 & 0.8025 & 0 \\ \text { 62 SNIF SECI } & 1 & 307 & 1.62 E-18 & 1 & 0.0918 & 1.4372\end{array}$

King is most similar to Simmonds and Snif security, therefore its market value ranges from $\$ 307,000$ to $\$ 2,854,000$

UPPER BOUND:

Market Capitalization of KING based on EFFICIENT PEERS

$\$ 1,072$ thousand

King is overvalued according to its peers

\section{Valuation Analysis of SIMMONDS CAPITAL LIMITED (SIC3600)}

Simmond is closest to King and Pacific E-link

Market value range is $\$ 3.8$ to $\$ 7.7$ million

Market Capitalization of SIMMOND based on EFFICIENT PEERS

$\$ 3,334$ thousand

Simmond is undervalued according to its peers

\section{MICROCELL TELECOMMUNICATIONS INC (SIC3600)}

$\begin{array}{lrrrrr}\begin{array}{l}\text { DMU } \\ \text { \# }\end{array} & \text { Score } & \begin{array}{l}\text { Market Cap } \\ \text { S(000s) }\end{array} & 7 & 60 \text { distance } \\ \text { 26 MICROCE } & 6.64 E-02 & 307,087 & 0.184519 & 0.815481 & 0 \\ 7 \text { CAMCO IN } & 1 & 100,000 & 1 & 0 & 1.33 \\ \text { 60 PACIFIC E } & 1 & 3,878 & 0 & 1 & 0.0681\end{array}$

Microcell is at least $\$ 3,878,000$, based on its one peer.

Upper bound

$\$ 21,615$ thousand 


\section{LAMBUS ENTERPRISES INC (SIC 3600)}

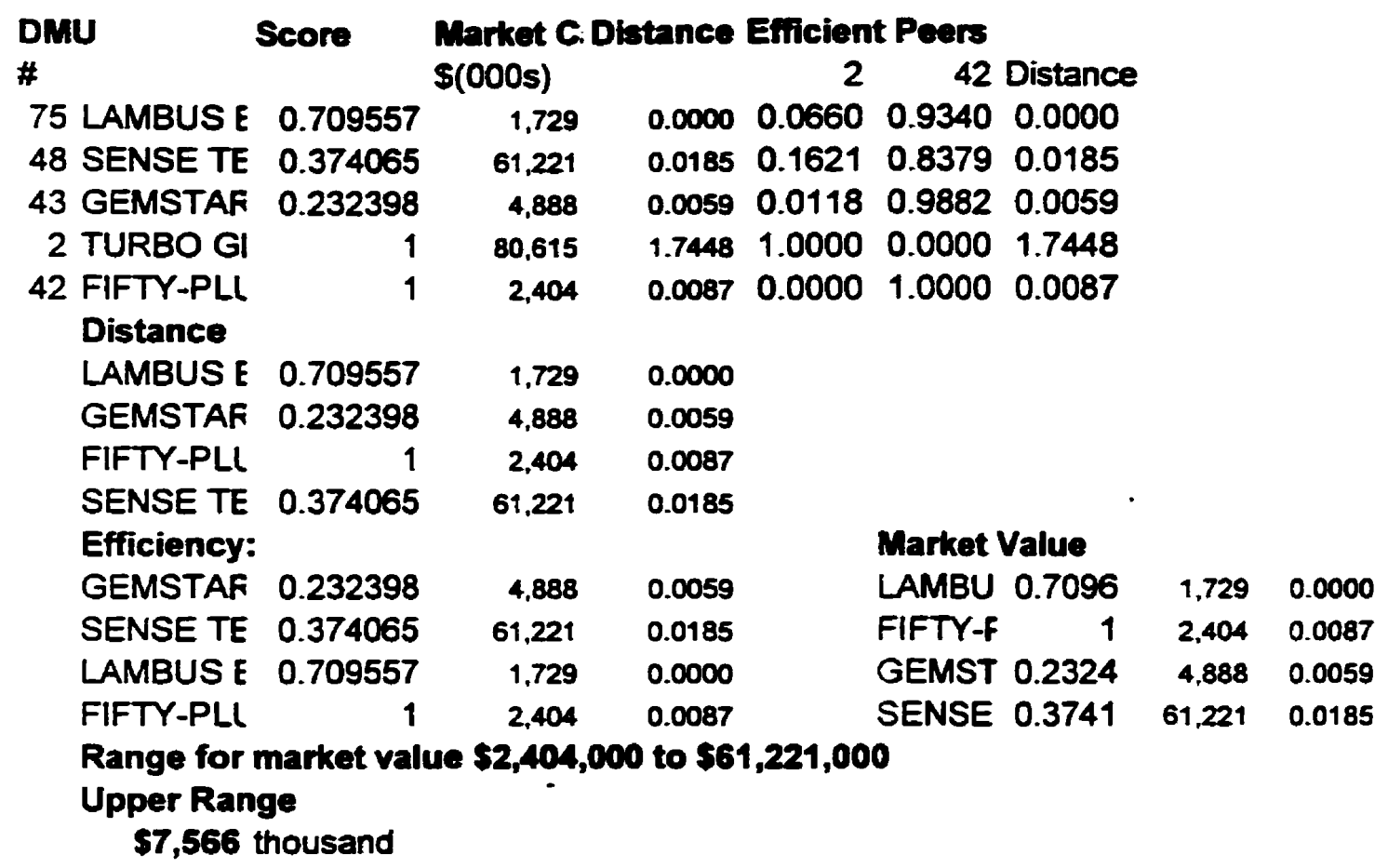

\begin{tabular}{|c|c|c|c|c|c|c|c|}
\hline \multicolumn{8}{|c|}{ FOR LG TECHNOLOGIES GROUP INC (6) } \\
\hline DMU & Score & Market C. & Distance & Efricien & It Peers & & Uistice \\
\hline \# & & $\$(000 s)$ & (displayed & 7 & 32 & 67 & (formula) \\
\hline 6 LG TECHA & 0.586585 & 27,707 & 0.00000 & 0.0060 & 0.7302 & 0.2637 & 1.4640 \\
\hline 1 HAMMONI & 0.756773 & 18,426 & 0.13148 & 0.2217 & 0.4467 & 0.3315 & 0.8169 \\
\hline 7 CAMCO IN & 1 & 100,000 & 1.59077 & 1.0000 & 0.0000 & 0.0000 & 0.0044 \\
\hline 32 TS TELEC & 1 & 11,832 & 0.14237 & 0.0000 & 1.0000 & 0.0000 & 1.8724 \\
\hline 34 CALIAN TI & 0.800142 & 33,191 & 0.02846 & 0.0599 & 0.5935 & 0.3466 & 1.2365 \\
\hline 67 PRIMETEC & 1 & 143,365 & 1.07534 & 0.0000 & 0.0000 & 1.0000 & 1.8724 \\
\hline 74 ELECTRO & 0.67333 & 11,398 & 0.15288 & 0.0752 & 0.4257 & 0.4990 & 1.1679 \\
\hline
\end{tabular}

Accordingly, LG TECH is closest to (in distance):

CALIAN TI 0.02846

HAMMONI 0.13148

TS TELEC $\quad 0.14237$

ELECTRO 0.15288

PRIMETEC 1.07534 (VALUES greater than one are ignored the analysis)

CAMCO IN 1.59077

Similarity of efficiency scores (LG TECH. to): Similarity in Market Caps:

Calian $\quad-0.213557$

Electrohon -0.086745

Calian $-5,484$

Electrot 16,309

TS telecon -0.413415

TS telec 15,875

Hammond -0.170187

Hammo 9,281

Range for LG TECH's market cap based on peer groups is $\$ 11,398,000$ to $\$ 33,191,000$

UPPER BOUND CALCULATION:

$\$ 47,055$ thousand 


\section{MARATHON FOODS INC (SIC 3600)}

\begin{tabular}{|c|c|c|c|c|c|c|c|}
\hline DMU & Score & art & tance & icient $f$ & ers: & & \\
\hline \# & & $\$(000 s)$ & & 42 & 60 & 62 & distance \\
\hline 46 MARATHC & 0.604497 & 623 & 0.0000 & 0.80157 & 0.128525 & 6.99E-02 & 0.0000 \\
\hline 31 TRADE $M$ & 0.676206 & 9,700 & 0.1781 & 0.46014 & 0.339707 & 0.200154 & 0.1781 \\
\hline 19 BCS TECF & 0.676619 & 1,027 & 0.0213 & 0.91557 & 4.17E-02 & $4.28 E-02$ & 0.0213 \\
\hline 56 TSI TELSY & 0.211188 & 12,193 & 0.0068 & 0.74767 & 0.120293 & 0.132032 & 0.0068 \\
\hline 63 STRATEG & 0.53425 & 1.720 & 0.0421 & 0.69985 & 6.42E-02 & 0.235936 & 0.0421 \\
\hline 71 SHELLCA! & 8.47E-02 & 15,698 & 0.0207 & 0.85545 & $1.13 E-02$ & 0.133211 & 0.0207 \\
\hline 81 COMPRES & 0.310462 & 717 & 0.0452 & 0.97158 & $1.31 E-02$ & $1.53 E-02$ & 0.0452 \\
\hline 42 FIFTY-PLL & 1 & 2,404 & 0.0608 & 1 & 0 & 0 & 0.0608 \\
\hline 60 PACIFIC E & 1 & 3,878 & 1.4069 & 0 & 1 & 7.15E-16 & 1.4069 \\
\hline 62 SNIF SECI & 1 & 307 & 1.5241 & 0 & 1.62E-18 & 1 & 1.5241 \\
\hline
\end{tabular}

Ranking, according to the distances that are less than 1 (for MARATHON):

$\begin{array}{lrrr}\text { MARATHC } & 0.604497 & 623 & 0.0000 \\ \text { TSI TELSY } & 0.211188 & 12,193 & 0.0068 \\ \text { SHELLCA! } & 8.47 E-02 & 15,698 & 0.0207 \\ \text { BCS TECH } & 0.676619 & 1,027 & 0.0213 \\ \text { STRATEG } & 0.53425 & 1,720 & 0.0421 \\ \text { COMPRES } & 0.310462 & 717 & 0.0452 \\ \text { FIFTY-PLL } & 1 & 2,404 & 0.0608 \\ \text { TRADE W } & 0.676206 & 9,700 & 0.1781\end{array}$

Similarity of the efficiency scores (difference between MARATHON's score):

$\begin{array}{lrrr}\text { SHELLCA: } & 8.47 E-02 & 15,698 & 0.0207 \\ \text { TSI TELSY } & 0.211188 & 12,193 & 0.0068 \\ \text { COMPRES } & 0.310462 & 717 & 0.0452 \\ \text { STRATEG } & 0.53425 & 1,720 & 0.0421 \\ \text { MARATHC } & 0.604497 & 623 & 0.0000 \\ \text { TRADE W } & 0.676206 & 9,700 & 0.1781 \\ \text { BCS TECF } & 0.676619 & 1,027 & 0.0213 \\ \text { FIFTY-PLL } & 1 & 2,404 & 0.0608\end{array}$

Similarity of the Market Cap. (difference between MARATHON's market cap.):

$\begin{array}{lrrr}\text { MARATHC } & 0.604497 & 623 & 0.0000 \\ \text { COMPRES } & 0.310462 & 717 & 0.0452 \\ \text { BCS TECF } & 0.676619 & 1,027 & 0.0213 \\ \text { STRATEG } & 0.53425 & 1,720 & 0.0421 \\ \text { FIFTY-PLL } & 1 & 2,404 & 0.0608 \\ \text { TRADE W } & 0.676206 & 9,700 & 0.1781 \\ \text { TSI TELSY } & 0.211188 & 12,193 & 0.0068 \\ \text { SHELLCA! } & 8.47 E-02 & 15,698 & 0.0207\end{array}$

Range for MARATHON's market cap. based on peer group is $\$ 717,000$ to $\$ 15,698,000$ Marathon seems to be undervalued

Market Capitalization of MARATHON based on EFFICIENT PEERS $\$ 2,447$ thousand 


\section{Valuation Analysis for MEMOTEC (SIC3600)}

\begin{tabular}{|c|c|c|c|c|c|c|}
\hline DMU & Score & Market C. & Efficien & sers & & \\
\hline \# & & $\$(000 s)$ & 32 & 67 & 76 & ce \\
\hline 25 MEMOTEC & 0.6492 & 4,953 & 0.8199 & 0.1655 & 0.0146 & 0.0000 \\
\hline 50 SPECTRU & 0.7867 & 38,637 & 0.8465 & 0.0760 & 0.0775 & 0.0127 \\
\hline 57 WESCAM & 0.6285 & 76,678 & 0.1979 & 0.7437 & 0.0584 & 0.7232 \\
\hline 32 TS TELEC & 1 & 11,832 & 1.0000 & 0.0000 & 0.0000 & 0.0601 \\
\hline 67 PRIMETEC & 1 & 143,365 & 0.0000 & 1.0000 & 0.0000 & 1.3688 \\
\hline 76 LEITCH TE & 1 & $1,031,559$ & 0.0000 & 0.0000 & 1.0000 & 1.6706 \\
\hline
\end{tabular}

Memotec's peers are: Spectrum, TS Tel, and Wescam

Market Value

Range $\$ 11,832,000$ to $\$ 76,678,000$

Upper bound

$\$ 48,488$ thousand

\begin{tabular}{|c|c|c|c|c|c|c|}
\hline DMU & Score & Market C. & Efiticien & Peers & & \\
\hline \# & & $\$(000 s)$ & 32 & 67 & 76 & nce \\
\hline 50 SPECTRU & 0.7867 & 38,637 & 0.8465 & 7.60E-02 & 7.75E-02 & 0.00000 \\
\hline 25 MEMOTEC & 0.6492 & 4,953 & 0.8199 & 0.165499 & 1.46E-02 & 0.01268 \\
\hline 57 WESCAM & 0.6285 & 76,678 & 0.1979 & 0.743748 & 5.84E-02 & 0.86696 \\
\hline 32 TS TELEC & 1 & 11,832 & 1 & 0 & 0 & 0.03535 \\
\hline 67 PRIMETEC & 1 & 143,365 & 0 & 1 & 0 & 1.57633 \\
\hline 76 LEITCH TE & 1 & $1,031,559$ & 0 & 0 & 1 & 1.57333 \\
\hline
\end{tabular}

Spectrum is nearest Memotec, Ts Tel and Wescam

Market Value

Range $\$ 4,953,000$ to $\$ 76,678,000$

Upper bound

$\$ 100,858$ thousand

\section{Valuation Analysis for WESCAM (SIC3600)}

\begin{tabular}{|c|c|c|c|c|c|c|}
\hline DMU & Score & Market C. & Efficien & eers & & \\
\hline$\#$ & & $\$(000 s)$ & 32 & 67 & 76 & \\
\hline 57 WESCAM & 0.6285 & 76,678 & 0.1979 & 0.7437 & 0.0584 & 0.00 \\
\hline 50 SPECTRU & 0.7867 & 38,637 & 0.8465 & 0.0760 & 0.0775 & 0.86 \\
\hline MOTEC & 0.6492 & 4,953 & 0.8199 & 0.1655 & 0.0146 & 0.72 \\
\hline 32 TS TELEC & 1 & 11,832 & 1.0000 & 0.0000 & 0.0000 & 1.20 \\
\hline 67 PRIMETEC & $\uparrow$ & 143,365 & 0.0000 & 1.0000 & 0.0000 & 0.10 \\
\hline 76 LEITCH TE & 1 & $1,031,559$ & 0.0000 & 0.0000 & 1.0000 & 1.47 \\
\hline
\end{tabular}

Wescam is nearest Primetech, Memotec, then Spectrum

Market Value

Range \$4,953,000 to $\$ 143,365,000$

Upper bound

$\$ 169,212$ thousand 


\section{NEXTRON (SIC 3600)}

\begin{tabular}{|c|c|c|c|c|c|c|c|}
\hline$M$ & 6010 & Marke & Diatan & . & & & Dintance \\
\hline & & $\$(000$ & $\begin{array}{l}\text { (displaye } \\
\text { better) }\end{array}$ & 30 & 32 & 42 & \\
\hline 3 NEXTRO & 0.534 & 2,426 & 0.00000 & 0.0032 & 0.0452 & 0.9516 & 000 \\
\hline 7 PLAINTF & 0.866 & 14,946 & 0.49728 & 34 & 358 & & \\
\hline AN I & 0.873 & 19,339 & 94 & 9 & & 242 & 59 \\
\hline RPC & 0.545 & 7,179 & 1.54824 & 6 & 08 & 76 & 182 \\
\hline JTE & 0.583 & 2,302 & 0.00120 & & 10 & 0.9763 & 12 \\
\hline $30 \mathrm{~F}$ & 1 & 585,308 & 1.90112 & 0 & 100 & 000 & 11 \\
\hline 327 & 1 &, 832 & 1.81716 & & & 00 & 172 \\
\hline$-P I$ & 1 & 04 & 40 & & 0.0000 & 1.0000 & 0.0044 \\
\hline 33 & & 19,928 & 0.00474 & & 91 & 92 & 0.0047 \\
\hline $45 k$ & 0.995 & 23,569 & 1.20819 & & & & 082 \\
\hline 85 WE X.L. I & 0.944 & 17,083 & 0.00271 & 0.0088 & 0.0060 & 0.9853 & 0.0027 \\
\hline
\end{tabular}

Ranking, according to the distances that are less than 1 (for NEXTRON):

$\begin{array}{lrrr}\text { NEXTRO } & 0.534 & 2,426 & 0.00000 \\ \text { AVANTE } & 0.583 & 2,302 & 0.00120 \\ \text { WE X.L. I } & 0.944 & 17,083 & 0.00271 \\ \text { FIFTY-PI } & 1 & 2,404 & 0.00440 \\ \text { ADVANT } & 0.18 & 19,928 & 0.00474 \\ \text { WI-LAN I } & 0.873 & 329,339 & 0.03594 \\ \text { PLAINTR } & 0.866 & 14,946 & 0.49728\end{array}$

Similarity of the efficiency scores (difference between NEXTRON's score (0.534):

$\begin{array}{lrrr}\text { ADVANT } & 0.18 & 19,928 & 0.00474 \\ \text { NEXTRO } & 0.534 & 2,426 & 0.00000 \\ \text { AVANTE } & 0.583 & 2,302 & 0.00120 \\ \text { PLAINTF } & 0.866 & 14,946 & 0.49728 \\ \text { WI-LAN I } & 0.873 & 329,339 & 0.03594 \\ \text { WE X.L. I } & 0.944 & 17,083 & 0.00271 \\ \text { FIFTY-PI } & 1 & 2,404 & 0.00440\end{array}$

Similarity of the Market Cap. (difference between NEXTRON's market cap. $(\$ 2, \mathbf{4 2 6 , 0 0 0 ) :}$

AVANTE $0.583 \quad 2,302 \quad 0.00120$

FIFTY-PI $\quad 1 \quad 2,404 \quad 0.00440$

$\begin{array}{llll}\text { NEXTRC } & 0.534 & 2,426 & 0.00000\end{array}$

PLAINTF $0.866 \quad 14,946 \quad 0.49728$

WE X.L. I $0.944 \quad 17,083 \quad 0.00271$

ADVANT $\quad 0.18 \quad 19,928 \quad 0.00474$

WI-LAN I $0.873 \quad 329,339 \quad 0.03594$

Range for NEXTRON's market cap. based on peer group is $\$ 2,302,000$ and $\$ 329,339,000$

NEXTRON's real market cap of $\$ 2,426,000$ is right in this range

Market Capitalization of NEXTRON based on EFFICIENT PEERS

$\$ 4,707$ thousand 


\section{Valuation Analysis for NHC COMMUNICATIONS INC (SIC3600)}

\begin{tabular}{|c|c|c|c|c|c|c|c|}
\hline \multirow{2}{*}{$\begin{array}{l}\text { DMU } \\
\text { \# }\end{array}$} & \multirow[t]{2}{*}{ Score } & \multicolumn{6}{|c|}{ Market C. Efficient Peers: } \\
\hline & & $\$(000 s)$ & 30 & 42 & 44 & & Distance \\
\hline 28 NHC COMN & 0.670855 & 7,317 & 1.32E-02 & 0.92567 & 0.0279 & 3.33E-02 & 0.0000 \\
\hline 30 RESEARCr & 1 & 585,308 & 1 & $6.18 E-16$ & 0 & 0 & 1.8325 \\
\hline 42 FIFTY-PLU! & 1 & 2,404 & 0 & 1 & 0 & 0 & 0.0076 \\
\hline 44 INTERNATI & 1 & 3,893 & 0 & 1.30E-17 & 1 & 0 & 1.8032 \\
\hline 76 LEITCH TEI & 1 & $1,031,559$ & 0 & 0 & 0 & 1 & 1.7923 \\
\hline
\end{tabular}

NHC is only similar to Fifty plus

therefore, minimum range is $\$ 2,404,000$

UPPER BOUND:

Market Capitalization of NHC based on EFFICIENT PEERS

$\$ 44,411$ thousand

\section{Valuation Analysis for NORON TECH LTD (SIC3600)}

\begin{tabular}{|c|c|c|c|c|c|c|}
\hline \multirow{2}{*}{$\begin{array}{l}\text { DMU } \\
\#\end{array}$} & \multirow[t]{2}{*}{ Score } & \multicolumn{5}{|c|}{ Market C. Efficient Peers } \\
\hline & & $\$(000 s)$ & 42 & 62 & \multirow{2}{*}{\multicolumn{2}{|c|}{2 distancDistance }} \\
\hline & & & & & & \\
\hline NOR & 6.53E-02 & 7,029 & 0.98995 & 1.01E-02 & 0.0000 & \\
\hline UE & 1 & 2,404 & 1 & 0 & 0.0002 & 203 \\
\hline 62 SNIF SECU & 1 & 307 & 0 & 1 & 1.9599 & 1.959903 \\
\hline
\end{tabular}

Noron only has Fifty plus close to it in terms of distance, therefore its market value should be near $\$ 2.4$ million

Upper Bound

$\$ 2,383$ thousand

According to the upper bound Noron is overvalued

\section{VALUATION ANALYSIS FOR SEMI-TECH CORPORATION (SIC 3600)}

\begin{tabular}{lrrrrr}
$\begin{array}{l}\text { DMU } \\
\text { \# }\end{array}$ & Score & \multicolumn{2}{c}{$\begin{array}{l}\text { Market Cap } \\
\$(000 s)\end{array}$} & 7 & 68 Distance \\
& & & & & \\
10 SEMI-TECF & 0.214508 & 10,026 & 0.774623 & 0.22538 & 0 \\
7 CAMCO INC & 1 & 100,000 & 1 & 0 & 0.1016 \\
68 CELESTICA & 1 & $2,854,867$ & $2.81 E-16$ & 1 & 1.2001
\end{tabular}

In terms of distance only Camco is close, therefore lower bound of $\$ 100$ million

Upper bound:

$\$ 720,885$ thousand 


\begin{tabular}{|c|c|c|c|c|c|c|c|}
\hline $\begin{array}{l}\text { DMU } \\
\#\end{array}$ & Score & $\begin{array}{l}\text { Market } \\
\$(000 s)\end{array}$ & & 30 & $\begin{array}{r}\text { Peers } \\
32\end{array}$ & 42 & $\begin{array}{l}\text { Distance } \\
\text { Formula }\end{array}$ \\
\hline 77 PLAINTRE & 0.8663 & 14,946 & 0.00000 & 0.0884 & 0.4958 & 0.4159 & 0.0000 \\
\hline 5 W-LAN I & 0.8732 & 329,339 & 0.26639 & 0.0359 & 0.1599 & 0.8042 & 0.2664 \\
\hline 3 INVERPOI & 0.5446 & 7,179 & 0.30786 & 0.0116 & 0.9208 & 0.0676 & 0.3079 \\
\hline 9 AVANTE T & 0.583 & 2,302 & 0.54681 & 0.0028 & 0.0210 & 0.9763 & 0.5468 \\
\hline 30 RESEARC & 1 & 585,308 & 1.24976 & 1.0000 & 0.0000 & 0.0000 & 1.2498 \\
\hline 32 TS TELEC & 1 & 11,832 & 0.43498 & 0.0000 & 1.0000 & 0.0000 & 0.4350 \\
\hline 42 FIFTY-PLL & 1 & 2,404 & 0.59484 & 0.0000 & 0.0000 & 1.0000 & 0.5948 \\
\hline DVAI & 0.1804 & 19,928 & 0.40491 & 0.0117 & 0.0891 & 0.8992 & 0.4049 \\
\hline STEN C & 0.9949 & 23.569 & 0.15575 & 0.1130 & 0.7617 & 0.1253 & 0.1557 \\
\hline EXTRON & 0.5345 & 2,426 & 0.49728 & 0.0032 & 0.0452 & 0.9516 & 0.4973 \\
\hline 85 WE X.L. H & 0.9437 & 17,083 & 0.57049 & 0.0088 & 0.0060 & 0.9853 & 0.5705 \\
\hline
\end{tabular}

Ranking, according to the distances that are less than 1 (for PLAINTREE):

$\begin{array}{lrrr}\text { PLAINTRE } & 0.8663 & 14,946 & 0.00000 \\ \text { KASTEN C } & 0.9949 & 23,569 & 0.15575 \\ \text { WI-LAN IN } & 0.8732 & 329,339 & 0.26639 \\ \text { INVERPOI } & 0.5446 & 7,179 & 0.30786 \\ \text { ADVANTE } & 0.1804 & 19,928 & 0.40491 \\ \text { TS TELEC } & 1 & 11,832 & 0.43498 \\ \text { NEXTRON } & 0.5345 & 2.426 & 0.49728 \\ \text { AVANTE T } & 0.583 & 2.302 & 0.54681 \\ \text { WE X.L. H } & 0.9437 & 17,083 & 0.57049 \\ \text { FIFTY-PLL } & 1 & 2.404 & 0.59484\end{array}$

Similarity of the efficiency scores:

ADVANTE $0.1804 \quad 19.928 \quad 0.40491$

NEXTRON $0.5345 \quad 2,426 \quad 0.49728$

INVERPOI $0.5446 \quad 7.179 \quad 0.30786$

AVANTE T $0.583 \quad 2,302 \quad 0.54681$

PLAINTRE $0.8663 \quad 14,946 \quad 0.00000$

WI-LAN IN $0.8732 \quad 329,339 \quad 0.26639$

WE X.L. H1 $0.9437 \quad 17,083 \quad 0.57049$

KASTEN C $0.9949 \quad 23.569 \quad 0.15575$

$\begin{array}{llll}\text { TS TELEC } & 1 & 11,832 & 0.43498\end{array}$

FIFTY-PLL $\quad 1 \quad 2,404 \quad 0.59484$

Similarity of the Market Cap.:

$\begin{array}{llll}\text { AVANTI } & 0.583 & 2.302 & 0.54681\end{array}$

$\begin{array}{lrrrr}\text { FIFTY-F } & 1 & 2,404 & 0.59484\end{array}$

$\begin{array}{llll}\text { NEXTRI } 0.5345 & 2,426 & 0.49728\end{array}$

$\begin{array}{llll}\text { INVERF } 0.5446 & 7,179 & 0.30786\end{array}$

$\begin{array}{lrrrr}\text { TS TELI } & 1 & 11,832 & 0.43498\end{array}$

PLAINT $0.8663 \quad 14,946 \quad 0.00000$

WE X.L. $0.9437 \quad 17.083 \quad 0.57049$

ADVAN $0.1804 \quad 19,928 \quad 0.40491$

KASTEI $0.9949 \quad 23,569 \quad 0.15575$

WI-LAN $0.8732 \quad 329,339 \quad 0.26639$

Range for PLAINTREE's market cap. based on peer group is $\$ 2,302,000$ and $\$ 329,339,000$

Market Capitalization of PLAINTREE based on EFFICIENT PEERS

$\$ 58,607$ thousand 


\section{SENSE TECHNOLOGIES INC (SIC 3600)}

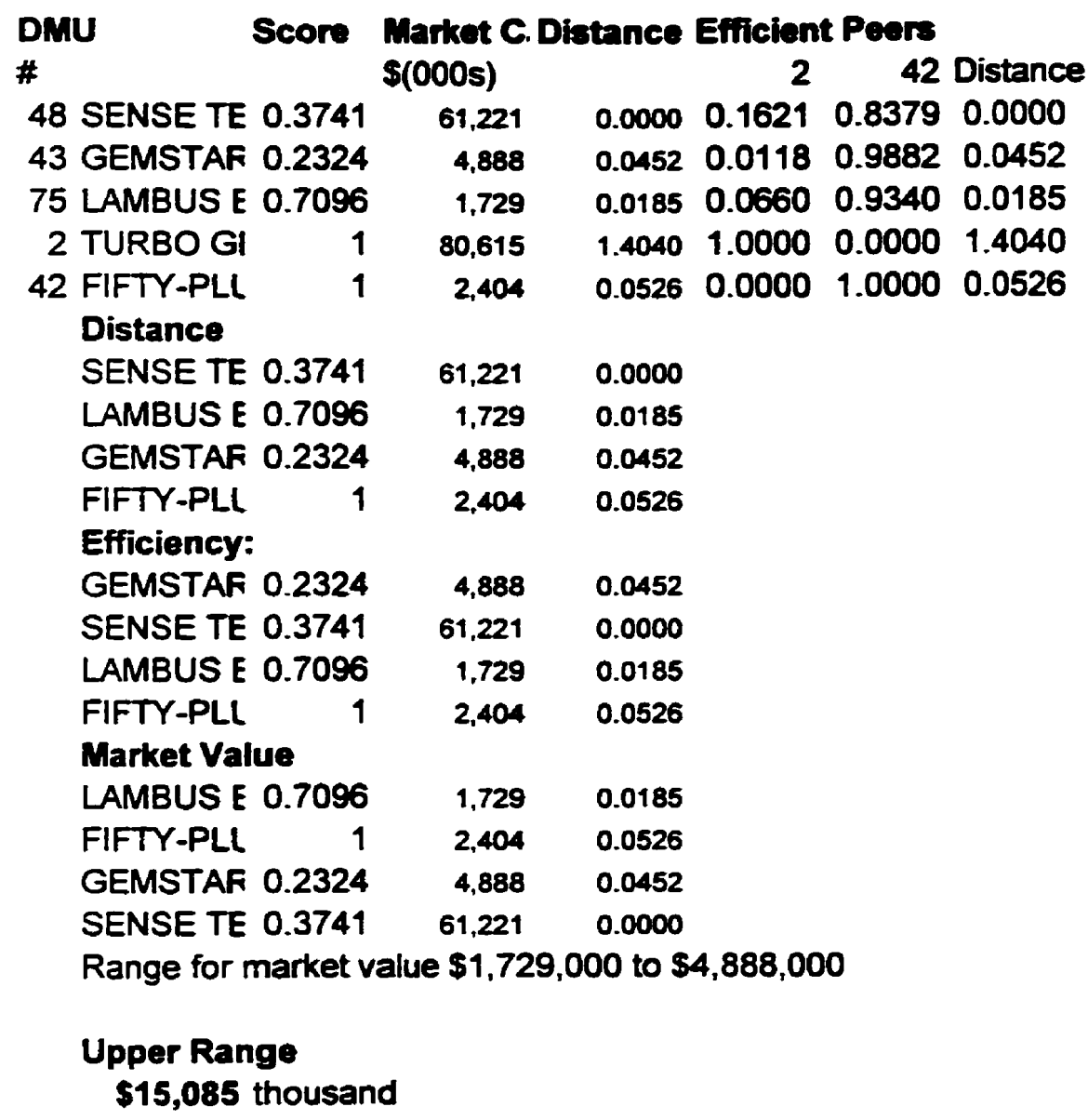

\section{Valuation Analysis for STRATEGIC TECHNOLOGIES INC (SIC3600)}

\begin{tabular}{|c|c|c|c|c|c|c|c|}
\hline \multirow{2}{*}{$\begin{array}{l}\text { DMU } \\
\text { \# }\end{array}$} & \multirow[t]{2}{*}{ Score } & \multicolumn{6}{|c|}{ Market C. Efificient Peers } \\
\hline & & $\$(000 s)$ & 5 & 7 & 42 & & Dist \\
\hline 52 STRATEG & 0.9832 & 3.943 & 0.3983 & 0.0012 & 1 & 0.1 & 00 \\
\hline 5 & 1 & 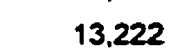 & 0 & 0.0 & 0.0000 & 0.0000 & 0.6122 \\
\hline & 1 & 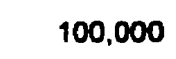 & & 100 & 200 & 0.0000 & 1. \\
\hline & 1 & 2,4 & & 300 & 1.0000 & 0.0000 & 45 \\
\hline 59 JEMTEC II & 1 & 330 & 0.0000 & 0.0000 & 0.0000 & 1.0000 & 1.1822 \\
\hline
\end{tabular}

In terms of distance, similar to Global and Fifty plus

Range for market value $\$ 2,404,000$ to $\$ 13,222,000$

Upper bound

$\$ 6,597$ thousand 


\section{Based on BCC-I for public company SHELLCASE (SIC 3600)}

\begin{tabular}{|c|c|c|c|c|c|c|c|}
\hline \multirow{2}{*}{$\begin{array}{l}\text { DMU } \\
\#\end{array}$} & \multirow[t]{2}{*}{ Score } & \multicolumn{6}{|c|}{ Market C. Distance Efficient Peers } \\
\hline & & $\$(000 s)$ & & 42 & 60 & & distance \\
\hline 71 SHELLCA! & 8.47E-02 & 15,698 & 0.0000 & 0.8555 & 0.0113 & 0.1332 & 0.0000 \\
\hline 63 STRATEG & 0.53425 & 1,720 & 0.0376 & 0.6999 & 0.0642 & 0.2359 & 0.0376 \\
\hline 56 TSI TELSY & 0.211188 & 12,193 & 0.0235 & 0.7477 & 0.1203 & 0.1320 & 0.0235 \\
\hline 46 MARATHC & 0.604497 & 623 & 0.0207 & 0.8016 & 0.1285 & 0.0699 & 0.0207 \\
\hline 31 TRADE $M$ & 0.676206 & 9,700 & 0.2686 & 0.4601 & 0.3397 & 0.2002 & 0.2686 \\
\hline $19 \mathrm{BCS}$ & 0.676619 & 1.027 & 0.0127 & 0.9156 & 0.0417 & 0.0428 & 0.0127 \\
\hline 81 COMPRES & 0.310462 & 717 & 0.0274 & 0.9716 & 0.0131 & 0.0153 & 0.0274 \\
\hline 42 FIFTY-PLL & 1 & 2.404 & 0.0388 & 1.0000 & 0.0000 & 0.0000 & 0.0388 \\
\hline 60 PACIFIC E & 1 & 3,878 & 1.7271 & 0.0000 & 1.0000 & 0.0000 & 1.7271 \\
\hline 62 SNIF SECI & 1 & 307 & 1.4832 & 0.0000 & 0.0000 & 1.0000 & 1.4832 \\
\hline
\end{tabular}

Ranking, according to the distances that are less than 1 (for SHELLCASE):

$\begin{array}{lrrr}\text { SHELLCA: } 8.47 E-02 & 15.698 & 0.0000 \\ \text { BCS TECH } 0.676619 & 1.027 & 0.0127 \\ \text { MARATHC } 0.604497 & 623 & 0.0207 \\ \text { TSI TELSY } 0.211188 & 12,193 & 0.0235 \\ \text { COMPRES } 0.310462 & 717 & 0.0274 \\ \text { STRATEG } & 0.53425 & 1,720 & 0.0376 \\ \text { FIFTY-PLL } & 1 & 2,404 & 0.0388 \\ \text { TRADE W } & 0.676206 & 9,700 & 0.2686\end{array}$

Similarity of the efficiency scores (difference between SHELLCASE's score):

SHELLCA: 8.47E-02 $15,698 \quad 0.0000$

TSI TELSY $0.211188 \quad 12.193 \quad 0.0235$

COMPRES $0.310462 \quad 717 \quad 0.0274$

STRATEG $0.53425 \quad 1.720 \quad 0.0376$

MARATHC $0.604497 \quad 623 \quad 0.0207$

TRADE W $0.676206 \quad 9.700 \quad 0.2686$

BCS TECF $0.676619 \quad 1,027 \quad 0.0127$

$\begin{array}{llll}\text { FIFTY-PLL } & 1 & 2,404 & 0.0388\end{array}$

Similarity of the Market Cap. (difference between SHELLCASE's market cap.):

$\begin{array}{lrrr}\text { MARATHC } 0.604497 & 623 & 0.0207 \\ \text { COMPRES } 0.310462 & 717 & 0.0274 \\ \text { BCS TECH } 0.676619 & 1.027 & 0.0127 \\ \text { STRATEG } & 0.53425 & 1.720 & 0.0376 \\ \text { FIFTY-PLL } & 1 & 2.404 & 0.0388 \\ \text { TRADE W } & 0.676206 & 9,700 & 0.2686 \\ \text { TSI TELSY } 0.211188 & 12,193 & 0.0235 \\ \text { SHELLCA: } 8.47 E-02 & 15,698 & 0.0000\end{array}$

Range for SHELLCASE's market cap. based on peer group is $\$ 623,000$ to $\$ 12,193,000$

Market Capitalization of SHELLCASE based on EFFICIENT PEERS

$\$ 2,141$ thousand 


\section{VALUATION ANALYSIS FOR SR TELECOM INC (SIC3600)}

\begin{tabular}{|c|c|c|c|c|c|c|}
\hline \multirow{2}{*}{\multicolumn{2}{|c|}{ 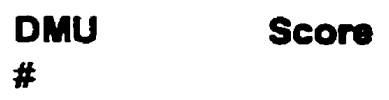 }} & \multicolumn{5}{|c|}{ Market C. Efificient Peors: } \\
\hline & & $\$(000 s)$ & 7 & 67 & & dis \\
\hline $51 \mathrm{SI}$ & 0.447 & 112,897 & 0.1363 & 0.4192 & 0.4445 & 0.0000 \\
\hline JESTAI & 0.5548 & 44,404 & 0.0926 & 0.8695 & 0.0379 & 0.3699 \\
\hline 37 COM DEV & 0.8 & 252,315 & 0.0824 & 0.1168 & 0.8008 & 0.2213 \\
\hline 54 TEKLOGIX & 0.8099 & 243,501 & 0.0755 & 0.8796 & 0.0449 & 0.3753 \\
\hline 7 CAMCO IA & 1 & 100,000 & 1.0000 & 0.0000 & 0.0000 & 1.1194 \\
\hline 67 PRIMETEC & 1 & 143,365 & 0.0000 & 1.0000 & 0.0000 & 0.5534 \\
\hline 76 LEITCH TE & 1 & $1,031,559$ & 0.0000 & 0.0000 & 1.0000 & 0.5029 \\
\hline
\end{tabular}

Companies ranked by Distance:

$\begin{array}{lrrr}\text { SR TELEC } & 0.447 & 112,897 & 0 \\ \text { COM DEV } & 0.8633 & 252.315 & 0.2213 \\ \text { BLUESTAI } & 0.5548 & 44,404 & 0.3699 \\ \text { TEKLOGIX } & 0.8099 & 243,501 & 0.3753 \\ \text { LEITCH TE } & 1 & 1,031,559 & 0.5029 \\ \text { PRIMETEC } & 1 & 143,365 & 0.5534\end{array}$

Rank by Efficiency score

$\begin{array}{lrrr}\text { SR TELEC } & 0.447 & 112,897 & 0 \\ \text { BLUESTAI } & 0.5548 & 44,404 & 0.3699 \\ \text { TEKLOGI) } & 0.8099 & 243,501 & 0.3753 \\ \text { COM DEV } & 0.8633 & 252,315 & 0.2213 \\ \text { LEITCH TE } & 1 & 1,031,559 & 0.5029 \\ \text { PRIMETEC } & 1 & 143,365 & 0.5534\end{array}$

By market value

BLUESTAI $0.5548 \quad 44,404 \quad 0.3699$

$\begin{array}{llll}\text { SR TELEC } & 0.447 & 112,897 & 0\end{array}$

$\begin{array}{lrrr}\text { PRIMETEC } & 1 & 143,365 & 0.5534\end{array}$

TEKLOGI) $0.8099 \quad 243,501 \quad 0.3753$

COM DEV 0.8633 ～252.315 0.2213

LEITCH TE $\quad 1 \quad 1,031,5590.5029$

Market value range: $\$ 44,404,000$ to $\$ 1,031,559,000$

Upper bound

$\$ 532,269$ thousand 


\section{STRATEGIC VISTA (SIC 3600)}

\begin{tabular}{|c|c|c|c|c|c|c|c|}
\hline M & Score & & & & & & \\
\hline \# & & $\$(000 s)$ & & 42 & 60 & 62 & disth \\
\hline 63 STRATEG & 0.53425 & 1,720 & 0.0000 & 0.6999 & 0.0642 & 0.2359 & \\
\hline SI TELSY & 0.211188 & 12,193 & 0.0162 & 177 & & 0.1320 & \\
\hline $\mathrm{HC}$ & 0.604497 & 623 & & 0.8 & & 0.0 & \\
\hline $31 T$ & 0.67 & 9,700 & 16 & 0.4601 & & 0.2002 & \\
\hline ECr & 0.67 & 1.027 & 43 & 56 & 17 & 0.0428 & \\
\hline 71 & 8.4 & 5,698 & 0.0376 & 55 & & 0.1332 & 0 \\
\hline 81 COMPRES & 0.310462 & 717 & .1251 & 0.9716 & 0.0131 & 0.0153 & 0.1251 \\
\hline TY-PLL & 1 & 4 & 19 & 1.0000 & 0.0000 & 0.0000 & 0.1499 \\
\hline & 1 & 3,878 & & & & & \\
\hline SECI & 1 & 307 & 1.0777 & 0.0000 & 0.0000 & 1.0000 & 1.0777 \\
\hline
\end{tabular}

Ranking, according to the distances that are less than 1 (for STRATEGIC VISTA):

$\begin{array}{lrrr}\text { STRATEG } & 0.53425 & 1,720 & 0.0000 \\ \text { TSI TELSY } & 0.211188 & 12,193 & 0.0162 \\ \text { SHELLCA: } & 8.47 E-02 & 15,698 & 0.0376 \\ \text { MARATHC } & 0.604497 & 623 & 0.0421 \\ \text { BCS TECH } & 0.676619 & 1,027 & 0.0843 \\ \text { COMPRES } & 0.310462 & 717 & 0.1251 \\ \text { TRADE W } & 0.676206 & 9,700 & 0.1346 \\ \text { FIFTY-PLC } & 1 & 2,404 & 0.1499\end{array}$

Similarity of the efficiency scores (difference between STRATEGIC VISTA's score):

$\begin{array}{lrrr}\text { SHELLCA: } & 8.47 E-02 & 15,698 & 0.0376 \\ \text { TSI TELSY } & 0.211188 & 12,193 & 0.0162 \\ \text { COMPRES } & 0.310462 & 717 & 0.1251 \\ \text { STRATEG } & 0.53425 & 1,720 & 0.0000 \\ \text { MARATHC } & 0.604497 & 623 & 0.0421 \\ \text { TRADE W } & 0.676206 & 9,700 & 0.1346 \\ \text { BCS TECF } & 0.676619 & 1,027 & 0.0843 \\ \text { FIFTY-PLL } & 1 & 2,404 & 0.1499\end{array}$

Similarity of the Market Cap. (difference between STRATEGIC VSTA's market cap.):

$\begin{array}{llll}\text { MARATHC } & 0.604497 & 623 & 0.0421\end{array}$

$\begin{array}{llll}\text { COMPRES } & 0.310462 & 717 & 0.1251\end{array}$

BCS TECF $0.676619 \quad 1,027 \quad 0.0843$

STRATEG $0.53425 \quad 1,720 \quad 0.0000$

$\begin{array}{lrrr}\text { FIFTY-PLL } & 1 & 2,404 & 0.1499\end{array}$

TRADE W $0.676206 \quad 9,700 \quad 0.1346$

TSI TELSY $0.211188 \quad 12,193 \quad 0.0162$

SHELLCA: $8.47 E-02 \quad 15,698 \quad 0.0376$

Range for STRATEGIC VISTA's market cap. based on peer group is $\$ 623,000$ to $\$ 15,698,000$

Market Capitalization of STRATEGIC VISTA based on EFFICIENT PEERS $\$ 2,004$ thousand 


\section{SYMPLEX (SIC 3600)}

\begin{tabular}{|c|c|c|c|c|c|c|c|}
\hline \multirow{2}{*}{$\begin{array}{l}\text { DMU } \\
\text { \# }\end{array}$} & \multicolumn{7}{|l|}{ Score } \\
\hline & & 00s) & & 32 & 42 & 60 & stance \\
\hline 4 SYMPLE & 0.562 & 5,879 & 0.0000 & 0.01 & 0.9054 & 0.0802 & 0.0000 \\
\hline 55 TRIPLE & 0.526 & 4,979 & 0.0942 & 0.2507 & 0.7153 & 0.0339 & 0.0942 \\
\hline 2 DBA TEL & 0.64 & 1,956 & 0.0255 & 0.1446 & 0.8450 & 0.0104 & 0.0255 \\
\hline $18 \mathrm{ABL} C A \wedge$ & 0.399 & 13,382 & 0.5356 & 0.5432 & 0.4001 & 0.0567 & 0.5356 \\
\hline $3 T$ & 0.656 & 1.710 & 0.0179 & 98 & 0.8776 & 0.0027 & 0.0179 \\
\hline $12 A$ & 47 & 2,429 & 0.0056 & 0.0245 & 0.9525 & 0.0230 & 0.0056 \\
\hline 32 TS TELE & 1 & 11,832 & 1.7978 & 1.0000 & 0.0000 & 0.0000 & 1.7978 \\
\hline 42 FIFTY-PI & 1 & 2,404 & 0.0156 & 0.0000 & 1.0000 & 0.0000 & 0.0156 \\
\hline 60 PACIFIC & 1 & 3,878 & 1.6660 & 0.0000 & 0.0000 & 1.0000 & 1.6660 \\
\hline
\end{tabular}

Ranking, according to the distances that are less than 1 (for SYMPLEX):

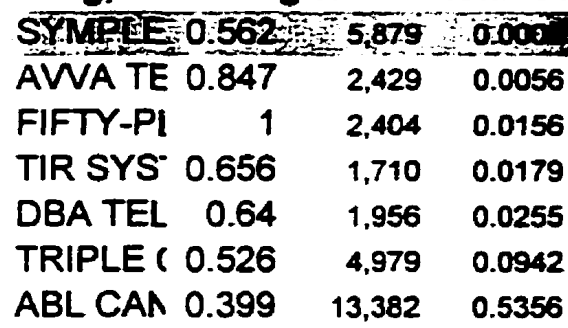

Similarity of the efficiency scores (difference between SYMPLEX's score):

ABL CAN $0.399 \quad 13,382 \quad 0.5356$

TRIPLE $(0.526 \quad 4,979 \quad 0.0942$

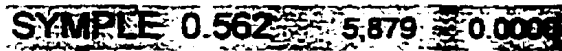

\begin{tabular}{lllll}
\hline DBA TEL & 0.64 & 1.956 & 0.0255
\end{tabular}

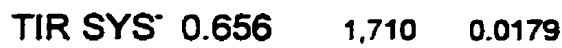

AWA TE $0.847 \quad 2,429 \quad 0.0056$

FIFTY-PI $\quad 1 \quad 2.404 \quad 0.0156$

Similarity of the Market Cap. (difference between SYMPLEX's market cap.):

TIR SYS $0.656 \quad 1,710 \quad 0.0179$

DBA TEL $\quad 0.64 \quad 1,956 \quad 0.0255$

FIFTY-PI $\quad 1 \quad 2,404 \quad 0.0156$

AWA TE $0.847 \quad 2.429 \quad 0.0056$

TRIPLE $\left(\begin{array}{lll}0.526 & 4,979 & 0.0942\end{array}\right.$

SYMPED 062 DSP 70009

ABL CAN $0.399 \quad 13,382 \quad 0.5356$

Range for SYMPLEX's market cap. based on peer group is $\$ 1,710,000$ and $\$ 13,382,000$

Market Capitalization of SYMPLEX based on EFFICIENT PEERS

$\$ 2,657$ thousand 


\section{SYSCAN INTERNATIONAL INC (SIC 3600)}

\begin{tabular}{|c|c|c|c|c|c|c|c|}
\hline $\begin{array}{l}\text { DMU } \\
\#\end{array}$ & Score & $\begin{array}{l}\text { Market C } \\
\text { \$(O0Os) }\end{array}$ & 17 & 38 & 42 & & Distan \\
\hline 53 SYSCAN \| & 0.6574 & 7.260 & 0.052205 & 0.423308 & 0.521971 & 2.52E-03 & 0.0000 \\
\hline 17 AASTRAT & 1 & 46.091 & 1 & 0 & 0 & 0 & 1.3500 \\
\hline 38 COMMUNI & 1 & 3,855 & 0 & 1 & $1.29 E-18$ & 0 & 0.6078 \\
\hline 42 FIFTY-PLL & 1 & 2.404 & 0 & 0 & 1 & 0 & 0.4104 \\
\hline 67 PRIMETEC & 1 & 143,365 & 0 & $8.70 E-17$ & 0 & 1 & 1.4493 \\
\hline
\end{tabular}

Range for mv: $\$ 2.4$ to 3.8 million

Upper bound

$\$ 5,654$ thousand

VALUATION ANALYSIS FOR TEKLOGIX INTERNATIONAL INC (SIC3600)

\begin{tabular}{|c|c|c|c|c|c|c|}
\hline \multirow[t]{2}{*}{ DMU } & \multirow[t]{2}{*}{ Score } & \multicolumn{5}{|c|}{ Market C. Efificient Peers: } \\
\hline & & $\$(000 s)$ & 7 & 67 & \multicolumn{2}{|c|}{76 distance } \\
\hline 54 TEKLOG & 0.8099 & 243.501 & $7.55 E-02$ & 0.879623 & 4.49E-02 & 0.00000 \\
\hline 51 SR TELEC & 0.447 & 112.897 & 0.13625 & 0.419239 & 0.444511 & 0.37533 \\
\hline 80 BLUESTAI & 0.5548 & 44,404 & $9.26 E-02$ & 0.869458 & 3.79E-02 & 0.00044 \\
\hline 37 COM DEV & 0.8633 & 252.315 & 8.24E-02 & 0.116802 & 0.800779 & 1.15330 \\
\hline 7 CAMCO IN & 1 & 100,000 & 1 & 0 & 0 & 1.63045 \\
\hline 67 PRIMETEC & 1 & 143.365 & 0 & 1 & 0 & 0.02221 \\
\hline 76 LEITCH TE & 1 & $1,031,559$ & 0 & 0 & 1 & 1.69165 \\
\hline
\end{tabular}

Three peers: Bluestar, Primetech, and SR Tel

Market value range: $\$ 44,404,000$ to $\$ 143,365,000$

Upper bound

$\$ 179,974$ thousand 


\section{Public company TIR (SIC 3600)}

\begin{tabular}{|c|c|c|c|c|c|c|c|}
\hline \multirow{2}{*}{\multicolumn{2}{|c|}{ DMU Score }} & \multicolumn{6}{|c|}{ Market C. Distance Efficient Peers } \\
\hline & & \multicolumn{2}{|l|}{$s(000 s)$} & \multirow{2}{*}{32} & \multirow{2}{*}{$\begin{array}{r}42 \\
0.8776\end{array}$} & \multicolumn{2}{|c|}{60 Distance } \\
\hline 13 TIR SYSTE & 0.6557 & 1,710 & 0.0000 & & & 0.0027 & 0.0000 \\
\hline 12 AWA TEC & 0.8473 & 2,429 & 0.0151 & 0.0245 & 0.9525 & 0.0230 & 0.0151 \\
\hline 18 ABL CANA & 0.3991 & 13,382 & 0.4101 & 0.5432 & 0.4001 & 0.0567 & 0.4101 \\
\hline 55 TRIPLE CF & 0.526 & 4,979 & 0.0444 & 0.2507 & 0.7153 & 0.0339 & 0.0444 \\
\hline 22 DBA TELE & 0.6399 & 1,956 & 0.0017 & 0.1446 & 0.8450 & 0.0104 & 0.0017 \\
\hline 64 SYMPLEX & 0.5622 & 5,879 & 0.0179 & 0.0143 & 0.9054 & 0.0802 & 0.0179 \\
\hline 32 TS TELEC & 1 & 11,832 & 1.5449 & 1.0000 & 0.0000 & 0.0000 & 1.5449 \\
\hline 42 FIFTY-PLL & 1 & 2,404 & 0.0293 & 0.0000 & 1.0000 & 0.0000 & 0.0293 \\
\hline 60 PACIFIC E & 1 & 3,878 & 1.7791 & 0.0000 & 0.0000 & 1.0000 & 1.7791 \\
\hline \multicolumn{8}{|c|}{ Ranking, according to the distances that are less than 1 (for TIR): } \\
\hline TIR SYSTE & 0.6557 & 1.710 & 0.0000 & & & & \\
\hline DBA TELE & 0.6399 & 1,956 & 0.0017 & & & & \\
\hline AWA TEC & 0.8473 & 2,429 & 0.0151 & & & & \\
\hline SYMPLEX & 0.5622 & 5,879 & 0.0179 & & & & \\
\hline FIFTY-PLL & 1 & 2,404 & 0.0293 & & & & \\
\hline TRIPLE CF & 0.526 & 4,979 & 0.0444 & & & & \\
\hline ABL CANA & 0.3991 & 13,382 & 0.4101 & & & & \\
\hline
\end{tabular}

Similarity of the efficiency scores (difference between TIR's score):

$\begin{array}{lrrr}\text { ABL CANA } & 0.3991 & 13,382 & 0.4101 \\ \text { TRIPLE CF } & 0.526 & 4,979 & 0.0444 \\ \text { SYMPLEX } & 0.5622 & 5,879 & 0.0179 \\ \text { DBA TELE } & 0.6399 & 1,956 & 0.0017 \\ \text { TIR SYSTI } & 0.6557 & 1,710 & 0.0000 \\ \text { AVWA TEC } & 0.8473 & 2.429 & 0.0151 \\ \text { FIFTY-PLL } & 1 & 2.404 & 0.0293 \\ \text { FIFTY-PLL } & 1 & 2,404 & 0.0034\end{array}$

Similarity of the Market Cap. (difference between TIR's market cap.):

$\begin{array}{lrrr}\text { TIR SYSTI } & 0.6557 & 1,710 & 0.0000 \\ \text { DBA TELE } & 0.6399 & 1,956 & 0.0017 \\ \text { FIFTY-PLL } & 1 & 2,404 & 0.0293 \\ \text { FIFTY-PLL } & 1 & 2,404 & 0.0034 \\ \text { AWVA TEC } & 0.8473 & 2,429 & 0.0151 \\ \text { TRIPLE CI } & 0.526 & 4,979 & 0.0444 \\ \text { SYMPLEX } & 0.5622 & 5,879 & 0.0179 \\ \text { ABL CANA } & 0.3991 & 13,382 & 0.4101\end{array}$

Range for TiR's market cap. based on peer group is $\$ 1,956,000$ and $\$ 13,382,000$ TIR's real market cap of $\$ 1,710,000$ falls just short of this amount

Market Capitalization of TIR based on EFFICIENT PEERS $\$ 3,537$ thousand 


\section{TRADE WIND COMMUNICATIONS LTD (SIC 3600)}

\begin{tabular}{|c|c|c|c|c|c|c|c|}
\hline DMU & ore & & & fficion & t Peers & & \\
\hline \# & & Doos) & & 42 & 60 & 62 & distance \\
\hline 31 TRADE W & 0.67621 & 9,700 & 0.0000 & 0.4601 & 0.3397 & 0.2002 & 0.0000 \\
\hline 19 BCS TECF & 0.67662 & 1,027 & 0.3210 & 0.9156 & 0.0417 & 0.0428 & 0.3210 \\
\hline 46 MARATHC & 0.60450 & 623 & 0.1781 & 0.8016 & 0.1285 & 0.0699 & 0.1781 \\
\hline 56 TSI TELSY & 0.21119 & 12.193 & 0.1355 & 0.7477 & 0.1203 & 0.1320 & 0.1355 \\
\hline 63 STRATEG & 0.53425 & 1,720 & 0.1346 & 0.6999 & 0.0642 & 0.2359 & 0.1346 \\
\hline 71 SHELLCA: & 0.08470 & 15,698 & 0.2686 & 0.8555 & 0.0113 & 0.1332 & 0.2686 \\
\hline 81 COMPRES & 0.31046 & 717 & 0.4024 & 0.9716 & 0.0131 & 0.0153 & 0.4024 \\
\hline 42 FIFTY-PLL & 1.00000 & 2,404 & 0.4469 & 1.0000 & 0.0000 & 0.0000 & 0.4469 \\
\hline 60 PACIFICE & 1.00000 & 3.878 & 0.6878 & 0.0000 & 1.0000 & 0.0000 & 0.6878 \\
\hline 62 SNIF SECI & 1.00000 & 307 & 0.9669 & 0.0000 & 0.0000 & 1.0000 & 0.9669 \\
\hline
\end{tabular}

Ranking, according to the distances that are less than 1 (for TRADE WMN):

\begin{tabular}{|c|c|c|c|c|c|c|c|}
\hline STRATEG & 0.53425 & 1,720 & 0.1346 & & & & \\
\hline TSI TELSY & 0.21119 & 12,193 & 0.1355 & & & & \\
\hline MARATHC & 0.60450 & 623 & 0.1781 & & & & \\
\hline SHELLCA: & 0.08470 & 15,698 & 0.2686 & & & & \\
\hline BCS TECr & 0.67662 & 1,027 & 0.3210 & & & & \\
\hline COMPRES & 0.31046 & 717 & 0.4024 & & & & \\
\hline FIFTY-PLL & 1.00000 & 2.404 & 0.4469 & & & & \\
\hline PACIFICE & 1.00000 & 3,878 & 0.6878 & & & & \\
\hline SNIF SECI & 1.00000 & 307 & 0.9669 & & & & \\
\hline \multicolumn{4}{|c|}{ Similarity of the efficiency scores: } & \multicolumn{4}{|c|}{ Similarity of the Market Cap.: } \\
\hline SHELLCA: & 0.08470 & 15,698 & 0.2686 & SNIF St & 1 & 307 & 0.9669 \\
\hline TSI TELSY & 0.21119 & 12,193 & 0.1355 & MARAT & 0.6045 & 623 & 0.1781 \\
\hline COMPRES & 0.31046 & 717 & 0.4024 & COMPF & 0.31046 & 717 & 0.4024 \\
\hline STRATEG & 0.53425 & 1,720 & 0.1346 & BCS TE & 0.67662 & 1,027 & 0.3210 \\
\hline MARATHC & 0.60450 & 623 & 0.1781 & STRATI & 0.53425 & 1,720 & 0.1346 \\
\hline TRADE $\mathbf{M}$ & 0.67621 & $9,700_{-2}^{-2}$ & 00000 & FIFTY-F & 1 & 2,404 & 0.4469 \\
\hline BCS TECP & 0.67662 & 1,027 & 0.3210 & PACIFIC & 1 & 3,878 & 0.6878 \\
\hline FIFTY-PLL & 1.00000 & 2,404 & 0.4469 & TRADE & 0.67621 & 9,700 & 0.0000 \\
\hline PACIFICE & 1.00000 & 3,878 & 0.6878 & TSI TEL & 0.21119 & 12.193 & 0.1355 \\
\hline SNIF SECI & 1.00000 & 307 & 0.9669 & SHELLC & 8.47E-02 & 15,698 & 0.2686 \\
\hline
\end{tabular}

Range for TRADE MND's market cap. based on peer group is $\$ 307,000$ to $\$ 15,698,000$

Market Capitalization of TRADE WIND based on EFFICIENT PEERS $\$ 2,485$ thousand 


\section{For public company TRIPLE CROWN (SIC 3600)}

\begin{tabular}{|c|c|c|c|c|c|c|c|}
\hline DMU & Score & 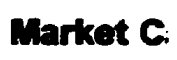 & קח & icien & Peers: & & \\
\hline \# & & $\$(000 s)$ & & 32 & 42 & 60 & Distance \\
\hline 55 TRIPLE CF & 0.526 & 4,979 & 0.0000 & 0.2507 & 0.7153 & 0.0339 & 0.0000 \\
\hline BA TEL & 0.6399 & 1,956 & 0.0286 & 0.1446 & 0.8450 & 0.0104 & 0.0286 \\
\hline L CANA & 0.3991 & 13,382 & 0.1854 & 0.5432 & 0.4001 & 0.0567 & 0.1854 \\
\hline $13 \mathrm{~T}$ & 0.6557 & 1.710 & 0.0444 & 0.1198 & 0.8776 & 0.0027 & 0.0444 \\
\hline $12 A$ & 0.8473 & 2.429 & 0.1076 & 0.0245 & 0.9525 & 0.0230 & 0.1076 \\
\hline 64 SYMPLEX & 0.5622 & 5,879 & 0.0942 & 0.0143 & 0.9054 & 0.0802 & 0.0942 \\
\hline 32 TS TELEC & 1 & 11,832 & 1.0742 & 1.0000 & 0.0000 & 0.0000 & 1.0742 \\
\hline 42 FIFTY-PLL & 1 & 2,404 & 0.1451 & 0.0000 & 1.0000 & 0.0000 & 0.1451 \\
\hline 60 PACIFIC E & 1 & 3.878 & 1.5079 & 0.0000 & 0.0000 & 1.0000 & 1.5079 \\
\hline
\end{tabular}

Ranking, according to the distances that are less than 1 (for TRIPLE CROWN):

$\begin{array}{lrrr}\text { TRIPLE CF } & 0.526 & 4,979 & 0.0000 \\ \text { DBA TELE } & 0.6399 & 1.956 & 0.0286 \\ \text { TIR SYSTI } & 0.6557 & 1,710 & 0.0444 \\ \text { SYMPLEX } & 0.5622 & 5,879 & 0.0942 \\ \text { AWWA TEC } & 0.8473 & 2,429 & 0.1076 \\ \text { FIFTY-PLL } & 1 & 2,404 & 0.1451 \\ \text { ABL CANP } & 0.3991 & 13,382 & 0.1854\end{array}$

Similarity of the efficiency scores (difference between TRIPLE CROWN's score):

$\begin{array}{lrrr}\text { ABL CANA } & 0.3991 & 13.382 & 0.1854 \\ \text { TRIPLE CI } & 0.526 & 4.979 & 0.0000 \\ \text { SYMPLEX } & 0.5622 & 5.879 & 0.0942 \\ \text { DBA TELE } & 0.6399 & 1.956 & 0.0286 \\ \text { TIR SYSTI } & 0.6557 & 1.710 & 0.0444 \\ \text { AWVA TEC } & 0.8473 & 2.429 & 0.1076 \\ \text { FIFTY-PLL } & 1 & 2.404 & 0.1451\end{array}$

Similarity of the Market Cap. (difference between TRIPLE CROWN's market cap.):

TIR SYSTI $0.6557 \quad 1.710 \quad 0.0444$

DBA TELE $0.6399 \quad 1,956 \quad 0.0286$

$\begin{array}{llll}\text { FIFTY-PLL } & 1 & 2.404 & 0.1451\end{array}$

AWA TEC $0.8473 \quad 2.429 \quad 0.1076$

TRIPLE Cl $0.526 \quad 4.979 \quad 0.0000$

SYMPLEX $0.5622 \quad 5.879 \quad 0.0942$

ABL CANA $0.3991 \quad 13,382 \quad 0.1854$

Range for TRIPLE CROWN's market cap. based on peer group is $\$ 1,710,000-\$ 13,382,000$

Market Capitalization of TRIPLE CROWN based on EFFICIENT PEERS

$\$ 4,818$ thousand

VAluing PRIVATE Companies: A DEA APPROACH 


\section{Valuation Analysis for TRI-VISION INTERNATIONAL LTD (SIC3600)}

\begin{tabular}{|c|c|c|c|c|c|c|c|}
\hline DMU & Score & Narket & & 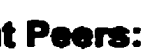 & & & \\
\hline \# & & $\$(000 s)$ & 30 & 32 & 38 & 42 & distance \\
\hline 78 TRI-VISIC & 7426 & 29,930 & 0.0850 & 1415 & 0.1094 & 0.6641 & 0.0000 \\
\hline 30 RESEARC & 1 & 585,308 & 1.0000 & 0.0000 & 0.0000 & 0.0000 & 1.3101 \\
\hline 32 & 1 & 11,832 & 0.0000 & 1.0000 & 0.0000 & 0.0000 & 1.1973 \\
\hline 38 COMMUNI & 1 & 3,855 & 0.0000 & 0.0000 & 1.0000 & 0.0000 & 1.2614 \\
\hline 42 FIFTY-PLL & 1 & 2,404 & 0.0000 & 0.0000 & 0.0000 & 1.0000 & 0.1521 \\
\hline
\end{tabular}

Minimum mv $\$ 2.4$ million, one peer

UPPER BOUND:

Market Capitalization of TRI based on EFFICIENT PEERS

$\$ 53,470$ thousand

\section{TUNDRA SEMICONDUCTOR CORP (SIC3600)}

\begin{tabular}{|c|c|c|c|c|c|c|c|}
\hline DMU & Score & Ma & & 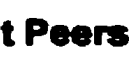 & & & \\
\hline 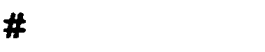 & & $s(000 s)$ & 32 & 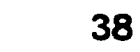 & 67 & & \\
\hline 72 & 317 & 120,705 & 1004 & 76 & 0710 & & \\
\hline & 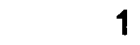 & 2 & & & & & \\
\hline & & & 10 & & 50 & & \\
\hline & 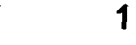 & 43,365 & 0.0000 & & 1.0000 & & \\
\hline 76 & 1 & $1,031,559$ & 0.0000 & 0.0000 & 0.0000 & 1.0000 & 1.5900 \\
\hline
\end{tabular}

UPPER BOUND:

Market Capitalization of TUNDRA based on EFFICIENT PEERS

$\$ 46,523$ thousand

\section{Valuation Analysis for UNITEC INTERNATIONAL CONTROLS (SIC3600)}

\begin{tabular}{|c|c|c|c|c|c|c|c|c|}
\hline DMU & Score & Mat & ieta & 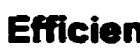 & Peers & & & \\
\hline \# & & $\$(000 s)$ & & 5 & 17 & 42 & 67 & distance \\
\hline 4 UNITEC ! & 0.4349 & 5,571 & 0.0000 & 0.0217 & 0.0472 & 0.9285 & 0.0025 & 0.0000 \\
\hline 5 GLOBAL T & 1 & 13.222 & 1.8215 & 1.0000 & 0.0000 & 0.0000 & 0.0000 & 1.8215 \\
\hline 17 & 1 & 46,091 & 1.7705 & 0.0000 & 1.0000 & 0.0000 & 0.0000 & 1.7705 \\
\hline $42 \mathrm{~F}$ & 1 & 2,404 & 0.0078 & 0.0000 & 0.0000 & 1.0000 & 0.0000 & 0.0078 \\
\hline 67 PRIMETEC & 1 & 143,365 & 1.8598 & 0.0000 & 0.0000 & 0.0000 & 1.0000 & 1.8598 \\
\hline
\end{tabular}

Fifty-Plus is only similar to Unitec in terms of distance, therefore it should have a market cap near $\$ 2.4$ millione

Market Capitalization of UNITEC based on EFFICIENT PEERS UPPER BOUND

$\$ 5,057$ thousand 


\section{TSI TEL (SIC 3600)}

\begin{tabular}{|c|c|c|c|c|c|c|c|}
\hline DMU & ore & larket & nee & Efficien & Peers & & \\
\hline \# & & \$(000s) & & 42 & 60 & 62 & distance \\
\hline 56 TSI TELSY & 0.21119 & 12,193 & 0.0000 & 0.7477 & 0.1203 & 0.1320 & 0.0000 \\
\hline 46 MARATHC & 0.60450 & 623 & 0.0068 & 0.8016 & 0.1285 & 0.0699 & 0.0068 \\
\hline 31 TRADE W & 0.67621 & 9,700 & 0.1355 & 0.4601 & 0.3397 & 0.2002 & 0.1355 \\
\hline 19 BCS TECr & 0.67662 & 1,027 & 0.0423 & 0.9156 & 0.0417 & 0.0428 & 0.0423 \\
\hline 63 STRATEG & 0.53425 & 1,720 & 0.0162 & 0.6999 & 0.0642 & 0.2359 & 0.0162 \\
\hline 71 SHELLCA: & 0.08470 & 15,698 & 0.0235 & 0.8555 & 0.0113 & 0.1332 & 0.0235 \\
\hline 81 COMPRES & 0.31046 & 717 & 0.0752 & 0.9716 & 0.0131 & 0.0153 & 0.0752 \\
\hline 42 FIFTY-PLL & 1.00000 & 2,404 & 0.0956 & 1.0000 & 0.0000 & 0.0000 & 0.0956 \\
\hline $60 \mathrm{PAC}$ & 1.00000 & 3,878 & 1.3503 & 0.0000 & 1.0000 & 0.0000 & 1.3503 \\
\hline 62 SNIF SECI & 1.00000 & 307 & 1.3269 & 0.0000 & 0.0000 & 1.0000 & 1.3269 \\
\hline
\end{tabular}

Ranking, according to the distances that are less than 1 (for TSI TEL):

$\begin{array}{llrl}\text { TSI TELSY } & 0.21119 & 12,193 & 0.0000 \\ \text { MARATHC } & 0.60450 & 623 & 0.0068 \\ \text { STRATEG } & 0.53425 & 1,720 & 0.0162 \\ \text { SHELLCA: } & 0.08470 & 15,698 & 0.0235 \\ \text { BCS TECF } & 0.67662 & 1,027 & 0.0423 \\ \text { COMPRES } & 0.31046 & 717 & 0.0752 \\ \text { FIFTY-PLL } & 1.00000 & 2,404 & 0.0956 \\ \text { TRADE W } & 0.67621 & 9,700 & 0.1355\end{array}$

Similarity of the efficiency scores (difference between TSI TEL's score ):

$\begin{array}{llrr}\text { SHELLCA: } & 0.08470 & 15,698 & 0.0235 \\ \text { TSI TELSY } & 0.21119 & 12,193 & 0.0000 \\ \text { COMPRES } & 0.31046 & 717 & 0.0752 \\ \text { STRATEG } & 0.53425 & 1,720 & 0.0162 \\ \text { MARATHC } & 0.60450 & 623 & 0.0068 \\ \text { TRADE W } & 0.67621 & 9,700 & 0.1355 \\ \text { BCS TECH } & 0.67662 & 1,027 & 0.0423 \\ \text { FIFTY-PLL } & 1.00000 & 2,404 & 0.0956\end{array}$

Similarity of the Market Cap. (difference between TSI TEL's market cap.):

$\begin{array}{llrl}\text { MARATHC } & 0.60450 & 623 & 0.0068 \\ \text { COMPRES } & 0.31046 & 717 & 0.0752 \\ \text { BCS TECF } & 0.67662 & 1.027 & 0.0423 \\ \text { STRATEG } & 0.53425 & 1,720 & 0.0162 \\ \text { FIFTY-PLL } & 1.00000 & 2,404 & 0.0956 \\ \text { TRADE W } & 0.67621 & 9,700 & 0.1355 \\ \text { TSI TELSY } & 0.21119 & 12,193 & 0.0000 \\ \text { SHELLCA: } & 0.08470 & 15,698 & 0.0235\end{array}$

Range for TSI TEL's market cap. based on peer group is $\$ 623,000$ to $\$ 15,698,000$

Market Capitalization of TSI TEL based on EFFICIENT PEERS $\$ 2,304$ thousand 


\section{WE X.L (SIC 3600)}

\begin{tabular}{|c|c|c|c|c|c|c|c|}
\hline y & re & Market & & & & & tance \\
\hline & & $\$(000 s)$ & & 30 & 32 & 42 & \\
\hline WE X.L. $H^{\prime}$ & 0.9 & 17,083 & 0.00000 & 79 & 95 & & \\
\hline EXTRON & & & & & & & \\
\hline E & 0.8 & 16 & & & & & 049 \\
\hline N & 21 & 339 & & & 89 & 20 & 722 \\
\hline 01 & 65 & 9 & 67913 & & & & 913 \\
\hline 9 & & . & 14 & & 00 & 26 & 034 \\
\hline ( & & & & & 00 & 00 & 26 \\
\hline$T$ & 1.0 & & & & & & \\
\hline & & & & & 100 & 300 & 0.00033 \\
\hline & & & & & & & 0.01432 \\
\hline 1 & 88 & 3,569 & 32157 & 00 & 171 & 1529 & 1.3215 \\
\hline
\end{tabular}

Ranking, according to the distances that are less than 1 (for WE X.L):

$\begin{array}{lrrr}\text { WE X.L. HI } & 0.94369 & 17,083 & 0.00000 \\ \text { FIFTY-PLL } & 1.00000 & 2,404 & 0.00033 \\ \text { AVANTE T } & 0.58296 & 2,302 & 0.00034 \\ \text { NEXTRON } & 0.53445 & 2,426 & 0.00271 \\ \text { ADVANTE } & 0.18038 & 19,928 & 0.01432 \\ \text { WI-LAN IN } & 0.87321 & 329,339 & 0.05722 \\ \text { PLAINTRE } & 0.86634 & 14,946 & 0.57049\end{array}$

Similarity of the efficiency scores (difference between WE X.L's score (0.94):

$\begin{array}{lrrr}\text { ADVANTE } & 0.18038 & 19,928 & 0.01432 \\ \text { NEXTRON } & 0.53445 & 2,426 & 0.00271 \\ \text { AVANTE T } & 0.58296 & 2,302 & 0.00034 \\ \text { PLAINTRE } & 0.86634 & 14,946 & 0.57049 \\ \text { WI-LAN IN } & 0.87321 & 329,339 & 0.05722 \\ \text { WE X.L. H } & 0.94369 & 17,083 & 0.00000 \\ \text { FIFTY-PLL } & 1.00000 & 2,404 & 0.00033\end{array}$

Similarity of the Market Cap. (difference between WE X.L's market cap. $(\$ 17,083,000)$ :

$\begin{array}{lrrr}\text { AVANTE T } & 0.58296 & 2,302 & 0.00034 \\ \text { FIFTY-PLL } & 1.00000 & 2,404 & 0.00033 \\ \text { NEXTRON } & 0.53445 & 2,426 & 0.00271 \\ \text { PLAINTRE } & 0.86634 & 14,946 & 0.57049 \\ \text { WE X.L. H } & 0.94369 & 17,083 & 0.00000 \\ \text { ADVANTE } & 0.18038 & 19,928 & 0.01432 \\ \text { WI-LAN IN } & 0.87321 & 329,339 & 0.05722\end{array}$

Range for WE X.L's market cap. based on peer group is $\$ 2,302,000$ and $\$ 329,339,000$ WE X.L's real market cap of $\$ 17,083,000$ is right in this range

Especially after ignoring the effect of Wi-lan, the range is betwee $\$ 2.3$ and $\$ 20$ million

\section{Market Capitalization of WE X.L based on EFFICIENT PEERS $\$ 7,584$ thousand}




\section{Valuation Analysis for WI-LAN (SIC 3600)}

\begin{tabular}{|c|c|c|c|c|c|c|c|}
\hline DMU & Score & Market C & stane & Efricien & Peers & & Distance \\
\hline \# & & $\$(000 s)$ & & 30 & 32 & 42 & Formula \\
\hline 65 WI-LAN IN & 0.87321 & 329,339 & 0.00000 & 0.0359 & 0.1599 & 0.8042 & 0.0000 \\
\hline 3 INVERPOI & 0.54465 & 7,179 & 1.12221 & 0.0116 & 0.9208 & 0.0676 & 1.1222 \\
\hline 9 AVANTE T & 0.58296 & 2,302 & 0.05000 & 0.0028 & 0.0210 & 0.9763 & 0.0500 \\
\hline 30 RESEARC & 1.00000 & 585,308 & 1.60178 & 1.0000 & 0.0000 & 0.0000 & 1.6018 \\
\hline 32 TS TELEC & 1.00000 & 11,832 & 1.35380 & 0.0000 & 1.0000 & 0.0000 & 1.3538 \\
\hline 33 ADVANTE & 0.18038 & 19,928 & 0.01463 & 0.0117 & 0.0891 & 0.8992 & 0.0146 \\
\hline 42 FIFTY-PLL & 1.00000 & 2,404 & 0.06519 & 0.0000 & 0.0000 & 1.0000 & 0.0652 \\
\hline 45 KASTEN C & 0.99488 & 23,569 & 0.82904 & 0.1130 & 0.7617 & 0.1253 & 0.8290 \\
\hline 77 PLAINTRE & 0.86634 & 14,946 & 0.26639 & 0.0884 & 0.4958 & 0.4159 & 0.2664 \\
\hline 83 NEXTRON & 0.53445 & 2,426 & 0.03594 & 0.0032 & 0.0452 & 0.9516 & 0.0359 \\
\hline 85 WE X.L. H & 0.94369 & 17,083 & 0.05722 & 0.0088 & 0.0060 & 0.9853 & 0.0572 \\
\hline Ranking, acco & rding to th & he distanc & & & & & \\
\hline W-LAN IN & 0.87321 & 329,339 & 0.00000 & & & & \\
\hline ADVANTE & 0.18038 & 19,928 & 0.01463 & & & & \\
\hline NEXTRON & 0.53445 & 2,426 & 0.03594 & & & & \\
\hline AVANTE T & 0.58296 & 2,302 & 0.05000 & & & & \\
\hline WE X.L. HI & 0.94369 & 17,083 & 0.05722 & & & & \\
\hline FIFTY-PLL & 1.00000 & 2.404 & 0.06519 & & & & \\
\hline PLAINTRE & 0.86634 & 14,946 & 0.26639 & & & & \\
\hline KASTEN C & 0.99488 & 23,569 & 0.82904 & & & & \\
\hline
\end{tabular}

Similarity of the efficiency scores (difference between W-LAN's score (0.873):

$\begin{array}{lrrr}\text { ADVANTE } & 0.18038 & 19,928 & 0.01463 \\ \text { NEXTRON } & 0.53445 & 2,426 & 0.03594 \\ \text { AVANTE T } & 0.58296 & 2,302 & 0.05000 \\ \text { PLAINTRE } & 0.86634 & 14,946 & 0.26639 \\ \text { W-LAN IN } & 0.87321 & 329,339 & 0.00000 \\ \text { WE X.L. H } & 0.94369 & 17,083 & 0.05722 \\ \text { KASTEN C } & 0.99488 & 23,569 & 0.82904 \\ \text { FIFTY-PLL } & 1.00000 & 2,404 & 0.06519\end{array}$

Similarity of the Market Cap. (difference between WI-LAN's market cap. (\$329,339,000):

$\begin{array}{lrrr}\text { AVANTE T } & 0.58296 & 2,302 & 0.05000 \\ \text { FIFTY-PLL } & 1.00000 & 2,404 & 0.06519 \\ \text { NEXTRON } & 0.53445 & 2,426 & 0.03594 \\ \text { PLAINTRE } & 0.86634 & 14,946 & 0.26639 \\ \text { WE X.L. H } & 0.94369 & 17,083 & 0.05722 \\ \text { ADVANTE } & 0.18038 & 19,928 & 0.01463 \\ \text { KASTEN C } & 0.99488 & 23,569 & 0.82904 \\ \text { W-LAN IN } & 0.87321 & 329,339 & 0.00000\end{array}$

Range for WI-LAN's market cap. based on peer group is $\$ 2,302,000$ and $\$ 23,569,000$

WI-LAN CONTROLS LTD real market cap of $\$ 329,339,000$ is far above this range

Market Capitalization of WI-LAN based on EFFICIENT PEERS

$\$ 24,838$ thousand 
APPENDIX C

\section{Efficient Companies-SIC 3600 Market Value Analysis}




\section{Based on BCC-I}

For Company Aastra (17)

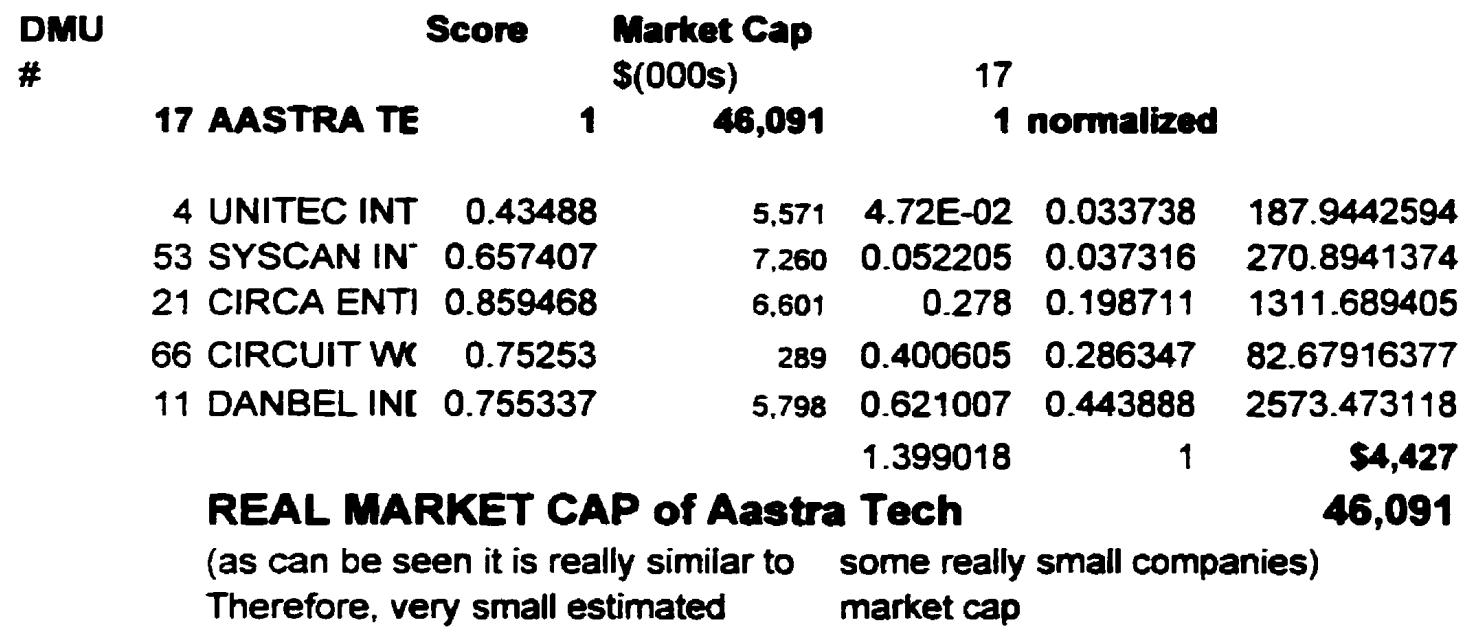

\section{Based on BCC-I}

For Company Research in Motion (30)

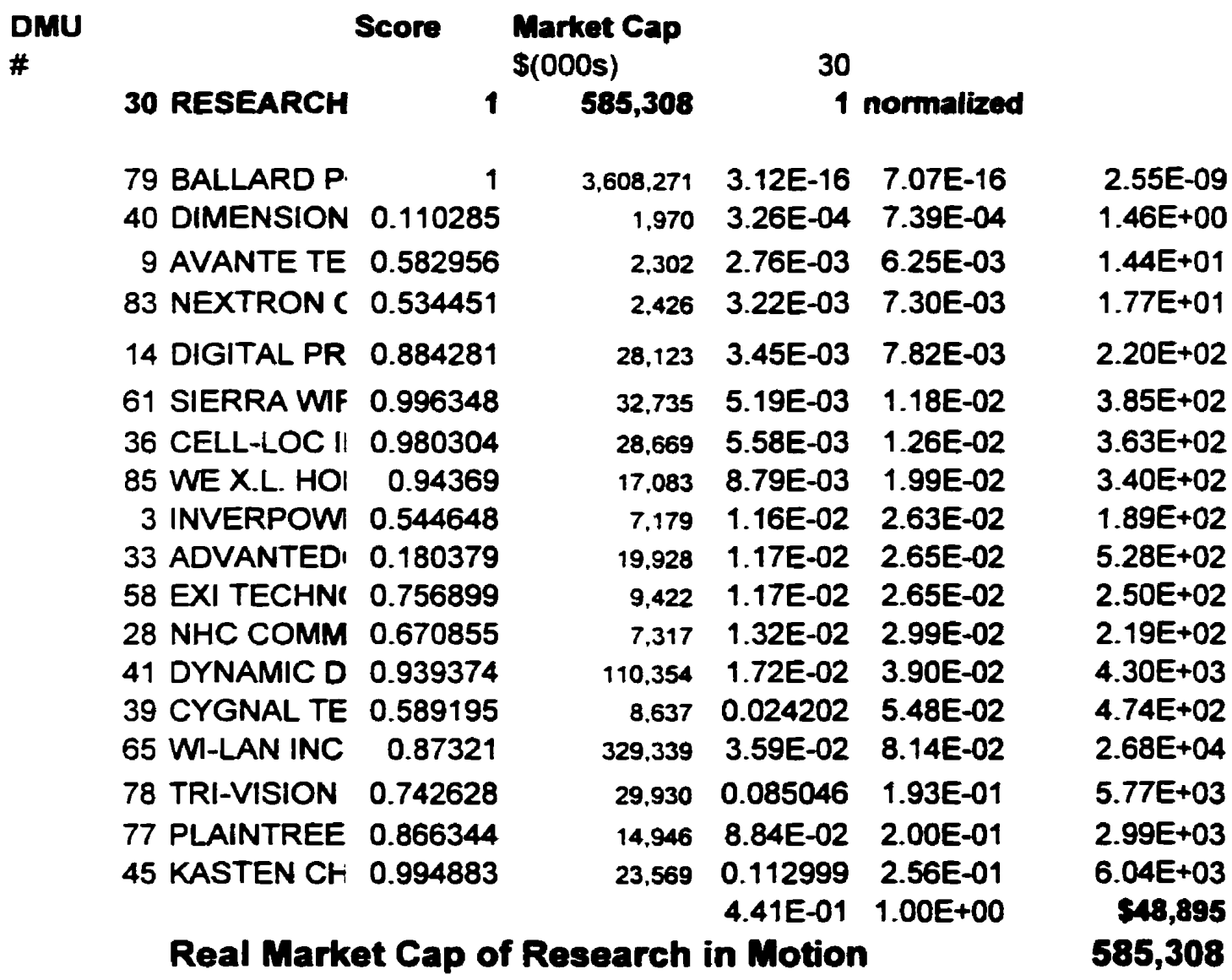

Valuing Private Companies: A dea Approach 


\section{Lower Bound for LEITCH TECHNOLOGY CORPORATION (76)}

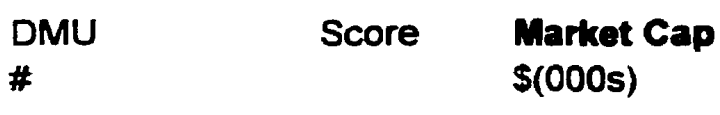

76

\begin{tabular}{|c|c|c|c|c|c|}
\hline 14 DIGITAL P & 0.884281 & 28,123 & 0.137482 & 3.46 & $=02$ \\
\hline 20 BELL CAN & 0.254057 & $1,371,120$ & 0.409041 & 1.03E-01 & 1.41E+05 \\
\hline 25 MEMOTEC & 0.649191 & 4.953 & 1.46E-02 & $3.68 E-03$ & $1.82 E+01$ \\
\hline $28 \mathrm{NHC}$ COM & 0.670855 & 7,317 & 3.33E-02 & $8.38 E-03$ & $6.13 E+01$ \\
\hline 35 CANADIAR & 1 & 426.808 & 4.53E-17 & $1.14 \mathrm{E}-17$ & 4.87E-12 \\
\hline 37 COM DEV & 0.863264 & 252,315 & 0.800779 & $2.02 E-01$ & $5.09 E+04$ \\
\hline 39 CYGNAL T & 0.589195 & 8.637 & 2.65E-02 & $6.67 E-03$ & $5.76 E+01$ \\
\hline 50 SPECTRU & 0.78669 & 38.637 & 7.75E-02 & $1.95 E-02$ & $7.54 E+02$ \\
\hline 51 SR TELEC & 0.446954 & $\$ 12,897$ & 0.444511 & $1.12 E-01$ & $1.26 E+04$ \\
\hline 54 TEKLOGIX & 0.809908 & 243,501 & 4.49E-02 & $1.13 E-02$ & $2.75 E+03$ \\
\hline 57 WESCAM & 0.628467 & 76.678 & $5.84 E-02$ & $1.47 E-02$ & $1.13 E+03$ \\
\hline 58 EXI TECHI & 0.756899 & 9,422 & 4.43E-03 & $1.12 E-03$ & $1.05 E+01$ \\
\hline 61 SIERRA $W$ & 0.996348 & 32,735 & 9.59E-02 & 2.41E-02 & $7.90 E+02$ \\
\hline 68 CELESTIC & 1 & $2.854,867$ & $3.97 E-16$ & $9.99 E-17$ & 2.85E-10 \\
\hline 69 CORECO I & 0.983382 & 44,923 & 0.140155 & 3.53E-02 & $1.58 E+03$ \\
\hline 70 GENNUM । & 1 & 576,578 & $1.21 E-18$ & 3.05E-19 & $1.76 \mathrm{E}-13$ \\
\hline 72 TUNDRA 5 & 0.98174 & 120.705 & 3.11E-02 & 7.83E-03 & $9.45 E+02$ \\
\hline 73 C-MAC INI & 0.817145 & 291,127 & 0.56102 & 1.41E-01 & $4.11 E+04$ \\
\hline 80 BLUESTAF & 0.55479 & 44,404 & $3.79 E-02$ & 9.54E-03 & $4.24 E+02$ \\
\hline 82 GSI LUMO & 0.916721 & 129.626 & 0.966892 & 2.43E-01 & $3.16 E+04$ \\
\hline 84 ROYAL LA & 0.683747 & 51.561 & 8.81E-02 & 2.22E-02 & $1.14 E+03$ \\
\hline \multicolumn{3}{|c|}{ TOTAL__ } & 509 & 1 & $\$ 287,982$ Lower bound \\
\hline
\end{tabular}

\section{Lower Bound For Efficient Company CANADIAN MARCONI(35) Based on BCC-I (for public companies only)}

\begin{tabular}{llllr} 
DMU & $\begin{array}{c}\text { Score } \\
\text { theta }\end{array}$ & \multicolumn{2}{c}{$\begin{array}{l}\text { Market Cap } \\
\text { s(000s) }\end{array}$} & \\
35 CANADIAR & 1 & 426808.3836 & 1 \\
& & & \\
16 CINRAM if & 1 & 1075690.711 & $8.52 E-17$ \\
47 NEWBRIDI & 1 & 8125481.339 & $6.94 E-17$
\end{tabular}

CANADIAN MARCONI is a self evaluator 


\section{Valuation Analysis for Efficient Company SNIF SECURITY INC (SIC3600)}

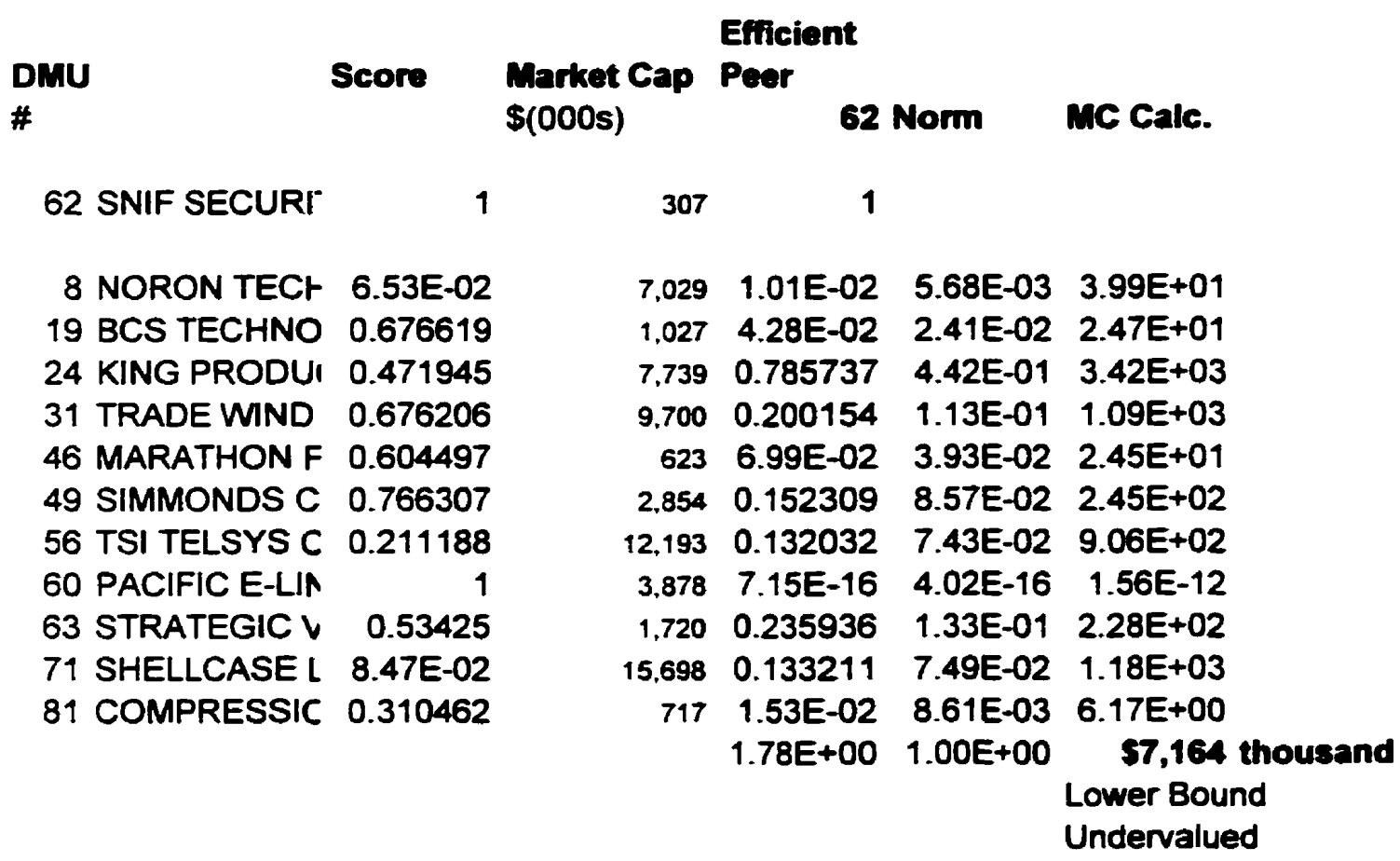


For Efficient Company Primetech Elect. (67) Based on BCC-I (for public companies only, SIC 3600s)

DMU \#
Score

theta

\section{Market Cap Efficient}

S(000s) Peers
Normalized Market Cap Calculation
67 PRIMETECH ELECTRO

53 SYSCAN INTERNATION 0.657407

4 UNITEC INTERNATION, 0.43488

21 CIRCA ENTERPRISES I 0.859468

72 TUNDRA SEMICONDUC $\mathbf{0 . 9 8 1 7 4}$

50 SPECTRUM SIGNAL PF 0.78669

37 COM DEV INTERNATIO 0.863264

25 MEMOTEC COMMUNIC 0.649191

6 LG TECHNOLOGIES GF 0.586585

1 HAMMOND MANUFACT 0.756773

34 CALIAN TECHNOLOGY 0.800142

51 SR TELECOM INC $\quad 0.446954$

74 ELECTROHOME LIMITE 0.67333

57 WESCAM INC

0.628467

80 BLUESTAR BATTERY $\subseteq \quad 0.55479$

54 TEKLOGIX INTERNATIC 0.809908

\begin{tabular}{rrr}
143,365 & 1 & \\
& & \\
7,260 & $2.52 E-03$ & 0.000521 \\
5,571 & $2.53 E-03$ & 0.000523 \\
6,601 & $4.74 E-02$ & 0.009804 \\
120,705 & $7.10 E-02$ & 0.014685 \\
38,637 & $7.60 E-02$ & 0.015720 \\
252,315 & 0.116802 & 0.024159 \\
4,953 & 0.165499 & 0.034231 \\
27,707 & 0.263744 & 0.054552 \\
18,426 & 0.331523 & 0.068571 \\
33,191 & 0.346617 & 0.071693 \\
112,897 & 0.419239 & 0.086714 \\
11,398 & 0.499049 & 0.103221 \\
76,678 & 0.743748 & 0.153834 \\
44,404 & 0.869458 & 0.179835 \\
243,501 & 0.879623 & 0.181938 \\
& 4.834752 & 1.000000 \\
& \multicolumn{3}{c}{ REAL CAP }
\end{tabular}

3.783845053

2.915121209

64.71617937

1772.599234

607.3594372

6095.657577

169.5303344

1511.462381

1263.491358

2379.555791

9789.678782

1176.509313

11795.71314

7985.415051

44302.0801

$\$ 88,920$

$\$ 143,365$ 


\section{Lower Bound for PACIFIC E-LINK CORPORATION (60) Based on BCC-I}

\begin{tabular}{|c|c|c|c|c|c|}
\hline & Score & $\begin{array}{l}\text { ket Cap } \\
\text { OOs) }\end{array}$ & $\begin{array}{l}\text { Lambda } \\
\qquad 60\end{array}$ & & \\
\hline 60 PACIFIC E & 1 & 3,878 & & Norm & MC Calc \\
\hline 12 AWA TEC & 0.847256 & 2429.2787 & 0.023 & 0.007533 & 18. \\
\hline 13 TIR SYSTE & 0.655687 & 1709.641 & 0.00267 & 0.000874 & 1.4950721 \\
\hline 18 ABL CANA & 0.399144 & 13381.932 & 0.0567 & 0.018571 & 248.51227 \\
\hline 19 BCS TECP & 0.676619 & 1026.6865 & 0.0417 & 0.013658 & 14.02232 \\
\hline 22 DBA TELE & 0.639866 & 1955.55915 & 0.0104 & 0.003406 & 6.661166 \\
\hline 23 EIGER TEI & 0.815085 & 8289 & 0.250062 & 0.081902 & 678.88359 \\
\hline 24 KING PRO & 0.471945 & 7738.941 & 0.214263 & 0.070177 & 543.09339 \\
\hline 26 MICROCEI & 0.0664 & 307086.6603 & 0.815481 & 0.267091 & 82020.155 \\
\hline 31 TRADE $M$ & 0.676206 & 9699.5409 & 0.339707 & 0.111263 & 1079.2008 \\
\hline 32 TS TELEC & 1 & 11832.45295 & 0 & 0 & 0 \\
\hline 46 MARATHC & 0.604497 & 622.9986 & 0.128525 & 0.042095 & 26.2 \\
\hline 49 SIMMOND & 0.766307 & 2854.08 & 0.847691 & 0.277641 & 792. \\
\hline 55 TRIPLE CF & 0.525957 & 4978.951 & 0.0339 & 0.011103 & 55.28197 \\
\hline 56 TSI TELSY & 0.211188 & 12192.7525 & 0.120293 & 0.039399 & 480.38494 \\
\hline 62 SNIF SECl & 1 & 306.57981 & $1.62 E-18$ & 5.31E-19 & 1.627E-16 \\
\hline 63 STRATEGI & 0.53425 & 1719.7179 & 0.0642 & 0.021027 & 36.160814 \\
\hline 64 SYMPLEX & 0.562167 & 5879.226 & 0.0802 & 0.026268 & 154.43313 \\
\hline 71 SHELLCAS & 0.0847 & 15697.57 & 0.0113 & 0.003701 & 58.097418 \\
\hline 81 COMPRES & 0.310462 & 717.01003 & 0.0131 & 0.004291 & 3.0763978 \\
\hline
\end{tabular}

$\begin{array}{rrr}\text { TOTAL: } \quad 3.053191 & 1 & \$ 86,216 \text { (000s) } \\ & \text { REAL } & 3,878 \text { (000s) }\end{array}$


For Company SONY (15)

\begin{tabular}{|c|c|c|c|c|}
\hline $\begin{array}{l}\text { DMU } \\
\text { \# }\end{array}$ & & Score & $\begin{array}{l}\text { Market Cap } \\
\$(000 s)\end{array}$ & $\begin{array}{c}\text { Efficient Peers } \\
15\end{array}$ \\
\hline & 15 SONY CORI & 1 & $52,935,385$ & 1 \\
\hline & 1 HAMMOND & 0.756773 & 18,426 & 0 \\
\hline & 2 TURBO GEP & 1 & 80,615 & 0 \\
\hline & 3 INVERPOW & 0.544648 & 7,179 & 0 \\
\hline & 4 UNITEC INT & 0.43488 & 5.571 & 0 \\
\hline
\end{tabular}

For Company Cinram (16)

$\begin{array}{crrr}16 \text { CINRAM INT } & 1 & 1,075,691 & 1 \\ 1 \text { HAMMOND } & 0.756773 & 18,426 & 0 \\ 2 \text { TURBO GEP } & 1 & 80,615 & 0 \\ 3 \text { INVERPOW } & 0.544648 & 7,179 & 0\end{array}$

Cinram is a self evaluator

For Company MITEL (27)

$\begin{array}{lrrr}27 \text { MITEL COR } & 1 & 1,257,378 & 1 \\ 15 \text { SONY CORI } & 1 & 52,935,385 & 1.38 E-15 \\ 73 \text { C-MAC INDI } & 0.817145 & 291.127 & 0.159901 \\ & & & 0.159901\end{array}$

MITEL Corp is a SELF evaluator

\section{Based on BCC-I}

For Company Nortel (29)

\begin{tabular}{lrrrr}
$\begin{array}{l}\text { DMU } \\
\text { \# }\end{array}$ & \multicolumn{1}{c}{ Score } & \multicolumn{1}{l}{$\begin{array}{l}\text { Market Cap } \\
\$(000 s)\end{array}$} & 29 \\
& 29 NORTEL NE & 1 & $50,495,406$ & 1 \\
& & & & \\
& & & & \\
& 80 BLUESTAR & 0.55479 & 44,404 & 0 \\
81 COMPRES & 0.310462 & 717 & 0 \\
82 GSI LUMON & 0.916721 & 129,626 & 0
\end{tabular}

NORTEL is a Self Evaluator 
Lower Bound for NEWBRIDGE NETWORKS CORPORATION (47) based on BCC-1

\begin{tabular}{|c|c|c|c|c|c|}
\hline $\begin{array}{l}\text { DMU } \\
\#\end{array}$ & & $\begin{array}{l}\text { arket Cap } \\
\text { 000s) }\end{array}$ & 47 & & \\
\hline 47 NEWBRIDGE & 1 & $8,125,481$ & 1 & & \\
\hline 15 SONY CORPC & 1 & $52,935,385$ & 4.25E-16 & 5.58E-01 & $2.96 E+07$ \\
\hline 29 NORTEL NET & 1 & $50,495,406$ & $3.36 E-16$ & 4.42E-01 & $2.23 E+07$ \\
\hline & & & $7.61 \mathrm{E}-16$ & $1.00 E+00$ & $\begin{array}{r}\$ 51,858,075 \\
51,858,075\end{array}$ \\
\hline
\end{tabular}

Lower Bound for efficient JEMTEC INC (59)

Based on BCC-1

\begin{tabular}{|c|c|c|c|c|}
\hline $\begin{array}{l}\text { DMU } \\
\#\end{array}$ & Score & $\begin{array}{l}\text { Market Cap } \\
\text { \$(OOOs) }\end{array}$ & 59 & \\
\hline 59 JEMTEC INC & 1 & 330 & 1 & \\
\hline 52 STRATEGIC T & 0.983221 & 3.943 & $\begin{array}{l}0.113323 \\
0.113323\end{array}$ & $\begin{array}{l}1 \quad 3,943,000 \text { lower bound } \\
\text { undervalued }\end{array}$ \\
\hline
\end{tabular}

Lower Bound for INTERNATIONAL DATACASTING CORP based on BCC-I

\begin{tabular}{|c|c|c|c|c|c|}
\hline $\begin{array}{l}\text { DMU } \\
\#\end{array}$ & Score & $\begin{array}{l}\text { Market Cap } \\
\$(000 s)\end{array}$ & 44 & & \\
\hline 44 INTERNATION & 1 & 3,893 & & norm & me calc \\
\hline 5 GLOBAL THEI & 1 & 13221.8604 & $9.54 E-18$ & $1.69 \mathrm{E}-16$ & $2.2342 E-12$ \\
\hline 11 DANBEL INDL & 0.755337 & 5797.576 & 0.0135 & 0.239124 & 1386.34114 \\
\hline 28 NHC COMMUI & 0.670855 & 7317.08222 & 0.027856 & 0.493411 & 3610.32741 \\
\hline \multirow[t]{2}{*}{66 CIRCUIT WOF } & 0.75253 & 288.73734 & 0.0151 & 0.267465 & 77.2271112 \\
\hline & & & $5.65 E-02$ & $1.00 E+00$ & $\$ 5,074$ (000s) \\
\hline
\end{tabular}

\section{Lower Bound for GENNUM CORPORATION (70)} Based on BCC-I

\begin{tabular}{|c|c|c|c|c|c|c|}
\hline $\begin{array}{l}\text { DMU } \\
\#\end{array}$ & Score & \multicolumn{2}{|c|}{$\begin{array}{l}\text { Market Cap } \\
\$(000 s)\end{array}$} & 70 & & \\
\hline 70 GENNUM COF & & 1 & 576.578 & 1 & & \\
\hline 16 CINRAM INTE & & 1 & $1,075,691$ & $2.20 E-17$ & $1.93 E-16$ & $2.08 E-10$ \\
\hline 27 MITEL CORPC & & 1 & $1,257,378$ & $5.55 E-17$ & 4.87E-16 & $6.12 E-10$ \\
\hline 47 NEWBRIDGE & & 1 & $8,125,481$ & $1.20 \mathrm{E}-16$ & $1.05 E-15$ & 8.55E-09 \\
\hline 69 CORECO INC & 0.98338 & & 44,923 & $1.19 E-02$ & $1.04 E-01$ & $4.69 E+03$ \\
\hline 84 ROYAL LASEF & 0.68374 & & 51,561 & $\begin{array}{l}0.102096 \\
1.14 E-01\end{array}$ & $\begin{array}{l}8.96 E-01 \\
1.00 E+00\end{array}$ & $\begin{array}{l}\text { 4.62E+04 } \\
\$ 50,868 \text { lower bound }\end{array}$ \\
\hline
\end{tabular}




\section{FIFTY-PLUS.NET INTERNATIONAL INC (42) (SIC 3600s)}

$\begin{array}{lll}\text { DMU } & \text { Score } & \text { Market Caf Efricient Peers } \\ \# & & \text { S(000s) }\end{array}$

42 FIFTY-PLUS.NET $\mathrm{n}$

8 NORON TECH LTD 6.53E-02

43 GEMSTAR COMML 0.232398

85 WE X.L. HOLDING؛ 0.94369

9 AVANTE TECHNOI 0.582956

81 COMPRESSION \& E 0.310462

19 BCS TECHNOLOGY 0.676619

12 AVVA TECHNOLO 0.847256

83 NEXTRON CORPOF 0.534451

75 LAMBUS ENTERPR 0.709557

4 UNITEC INTERNA] 0.43488

28 NHC COMMUNICA 0.670855

64 SYMPLEX COMMU 0.562167

33 ADVANTEDGE INT 0.180379

13 TIR SYSTEMS LTD 0.655687

46 MARATHON FOOD 0.604497

40 DIMENSIONS WES 0.110285

71 SHELLCASE LTD $\quad$ 8.47E-02

69 CORECO INC $\quad 0.983382$

22 DBA TELECOM CO 0.639866

48 SENSE TECHNOLO 0.374065

84 ROYAL LASER TEC 0.683747

65 WI-LAN INC $\quad 0.87321$

24 KING PRODUCTS $n 0.471945$

36 CELL-LOC INC $\quad 0.980304$

58 EXI TECHNOLOGIE 0.756899

56 TSI TELSYS CORPC 0.211188

55 TRIPLE CROWN EL 0.525957

63 STRATEGIC VISTA 0.53425

78 TRI-VISION INTERI 0.742628

31 TRADE WIND COM 0.676206

23 EIGER TECHNOLO 0.815085

53 SYSCAN INTERNA' 0.657407

52 STRATEGIC TECHP 0.983221

77 PLAINTREE SYSTE 0.866344

18 ABL CANADA INC 0.399144

11 DANBEL INDUSTR 0.755337

66 CIRCUIT WORLD C 0.75253

49 SIMMONDS CAPIT، 0.766307

45 KASTEN CHASE AI 0.994883

3 INVERPOWER CON 0.544648

\begin{tabular}{|c|c|c|c|}
\hline & mbda) & Normaliza & Market Caps \\
\hline 2,404 & $\mathbf{l}$ & & \\
\hline 7.029 & 0.9899 & 0.0342 & 240.374 \\
\hline 4.888 & 0.9882 & 0.0341 & 166.850 \\
\hline 17.083 & 0.9853 & 0.0340 & 581.417 \\
\hline 2.302 & 0.9763 & 0.0337 & 77.645 \\
\hline 717 & 0.9716 & 0.0336 & 24.064 \\
\hline 1.027 & 0.9576 & 0.0331 & 33.963 \\
\hline 2.429 & 0.9525 & 0.0329 & 79.931 \\
\hline 2.426 & 0.9516 & 0.0329 & 79.749 \\
\hline 1.729 & 0.9340 & 0.0323 & 55.794 \\
\hline 5.571 & 0.9285 & 0.0321 & 178.676 \\
\hline 7.317 & 0.9257 & 0.0320 & 233.968 \\
\hline 5.879 & 0.9054 & 0.0313 & 183.879 \\
\hline 19.928 & 0.8992 & 0.0311 & 618.990 \\
\hline 1.710 & 0.8776 & 0.0303 & 51.826 \\
\hline 623 & 0.8703 & $0.030 \mathrm{I}$ & 18.729 \\
\hline 1.970 & 0.8687 & 0.0300 & 59.118 \\
\hline 15.698 & 0.8555 & 0.0295 & 463.863 \\
\hline 44.923 & 0.8480 & 0.0293 & 1315.834 \\
\hline 1.956 & 0.8450 & 0.0292 & 57.081 \\
\hline 61.221 & 0.8379 & 0.0289 & 1771.866 \\
\hline 51.561 & 0.8098 & 0.0280 & 1442.287 \\
\hline 329.339 & 0.8042 & 0.0278 & 9148.869 \\
\hline 7.739 & 0.7727 & 0.0267 & 206.551 \\
\hline 28.669 & 0.7599 & 0.0263 & 752.576 \\
\hline 9.422 & 0.7599 & 0.0262 & 247.298 \\
\hline 12.193 & 0.7477 & 0.0258 & 314.903 \\
\hline 4.979 & 0.7153 & 0.0247 & 123.029 \\
\hline 1.720 & 0.6999 & 0.0242 & 41.574 \\
\hline 29.930 & 0.6641 & 0.0229 & 686.587 \\
\hline 9.700 & 0.6570 & 0.0227 & 220.116 \\
\hline 8.289 & 0.5594 & 0.0193 & 160.181 \\
\hline 7.260 & 0.5220 & 0.0180 & 130.893 \\
\hline 3.943 & 0.4871 & 0.0168 & 66.354 \\
\hline 14.946 & 0.4159 & 0.0144 & 214.702 \\
\hline 13.382 & $0.400 \mathrm{I}$ & 0.0138 & 184.965 \\
\hline 5.798 & 0.3099 & 0.0107 & 62.056 \\
\hline 289 & 0.1531 & 0.0053 & 1.527 \\
\hline 2.854 & 0.1498 & 0.0052 & 14.766 \\
\hline 23.569 & 0.1253 & 0.0043 & 102.007 \\
\hline \multirow[t]{3}{*}{7.179} & 0.0676 & 0.0023 & 16.764 \\
\hline & 28.9493 & 1.0000 & $\$ 20,432$ (000s) \\
\hline & \multicolumn{2}{|c|}{ Real } & $\$ 2,404$ (000s) \\
\hline
\end{tabular}


FOR TS TELECOM(32) (SIC3600)

\begin{tabular}{|c|c|c|c|c|c|}
\hline Seore & Market Caf & ient Pee & & & \\
\hline \# & $\$(000 s)$ & 32 & ormalized & & \\
\hline 85 WE X.L. HI 0.94369 & 17.083 & 0.0060 & 0.0006 & 10.203 & \\
\hline 64 SYMPLEX 0.562167 & 5.879 & 0.0143 & 0.0014 & 8.439 & \\
\hline 9 AVANTE I 0.582956 & 2.302 & 0.0210 & 0.0021 & 4.853 & \\
\hline 12 AVVA TEC 0.847256 & 2.429 & 0.0245 & 0.0025 & 5.974 & \\
\hline 83 NEXTRON 0.534451 & $2-426$ & 0.0452 & 0.0045 & 11.007 & \\
\hline 21 CIRCA EN 0.859468 & 6.601 & 0.0737 & 0.0074 & 48.832 & \\
\hline 33 ADVANTE 0.180379 & 19.928 & 0.0891 & 0.0089 & 178.221 & \\
\hline 72 TUNDRA $\leq \quad 0.98174$ & 120.705 & 0.1004 & 0.0101 & 1216.243 & \\
\hline 13 TIR SYSTE 0.655687 & 1.710 & 0.1198 & 0.0120 & 20.554 & \\
\hline 78 TRI-VISIOI 0.742628 & 29.930 & 0.1415 & 0.0142 & 425.022 & \\
\hline 22 DBA TELE 0.639866 & 1.956 & 0.1446 & 0.0145 & 28.377 & \\
\hline 65 WI-LAN IN 0.87321 & 329.339 & 0.1599 & 0.0160 & 5285.542 & \\
\hline 23 EIGER TEC 0.815085 & 8.289 & 0.1798 & 0.0180 & 149.603 & \\
\hline 57 WESCAM: 0.628467 & 76.678 & 0.1979 & 0.0199 & 1522.969 & \\
\hline 55 TRIPLE CF 0.525957 & 4.979 & 0.2507 & 0.0252 & 125.311 & \\
\hline 61 SIERRA W 0.996348 & 32.735 & 0.2631 & 0.0264 & 864.595 & \\
\hline 74 ELECTROI 0.67333 & 11.398 & 0.4257 & 0.0427 & 487.049 & \\
\hline I HAMMON 0.756773 & 18.426 & 0.4467 & 0.0448 & 826.268 & \\
\hline 77 PLAINTRE 0.866344 & 14.946 & 0.4958 & 0.0498 & 743.788 & \\
\hline 18 ABL CANE 0.399144 & 13.382 & 0.5432 & 0.0545 & 729.641 & \\
\hline 34 CALIAN T: 0.800142 & $33.19 !$ & 0.5935 & 0.0596 & 1977.292 & \\
\hline 39 CYGNAL 70.589195 & 8.637 & $0.688 I$ & 0.0691 & 596.540 & \\
\hline 6 LG TECHN 0.586585 & 27.707 & 0.7302 & 0.0733 & 2030.833 & \\
\hline 45 KASTEN C 0.994883 & 23.569 & 0.7617 & 0.0765 & 1802.024 & \\
\hline 25 MEMOTEC 0.649191 & 4.953 & 0.8199 & 0.0823 & 407.562 & \\
\hline 50 SPECTRUN 0.78669 & 38.637 & 0.8465 & 0.0850 & 3282.881 & \\
\hline [4 DIGITAL F 0.88428 ] & 28.123 & 0.8591 & 0.0862 & 2425.045 & \\
\hline 3 INVERPOV 0.544648 & 7.179 & 0.9208 & 0.0924 & 663.557 & \\
\hline & & 9.96 & 1.00 & 25,878 REAL MC & \\
\hline
\end{tabular}

\section{FOR CAMCO INC (7)}

\begin{tabular}{rrrrrr}
\hline 52 STRATEGI $0.98322 I$ & 3943.1541 & 0.00122 & 0.00062 & 2.454 \\
6 LG TECHN 0.586585 & 27706.969 & 0.00603 & 0.00308 & 85.218 \\
23 EIGER TEC 0.815085 & 8289 & 0.0107 & 0.00546 & 45.239 \\
82 GSI LUMO 0.916721 & 129625.6 & 0.0196 & 0.01000 & 1295.904 \\
34 CALIAN T. 0.800142 & 33191.018 & 0.0599 & 0.03055 & 1014.082 \\
74 ELECTROI 0.67333 & 11397.939 & 0.0752 & 0.03836 & 437.190 \\
54 TEKLOGD 0.809908 & 243501.46 & 0.0755 & 0.03851 & 9377.226 \\
37 COM DEV 0.863264 & 252315.3 & 0.0824 & 0.04203 & 10604.658 \\
80 BLUESTAI 0.55479 & 44404.112 & 0.0926 & 0.04723 & 2097.297 \\
51 SR TELECI 0.446954 & 112896.71 & 0.1363 & 0.06950 & 7845.925 \\
26 MICROCEI 0.0664 & 307086.66 & 0.1845 & 0.09412 & 28902.052 \\
73 C-MAC IN 0.817145 & 291126.88 & 0.2203 & 0.11235 & 32707.433 \\
I HAMMON. 0.756773 & 18426.08 & 0.2217 & 0.11310 & 2083.925 & \\
10 SEMI-TECI 0.214508 & 10025.976 & 0.7746 & 0.39511 & 3961.346 \\
& & 1.9605 & 1 & $\mathbf{S 1 0 0 , 4 6 0}$ REAL MC & $\mathbf{5 1 0 0 , 0 0 0}$
\end{tabular}




\section{APPENDIX D}

\section{Analysis of Efficient and Inefficient Companies SIC 3700}


BUDD CANADA INC (3) (SIC 3700s)

Based on BCC-l for public companies

DMU
\#

This is a lower bound for the efficient company, BUDD Canada, based on the inefficient companies being compared to it

Thus it seems that BUDD CANADA is rather undervalued 


\section{LINAMAR CORPORATION (6) (SIC 3700s) \\ Based on BCC-I for public companies}

\begin{tabular}{|c|c|c|c|c|c|c|}
\hline $\begin{array}{l}\text { DMU } \\
\#\end{array}$ & Score & \multicolumn{2}{|c|}{$\begin{array}{c}\text { Market } \\
\text { PRImn Capitalizetir }\end{array}$} & \multicolumn{2}{|c|}{$\begin{array}{l}\text { Efricient Peer } \\
6\end{array}$} & \\
\hline 6 LINAMAR CC & 1 & 3714 & $\begin{array}{r}10003) 1998 \\
1,792,517\end{array}$ & 1 & & \\
\hline & & & & \multicolumn{2}{|c|}{1 Norm Mc Calc. } & \\
\hline 3 BUDD CANAC & 1 & 3714 & 116.772 & 0.0000 & 0 & 0.0000 \\
\hline 1 GENERAL MC & 1 & 3711 & $86,392,582$ & 0.0000 & 0 & 0.0000 \\
\hline 2 A.E. VENTUR & 0.79684 & 3714 & 627 & 0.0000 & 0 & 0.0000 \\
\hline 4 DECOMA INT & 0.57823 & 3714 & 560,656 & 0.4793 & 0.386 & 216331.3983 \\
\hline 5 DEVTEK COF & 0.66674 & 3714 & 99,709 & 0.1181 & 0.095 & 9481.6534 \\
\hline 7 MAGNA INTE & 1 & 3714 & $7,374,103$ & 0.0000 & 0 & 0.0000 \\
\hline 8 MERCH PERI & 0.65439 & 3714 & 2,869 & 0.0000 & 0 & 0.0000 \\
\hline 9 NORTHSIDE & 0.89812 & 3714 & 14,056 & 0.0227 & 0.018 & 256.8636 \\
\hline 10 ROSE CORPI & 0.70626 & 3714 & 25,150 & 0.0000 & 0 & 0.0000 \\
\hline 11 SPECTRA PF & 1 & 3714 & 525,280 & 0.0000 & 0 & 0.0000 \\
\hline 12 STACKPOLE & 0.63128 & 3714 & 131,497 & 0.0000 & 0 & 0.0000 \\
\hline 13 TESMA INTEI & 0.99948 & 3714 & 570.124 & 0.4697 & 0.378 & 215595.3103 \\
\hline 14 WESCAST IN & 1 & 3714 & 574,300 & 0.0000 & $7 E-17$ & 0.0000 \\
\hline 15 TRAILMOBILI & 0.97208 & 3715 & 14,342 & 0.0000 & 0 & 0.0000 \\
\hline 16 GLENDALE If & 0.51504 & 3716 & 47,948 & 0.0000 & 0 & 0.0000 \\
\hline 17 AVCORP IND & 0.50231 & 3728 & 45,730 & 0.0000 & 0 & 0.0000 \\
\hline 18 HEROUX INC & 0.5871 & 3728 & 62,462 & 0.0000 & 0 & 0.0000 \\
\hline 19 MAGELLAN A & 0.62997 & 3728 & 496,389 & 0.1523 & 0.123 & 60868.6475 \\
\hline 20 SERENA RES & 0.72956 & 3731 & 572 & 0.0000 & 0 & 0.0000 \\
\hline 21 TEMPLAR RE & 1 & 3732 & 4,576 & 0.0000 & 0 & 0.0000 \\
\hline 22 BOMBARDIEI & 1 & 3743 & $7,502,049$ & 0.0000 & 0 & 0.0000 \\
\hline & & & Sum: & 1.24244 & 1 & $\begin{array}{l}\$ 502,534 \text { Calculated } \\
\$ 1,792,517 \text { Real }\end{array}$ \\
\hline
\end{tabular}

This is a lower bound for the efficient company, LINAMAR CORP., based on the inefficient companies being compared to it 


\section{AVCORP INDUSTRIES INC (SIC 3700) Based on BCC-I for public company}

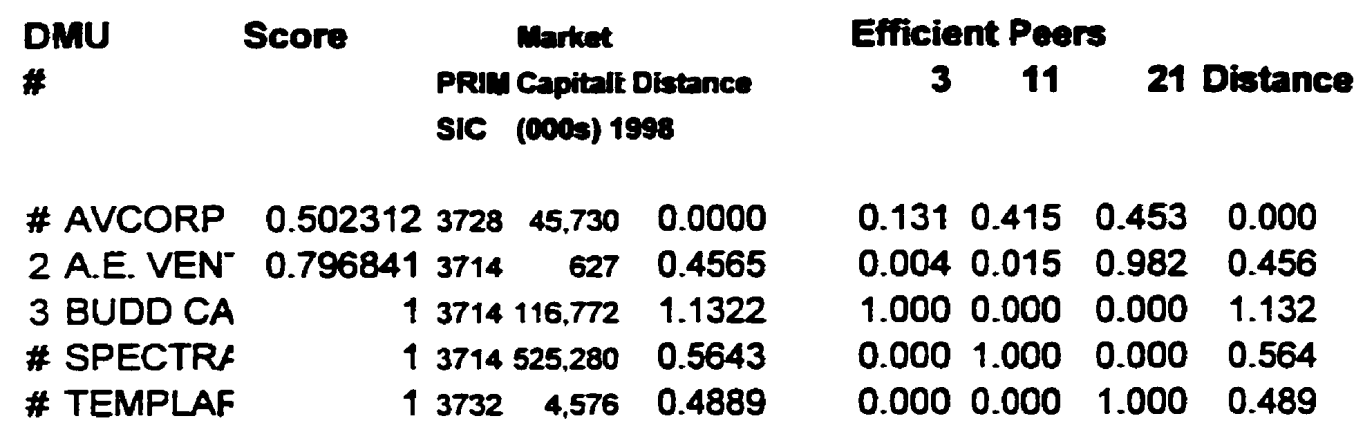

AVCORP only has 4 other peers, 3 of which are efficient

As can be seen from the distances, AVCORP is closest to AE Venture's ( $d=0.456$ )

Similarity of the efficiency scores (difference between AVCORP score (0.50):

AE Ventur -0.294529

Templar $\quad-0.497688$

Spectra $\quad-0.497688$

AVCORP efficiency score is not close to any of the others, the closest is AE Venture at 0.797

Similarity of the Market Cap. (difference between AVCORP market cap. $(\$ 45,730,000)$ :

AE Ventur $\quad 45,103$

Templar $\quad 41,154$

Spectra $\quad-479,550$

AVCORP market cap is not close to any of the others.

Range for AVCORP market cap. based on peer group is between $\$ 627,000$ and $\$ 525,280,000$ AVCORP real market cap. of $\$ 45,730,000$ falls into such a great range with ease

\section{Market Capitalization of AVCORP based on EFFICIENT PEERS}

$[(0.131 * 116772)+(0.415 * 525280)+(0.45 * 4576)$

is $\$ 235,632$ million 


\section{APPENDIX E}

\section{Analysis of Efficient and Inefficient Companies SIC 2000}


Valuation Analysis for A. L. VAN HOUTTE LTEE (SIC2000)

\begin{tabular}{|c|c|c|c|c|c|c|}
\hline \multirow{2}{*}{$\begin{array}{l}\text { DMU } \\
\begin{array}{l}\text { \# } \\
43 \text { A. L. VF }\end{array}\end{array}$} & Score & \multicolumn{2}{|c|}{$\begin{array}{c}\text { Masket } \\
\text { PRImaR) Capibulizat }\end{array}$} & \multicolumn{2}{|c|}{ 43.0000 Norm. } & \multirow[t]{2}{*}{ MC Calc. } \\
\hline & 1 & 2095 & 632,441 & 1.0000 & & \\
\hline 7 SAPUT. & 0.787 & 2022 & $2,107,819$ & 0.8086 & 0.2161 & $\$ 455,509$ \\
\hline 15 RIDLEY & 0.9894 & 2048 & 160.050 & 0.7010 & 0.1873 & $\$ 29,983$ \\
\hline 10 LASSO & 0.9632 & 2034 & 17.825 & 0.4980 & 0.1331 & $\$ 2,372$ \\
\hline $31 \mathrm{VINCOI}$ & 0.7498 & 2084 & 192,114 & 0.4271 & 0.1141 & $\$ 21,928$ \\
\hline 25 SLEEM & 0.8323 & 2082 & 126,836 & 0.3086 & 0.0825 & $\$ 10,462$ \\
\hline 35 CLEAR & 0.9535 & 2086 & 5,135 & 0.2984 & 0.0798 & $\$ 410$ \\
\hline 28 ANDRE & 0.7103 & 2084 & 79,826 & 0.1964 & 0.0525 & $\$ 4,189$ \\
\hline 27 UNIBRC & 0.9878 & 2082 & 33,828 & 0.1176 & 0.0314 & $\$ 1,063$ \\
\hline 44 ARCTIC & 0.6402 & 2097 & 38,002 & 0.1053 & 0.0281 & $\$ 1,069$ \\
\hline 22 BIG RO & 0.6985 & 2082 & 19,445 & 0.1013 & 0.0271 & $\$ 527$ \\
\hline 23 BRICK & 0.7797 & 2082 & 15,421 & 0.0669 & 0.0179 & $\$ 276$ \\
\hline 29 MAGNC & 0.6915 & 2084 & 13,310 & 0.0614 & 0.0164 & $\$ 218$ \\
\hline 8 DELICII & 0.5398 & $20<4$ & 17.246 & 0.0308 & 0.0082 & $\$ 142$ \\
\hline 39 URBAN & 0.8089 & 2086 & 12,878 & 0.0083 & 0.0022 & $\$ 28$ \\
\hline 11 GLOBA & 0.5749 & 2038 & 14,410 & 0.0037 & 0.0010 & $\$ 14$ \\
\hline 20 AFRICF & 0.8332 & 2066 & 683 & 0.0031 & 0.0008 & $\$ 1$ \\
\hline 34 ARROV & 0.8705 & 2086 & 962 & 0.0030 & 0.0008 & $\$ 1$ \\
\hline 32 HIGHW & 0.7103 & 2085 & 2,373 & 0.0022 & 0.0006 & $\$ 1$ \\
\hline 26 TREE E & 0.8365 & 2082 & 1,917 & 0.0002 & 0.0000 & so \\
\hline 24 FOSTE & 1 & 2082 & 556,622 & 0.0000 & 0.0000 & $\$ 0$ \\
\hline 17 CANAD & 1 & 2051 & 449,753 & 0.0000 & 0.0000 & so \\
\hline & & & & 3.7418 & 1.0000 & $\begin{array}{l}\text { \$528,193 thousand } \\
\text { LOWER BOUND }\end{array}$ \\
\hline
\end{tabular}




\section{Valuation Analysis of AMT Fine Food (SIC2000)}

\begin{tabular}{|c|c|c|c|c|c|}
\hline $\begin{array}{l}\text { DMU } \\
\#\end{array}$ & Score & $\begin{array}{l}\text { Market } \\
\text { Capitaliza } \\
\text { (0000) 19: }\end{array}$ & $\begin{array}{l}\text { Efficient } \\
\text { Peer } \\
\text { AMT }\end{array}$ & norm. & me calc. \\
\hline 4 AMT FINE FI & 1 & 11,173 & 1 & & \\
\hline 34 ARROWHEA & 0.8705 & 962 & 0.9897 & 0.082 & $\$ 79$ \\
\hline 6 TML FOODS & 0.2571 & 1,782 & 0.9410 & 0.078 & $\$ 139$ \\
\hline 29 MAGNOTTA & 0.6915 & 13,310 & 0.9376 & 0.078 & $\$ 1.037$ \\
\hline 18 BETA BRAN & 0.3039 & 47,999 & 0.9359 & 0.078 & $\$ 3,732$ \\
\hline 23 BRICK BRE & 0.7797 & 15,421 & 0.9307 & 0.077 & $\$ 1,192$ \\
\hline 37 LEADING BF & 0.4515 & 8,570 & 0.9256 & 0.077 & $\$ 659$ \\
\hline 27 UNIBROUE I & 0.9878 & 33,828 & 0.8817 & 0.073 & $\$ 2.478$ \\
\hline 39 URBAN JUIC & 0.8089 & 12,878 & 0.8568 & 0.071 & $\$ 917$ \\
\hline 14 AGRO PACII & 0.7703 & 10,874 & 0.8567 & 0.071 & $\$ 774$ \\
\hline 42 LEF MCLEA & 0.7971 & 3,381 & 0.8124 & 0.067 & $\$ 228$ \\
\hline 3 SEPP'S GOI & 0.5941 & 27,532 & 0.7773 & 0.065 & $\$ 1,778$ \\
\hline 25 SLEEMAN B & 0.8323 & 126.836 & 0.6861 & 0.057 & $\$ 7,230$ \\
\hline 22 BIG ROCKE & 0.6985 & 19,445 & 0.6795 & 0.056 & $\$ 1,098$ \\
\hline 19 SMALL FRY & 0.7801 & 26,740 & 0.3538 & 0.029 & $\$ 786$ \\
\hline 28 ANDRES W & 0.7103 & 79,826 & 0.2890 & 0.024 & $\$ 1,917$ \\
\hline 32 HIGHWOOD & 0.7103 & 2.373 & 0.1831 & 0.015 & $\$ 36$ \\
\hline 24 FOSTER'S E & 1 & 556,622 & 0.0000 & 0.000 & so \\
\hline 12 DOVER INDI & 1 & 53,129 & 0.0000 & 0.000 & so \\
\hline \multirow[t]{2}{*}{9 SUN-RYPE $F$} & 1 & 15,889 & 0.0000 & 0.000 & so \\
\hline & & & 12.037 & \multicolumn{2}{|r|}{ lower bound } \\
\hline
\end{tabular}




\section{Valuation Analysis for AGRO \& LEADING SIC2000}

\begin{tabular}{|c|c|c|c|c|c|}
\hline Score & $\begin{array}{l}M C \\
\$(000-3)\end{array}$ & $\begin{array}{l}\text { Efficient } \\
\text { SCHNEIt }\end{array}$ & $\begin{array}{l}\text { eer } \\
\text { AMT FIN FLETCH }\end{array}$ & Distance & \\
\hline$A G R O$ & 10,874 & $6.91 E-02$ & $0.856667 .43 E-02$ & 0.0000 & 0.00 \\
\hline LES & 8,570 & $1.23 E-03$ & $0.925617 .32 E-02$ & 0.0094 & 0.000 \\
\hline 2 SCHNEIDE 1 & 139,628 & 1 & & 1.6060 & $1.85 \mathrm{~s}$ \\
\hline 4 AMT FII & 11,173 & & 1 & 0.0308 & 0.010 \\
\hline 5 FLETCHER 1 & 5,936 & & 1 & 1.5956 & 1.715 \\
\hline
\end{tabular}

Agro is similar to Leading and AMT

Market Value range: $\$ 8,570,000$ to $\$ 11,173,000$

Upper Bound

$\$ 19,654$ thousand

Leading is similar to Agro and AMT

Market Value: $\$ 10,874,000$ to $\$ 11,173,000$

Upper Bound

\& 10,947 thousand 


\title{
APPENDIX F
}

\author{
Analysis Utilizing All \\ 452 Companies
}




\section{HAMMOND compared to all 452 Companies}

\begin{tabular}{|c|c|c|c|c|c|c|c|c|}
\hline \multirow{2}{*}{$\begin{array}{l}\text { DMU } \\
\text { \# }\end{array}$} & \multirow[t]{2}{*}{ Score } & \multirow{2}{*}{\multicolumn{2}{|c|}{ Market Value SIC }} & \multirow[t]{2}{*}{ Distance } & \multicolumn{2}{|c|}{ Efficient Peers } & \multirow[b]{2}{*}{372} & \multirow{3}{*}{$\begin{array}{r}443 \\
0.075\end{array}$} \\
\hline & & & & & 73 & 322 & & \\
\hline 175 HAMMOP & 0.51431 & $18,426,080$ & 3612 & 0.0000 & 0.667 & 0.187 & 0.070 & \\
\hline 83 CHATEA & 0.82904 & $45,927,284$ & 2331 & 0.0268 & 0.764 & 0.064 & 0.053 & \\
\hline 59 BUHLER & 0.87389 & $66,664,560$ & 3523 & 0.0248 & 0.751 & 0.088 & 0.016 & \\
\hline 296 PATHEO & 0.52526 & $142,814,041$ & 2834 & 0.0366 & 0.565 & 0.341 & 0.019 & 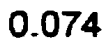 \\
\hline 226 LASSON & 0.63848 & $17,824,705$ & 2034 & 0.0463 & 0.543 & 0.156 & 0.054 & \\
\hline 231 LEF MCL & 0.58608 & $3,380,635$ & 2092 & 0.1897 & 0.440 & 0.547 & 0.010 & \\
\hline 141 EXCO TE & 0.73515 & $138,405,738$ & 3544 & 0.1483 & 0.383 & 0.305 & 0.012 & 1.0 \\
\hline 99 CONSOL & 0.44399 & $5,177,589$ & 2875 & 0.4791 & 0.249 & 0.732 & 0.007 & 0 \\
\hline 302 PFB COF & 0.94048 & $24,080,255$ & 2821 & 0.4206 & 0.245 & 0.675 & 0.007 & .07 \\
\hline 284 NTS CON & 0.60877 & $48,091,341$ & 3571 & 0.4685 & 0.226 & 0.707 & 0.005 & \\
\hline 163 GLENDA & 0.31597 & $47,948,068$ & 3716 & 0.5248 & 0.164 & 0.708 & 0.073 & 0 \\
\hline 360 SICO INC & 0.5653 & $71,058,787$ & 2851 & 0.4547 & 0.158 & 0.625 & 0.089 & 0.12 \\
\hline 242 MAGNO1 & 0.39093 & $13,310,001$ & 2084 & 0.6923 & 0.147 & 0.831 & 0.003 & 0.02 \\
\hline 210 IPL INC & 0.69724 & $80,755,275$ & 3081 & 0.5509 & 0.110 & 0.658 & 0.028 & 0.20 \\
\hline 3 AASTRA & 0.69365 & $46,090,505$ & 3661 & 0.8635 & 0.075 & 0.899 & 0.016 & 0.01 \\
\hline 308 POLYAIF & 0.41828 & $27,260,000$ & 3086 & 0.7992 & 0.054 & 0.838 & 0.043 & 0.06 \\
\hline 93 CML IND & 0.50334 & $7,109,353$ & 2621 & 0.9865 & 0.029 & 0.944 & 0.014 & 0.0 \\
\hline 261 MOBILE & 0.52422 & $33,407,325$ & 3585 & 0.9949 & 0.013 & 0.937 & 0.007 & 0.0 \\
\hline 73 CARBITE & 1 & $9,240,498$ & 3949 & 0.1564 & 1.000 & 0.000 & 0.000 & 0.00 \\
\hline 322 PROMAT & 1 & $10,374,300$ & 3841 & 1.1160 & 0.000 & 1.000 & 0.000 & 0.00 \\
\hline 372 SMED IN & 1 & $87,643,098$ & 2522 & 1.3514 & 0.000 & 0.000 & 1.000 & 0.00 \\
\hline 443 WESCAS & 1 & $574,299,775$ & 3714 & 1.3404 & 0.000 & 0.000 & 0.000 & 1.00 \\
\hline
\end{tabular}

Initially, Hammond was found to have 21 peers

\begin{tabular}{lrrrr}
\multicolumn{5}{c}{ RANKED BY DISTANCE TO HAMMOND } \\
HAMMOP & 0.51431 & $18,426,080$ & 3612 & 0.0000 \\
BUHLER & 0.87389 & $66,664,560$ & 3523 & 0.0248 \\
CHATEA & 0.82904 & $45,927,284$ & 2331 & 0.0268 \\
PATHEO & 0.52526 & $142,814,041$ & 2834 & 0.0366 \\
LASSON & 0.63848 & $17,824,705$ & 2034 & 0.0463 \\
EXCO TE & 0.73515 & $138,405,738$ & 3544 & 0.1483 \\
CARBITE & 1 & $9,240,498$ & 3949 & 0.1564 \\
LEF MCL & 0.58608 & $3,380,635$ & 2092 & 0.1897 \\
PFB COF & 0.94048 & $24,080,255$ & 2821 & 0.4206 \\
SICO INC & 0.5653 & $71,058,787$ & 2851 & 0.4547 \\
NTS CO & 0.60877 & $48,091,341$ & 3571 & 0.4685 \\
CONSOL & 0.44399 & $5,177,589$ & 2875 & 0.4791 \\
GLENDA & 0.31597 & $47,948,068$ & 3716 & 0.5248 \\
IPL INC & 0.69724 & $80,755,275$ & 3081 & 0.5509
\end{tabular}




\begin{tabular}{|c|c|c|c|c|}
\hline MAGNOT & 0.39093 & $13,310,001$ & 2084 & 0.6923 \\
\hline POLYAIF & 0.41828 & $27,260,000$ & 3086 & 0.7992 \\
\hline AASTRA & 0.69365 & $46,090,505$ & 3661 & 0.8635 \\
\hline CML IND & 0.50334 & $7,109,353$ & 2621 & 0.9865 \\
\hline MOBILE & 0.52422 & $33,407,325$ & 3585 & 0.9949 \\
\hline \multicolumn{5}{|c|}{ RANKED BY EFFICIENCY } \\
\hline GLENDA & 0.31597 & $47,948,068$ & 3716 & 0.5248 \\
\hline MAGNOT & 0.39093 & $13,310,001$ & 2084 & 0.6923 \\
\hline POLYAIF & 0.41828 & $27,260,000$ & 3086 & 0.7992 \\
\hline CONSOL & 0.44399 & $5,177,589$ & 2875 & 0.4791 \\
\hline CML IND & 0.50334 & $7,109,353$ & 2621 & 0.9865 \\
\hline HAMMOI & 0.51431 & $18,426,080$ & 3612 & 0.0000 \\
\hline MOBILE. & 0.52422 & $33,407,325$ & 3585 & 0.9949 \\
\hline PATHEO & 0.52526 & $142,814,041$ & 2834 & 0.0366 \\
\hline SICO INC & 0.5653 & $71,058,787$ & 2851 & 0.4547 \\
\hline LEF MCL & 0.58608 & $3,380,635$ & 2092 & 0.1897 \\
\hline NTS CON & 0.60877 & $48,091,341$ & 3571 & 0.4685 \\
\hline LASSON & 0.63848 & $17,824,705$ & 2034 & 0.0463 \\
\hline AASTRA & 0.69365 & $46,090,505$ & 3661 & 0.8635 \\
\hline IPL INC & 0.69724 & $80,755,275$ & 3081 & 0.5509 \\
\hline EXCO TE & 0.73515 & $138,405,738$ & 3544 & 0.1483 \\
\hline CHATEA & 0.82904 & $45,927,284$ & 2331 & 0.0268 \\
\hline CHATEA & 0.87389 & $66,664,560$ & 3523 & 0.0248 \\
\hline CHATEA & 0.94048 & $24,080,255$ & 2821 & 0.4206 \\
\hline $\mathrm{Cr}$ & 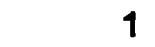 & $9,240,498$ & 3949 & 0.1564 \\
\hline
\end{tabular}

RANKED BY MARKET CAPITALIZATION

$\begin{array}{lrrrr}\text { LEF MCL } & 0.58608 & 3,380,635 & 2092 & 0.1897 \\ \text { CONSOL } & 0.44399 & 5,177,589 & 2875 & 0.4791 \\ \text { CML IND } & 0.50334 & 7,109,353 & 2621 & 0.9865 \\ \text { CARBITE } & 1 & 9,240,498 & 3949 & 0.1564 \\ \text { MAGNO1 } & 0.39093 & 13,310,001 & 2084 & 0.6923 \\ \text { LASSON } & 0.63848 & 17,824,705 & 2034 & 0.0463 \\ \text { HAMMOF } & 0.51431 & 18,426,080 & 3612 & 0.0000 \\ \text { PFB COF } & 0.94048 & 24,080,255 & 2821 & 0.4206 \\ \text { POLYAIF } & 0.41828 & 27,260,000 & 3086 & 0.7992 \\ \text { MOBILE } & 0.52422 & 33,407,325 & 3585 & 0.9949 \\ \text { CHATEA } & 0.82904 & 45,927,284 & 2331 & 0.0268 \\ \text { AASTRA } & 0.69365 & 46,090,505 & 3661 & 0.8635 \\ \text { GLENDA } & 0.31597 & 47,948,068 & 3716 & 0.5248 \\ \text { NTS CON } & 0.60877 & 48,091,341 & 3571 & 0.4685 \\ \text { BUHLER } & 0.87389 & 66,664,560 & 3523 & 0.0248 \\ \text { SICO INC } & 0.5653 & 71,058,787 & 2851 & 0.4547 \\ \text { IPL INC } & 0.69724 & 80,755,275 & 3081 & 0.5509 \\ \text { EXCO TE } & 0.73515 & 138,405,738 & 3544 & 0.1483 \\ \text { PATHEO } & 0.52526 & 142,814,041 & 2834 & 0.0366\end{array}$


MARKET VALUE Of WESCAST INDUSTRIES INC

Compared to All 452 Companies

\begin{tabular}{|c|c|c|c|c|c|c|c|}
\hline DMU & Score & C & MC & 443 & & & \\
\hline 443 WESCAST INDI & 1 & 3714 & 574,300 & & RM & C CALC & \\
\hline 33 ATS AUTOMATIC & 0.7513 & 3569 & 995,530 & 0.757 & 0.0400 & 39815.81 & 1 \\
\hline 300 PERKINS PAPER & 0.746 & 2676 & 293,634 & 0.744 & 0.0393 & 11538.89 & 2 \\
\hline 66 CANADIAN MARC & 0.8897 & 3663 & 426,808 & 0.688 & 0.0363 & 15499.48 & 3 \\
\hline 91 C-MAC INDUSTR & 0.5323 & 3679 & 291,127 & 0.679 & 0.0359 & 10438.65 & 4 \\
\hline 402 TESMA INTERNA & 0.8329 & 3714 & 570,124 & 0.668 & 0.0353 & 20112.65 & 5 \\
\hline 127 DOREL INDUSTF & 0.6254 & 2512 & 682,294 & 0.639 & 0.0338 & 23032.51 & 6 \\
\hline 114 DECOMA INTERP & 0.5014 & 3714 & 560,656 & 0.625 & 0.0330 & 18493.70 & 7 \\
\hline 344 SAMUEL MANU-7 & 0.5054 & 3316 & 310,901 & 0.618 & 0.0327 & 10154.30 & 8 \\
\hline 251 MDC CORPORAT & 0.3267 & 2759 & 242.559 & 0.617 & 0.0326 & 7909.67 & 9 \\
\hline 410 TOROMONT INDI & 0.5549 & 3585 & 456,602 & 0.569 & 0.0301 & 13723.41 & 10 \\
\hline 204 INTERTAPE POL' & 0.4225 & 2295 & 982,579 & 0.566 & 0.0299 & 29384.66 & 11 \\
\hline 239 MAGELLAN AERI & 0.5323 & 3728 & 496,389 & 0.505 & 0.0267 & 13248.18 & 12 \\
\hline 447 WINPAK LTD & 0.6517 & 2656 & 318.500 & 0.500 & 0.0264 & 8413.73 & 13 \\
\hline 432 VELAN INC & 0.7829 & 3494 & 793.613 & 0.500 & 0.0264 & 20946.55 & 14 \\
\hline 124 DOMCO TARKET & 0.7649 & 3996 & 207,110 & 0.480 & 0.0253 & 5247.18 & 15 \\
\hline 67 CANAM MANAC I & 0.4373 & 3441 & 177.740 . & 0.461 & 0.0243 & 4323.78 & 16 \\
\hline 416 TRITECH PRECIS & 0.4673 & 3369 & 194,222 & 0.447 & 0.0236 & 4588.68 & 17 \\
\hline 63 CANADA BREAD & 0.8189 & 2051 & 449,753 & 0.392 & 0.0207 & 9321.81 & 18 \\
\hline 1 A. L. VAN HOUTT & 0.9167 & 2095 & 632,441 & 0.391 & 0.0206 & $\{3055.57$ & 19 \\
\hline 32 AT PLASTICS INC & 0.4201 & 2821 & 153,632 & 0.382 & 0.0202 & 3100.59 & 20 \\
\hline 136 ENERFLEX SYST & 0.8131 & 3563 & 420,532 & 0.366 & 0.0193 & 8125.80 & 21 \\
\hline 232 LEITCH TECHNO & 0.9981 & 3679 & $1.031,559$ & 0.359 & 0.0189 & 19547.02 & 22 \\
\hline 406 TIMBERWEST FC & 0.761 & 2411 & 616,034 & 0.347 & 0.0183 & 11289.75 & 23 \\
\hline 294 PAPERBOARD IN & 0.3156 & 2631 & 95,201 & 0.333 & 0.0176 & 1673.56 & 24 \\
\hline 334 RIDLEY INC & 0.5976 & 2048 & 160.050 & 0.308 & 0.0163 & 2603.03 & 25 \\
\hline 433 VENTRA GROUP & 0.4732 & 3465 & 159,396 & 0.307 & 0.0162 & 2583.31 & 26 \\
\hline 141 EXCO TECHNOL & 0.7351 & 3544 & 138.406 & 0.300 & 0.0158 & 2191.58 & 27 \\
\hline 337 ROLLAND INC & 0.5274 & 2621 & 149,295 & 0.287 & 0.0152 & 2266.88 & 28 \\
\hline 345 SAPUTO GROUP & 0.5408 & 2022 & $2,107,819$ & 0.277 & 0.0146 & 30834.88 & 29 \\
\hline 357 SHAW INDUSTRI & 0.8167 & 2899 & 767.740 & 0.271 & 0.0143 & 10999.64 & 30 \\
\hline 226 LASSONDE INDL & 0.6385 & 2034 & 17,825 & 0.247 & 0.0131 & 232.77 & 31 \\
\hline 116 DEVTEK CORPO & 0.4756 & 3714 & 99,709 & 0.235 & 0.0124 & 1236.16 & 32 \\
\hline 210 IPL INC & 0.6972 & 3081 & 80,755 & 0.204 & 0.0108 & 871.24 & 33 \\
\hline 12 AINSWORTH LUN & 0.2531 & 2411 & $\mathbf{4 4 , 4 6 7}$ & 0.199 & 0.0105 & 467.50 & 34 \\
\hline 159 GENNUM CORPC & 0.9264 & 3674 & $\mathbf{5 7 6 , 5 7 8}$ & 0.188 & 0.0099 & 5715.96 & 35 \\
\hline 439 WAJAX LIMITED & 0.4234 & 3569 & 120,082 & 0.187 & 0.0099 & 1185.35 & 36 \\
\hline 382 STACKPOLE LIM & 0.6015 & 3714 & 131,497 & 0.184 & 0.0097 & 1276.12 & 37 \\
\hline 253 MERCER INTERฬ & 0.5056 & 2611 & 138,461 & 0.161 & 0.0085 & 1177.89 & 38 \\
\hline 318 PRIMETECH ELE & 0.943 & 3672 & 143,365 & 0.157 & 0.0083 & 1189.87 & 39 \\
\hline 59 BUHLER INDUST & 0.8739 & 3523 & 66,665 & 0.145 & 0.0076 & 509.71 & 40 \\
\hline 144 FANTOM TECHN & 0.7381 & 3589 & 137,839 & 0.134 & 0.0071 & 976.71 & 41 \\
\hline 435 VINCOR INTERN & 0.5921 & 2084 & 192,114 & 0.133 & 0.0070 & 1354.22 & 42 \\
\hline 324 PRUDENTIAL STI & 0.9378 & 3498 & 205,602 & 0.131 & 0.0069 & 1419.85 & 43 \\
\hline 360 SICO INC & 0.5653 & 2851 & 71,059 & 0.128 & 0.0067 & 478.55 & 44 \\
\hline 60 CAE INC & 0.4545 & 3812 & 917,070 & 0.122 & 0.0065 & 5932.56 & 45 \\
\hline 238 MAAX INC & 0.5946 & 3088 & 307,970 & 0.122 & 0.0065 & 1990.95 & 46 \\
\hline 162 GILDAN ACTIVEV & 0.4694 & 2329 & 116,913 & 0.121 & 0.0064 & 747.32 & 47 \\
\hline 8 & 0.829 & 2331 & 45,927 & 0.118 & 0.0063 & 287.17 & 48 \\
\hline
\end{tabular}




\begin{tabular}{|c|c|c|c|c|c|c|}
\hline 62 CAMCO INC & 0.6324 & 3631 & 100,000 & 0.115 & 0.0061 & 606.87 \\
\hline 367 SLATER STEEL I & 0.6055 & 3316 & 84,802 & 0.109 & 0.0058 & 488.52 \\
\hline 335 RIVERSIDE FORI & 0.432 & 2421 & 75,896 & 0.101 & 0.0053 & 403.70 \\
\hline 281 NORWALL GROL & 0.4815 & 2621 & 10,959 & 0.084 & 0.0044 & 48.50 \\
\hline 70 CANGENE CORP & 0.9171 & 2836 & 221,802 & 0.083 & 0.0044 & 974.63 \\
\hline 175 HAMMOND MANI & 0.5143 & 3612 & 18,426 & 0.075 & 0.0040 & 73.28 \\
\hline 296 PATHEON INC & 0.5253 & 2834 & 142,814 & 0.074 & 0.0039 & 560.42 \\
\hline 302 PFB CORPORATI & 0.9405 & 2821 & 24,080 & 0.073 & 0.0038 & 92.59 \\
\hline 283 NQL DRILLING Ti & 0.7518 & 3533 & 71.671 & 0.069 & 0.0036 & 260.05 \\
\hline 346 SCHNEIDER COF & 0.5659 & 2011 & 139,628 & 0.067 & 0.0036 & 496.29 \\
\hline 173 HALEY INDUSTR & 0.5094 & 3365 & 44,829 & 0.067 & 0.0035 & 158.63 \\
\hline 285 NU-GRO CORPO & 0.5592 & 2879 & 41,449 & 0.067 & 0.0035 & 146.45 \\
\hline 308 POLYAIR INTER ! & 0.4183 & 3086 & 27,260 & 0.065 & 0.0034 & 93.44 \\
\hline 284 NTS COMPUTER & 0.6088 & 3571 & 48,091 & 0.062 & 0.0033 & 157.47 \\
\hline 257 MILLTRONICS LT & 0.967 & 3823 & 222,793 & 0.060 & 0.0031 & 700.12 \\
\hline 243 MALETTE QUEBE & 0.5702 & 2672 & 56,024 & 0.057 & 0.0030 & 167.18 \\
\hline 163 GLENDALE INTE: & 0.316 & 3716 & 47,948 & 0.055 & 0.0029 & 139.28 \\
\hline 261 MOBILE CLIMATE & 0.5242 & 3585 & 33,407 & 0.043 & 0.0022 & 74.99 \\
\hline 369 SMALL FRY SNA & 0.4344 & 2064 & 26,740 & 0.034 & 0.0018 & 47.73 \\
\hline 56 BRAMPTON BRIC & 0.7719 & 3251 & 33,466 & 0.028 & 0.0015 & 49.84 \\
\hline 347 SCI INCOME TRL & 0.9085 & 2515 & 75,019 & 0.025 & 0.0013 & 99.95 \\
\hline 196 INTERNATIONAL & 0.4766 & 3585 & 440,175 & 0.022 & 0.0012 & 509.12 \\
\hline 242 MAGNOTTA WINI & 0.3909 & 2084 & 13,310 & 0.020 & 0.0011 & 14.20 \\
\hline 209 IPEC LTD & 0.5671 & 3533 & 26,958 & 0.019 & 0.0010 & 26.48 \\
\hline 58 BUDD CANADA II & 0.8532 & 3714 & 116.772 & 0.016 & 0.0009 & 99.56 \\
\hline 368 SLEEMAN BREW & 0.5592 & 2082 & 126,836 & 0.016 & 0.0008 & 105.17 \\
\hline 93 CML INDUSTRIE! & 0.5033 & 2621 & 7,109 & 0.014 & 0.0007 & 5.29 \\
\hline 99 CONSOLIDATED & 0.444 & 2875 & 5,178 & 0.012 & 0.0006 & 3.17 \\
\hline 389 SUN-RYPE PROC & 0.6215 & 2033 & 15,889 & 0.011 & 0.0006 & 9.15 \\
\hline 421 TUNDRA SEMICC & 0.8818 & 3674 & 120,705 & 0.011 & 0.0006 & 66.94 \\
\hline 3 AASTRA TECHNC & 0.6936 & 3661 & 46,091 & 0.010 & 0.0005 & 24.59 \\
\hline 309 POLYCORP INC & 0.7287 & 3061 & 28,084 & 0.010 & 0.0005 & 14.98 \\
\hline 165 GLOBAL THERMI & 0.8089 & 3629 & 13,222 & 0.009 & 0.0005 & 6.23 \\
\hline 131 EAGLE PRECISIC & 0.5777 & 3542 & $\mathbf{5 7 , 3 9 5}$ & 0.007 & 0.0004 & 21.58 \\
\hline 219 KELMAN TECHN & 0.6784 & 2911 & 15,111 & 0.007 & 0.0004 & 5.36 \\
\hline 135 ENERCHEM INTE & 0.6288 & 2911 & 19,094 & 0.005 & 0.0003 & 5.50 \\
\hline 106 CPI PLASTICS GI & 0.4861 & 3089 & 60,851 & 0.005 & 0.0003 & 15.72 \\
\hline 89 CIRCUIT WORLD & 0.5216 & 3672 & 289 & 0.005 & 0.0003 & 0.07 \\
\hline 384 STELLA-JONES I & 0.6417 & 2491 & 19,540 & 0.004 & 0.0002 & 4.24 \\
\hline 167 GROUPE BOCEN & 0.5427 & 3442 & 27,022 & 0.004 & 0.0002 & 5.29 \\
\hline 107 CRS ROBOTICS I & 0.55 & 3569 & 3,765 & 0.004 & 0.0002 & 0.71 \\
\hline 231 LEF MCLEAN BR & 0.5861 & 2092 & 3,381 & 0.003 & 0.0002 & 0.62 \\
\hline 88 CIRCA ENTERPF & 0.6802 & 3661 & 6,601 & 0.003 & 0.0001 & 0.98 \\
\hline 100 CONSUMERS PA & 0.2496 & 3221 & 204,373 & 0.002 & 0.0001 & 26.44 \\
\hline 120 DIVERSIFIED INI & 0.9812 & 2899 & 13,328 & 0.002 & 0.0001 & 1.46 \\
\hline 430 UPLAND GLOBAI & 0.7845 & 2834 & 11,221 & 0.001 & 0.0001 & 0.65 \\
\hline 289 OTATCO INC & 0.7962 & 3533 & 40,576 & 0.001 & 0.0000 & 1.80 \\
\hline 47 BIOCHEM PHARI & 1 & 2835 & $4,708,260$ & 0.000 & 0.0000 & 0.00 \\
\hline \multirow{2}{*}{234 LINAMAR CORPC } & 1 & 3714 & $1,792,517$ & 0.000 & 0.0000 & 0.00 \\
\hline & & & & \multicolumn{3}{|c|}{ Real Market Cap $\quad 574,300$ thousand } \\
\hline
\end{tabular}

VALUing PrIVATE CompaniEs: A DEA APproAch 
APPENDIX G

SIC 2800 
DMU nal Score MC min max INEFFICIENT COMPANIES

50 ACETEX 0.486

15 ALTARE 0.858

1 AMR TE 0.697

5 AT PLAS 0.516

17 AXCAN 0.954

39 BESTAF 0.754

18 BIOTEC 0.554

51 CANHOI 0.385

44 CANTOL 0.902

45 CCL INC 0.877

46 CEAPRC 0.991

61 CHEMBI 0.752

47 CONSOI 0.515

57 CONSOI 0.629

34 CV TECI 0.778

35 DIAGNC 0.630

66 DIVERS 0.748

12 FYTOKE 0.883

36 GENOM 0.823

20 HAEMAC 0.474

58 HEDLEY 0.753

21 HILLES7 0.811

37 IBEX TE 0.871

38 IMI INTE 0.960

22 INEX PF 0.937

62 KRYSTA 0.745

23 LABOPF 0.886

4 LITHOS 0.489

7 MAGNIF 0.821

13 MARINE 0.621

59 NAPIER 0.880

63 NORDE: 0.727

8 NOVA C 0.679

60 NU-GRC 0.866

25 ORALIFI 0.985

26 PATHEC 0.684

27 PHARMI 0.177

14 PROME 0.591

29 SALIX P 0.861

41 SIGNALI 0.766

42 STRES 0.825

43 SYNSOF 0.489

30 TECHNI 0.871

31 THERAT 0.903

32 UPLANC 0.868

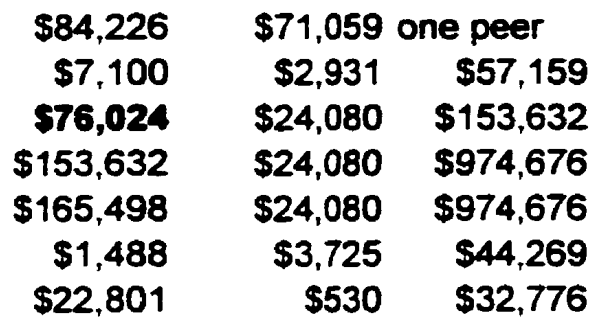

$\$ 1,792$

$\$ 2,108$

$\$ 698,733$

$\$ 10,546$

$\$ 2,917$

$\$ 936$

$\$ 5,178$

$\$ 12,657$

$\$ 13,124$

$\$ 1,096$

$\$ 2,996$

$\$ 20,562$

$\$ 55,116$

$\$ 936$

$\$ 1,294$

$\$ 10,029$

$\$ 11,881$

$\$ 18,596$

$\$ 1,398$

$\$ 44,269$

$\$ 10,733$

$\$ 20,940$

$\$ 19,046$

$\$ 32,776$

$\$ 530$

$\$ 1,838,447$

$\$ 41,449$

$\$ 2,931$

$\$ 142,814$

$\$ 4,651$

$\$ 78,451$

$\$ 14,803$

$\$ 17,484$

$\$ 44,932$

$\$ 77,292$

$\$ 107,756$

$\$ 57,159$

$\$ 11,221$
$\$ 6,577$ one peer

$\$ 3,725 \quad \$ 6,577$

$\$ 767,740$ one peer

$\$ 936$

$\$ 2,996$

$\$ 2,846 \quad \$ 3,207$

$\$ 2,846 \quad \$ 10,546$

$\$ 6,577$ one peer

$\$ 530 \quad \$ 32,776$

$\$ 2,846 \quad \$ 140,743$

$\$ 2,846$ one peer

$\$ 936 \quad \$ 10,546$

$\$ 2,846$ one peer

$\$ 19,046 \quad \$ 77,292$

$\$ 530 \quad \$ 32,776$

$\$ 2,846$ one peer

$\$ 2,931 \quad \$ 57,159$

$\$ 530 \$ \$ 32,776$

$\$ 2,931 \quad \$ 140,743$

$\$ 530 \$ \$ 32,776$

$\$ 1,488 \quad \$ 140,743$

$\$ 530 \quad \$ 32,776$

$\$ 3,725 \quad \$ 78,451$

$\$ 2,931 \quad \$ 77,292$

$\$ 530 \quad \$ 140,743$

$\$ 936 \quad \$ 12,657$

$\$ 4,081,770$ one peer

$\$ 24,080 \quad \$ 71,059$

$\$ 6,895 \quad \$ 57,159$

$\$ 24,080$ one peer

$\$ 2,846$ one peer

$\$ 20,940 \quad \$ 140,743$

$\$ 530 \$ \$ 32,776$

$\$ 2,931 \quad \$ 57,159$

$\$ 140,743$ one peer

$\$ 2,931 \quad \$ 140,743$

$\$ 24,080 \quad \$ 153,632$

$\$ 2,931 \quad \$ 140,743$

$\$ 3,725 \quad \$ 13,328$ upper boun (real-min) Ireal

$\$ 242,296$

$\$ 65,669$

$\$ 202,026$

$\$ 1,033,335$

$\$ 576,269$

$\$ 14,971$

$\$ 20,020$

$\$ 6,844$

$\$ 5,223$

$\$ 1,123,751$

$\$ 2,866$

$\$ 6,809$

$\$ 2,848$

$\$ 13,950$

$\$ 6,883$

$\$ 43,307$

$\$ 3,835$

$\$ 2,851$

$\$ 3,809$

$\$ 71,869$

$\$ 5,034$

$\$ 3,743$

$\$ 111,292$

$\$ 9,599$

$\$ 116,560$

$\$ 22,496$

$\$ 91,225$

$\$ 16,647$

$\$ 77,282$

$\$ 19,274$

$\$ 8,790$

$\$ 5,166$

$\$ 3,906,485$

$\$ 56,297$

$\$ 40,000$

$\$ 27,505$

$\$ 2,846$

$\$ 80,431$

$\$ 51,195$

$\$ 15,545$

$\$ 140,881$

$\$ 72,892$

$\$ 259,036$

$\$ 87,578$

$\$ 9,949$
$15.63 \%$

$58.72 \%$

$68.33 \%$

$84.33 \%$

$85.45 \%$

$97.68 \%$

$-267.05 \%$

$0.88 \%$

$-9.88 \%$
$91.12 \%$

$2.42 \%$

$-27.03 \%$

$95.81 \%$

$78.31 \%$

$-159.69 \%$

$68.76 \%$

$86.16 \%$

$65.44 \%$

$43.37 \%$

$-119.99 \%$

$70.77 \%$

$95.54 \%$

$84.24 \%$

$62.10 \%$

$96.64 \%$

$95.06 \%$

$82.21 \%$

$84.61 \%$

$98.38 \%$

$-122.02 \%$

$41.90 \%$

$83.14 \%$

$38.80 \%$

$73.31 \%$

$96.42 \%$

$83.24 \%$

$-213.23 \%$

$96.21 \%$

$77.65 \%$

$94.87 \%$

$66.80 \%$ (real-max) (real-upper)

Ireal Ireal

\#VALUE! $\quad-187.68 \%$

$-705.01 \% \quad-824.86 \%$

$-102.08 \% \quad-165.74 \%$

$-534.42 \% \quad-572.60 \%$

$-488.94 \% \quad-248.20 \%$

$-2875.48 \% \quad-906.25 \%$ $-43.75 \%$

\#VALUE! $\quad-281.96 \%$

$-211.97 \% \quad-147.75 \%$

\#VALUE! $\quad-60.83 \%$

$\therefore$.

$-1026.76 \% \quad-204.25 \%$

\#VALUE! - $169.43 \%$

$-158.95 \%$

$-972.45 \% \quad-229.99 \%$

\#VALUE! $\quad-249.93 \%$

$-252.04 \%$

\#VALUE!

$-40.24 \%$

\#VALUE! - $189.34 \%$

$-469.94 \%-1009.70 \%$

$-175.86 \%$

$-656.85 \% \quad-526.81 \%$

$-2243.72 \%-1508.61 \%$

$-217.92 \% \quad-106.07 \%$

$-205.37 \% \quad-55.10 \%$

$-274.65 \% \quad-269.07 \%$

$-305.82 \% \quad-1.20 \%$

$-329.41 \%$

$-2286.47 \% \quad-874.02 \%$

\#VALUE! $\quad-112.49 \%$

$-71.44 \% \quad-35.82 \%$

$-1849.89 \%-1264.54 \%$

\#VALUE!

\#VALUE!

$-79.40 \%$

$-121.42 \% \quad-245.85 \%$

$-226.92 \%$

\#VALUE!

$-82.09 \%$

$-42.57 \%$

$-146.23 \%$

$-18.78 \%$

$28 / 34$ within range 


\begin{tabular}{|c|c|c|c|c|}
\hline \multicolumn{5}{|c|}{ EFFICIENT COMPANIES } \\
\hline & & Real & Lower Boun & real-lower/real \\
\hline 2 BORDEI & 1 & $\$ 3,725$ & $\$ 17,264$ & $-363.51 \%$ \\
\hline 3 DUPON $^{-}$ & 1 & $\$ 4,081,770$ & $\$ 1,541,128$ & $62.24 \%$ \\
\hline 9 PFB CO & 1 & $\$ 24,080$ & $\$ 102,332$ & $-324.96 \%$ \\
\hline 10 POLY-P. & 1 & $\$ 1,251$ & self evaluato & \#VALUE! \\
\hline 11 ALTA N/ & 1 & $\$ 6,577$ & $\$ 2,622$ & $60.14 \%$ \\
\hline 16 ANGIOT & 1 & $\$ 140,743$ & $\$ 36,862$ & $73.81 \%$ \\
\hline 19 BIOVAIL & 1 & $\$ 1,404,647$ & self evaluato & \#VALUE! \\
\hline 24 NATRAC & 1 & $\$ 8,108$ & self evaluatoı & \#VALUE! \\
\hline 28 QLT PHI & 1 & $\$ 974,676$ & $\$ 139,816$ & $85.66 \%$ \\
\hline 33 BIOCHE & 1 & $\$ 4,708,260$ & $\$ 146,983$ & $96.88 \%$ \\
\hline 40 CANGEI & 1 & $\$ 221,802$ & $\$ 66,915$ & $69.83 \%$ \\
\hline 48 POLYME & 1 & $\$ 3,207$ & $\$ 3,600$ & $-12.27 \%$ \\
\hline 49 SICO IN & 1 & $\$ 71,059$ & $\$ 73,206$ & $-3.02 \%$ \\
\hline 52 LANDOI & 1 & $\$ 2,846$ & $\$ 9,042$ & $-217.67 \%$ \\
\hline 53 METHAP & 1 & $\$ 1,370,334$ & self evaluato & \#VALUE! \\
\hline 54 AGRIUN & 1 & $\$ 1,541,000$ & self evaluato & \#VALUE! \\
\hline 55 POTASt & 1 & $\$ 5,261,648$ & self evaluator & \#VALUE! \\
\hline 56 TERRA I & 1 & $\$ 716,918$ & self evaluatol & \#VALUE! \\
\hline 64 AQUA-P & 1 & $\$ 6,895$ & $\$ 25,847$ & $-274.87 \%$ \\
\hline 65 DIVERS & 1 & $\$ 13,328$ & self evaluato & \#VALUE! \\
\hline 67 SHAW II & 1 & $\$ 767,740$ & $\$ 539,758$ & $29.70 \%$ \\
\hline
\end{tabular}

